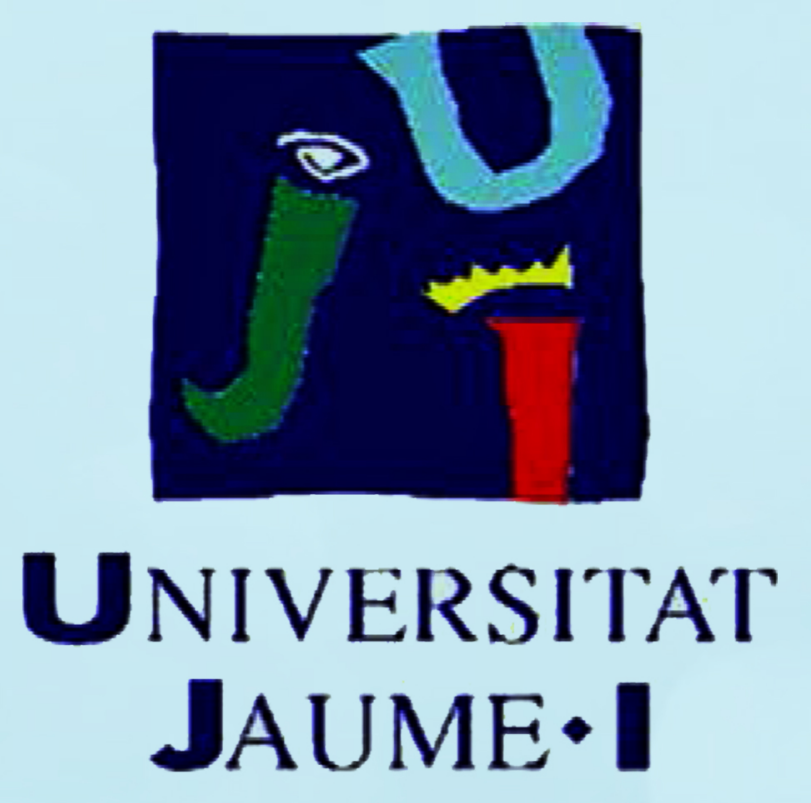

Escuela de Doctorado de la Universitat Jaume I

\title{
ANÁLISIS DE LAS FUNCIONES EJECUTIVAS DE MEMORIA DE TRABAJO Y CONTROL INHIBITORIO EN ALUMNADO CON IMPLANTE COCLEAR EN EDUCACIÓN INFANTIL
}

Tesis doctoral presentada por:

Marta Boronat Barbeta

\section{Dirección:}

Dra Rosa Ana Clemente Estevan, perteneciente a la Universidad Jaume I

Dra Núria Silvestre Benach, perteneciente a la Universidad Autonómica de Barcelona

Junio 2021 


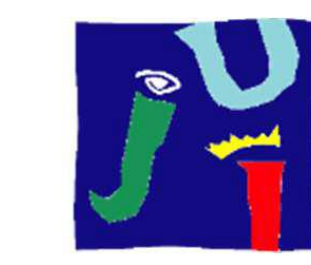

$\mathbf{U}_{\text {NIVERSITAT }}$

JAUME•I

Programa de Doctorado en Educación

Escuela de Doctorado de la Universitat Jaume I

\title{
ANÁLISIS DE LAS FUNCIONES EJECUTIVAS DE MEMORIA DE \\ TRABAJO Y CONTROL INHIBITORIO EN ALUMNADO CON IMPLANTE COCLEAR EN EDUCACIÓN INFANTIL
}

\author{
Memoria presentada por Marta Boronat Barbeta para optar al grado de doctora por \\ la Universidad Jaume I
}

Doctoranda

Marta Boronat Barbeta

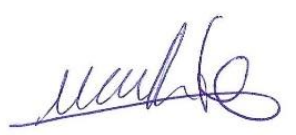

Directoras

Dra. Rosa Ana Clemente Estevan

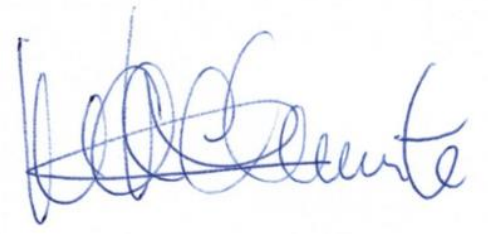

Dra. Núria Silvestre Benach

Muiria silvehe 
Se puede reutilizar contenido de la tesis doctoral, indicando expresamente la autoría. También se pueden crear otras obras a partir de ésta, siempre y cuando se mantenga la misma licencia que se indica en la presente.

\section{Financiación recibida}

La presente tesis doctoral no ha recibido financiación de la Universitat Jaume I de Castellón de la Plana para la realización del presente proyecto de investigación. 



\section{AGRADECIMIENTOS}

Me gustaría mostrar mis agradecimientos a todas las personas que estuvieron conmigo en la realización de este trabajo de investigación.

En primer lugar, a las directoras Dra. Rosa Ana Clemente Estevan y la Dra. Núria Silvestre Benach, por trasmitirme su pasión por la investigación y su afán por aportar un mayor conocimiento en el campo de la sordera para que pueda mejorar la intervención y el aprendizaje de este alumnado. También gracias a su paciencia y perseverancia por enseñarme técnicas de investigación, así como sus orientaciones para encauzar mi curiosidad hacia la investigación, que me han ayudado a mejorar y potenciar mis capacidades para la construcción de este trabajo de investigación.

En segundo lugar, me gustaría agradecer la colaboración de las asociaciones de padres y amigos del sordo (ASPAS) de Valencia y Castellón, así como de los centros de recursos educativos para deficientes auditivos de Tarragona, Barcelona y Baix Llobregat por su estimable colaboración, y la ayuda que me han prestado para la recogida de la muestra de participantes con sordera. También requiere de una mención especial el centro educativo de educación infantil y primaria Luís Fortich de Valencia por abrirme las puertas de su centro y ofrecer todo su apoyo y colaboración en la realización del programa de estimulación cognitiva con el alumnado de infantil. Su interés y atención por la educación del alumnado con sordera se ve reflejada en el interés por la formación continua en el campo y su disposición a colaborar en este trabajo de investigación.

En tercer lugar, quiero dar las gracias a Laura y su familia por ser el motor de mi inspiración y animarme a impulsar mi curiosidad en el campo de la investigación. Gracias a Laura y en especial a su madre, Amparo, busqué dar respuesta a los retos que nos planteaba el aprendizaje de Laura.

Por último, y no por ello menos importante, me gustaría dar las gracias a mi familia por ser inspiración eterna y grandes pilares de apoyo en este gran sueño. A Jordi por sus incansables ánimos para seguir hasta el final sin dejar de luchar. Siempre remando juntos.

También quiero dar las gracias a la Universidad Autónoma de Barcelona (UAB) de Barcelona por la oportunidad de realizar diversas estancias de investigación durante mi doctorado.

Muchísimas gracias a todos por vuestra inestimable y valiosa ayuda y apoyo. 



\section{ÍNDICE}

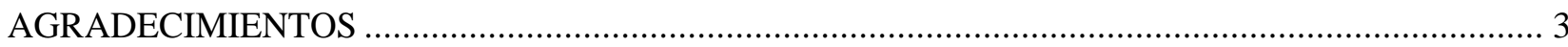

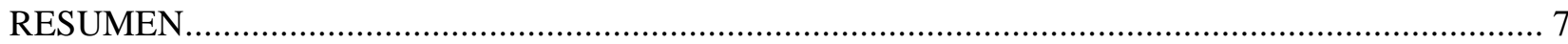

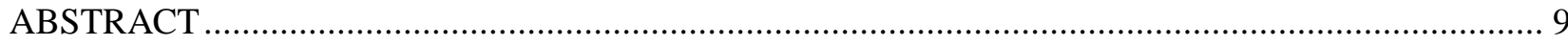

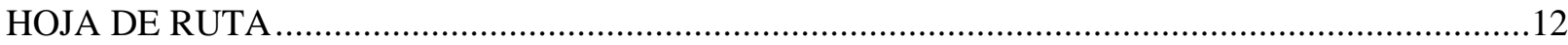

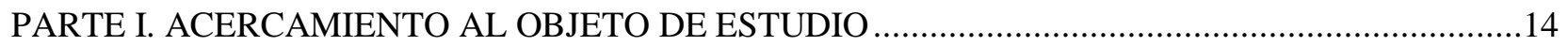

CAPÍTULO 1: EL ACCESO AL APRENDIZAJE DE LA POBLACIÓN CON SORDERA..................14

1.1. La necesidad de la audición temprana en la criatura con sordera..........................................14

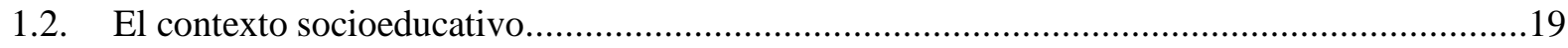

1.3. La repercusión de las políticas educativas en el ámbito socioeducativo en el contexto nacional .

RESUMEN .29

CAPÍTULO 2. LA RELACIÓN DE LOS PROCESOS PSICOLÓGICOS BÁSICOS Y EL LENGUAJE

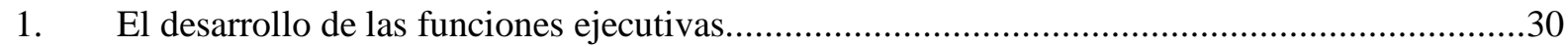

2. La relación entre el lenguaje oral y las funciones ejecutivas ...............................................33

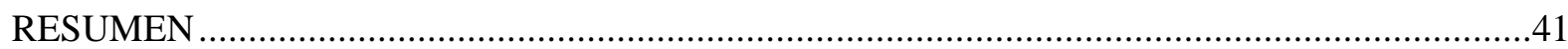

CAPÍTULO 3: EL DESARROLLO DEL LENGUAJE Y LAS HABILIDADES COGNITIVAS EN LAS

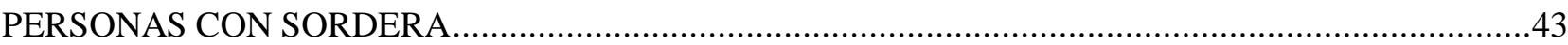

1. La competencia lingüística y las funciones ejecutivas en criaturas con sordera ......................43

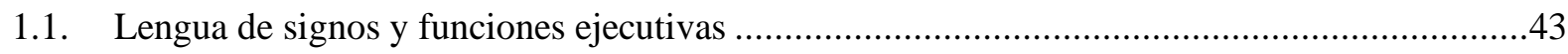

1.2. El lenguaje oral y las funciones ejecutivas en las criaturas con implante coclear IC …............47

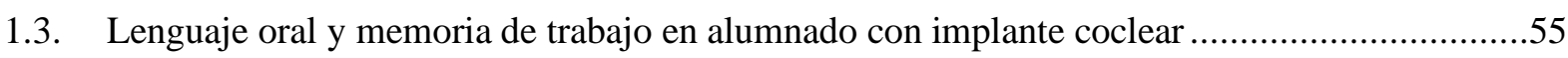

1.4. Lenguaje oral e inhibición en población con implante coclear .................................................64

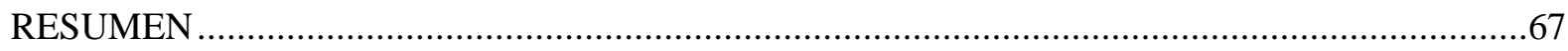

CAPÍTULO 4. LAS DIVERSAS INTERVENCIONES EN LA ESTIMULACIÓN DE LAS

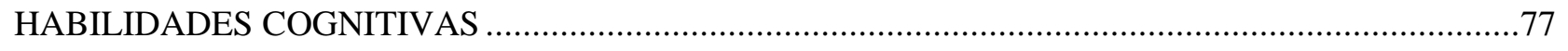

1. La intervención en FE dirigido a alumnado con sordera......................................................77 
PARTE II. DISEÑO METODOLÓGICO DE LA INVESTIGACIÓN …...................................................82

CAPITULO 5. MARCO GENERAL DE LA INVESTIGACIÓN EMPÍRICA Y OBJETIVOS .............82

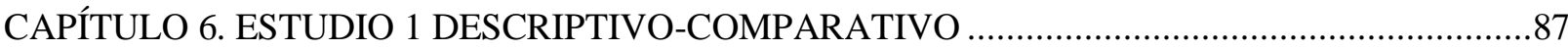

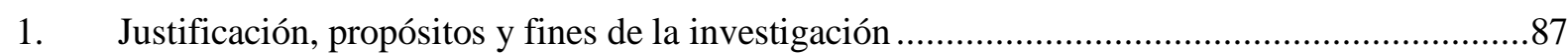

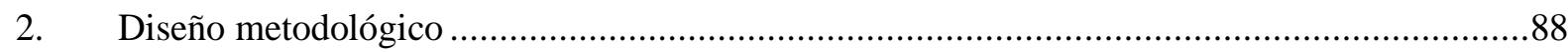

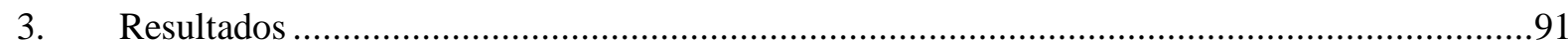

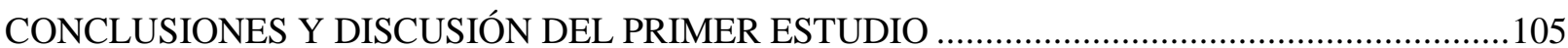

CAPÍTULO 7. ESTUDIO 2 ESTUDIO PILOTO DE INTERVENCIÓN EDUCATIVA SOBRE LAS FE

1. Justificación, propósitos y fines de la investigación ................................................................110

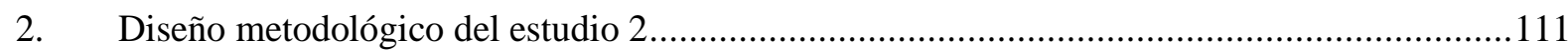

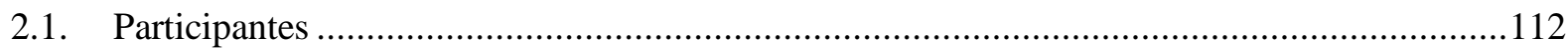

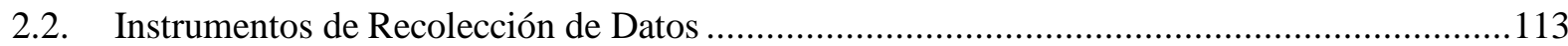

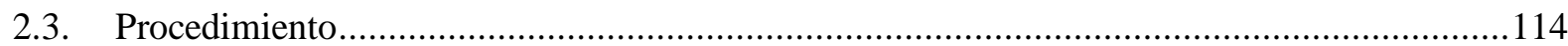

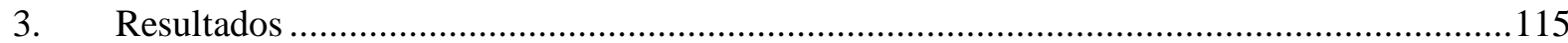

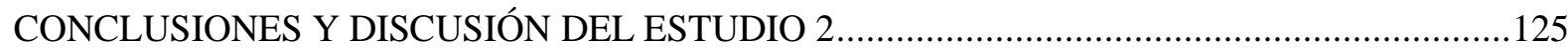

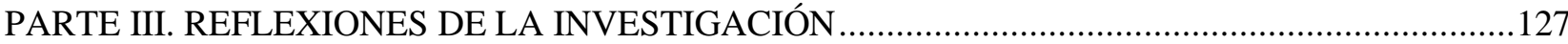

CAPÍTULO 8. Conclusiones de la investigación y proyección de propuestas......................................127

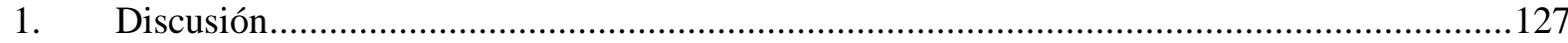

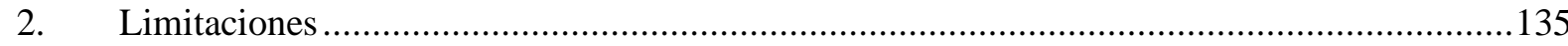

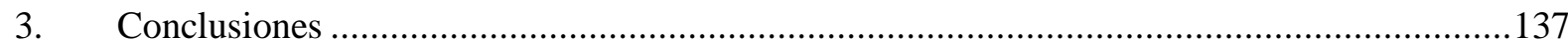

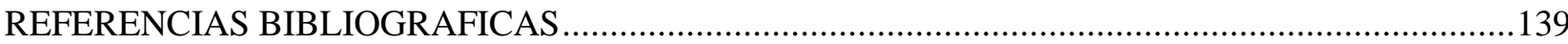

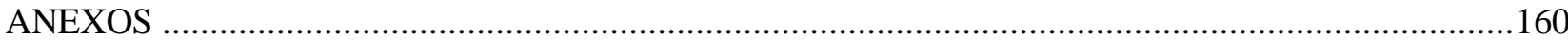




\section{RESUMEN}

La presente tesis doctoral consta de dos estudios sobre las funciones ejecutivas (FE)- memoria e inhibición- en alumnado con sordera en la etapa de Educación Infantil, que tiene como propósito principal estudiar si el alumnado con sordera presenta posibles déficits en el desarrollo del lenguaje así como de la memoria y la inhibición en edad preescolar (Estudio 1) y cuáles son los efectos del entrenamiento cognitivo en estas habilidades ejecutivas mediante actividades funcionales en situaciones de juego dirigido (Estudio 2).

Para ello, en el primer estudio participaron niños/as de 3 a 6 años: 32 preescolares con sordera, con implante coclear (IC) antes de los 36 meses de edad, y 39 preescolares normo-oyentes. Todos fueron evaluados con medidas normalizadas sobre lenguaje (escala del lenguaje Reynell) y diversas tareas sobre la memoria (verbal y espacial) y la inhibición (cognitiva y motora). Se realizaron comparaciones entre las diferentes habilidades de la memoria y la inhibición de los preescolares con IC con sus iguales normo-oyentes, así como las correlaciones que se establecen con el lenguaje según la condición auditiva (con sordera/normo-oyente).

En el segundo estudio se elaboró y aplicó un programa de intervención en las FE de la memoria y la inhibición mediante actividades funcionales cercanas al juego dirigido en dos aulas de un centro escolar de educación infantil de Valencia de integración preferente para alumnado con sordera. En el programa participaron preescolares con IC $(\mathrm{N}=4)$ y normo-oyentes $(\mathrm{N}=26)$.

En el primer estudio, el rendimiento de las FE del alumnado preescolar con IC muestra un posible riesgo en el desarrollo de la habilidad ejecutiva de la memoria verbal, así como en el lenguaje desde los 3-4 años, a pesar del uso temprano del IC y la intervención en terapia auditivo-oral. En cambio, las puntuaciones en inhibición son superiores en el alumnado con sordera en comparación con sus iguales normo-oyentes. Las habilidades ejecutivas de la memoria se relacionan con el lenguaje para ambas poblaciones (con sordera y normo-oyentes), salvo la memoria de dígitos de orden directo que se correlacionan de forma distinta según la condición auditiva y la memoria espacial que no se relaciona con el lenguaje. Las habilidades de la inhibición presentan diferente relación con el lenguaje según la condición auditiva.

En el segundo estudio, los resultados reflejan una mejora significativa de las puntuaciones en el alumnado normo-oyentes y una tendencia próxima al cambio significativo -probablemente debido al escaso número de participantes- en el alumnado con IC. De todos modos, las mejoras en las 
puntuaciones de todas las tareas evaluativas de la memoria y la inhibición después de la intervención perduran incluso tres meses después.

Este trabajo de investigación aporta el posible riesgo en el desarrollo de la memoria verbal en alumnado preescolar con IC, así como que el efecto madurativo de la edad no disminuye sus diferencias y, también, el efecto positivo de la intervención educativa desde una perspectiva educativa, que refleja la posibilidad de mejorar el rendimiento de las FE en edad infantil. 


\begin{abstract}
The current doctoral thesis is based on two studies over the field of Executive Functions (henceforward EF) in deaf pupils at the pre-school stage. The main purpose of the First Study is to determine whether the deaf student body it would have possible deficits in the development of the language, inhibition and the memory which are considered as key part of the executive functions at pre-school ages. The Second study aims to determine what are the effects and improvements - if anyon these EFs thanks to the cognitive training through the coordination of directive playing sessions.

In the first study, two groups of children aged 3 to 6 years participated: 32 deaf preschoolers, users of CI (Cochlear Implant), before 36 months of age and 39 normal-hearing preschoolers. All were assessed on standardised measures of language (Reynell language scale) and various tasks on the EFs of memory (verbal and spatial) and inhibition (cognitive and motor). Comparisons were made of the EF skills of preschoolers with CI with their normal-hearing peers, as well as correlations with language according to hearing status (deaf/normo-hearing).
\end{abstract}

In the second study, an intervention programme was developed and applied to memory and attention EFs through directed play activities in two classrooms of an early childhood education centre in Valencia with preferential integration for students with deafness. Preschoolers with $\mathrm{CI}(\mathrm{N}=4)$ and normal-hearing children $(\mathrm{N}=26)$ participated in the programme.

In the first study, the EF performance of preschool pupils with Intelligent Quotient (IQ) shows possible risk in the development of executive verbal memory skills as well as language from the age of 3-4 years, despite early use of cochlear implantation and auditory-oral therapy intervention. Some differences are found in the significant correlation between the EFs of memory and inhibition and language according to hearing status (deaf/hard of hearing).

In the second study, the research results reflect a significant improvement of scores in the normalhearing students and a trend close to significant change in the deaf students, due to the small number of participants. In any case, the high volume of scores in all tasks assessing memory and inhibition EFs reflect the possibility of improving performance in executive skills at a young age and its effects last three months after the intervention.

The studies in this research contribute to show that it is possible that deaf preschoolers would have risk in the development of the verbal memory and the age factor in the preschool pupils do not affect 
their differences. Furthermore, the intimate relationship of the EFs of memory, inhibition and language, as well as the improvements in performance with early cognitive stimulation, opens the possibility that intervention in the EFs from an educational perspective may contribute to language development. 


\section{HOJA DE RUTA}

La hoja de ruta que se presenta a continuación se ha diseñado con el objetivo de orientar al lector por el trayecto de esta investigación, mediante la introducción de apartados y capítulos que sitúan cada fase del estudio, así como un breve resumen de cada uno de los contenidos.

\section{PARTE I. ACERCAMIENTO AL OBJETO DE ESTUDIO: EL ACCESO AL APRENDIZAJE DE LA POBLACIÓN CON SORDERA}

CAPÍTULO 1. En este primer capítulo, el acceso al aprendizaje de la población con sordera, se introducen las implicaciones de la pérdida de audición en la primera infancia para el desarrollo del lenguaje oral y su repercusión en el aprendizaje. De este modo, se realiza una revisión cronológica de los avances en legislatura educativa desde la perspectiva europea y nacional, que han permitido promover el horizonte de la educación inclusiva.

CAPÍTULO 2. Se realiza una aproximación teórica del objeto de estudio a través de la revisión de evidencias científicas. Para obtener una mayor profundización teórica de la problemática, se ha realizado una división del contenido a investigar. De este modo, se inicia el capítulo con la introducción de distintas conceptualizaciones acerca de los procesos psicológicos básicos y, posteriormente, su relación con el desarrollo del lenguaje oral, abordado desde el enfoque de la población con sordera. Este fundamento teórico-conceptual constituye el contenido de la revisión científica del campo de estudio, dividido en dos apartados para ampliar el contenido sin perder su interrelación, a saber: El desarrollo de las funciones ejecutivas y la relación con el lenguaje oral, a fin de conocer la relación de dependencia que establecen ambas habilidades.

CAPÍTULO 3. En este capítulo se concreta la relación que estable entre las funciones ejecutivas y la competencia lingüística de participantes con sordera a través de la exposición de diferentes estudios de investigación. Además, el contenido de este capítulo se divide en diferentes apartados para tratar de abordar los estudios recientes sobre las funciones ejecutivas de la memoria y la inhibición en alumnado con sordera en las diferentes etapas educativas (preescolar, escolar y secundaria) para construir un paisaje del contexto científico actual.

CAPÍTULO 4. En este capítulo se exponen las diferentes formas de intervención que se han realizado para optimizar las habilidades cognitivas de la memoria y de la inhibición sobre población normo-oyente. Posteriormente, se concretan en la revisión de los programas de estimulación realizados 
en la población con sordera. El contenido del capítulo refleja la necesidad de estudiar las bases y los criterios de intervención educativa en este campo en el alumnado con sordera en la etapa infantil.

\section{PARTE II: DISEÑO METODOLÓGICO DE LA INVESTIGACIÓN}

CAPÍTULO 5. El presente capítulo realiza una introducción de la problemática que ha promovido el desarrollo de la investigación, mediante la definición, identificación y contextualización de la investigación, definiendo el enfoque epistemológico y el plan metodológico seleccionado para el desarrollo de los dos estudios: estudio descriptivo-comparativo y estudio piloto de intervención educativa.

CAPÍTULO 6. En este capítulo se realiza el análisis de los datos del estudio descriptivocomparativo de la muestra representativa de alumnado con sordera de 3-6 años con el grupo de referencia normo-oyente, a fin de recoger información acerca del desarrollo evolutivo de las FE de la memoria y la inhibición y su relación con el lenguaje.

CAPÍTULO 7. Este capítulo define el paisaje de investigación del segundo estudio, el cual aborda un programa de estimulación cognitiva infantil en el que participa el alumnado preescolar con sordera y normo-oyente. En él se describe el perfil metodológico que se ha utilizado para realizar la intervención en el alumnado, así como las fases y cronograma de implementación. Al final del capítulo se exponen los resultados de la intervención a través de un análisis comparativo para comprobar los beneficios de la intervención y la duración de sus efectos tres meses después. Además, también se presenta un análisis comparativo entre grupos de participantes según la condición auditiva (con sordera y normo-oyente) para conocer si existen diferencias en el desarrollo y resultados de la estimulación cognitiva.

\section{PARTE III: REFLEXIONES DE LA INVESTIGACIÓN}

CAPÍTULO 8. En esta última sección se establece la discusión de la investigación, se exponen las conclusiones más relevantes obtenidas de los datos de los estudios, así como las posibles implicaciones para la práctica educativa, que favorezca el aprendizaje del alumnado con sordera. Además, también se presentan las limitaciones que se han encontrado y las futuras propuestas de estudio. 


\section{PARTE I. ACERCAMIENTO AL OBJETO DE ESTUDIO}

\section{CAPÍTULO 1: EL ACCESO AL APRENDIZAJE DE LA POBLACIÓN CON SORDERA}

1.1. La necesidad de la audición temprana en la criatura con sordera.

La OMS estima que 360 millones de personas en todo el mundo presentan hipoacusia al nacer, ya que la pérdida de audición en los recién nacidos es una de las patologías más frecuentes con una prevalencia de aproximadamente 1.5 en 1000 nacimientos. Se denomina hipoacusia a la pérdida de audición mayor de 20 decibeles $(\mathrm{dB})$ para cada oído con frecuencias 0.5-1-2-4 Kilohertzio $(\mathrm{KHz})$ y según el grado de pérdida auditiva se establecen diferentes niveles de gravedad. En este caso, se atribuye a una pérdida auditiva leve cuando se sitúa entre los niveles de $26-40 \mathrm{~dB}$, se otorga un grado moderado cuando se encuentra la pérdida entre 41-70 dB, en rangos comprendidos entre 71-90 dB se considera severa y profunda cuando la ausencia de audición es igual o mayor a 90 dB. Así pues, según el rango de pérdida auditiva se utiliza la prótesis auditiva que más se ajusta a las necesidades auditivas (Silvestre y Laborda, 2005). Sin embargo, la sordera se ha podido revertir con la disposición de prestaciones tecnológicas como el audífono e incluso en sorderas neurosensoriales bilaterales profundas mediante el uso de implante coclear (Yoshinaga-Itano, 2011).

La alta incidencia de hipoacusia junto con las mejoras tecnológicas y las normativas gubernamentales han permitido establecer el cribado auditivo universal en los recién nacidos, con el propósito de detectar las deficiencias auditivas en los primeros meses de vida y promover la intervención apropiada antes de los seis meses de edad (Yoshinaga-Itano, 2011). El diagnóstico precoz de la pérdida auditiva con el screening auditivo favoreció acortar la edad de detección de la sordera y, por ende que las criaturas tuvieran un mayor acceso al lenguaje oral, así como la estimulación de las habilidades auditivas y lingüísticas de forma temprana (May-Mederake, 2012). En efecto según el grado de pérdida, las frecuencias afectadas y el momento en el que se produzca la hipoacusia, la sordera puede afectar al desarrollo del habla, el lenguaje y las habilidades cognitivas, especialmente si surge en la etapa prelocutiva, es decir, antes del desarrollo lingüístico (Ching, Cupples y Marnane, 2019; Colletti, Madanlà, Zoccante, Shannon y Colletti, 2011; Nicholas y Geers, 2018; Tobey et al., 2013).

Gracias a los avances en la tecnología biomédica, se han desarrollado dispositivos protésicos suficientemente eficientes (audífono e implante coclear) para ejercer, en parte, la función auditiva, incluso cuando existe una pérdida total de las células sensoriales ciliadas cocleares. En ese caso, las criaturas diagnosticadas con una pérdida auditiva neurosensorial severa o profunda son candidatas a 
un implante coclear, porque el uso del audífono solo o únicamente no aporta la suficiente ganancia auditiva para desarrollar plenamente el lenguaje (Silvestre y Laborda, 2005). Por esa razón, actualmente se trata de reducir la edad de implantación en sorderas prelocutivas profundas o severas antes de los 12 meses de edad, ya que la precocidad en la exposición a estímulos auditivos de manera incidental en los primeros años ya tiene importancia para la comprensión temprana del lenguaje oral, el desarrollo del lenguaje y el vocabulario (Nicholas y Geers, 2013; Yoshinaga-Itano, Sedey, Wiggin y Mason et al., 2018). Por tanto, la edad es un fuerte predictor para el aprendizaje rápido gracias a la plasticidad cerebral y el desarrollo del lenguaje de forma apropiada (May-Mederake, 2012; Nicholas y Geers, 2013; Vlastarakos et al., 2010). Además, cabe tener en cuenta que existen períodos críticos en la plasticidad cerebral para desarrollar las habilidades auditivas y el lenguaje, que comprenden sobre los cinco-seis años (Goberis, Beams , Dalpes, Abrisch, Baca y Yoshinaga-Itano, 2012), pero que se reducen notablemente a partir de los 4 años (Holt y Svirsky, 2008; Peterson, Pisoni y Miyamoto, 2010).

Otro factor que beneficia a la percepción de las habilidades lingüísticas es la implantación bilateral, dado que la binauralidad favorece: (1) la identificación del sonido (2) la mayor percepción del volumen (3) la mejor audición en ambientes silenciosos y ruidosos (Gordon, Jiwani y Papsin, 2013). También cabe tener en cuenta la edad de implantación del segundo IC, ya que al parecer la implantación secuencial dos años después del primer IC reduce las mejorías en la percepción del habla (Gordon et al., 2013; Lammers, Venekamp, Grolman, Van der Heijden, 2014).

Por todo ello, hay diferentes factores importantes que afectan en la variabilidad de los resultados de la adquisición del lenguaje y el habla como la edad de implantación, la rehabilitación y estimulación auditiva temprana, así como el modo de implantación de un segundo IC (secuencial o simultaneo) (Lammers et al., 2014; Peterson et al., 2010; Vlastarakos et al., 2010).

La rehabilitación auditiva, a través de la incorporación de los dispositivos protésicos, se debe realizar en colaboración con los diferentes profesionales que participan en la intervención del niño o niña como logopedas, psicopedagogos/as, maestros/as, terapeutas, entre otros, para que, de manera conjunta y coordinada, establezcan estrategias de intervención y evaluación audiológica y puedan minimizar la repercusión de la hipoacusia, en la manera de lo posible, sobre el desarrollo de la comunicación y el lenguaje y, por ende, en el desarrollo socio-emocional, cognitivo y académico (Silvestre y Laborda, 2005; Yoshinaga-Itano, 2003). Por tanto, el proceso de aprendizaje del lenguaje es gradual y constante y depende, en gran medida, de la plasticidad neurosensorial auditivo y factores cognitivos para asentar las bases del aprendizaje del lenguaje (Kral, 2013; Manrique Rodríguez y Irujo Huarte, 2004). 
Antes de iniciarse en el aprendizaje del idioma que hablan los progenitores o personas de crianza, la criatura debe realizar una discriminación auditiva del entorno sonoro que le rodea y que interviene como elemento precursor del lenguaje. De esta manera, las reacciones sensoriales provocan un efecto en la conducta frente al sonido en los primeros meses, permitiendo el desarrollo de la atención selectiva a través de la discriminación del ruido ambiental, el estímulo verbal, la entonación y el reconocimiento de voz de la madre entre otras voces (Borregón Sanz, 2016; Vlastarakos et al., 2010). En esta misma etapa, comienza su comunicación social con el entorno a través de la sonrisa u otras formas gestuales, así como los intentos de imitación vocálica mediante gritos y expresiones sonoras que le ayudan a descubrir y controlar los sonidos que emite. Progresivamente, esta comunicación adquiere expresiones orales más elaboradas como la formación del balbuceo canónico y, posteriormente, la expresión de palabras asignadas a objetos familiares y personales de su entorno próximo (Borregón Sanz, 2016).

Así pues, la audición es un elemento decisivo, que permite el progresivo aprendizaje del lenguaje oral, a través de las emisiones orales reflejas que se producen independientemente de la audición en los bebes con sordera congénita. Posteriormente, la imitación de los sonidos impulsa los balbuceos canónicos y potencia el desarrollo del balbuceo lingüístico, que darán lugar a las primeras palabras y las primeras formas de frase. De modo que, la pérdida auditiva grave constituye una gran dificultad para el desarrollo de la comunicación y el lenguaje oral de forma incidental, sobre todo cuando la sordera aparece en la etapa previa al desarrollo del lenguaje (prelocutiva). En efecto, esta condición influye no sólo al lenguaje, sino también a la comunicación, la socialización, la comprensión de la información del entorno y la estimulación de los procesos cognitivos. En definitiva, repercute en el aprendizaje y en el desarrollo socio-afectivo (Hípola Sánchez, 2004; Hunter, Kronenberger, Castellanos y Pisoni, 2017; Kral, Kronenberger, Pisoni y O’Donoghue, 2016).

La falta de audición conlleva a los progenitores, como agentes educativos próximos a la criatura, a incitar la estimulación oral para favorecer el desarrollo preverbal de su hijo o hija. No obstante, la imitación de un modelo articulatorio que no se percibe o se percibe deficitariamente no siempre se puede interpretar como un acto del habla, ya que no es sencilla y dificulta el acceso a la comprensión y aprendizaje del lenguaje, por tanto, limita el desarrollo comunicativo, social y cultural del sujeto con el entorno (Colletti et al., 2005; Kelly, Morgan, Bannard y Matthews, 2020).

Así pues, el acceso tardío a la comunicación prelingüística suele implicar el aprendizaje de un lenguaje tardío y pobre, que conduce al retraso en el desarrollo del pensamiento operativo formal o pensamiento lógico, así como la dificultad en comprender e interpretar el pensamiento de los demás, debido al esfuerzo que implica la representación mental del lenguaje. En efecto, se puede asegurar que 
la falta de un lenguaje verbal de calidad puede perjudicar, a su vez, al progreso de algunas dimensiones del juego simbólico, a la planificación de estrategias, a la capacidad de autorregulación y anticipación, así como a la capacidad de formular hipótesis y abstracción (Mood, Szarkowski, Brice y Wiley, 2020; Sundqvist, Lyxell, Jönsson y Heimann, 2014). El empobrecimiento comunicativo-lingüístico limita el desarrollo de las funciones superiores del pensamiento, ya que no son sólo una condición para la comunicación, sino que, a su vez, son el resultado que produce su estimulación mediante la interacción (Szarkowski, Young, Matthews y Meinzen-Derr, 2020; Villalba, 2010).

La dificultad en la comprensión del lenguaje abstracto, como expresión del razonamiento lógico, así como la producción de un menor número de interacciones y experiencias sociales, debido a un lenguaje de menor calidad, plantea la necesidad de potenciar el lenguaje y la comunicación a través de la intervención temprana que propicie el desarrollo de las funciones ejecutivas, así como de competencias lingüísticas para impulsar el aprendizaje de la lengua oral y estimular los procesos cognitivos complejos (Ferrández Mora y Villalba Pérez, 1996; Villalba, 2010).

En la actualidad, y gracias a los avances tecnológicos en las prótesis auditivas y en el campo diagnóstico audiológico, es posible realizar una detección y diagnóstico precoz y preciso, que permite optimizar la adaptación protésica y, por tanto, las posibilidades de audición de las criaturas con sordera y, en especial, de aquellas afectadas por la pérdida más extrema, lo cual permite afirmar que con la adecuada aplicación de los implantes cocleares, educación temprana y adecuación a la pérdida auditiva, las criaturas afectadas por sordera profunda o algunos casos por severa desde el nacimiento, pueden oír y percibir todos los sonidos del campo acústico del habla, así como alcanzar en las habilidades del lenguaje oral un nivel equiparable o próximo a sus compañeros/as normo-oyentes (Davidson, Geers y Nicholas, 2014; Ganek, McConkey Robbins y Niparko, 2012; Geers, Nicholas y Sedey, 2003; Niparko, Tobey, Thal, Eisenberg, Wang, Quittner y Fink, 2010; Tobey et al., 2013).

Por otra parte, las criaturas afectadas por sorderas menos graves deben de beneficiarse de audífonos convencionales que no requieren el IC. En definitiva, si se dan estas condiciones las prótesis auditivas que se usan actualmente comportan que la gran mayoría de personas con sordera puedan percibir la totalidad del campo acústico del habla, con excepción de casos minoritarios con determinadas malformaciones o afecciones añadidas (Trinidad y Jáudenes, 2011; Villalba, 2010).

El desarrollo de la estimulación y educación auditiva durante la intervención temprana estará condicionada en un contexto de interacción comunicativa y lingüística de forma incidental para mejorar la competencia comunicativa y lograr un aprendizaje funcional de la audición, así como un desarrollo cognitivo, social y afectivo dentro de los estándares de un modelo normo-típico (Borregón 
Sanz, 2016; Higuero y Juárez, 2010). En efecto, los programas de intervención siempre se desarrollan teniendo en cuenta dos parámetros: la audición y la comunicación, para trabajarlos de manera conjunta, pero también incluye el desarrollo cognitivo, social y afectivo del niño. Además, la importancia de una atención temprana se justifica ante la necesidad de intervenir durante el periodo de mayor plasticidad neuronal, dado que en edades tempranas los aprendizajes se realizan de manera global y cuando son funcionales (Yoshinaga-Itano, 2003).

Los programas de estimulación temprana son esenciales, debido a que la primera infancia, recogida de 0-3 años, es el período crítico para el aprendizaje óptimo de la lengua materna u otras lenguas en interacción natural, aunque se puede extender hasta los seis años (Borregón Sanz, 2016). Por ello, educadores y especialistas deben colaborar y ofrecer apoyo a las familias, las cuales son un agente educativo y rehabilitador esencial, mediante el asesoramiento y orientación en la comprensión de las necesidades que precisa la persona con sordera, así como la proporción de pautas para mejorar las situaciones de comunicación y aprovechar las oportunidades para asentar habilidades de interacción (Borregón Sanz, 2016; Yoshinaga-Itano, 2003).

Las criaturas con sordera neurosensorial profunda y severa suelen ser aptas para la implantación coclear, la cual se realiza de manera precoz para poder alcanzar una audición funcional y un aprendizaje del lenguaje oral óptimo. Su competencia lingüística dependerá de la consecución de ciertos requisitos que influyen en el desarrollo del lenguaje para alcanzar un nivel adecuado como la edad de aparición de la sordera, la detección temprana, los restos auditivos que conserva, la implantación temprana (Geers, Hayes y Louis, 2009; Geers y Nicholas, 2013; Hunter et al., 2017), el modo de comunicación oral (Peterson et al., 2010) y la rehabilitación logopédica, ya que son factores decisivos en la estimulación auditiva y el desarrollo de las habilidades lingüísticas, socioemocionales y cognitivas en la etapa de mayor plasticidad cerebral (Castellanos, Pisoni, Kronenberger y Beer, 2016; Yoshinaga-Itano, 2003).

Una vez se realiza la intervención quirúrgica, se debe aplicar inmediatamente una respuesta multidisciplinar de forma coordinada y colaborativa desde diferentes instituciones (sanitaria, educativa, social y asociativa) para responder a las necesidades comunicativas y lingüísticas de la persona con sordera. Así pues, tras la implantación, se aplica el programa de estimulación auditiva en un centro de Atención Temprana, en el caso de la comunidad autónoma valenciana, derivado de la Conselleria de Sanidad y Bienestar Social, o en un centro especializado, para potenciar el desarrollo comunicativo oral y de habilitación auditiva (Trinidad y Jáudenes, 2011). La metodología adecuada se fundamente en situaciones comunicativas significativas y relevantes para el niño o niña, a fin de 
propiciar su interacción comunicativa con su entorno lo antes posible y se establezca el vínculo familiar positivo y la formación de figuras de apego seguras. Estos vínculos subyacen a las interacciones reciprocas, el cuidado, la comunicación y la idea de influencia bidireccional que conducen las relaciones sociales entre padres-hijo/a (Demby, Riggs y Kaminski, 2017). Tras esta etapa, el seguimiento de su estimulación auditiva y comunicativa continuará en el centro educativo de infantil y primaria, donde intervendrá los agentes del sistema educativo: docente generalista (tutor/a del aula) y especifico (maestro/a de audición y lenguaje), así como también se puede realizar una complementariedad con servicios profesionales externos para una intervención más especializada (logopeda), inscrito a un centro o asociación especializada en rehabilitación auditiva.

Finalmente, la atención interdisciplinar debe estar coordinada para aunar los esfuerzos en conseguir el éxito en el desarrollo de la competencia comunicativa, la madurez social y la inclusión a partir de oportunidades de interacción social con sus iguales en contextos naturales o de intervención intencional que favorezca situaciones auditivas y comunicativas, así como de socialización y participación del alumnado con sordera con sus iguales normo-oyentes (Borregón Sanz, 2016).

\subsection{El contexto socioeducativo}

El proceso histórico que ha permitido la inclusión de niños y niñas con sordera en entornos educativos ordinarios ha sido largo, pero su logro ha permitido aprovechar las diferencias y la diversidad para el aprendizaje colectivo y cooperativo en beneficio, también, del alumnado normooyente.

Los antecedentes históricos se inician, en el siglo XVIII en diferentes ciudades europeas, en las que se establecen las primeras instituciones educativas, dirigidas a la atención del alumnado con sordera. En Francia se creó la primera Escuela Pública para Sordos (1775), fundada por Abate Carlos Miguel L'Epée (1712-1789), en Gran Bretaña aparece con la figura de Thomas Braidwood y sus familiares (Edimburgo, 1760) y en Italia, con la primera escuela de sordomudos, dirigida por Tomaso Silvestri (Roma, 1784). Este período se fundamenta en una concepción de la sordera como una patología anormal y el uso de una pedagogía desde una perspectiva estigmatizadora de las personas con sordera (Borregón Sanz, 2016; Torres, 2004), pero los adelantos científicos sobre las causas de las discapacidades propiciaron la creación, durante el siglo XIX, de instituciones, principalmente religiosas, donde se alojaban y prestaban atención asistencial y sanitaria a las personas con discapacidad en función de sus anomalías (físicas, sensoriales y/o psíquicas). 
A raíz del establecimiento de la obligatoriedad de la enseñanza en Europa y América del Norte a finales del siglo XIX y principios del siglo XX, comenzó la necesidad de la clasificación, etiquetación y segregación de las personas con algún déficit según los distintos grados y tipos de discapacidad para recibir enseñanza obligatoria, mediante actividades en terapia educativa, ocupacional y recreativa. Estas acciones pioneras como respuesta a una demanda social y económica tuvieron una buena aceptación por parte de las instituciones, profesionales y familias, a pesar de que todavía era difícil de alcanzar el propósito de la inclusión social. En efecto, aunque el internamiento en los centros favorecía la discriminación y segregación social, fue un acontecimiento relevante, ya que se acepta por primera vez que las personas con alguna discapacidad son educables. No obstante, ya adentrados en el siglo $\mathrm{XX}$, que se define como "la era de educación especial", comienza a producirse un cambio en la identidad que define este modelo y la orientación educativa se configura para atender al alumnado con discapacidad desde una educación específica, dentro del Sistema Educativo, es decir, se constituye un subsistema dentro del sistema educativo para atenderle desde preescolar hasta la edad adulta desde una perspectiva diferenciada y adaptada a sus necesidades educativas (Peirats y Marín, 2018).

Este modelo pretendía dar respuesta adaptada a las diferentes capacidades, necesidades, estilos cognitivos e intereses que muestra el alumnado. Para ello se considera de importancia la preparación del cuerpo docente en el ámbito de la Educación Especial, con el fin de que pudiera dedicarse profesionalmente a este campo y conseguir que el alumnado tuviera una adecuada adaptación curricular y el máximo desarrollo socio-emocional. De este modo, la integración educativa, social y laboral de las personas con necesidades educativas especiales comenzaba a iniciar sus primeros pasos, pero todavía requería de condiciones más ajustadas para que fuera posible la completa inclusión, ya que continuaba la segregación del alumnado en aulas específicas (Gonzáles Pérez, 2011; Peirats y Marín, 2018).

En los años 50 surgió el movimiento de integración en Europa y se crearon los primeros servicios de ayuda individualizada. Se defendió el principio de normalización en países como Dinamarca y Suecia, en base al derecho a la educación de las personas con discapacidad en el entorno menos restrictivo posible para desarrollarse en igualdad de condiciones que el resto de los ciudadanos. Este movimiento se vio reflejado en la Declaración de las Personas Deficientes, aprobada por la Asamblea General de las Naciones Unidas en 1957, en la Declaración de los Derechos Generales y Especiales del Deficiente Mental, realizada por la Liga Internacional de Asociaciones en pro de la Deficiencia Mental en Jerusalén en 1968 y en la Declaración de los Derechos Fundamentales del Deficiente Mental en 1971 (Peirats y Marín, 2018). 
Estos documentos declarativos pusieron de manifiesto las intenciones de reconocer la equidad de las personas con discapacidad con respecto al resto de ciudadanos. No obstante, se comenzaron a poner en práctica sus declaraciones sobre el principio de normalización a partir de la publicación del Informe Warnock en 1978 en Reino Unido, donde se refleja, por primera vez, un cambio en el lenguaje para referirse al alumnado con discapacidad, utilizando el término "alumnado con Necesidades Educativas Especiales (NEE)", como denominación que hacía referencia a la situación de aprendizaje, evitando la relación sobre la naturaleza de la propia persona. También, se puso de manifiesto el interés por la práctica educativa, impulsando la integración de los alumnos con NEE en las escuelas ordinarias, mediante la argumentación referente a los beneficios económicos que supondrían para la sociedad, así como los aspectos fundamentales para garantizar el aprendizaje para todo el alumnado según sus diferencias individuales, a través de la adaptación curricular (Medina García, 2018).

A pesar de que estas propuestas supusieron un hito en la historia de la política educativa internacional sobre la atención del alumnado con NEE, todavía era difícil su implementación sin el apoyo de la sociedad, con políticas educativas incompletas y recursos insuficientes, que favoreciesen su formación académica para el desarrollo en la vida social y laboral. De hecho no se produjo la regulación de medidas legislativas, que permitiera el acceso al currículo ordinario de las personas con discapacidad hasta finales de los años 80, ya que las anteriores declaraciones sobre educación priorizaban la discapacidad antes que la condición de persona al pleno derecho de tener las mismas condiciones de igualdad para acceder a todos los niveles de enseñanza educativa del marco ordinario (Peirats y Marín, 2018).

Los primeros indicios de este cambio de percepción social comenzaron en la Convención sobre los Derechos del Niño (20 de noviembre de 1989), aplicando importantes clarificaciones en la educación de personas con NEE y una exhaustiva descripción de los objetivos pretendidos en su educación e integración social para que logren alcanzar una vida plena y favorezca su participación activa, aunque viene marcada por una intención posibilista. Todo ello sin olvidar el reconocimiento del derecho a la educación "Los Estados Partes reconocen el derecho de todo niño a un nivel de vida adecuado para su desarrollo físico, mental, espiritual, moral y social”'(Asamblea General de las Naciones Unidas, 1989 art. 27) e incide en las condiciones fundamentales para acceder al derecho en igualdad de oportunidades, así como en la enseñanza secundaria y superior. De tal forma, el propósito principal del conjunto de artículos es el derecho a una educación basada en la equidad, centrada en los mismos fines para todos, sin importar condición, a fin de hacer posible su integración en la sociedad. Sin embargo, olvida detallar el reconocimiento del pleno derecho de las personas a la inclusión en las 
escuelas ordinarias, la participación e implicación de los progenitores, así como la aplicación del equipo docente de proyectos, estrategias y adaptaciones para la consecución de los objetivos educativos.

A partir de entonces comienza a emerger el concepto de inclusión, como un paso más allá de la integración y se refleja en el Marco de Acción de la Conferencia Mundial sobre Necesidades Educativas Especiales (UNESCO, 1994) celebrada en Salamanca, donde se reafirma el derecho de todas las personas a la educación, fundamentándose en la Declaración Universal de Derechos Humanos de 1948, recordando la igualdad de oportunidades en el acceso a la educación dentro del Sistema Educativo, poniendo mayor énfasis en el acceso de las personas con NEE, dada la escasez e insuficiencia de prácticas educativas reales. Esta declaración parte de la convicción de que la sociedad es plural y diversa, por lo que se promueve una educación de calidad, que dé la oportunidad a todas las personas a alcanzar los conocimientos apropiados, adaptando los proyectos y programas educativos a las características, intereses y capacidades de aprendizaje de cada uno. Además, se diferencia de las anteriores declaraciones, debido a que declara que sean acogidas todas las personas independientemente de sus condiciones personales, culturales o sociales en las instituciones educativas ordinarias. Junto a ello, a lo largo del último tercio del siglo XX, diferentes declaraciones internacionales, continuaron impulsando un cambio en la comprensión de la discapacidad y el planteamiento de diferentes objetivos para mejorar las oportunidades educativas de todo el alumnado, acorde a los planteamientos de una sociedad democrática. Todo ello supone cambios y modificaciones, no sólo en políticas universales que amplíen el concepto de educación para todas las personas, sino también el criterio de que se debe flexibilizar la estructura del sistema educativo para que todo el alumnado tenga garantía de alcanzar los objetivos de aprendizaje desde un enfoque inclusivo y puedan, en definitiva, tomar parte activa de la sociedad.

La práctica educativa debe estar respaldadas por medidas educativas que favorezca la inclusión de todo el alumnado a través de la implantación de proyectos, estrategias y recursos educativos de atención a la diversidad del alumnado, la puesta en práctica de mecanismos para la participación, supervisión y evaluación de la enseñanza, que favorezca la inclusión social, la formación permanente de los docentes en el uso y aplicación de ayudas técnicas, así como la coordinación con equipos interprofesionales para dar respuesta a las necesidades educativas del alumnado y la inclusión de los progenitores en la planificación, seguimiento y participación de la práctica educativa para coordinar las intervenciones educativas de manera conjunta. 
En definitiva, para avanzar en la plena inclusión del alumnado con NEE es preciso promover nuevos enfoques que permitan planificar, coordinar, organizar y diseñar desde una perspectiva inclusiva en colaboración con todos los agentes educativos implicados la puesta en práctica de proyectos, estrategias y propuestas educativas que promuevan un aprendizaje efectivo con especial atención a la diversidad curricular, con el fin de promover, asumir y compartir la equidad y la cohesión social que promueve la escuela desde la diversidad socio-cultural (Peirats y Marín, 2018).

1.3. La repercusión de las políticas educativas en el ámbito socioeducativo en el contexto nacional

En nuestro país, hubo que esperar hasta el siglo XVI para encontrar las primeras experiencias en el campo de la educación especial, donde entidades religiosas acogieron la labor de educar a niños/as con sordera. En este caso, tiene gran relevancia la figura de Ponce de León, que tuvo una gran implicación en la enseñanza de la comunicación para las personas con sordera y defendió una metodología oralista aplicada desde los primeros años, donde introduce la comprensión global de las palabras a través de la escritura de letras aisladas, así como el desarrollo de una gramática para enseñar a las personas con sordera. Ramírez de Carrión siguió sus pasos, utilizando la metodología para enseñar a los mudos en España. El tipo de enseñanza se caracterizaba por ser aislada y exclusivista, de índole privada y solicitada por familias pudientes y bien remuneradas y, finalmente, Bonet, también propuso el aprendizaje comprensivo a través del alfabeto dactilológico que crea, junto a la escritura de cada una de las letras. Sin embargo, la discapacidad era vista como un defecto y estaba ligada a sentimientos de vergüenza para la familia, por lo que las familias se veían forzadas a ocultar a la persona con discapacidad y excluirla de ser un ciudadano activo (Pérez Dalmeda y Chhabra, 2019).

El siglo XVIII y XIX se considera el periodo de la institucionalización, con el establecimiento de los primeros colegios para sordomudos y ciegos, a fin de agrupar al alumnado según la forma de interacción lingüística y social. Durante esos años, se establecen cambios relevantes sobre la percepción de la discapacidad, abandonando la acción de esconder la discapacidad y la percepción de culpabilidad para reconocer abiertamente la necesidad de crear colegios para atender al gran número de alumnos. Finalmente, el último cuarto de siglo XX los avances en la ciencia y la medicina supuso la reivindicación y planteamiento de metodologías eficaces para la enseñanza del alumnado con sordera, presentando diferentes modalidades (signada, combinada y oral) en numerosos encuentros nacionales e internacionales. Sin embargo, el debate sobre la modalidad más beneficiosa supuso el aumento de las discrepancias metodológicas, que quedaron diluidas a la supervivencia institucional y personal a consecuencia del impacto de la guerra civil con el cierre de muchas escuelas y la inactividad y la ausencia de profundización en el campo de la investigación (Torres, 2004). 
En lo referente a los esfuerzos de las políticas educativas nacionales, la década de los años 40 y 50 comienzan a emerger el modelo social tras la reivindicación social por la creación de centros e instituciones públicas que den respuesta a la necesidad de atención educativa de niños/as que no acudían a la escuela obligatoria a causa de su discapacidad. Estas iniciativas fueron respaldadas por la Ley de Enseñanza Primaria de 1945 y el Patronato Nacional de Educación Especial en 1953 que regulaba los centros e instituciones; la promulgación del Decreto sobre la Ordenación de Educación especial en Octubre de 1965, así como la iniciación de la formación de especialistas a través de la convocatoria de cursos sobre Pedagogía Terapéutica (González Moll, 2004). Sin embargo, la atención educativa del alumnado con sordera se mantuvo por iniciativas privadas e identidades religiosas, separados de la formación educativa ordinaria a causa de su discapacidad.

La Ley de 14/1970, de 4 de agosto, General de Educación y Financiamiento de la Reforma Educativa (LGE) es la primera medida general de atención educativa que reconoce por primera vez un cambio en las políticas educativas hacia una modalidad de educación integradora, que organiza y constituye la educación especial como un sistema paralelo al ordinario para atender al alumnado, cuyas necesidades no pueden ser cubiertas en las instituciones de régimen general (Peirats y Marín, 2018). Además, posteriormente fue respaldada por la Constitución Española (1978), que fundamentó las bases para la reforma de la política educativa con la Ley 13/1982 de Integración Social de los Minusválidos (LISMI), promulgada en 1982, que recoge los principios de normalización, integración, sectorización e individualización que difundían las políticas educativas internacionales para atender a cada alumno/a según sus necesidades en la consecución del aprendizaje.

A pesar del gran impulso que marcó la normativa educativa por hacer efectiva la integración escolar con la LISMI y el Real Decreto 334/1985, de 6 de marzo, de Ordenación de la Educación Especial para la dotación de recursos necesarios que favorezcan la integración del alumnado con discapacidad auditiva en centros ordinarios, existía una gran dificultad en la práctica educativa, debido a la falta de formación del docente, falta de recursos personales y rigidez en las actitudes sociales frente a la aceptación del alumnado con necesidades dentro de sus aulas (Peirats y Marín, 2018). Por ello, la Ley Orgánica General del Sistema Educativo (LOGSE), de 3 de octubre de 1990, reflejó un nuevo modo de entender la educación de las personas con discapacidad y modernizó la comprensión del modelo educativo a través de la consolidación de los principios y prácticas de normalización e integración iniciadas por la ley LISMI, la incorporación del concepto de necesidades educativas especiales y la formación de una nueva ordenación de la educación del alumnado con necesidades educativas especiales, en las que se encontraba adscritas las personas con discapacidad auditiva, permitiendo que 
pudieran ser escolarizados en centros ordinarios. Para reforzar este nuevo sistema educativo se promovieron medidas ordinarias de regulación de recursos materiales, organizativos y espaciales (Ley 20/1991, 5/1995 y el Real Decreto 696/1995). De este modo, la escolarización en centros específicos sólo será una alternativa cuando las necesidades del alumnado no puedan ser cubiertas desde un centro ordinario (Jimenez Lara, Huete García y Arías García, 2019; Palacios Blanco, 2004).

A partir del 2002 comienza un proceso de reformas educativas que fundamenta un nuevo cambio sociocultural en las políticas educativas sobre el alumnado con discapacidad, donde se propone avanzar hacia la inclusión de todo el alumnado. Así pues, se publica la Ley 10/2002, de 23 de diciembre, de Calidad de la Enseñanza (LOCE), donde se enfatiza la equidad de oportunidades para garantizar una adecuada respuesta educativa al alumnado con necesidades educativas especiales. Cuatro años más tarde, en el 2006, se aprobó la Ley Orgánica de Educación (LOE), 2/2006 de 3 de mayo, donde se dedica un apartado específico al alumnado con necesidad de apoyo educativo, que indica la necesidad de disponer de los recursos, apoyos y atenciones educativas específicas en un periodo o a lo largo de toda la escolarización (LOE, art. 73). Además, con el propósito de desarrollar la LOE, se publican varios Reales Decretos que hacen referencia al alumnado con necesidades educativas especiales y, por tanto, incluye al alumnado con discapacidad auditiva, donde se regulan medidas oportunas que garanticen el acceso al currículo y el curso de las enseñanzas, la formación y el ejercicio profesional en igualdad de condiciones con el resto del alumnado (Palacios Blanco, 2004). Por último, la aplicación de la Ley 8/2013 de Mejora de la Calidad Educativa (LOMCE) amplia el alumnado que puede recibir la atención educativa específica en el centro ordinario para garantizar los principios de normalización e inclusión (Jimenez Lara et al., 2019).

Así pues, la escolarización del alumnado que presenta necesidades educativas especiales derivadas de discapacidad auditiva ha sido posible gracias a las reformas educativas por parte de las Administraciones educativas, así como la reivindicación, colaboración y apoyo de asociaciones, padres y profesionales que aunaron sus esfuerzos por consolidar un modelo educativo de calidad que incluya al alumnado con discapacidad auditiva en convivencia con el resto de alumnado en centros educativos ordinarios.

La mayoría de los estados autonómicos asumieron las competencias educativas y establecieron la legislación pertinente según las orientaciones regidas por los órganos públicos de política educativa estatal como es el caso de la Comunidad Valenciana, que aplicó diversos Decretos para la ordenación de la educación para la atención del alumnado con necesidades educativas especiales en la Comunidad Valenciana (Decreto 47/1992, Decreto 39/1998). También establecieron diferentes órdenes para la 
atención a la diversidad, proporcionando recursos personales, materiales y espaciales para que alcancen los mismos objetivos curriculares que el resto de alumnado (Orden 16 julio 2001 y 18 junio 1999). Además, se ha promulgado un nuevo Decreto 104/2018 para impulsar los principios de equidad y de inclusión en el sistema educativo valenciano, así como la Orden 20/2019 que regule la organización de la respuesta educativa para la inclusión del alumnado. De este modo, la normativa educativa ha regulado la atención del alumnado con sordera mediante la dotación de recursos materiales y personales como el apoyo del especialista de audición y lenguaje en el centro educativo y la logopeda como profesional externo que apliquen programas de intervención comunicativas y auditivas, establecidas en el contexto ordinario del aula o fuera de ella para la consecución de los objetivos curriculares y de comunicación (Jimenez Lara et al., 2019).

La planificación de la respuesta educativa de los niños y niñas con sordera debe estar dirigida a al desarrollo comunicativo y lingüístico oral del alumno, estableciendo las modificaciones oportunas respecto al proyecto educativo de centro y curricular para que impere el acceso al lenguaje y las oportunidades comunicativas con el entorno social, así como el uso de recursos materiales que permitan reducir el ruido ambiental y el uso de recursos técnicos como la trasmisión de frecuencia modulada (FM), así como el uso de sistemas de comunicación aumentativos o alternativos que precise de forma temporal para un mejor acceso al lenguaje (Trinidad y Jáudenes, 2011). Como refuerzo educativo dentro de la escuela se encuentra el/la maestro/a de audición y lenguaje, que trata de estimular y mejorar su competencia lingüística a través de actividades de aprendizaje complementarias para alcanzar los objetivos curriculares. Además, también podemos optar por el/la maestro/a de pedagogía terapéutica, que tratará de reforzar los contenidos curriculares según el nivel de aprendizaje en el que se encuentre el/la alumno/a, en el caso de que el alumnado precise de la adaptación curricular individualizada de alguna didáctica, debido a la complejidad del material lingüístico o alguna dificultad en el desarrollo del aprendizaje (Monfort, 2004).

Para concluir y definir la situación actual, resultado de los logros históricos se exponen dos ejes importantes de actuaciones y dos de investigación psicoeducativa, referentes al campo específico del alumnado con sordera.

Las actuaciones legislativas más relevantes que han beneficiado el desarrollo de las personas con sordera para que puedan acceder a los recursos y medios de apoyo para el acceso y la comunicación oral están relacionadas con los avances vertiginosos de diferentes vertientes: sanitarias (medicina y audiología), educativas (rehabilitación educativa y pedagogía) y tecnológicas (la ciencia y tecnología). Se enumeran a continuación las más relevantes. 
- El screening neonatal universal que hace posible la educación temprana a través de las políticas de protección de la Salud mediante medidas preventivas y de las prestaciones de servicios necesarios. Concretamente, el 16 de marzo de 1999 en el Pleno del Congreso se aprobó por unanimidad, mediante una proposición no de ley, la creación de un Plan Nacional de Prevención de la Sordera Infantil en el Consejo Interterritorial del Sistema Nacional de Salud, en coordinación con las Comunidades Autónomas. En el año 2002 el Ministerio de Sanidad y Consumo constituyó con representantes de las Comunidades Autónomas un «Grupo para la Detección Precoz de la Hipoacusia Infantil», con el propósito de acordar los programas de prevención y detección precoz de hipoacusia infantil, sus indicadores de calidad, sus contenidos básicos y mínimos y un registro de los datos.

Los acuerdos establecidos se recogen en diferentes normativas jurídicas para regular la ordenación de las prestaciones sanitarias que garanticen condiciones adecuadas de atención integral y continuada (Ley 16/2003), así como también se reforzó con medidas y cartera de servicios comunes de salud pública que avalen la protección de la salud, la equidad y la accesibilidad a una adecuada atención sanitaria a todos los ciudadanos (Real Decreto 1030/2006).

- La aplicación de los Implantes Cocleares como servicio público, regulada por el Real Decreto 1030/2006, de 15 de septiembre, en la que se establece dentro de la cartera de servicios comunes del Sistema Nacional de Salud permite la equidad y accesibilidad a una prestación ortoprotésica sanitaria con independencia del lugar del territorio nacional en el que se encuentren los usuarios, atendiendo especialmente a las singularidades de los territorios insulares y de las Ciudades de Ceuta y Melilla.

- La regulación de los medios de apoyo a la comunicación oral de las personas con sordera, con discapacidad auditiva y sordociegas se realizó gracias a la promulgación de la Ley 27/2007, de 23 de octubre por la que se reconocen no solo las lenguas de signos españolas, sino también un aspecto fundamental como el reconocimiento de la profesión de logopedia para la atención especializada que comprende las actividades asistenciales, diagnósticas, terapéuticas y de rehabilitación y cuidados auditivos. También se exponen medidas concretas de apoyo a la comunicación oral en entornos educativos, en base a los términos establecidos en la Ley 51/2003, de 2 de diciembre, de igualdad de oportunidades, no discriminación y accesibilidad.

- La consolidación de la inclusión escolar a pesar del vacío que hay en la educación de 0 a 3 que permitiría un complemento necesario para la educación temprana, como se cita 
anteriormente con el establecimiento de los Reales Decretos, leyes orgánicas y órdenes que han impulsado la regulación de una atención educativa con garantía de calidad y en equidad para todo el alumnado.

Tal y como se expone anteriormente, la modalidad más extendida de inclusión para intervenir en el alumnado con sordera en nuestro país se lleva a cabo mediante los recursos del mismo centro educativo como el docente de audición y lenguaje para favorecer el desarrollo del lenguaje y el habla. Normalmente, se prioriza la atención del alumnado en el aula ordinaria para favorecer el desarrollo del lenguaje y la comunicación, aprovechando actividades conjuntas donde se priorice las oportunidades de interacción con sus iguales. Sin embargo, también es conveniente realizar una atención individualizada para una atención más personalizada y mejorar aquellos aspectos propios del lenguaje.

Por otro lado, en Cataluña, además de la atención educativa del maestro/a de audición y lenguaje, también presentan otro recurso la rehabilitación auditiva del alumnado con sordera. Concretamente, el alumnado que presenta dificultades en la comunicación y el lenguaje es derivado por el Equipo de Asesoramiento Psicopedagógico (EAP) de la zona a través de un protocolo de demanda específico para solicitar un servicio de apoyo intensivo de acuerdo con el régimen de autonomía del centro y con el apoyo de los servicios educativos. De esta manera, pueden intervenir directamente los profesionales que forman parte de los centros de recursos educativos para deficientes auditivos (CREDA), los cuales son logopedas con formación pedagógica en educación primaria. Dichos profesionales ofrecen servicios de apoyo a los centros educativos para que puedan proporcionar la adecuada respuesta educativa. En efecto, el centro precisa el soporte de los CREDA para que pueda desarrollar su intervención con el alumnado, la familia, el centro y el profesorado y la zona educativa, a fin de establecer de forma coordinada una respuesta ajustada a las necesidades educativas del alumnado.

Por último, cabe destacar que los avances vertiginosos en la medicina, pedagogía, ciencia y tecnología y su relación con la audición han promovido la extensión de estudios vinculados a la rehabilitación logopédica, así como las aportaciones de otras ramas de estudio han enriquecido el conocimiento y la comprensión del desarrollo de la comunicación y el lenguaje como son:

- Las aportaciones del área de la lingüística, han abierto el campo de actuación dentro de la logopedia a diferentes aspectos del lenguaje que habían pasado desapercibidas como la pragmática y el análisis del discurso, entre otras (Goberis et al., 2012; Paatsch y Toe, 2014; Rinaldi, Baruffaldi, Burdo y Caselli, 2013; Socher, Lyxell, Ellis, Gärskog, Hedström y Wass, 2019). 
- Las aportaciones de la psicología, han contribuido a la definición de la psicología del lenguaje, la cual ha aportado estudios sobre áreas vinculadas al lenguaje y la comunicación como las funciones superiores y la teoría de la mente en el alumnado con sordera (Figueroa, Darbra y Silvestre, 2020; Levrez, Bourdin, Le Driant, D'Arc, Vandromme, 2012; Meristo, Strid, Hjelmquist, 2016; Meristo y Hjelmquist, 2009).

\section{RESUMEN}

Las personas con sordera presentan dificultades para el desarrollo del lenguaje oral de forma espontánea a causa de la ausencia de la función auditiva para desempeñar el aprendizaje, en el caso de que no se puedan beneficiar de un apoyo audio protésico, acompañado con una adecuada rehabilitación logopédica. De esta manera, la sordera de nacimiento no permite ejercer la discriminación auditiva del entorno en los primeros meses de vida, así como la retroalimentación de la imitación de gestos vocálicos que constituya la formación de la etapa del balbuceo y desencadene en la expresión de las primeras palabras. El retraso en las fases previas al lenguaje perjudica indudablemente al desarrollo apropiado del lenguaje, pero afecta en consecuencia a otras áreas fundamentales que constituyen el desarrollo social, cognitivo y emocional de la persona como la comunicación y la socialización con su entorno, debido a las posibles dificultades en la comprensión e interpretación del estado mental, así como del juego simbólico, que puede derivar también en una baja estimulación de los procesos cognitivos (Liu et al., 2018; Meristo y Hjelmquist, 2009). No obstante, como hemos podido conocer en el recorrido del contexto histórico de las políticas educativas y sociales a través de la aplicación de las legislaciones educativas, así como el esfuerzo de las diversas administraciones de los diversos planes de actuación para garantizar el desarrollo de los medios tecnológicos y los servicios de rehabilitación, así como la capacidad de medios que garanticen el derecho a la educación del alumnado con sordera desde una perspectiva educativa inclusiva. 


\section{CAPÍTULO 2. LA RELACIÓN DE LOS PROCESOS PSICOLÓGICOS BÁSICOS Y EL LENGUAJE}

1. El desarrollo de las funciones ejecutivas

Las funciones cognitivas que han sido de amplio estudio científico son las que están comprendidas dentro de las áreas neurocognitivas de orden superior, denominadas como funciones ejecutivas (FE). Aunque no existe una definición universalmente aceptada de las FE, se suele adoptar una visión general de las FE como un constructo multidimensional que involucra diversas habilidades cognitivas relativamente distintas e independientes pero interrelacionadas entre sí, utilizadas para organizar, modificar, controlar y mantener la propia conducta intencionadamente (autorregulación), así como la actividad cognitiva y emocional para alcanzar un objetivo (Conway y Kronenberger, 2009).

Las FE se van diferenciando durante la primera infancia. A los tres años todavía no se aprecian habilidades independientes y se considera la conceptualización de un modelo unitario de un factor (Willoughby, Wirth y Blair, 2012). Sin embargo, el desarrollo significativo de las FE durante el transcurso de los tres y cuatro años impulsa la formación de un modelo de dos factores independientes, pero relacionados (la memoria de trabajo y el control inhibitorio) que se prolonga hasta los seis años según se van adquiriendo un mayor número de experiencias sociales mediante la recepción de información del entorno con los progresos en el desarrollo de la competencia auditiva y lingüística (Hughes y Ensor, 2011; Miller et al., 2013; Schoemaker et al., 2012; Willoughby et al., 2012). En concordancia con el desarrollo de las FE durante la etapa preescolar, se considera que la flexibilidad cognitiva también inicia su desarrollo en la infancia y promueven junto con los otros dos dominios el resto de las FE, como la organización, la planificación y la resolución de problemas (Diamond, 2013).

La memoria de trabajo es un mecanismo de la memoria a corto plazo, que ejerce la capacidad de retener información y de codificar los procesos de mantenimiento de la información verbal o visual, reelaborando la información, aplicando inferencias o consignas que permitan recordarla de manera temporal con mayor facilidad. Su actuación requiere de un alto nivel de atención mantenida y de una velocidad de procesamiento inmediata, por lo que está íntimamente relacionada con la habilidad ejecutiva de la inhibición (Cleary, Pisoni y Geers, 2001; Pisoni, Conway, Kronenberg, Henning y Anaya, 2010). En este sentido, el modelo más aceptado de la memoria de trabajo es el de Baddeley (Baddeley, 2003), el cual considera tres componentes: un área ejecutiva central que actúa de coordinador de la información que recoge de los dos subsistemas (bucle fonológico y representación viso-espacial). El bucle fonológico trata de interpretar la información fonológica y establecer representaciones temporales, estableciendo el aprendizaje del léxico y del vocabulario. La 
representación visoespacial ejecuta la misma función desde una perspectiva visual y espacial. Posteriormente, se añadió el regulador episódico, el cual se encarga de proporcionar unidades de almacenamiento temporal de la información recogida de manera verbal, espacial y visual (Baddeley, 2003).

La concentración-atención-inhibición es la capacidad de resistir impulsos, interrumpir un comportamiento o pensamiento, mantener la atención y reprimir, cohibir o moderar la interferencia de estímulos presentes en el contexto para lograr los objetivos conductuales (Barkley, 1997; Conway, Pisoni, Anaya, Karpicke y Henning, 2011). De este modo, permite a la persona permanecer en un nivel constante de atención y controlar y operar las respuestas que precisa de forma activa, manteniendo la concentración en el estímulo, así como la capacidad para ignorar los estímulos que le distraen.

Concretamente, el control inhibitorio conductual o motor se refiere a la atención selectiva, escogiendo aquello que deseamos atender y suprimiendo o ignorando los estímulos particulares. En cambio, el control de inhibición cognitiva implica la resistencia de interferencia proactiva de la información adquirida anteriormente e interferencia retroactiva de los elementos presentados posteriormente (Postle, Brush y Nick, 2004). Por tanto, el control de la información en la inhibición cognitiva precisa también el uso de la memoria de trabajo para recordar las interferencias verbales.

Respecto a la flexibilidad cognitiva, también citada como cambio de conjunto, se fundamenta en el desarrollo de las dos anteriores habilidades cognitivas (memoria de trabajo e inhibición) y se ejercita en el desarrollo individual de la persona más tardíamente, en comparación con las anteriores habilidades. Esta habilidad consiste en inhibir la perspectiva que otorgamos a un pensamiento para cambiarla o adaptarla por otras perspectivas o alternativas de manera eficiente, con el propósito de reemplazar la demanda según las necesidades del entorno y estímulos. Además, también implica la comprensión y recuerdo de los enfoques planteados por otros que sugieren adoptar otras estrategias de resolución. Por ello necesitamos la capacidad de la memoria de trabajo y de la inhibición (Diamond, 2013).

Estas tres habilidades ejecutivas desencadenan el desarrollo del resto de habilidades como la organización-integración, que se desarrolla como consecuencia de la evolución de las anteriores, e implica el control, la distribución y la planificación de la actuación de pensamientos, comportamientos y emociones que se aúnan para alcanzar el propósito mediante la organización de su ejecución (Kral et al., 2016). 
Estas habilidades no se desarrollan de forma aislada durante la infancia. Su estimulación se produce con la interacción dinámica y recíproca del lenguaje, las experiencias sensoriales y el desarrollo neurocognitivo y a su vez cada parte presenta una posición de dependencia respecto al resto para producir resultados funcionales. De esta manera, la edad auditiva de la criatura con sordera está íntimamente relacionada con el nivel de competencia lingüística que adquiere y el mayor número de interacciones sociales que establece con el entorno social, ya que permite el aumento de vocabulario, conceptos verbales, comprensión y razonamiento verbal (Figueras, Edwards y Langdon, 2008; Kral et al., 2016; Kronenberger, Colson, Henning y Pisoni, 2014). Así pues, la coincidencia en el proceso evolutivo del aprendizaje del lenguaje y el desarrollo de diferentes subsistemas de las FE que se desarrollan en diferentes momentos provoca la necesidad de que exista una compleja interdependencia entre ambas y su interacción interpersonal como resultado del proceso de cambio de los bebés sensoriomotores en procesadores simbólicos (Piaget, 1961).

Finalmente, hay que señalar, que diferentes investigaciones se han centrado en el conocimiento acerca de la relación entre las FE y el rendimiento académico durante la etapa preescolar para conocer la trascendencia del cargo que ejercen en el desarrollo. Una de las más relevantes de las FE, la memoria de trabajo, fue estudiada en este sentido por Miller, Müller, Giesbrecht, Carpendale y Kerns, (2013) que concretaron que la memoria de trabajo, se identificó como factor predictivo de habilidades preliminares en áreas de lenguaje y la aritmética y representando el 52\% y el 75\% de la varianza, respectivamente. Además, diferentes estudios longitudinales sobre la capacidad ejecutiva de la inhibición refuerzan la hipótesis de que la capacidad ejecutiva de la inhibición correlaciona con la capacidad aritmética y la alfabetización (Blair y Razza, 2007; Blair, Ursache, Greenberg y VernonFeagans, 2015; McClelland et al., 2007; Welsh, Nix, Blair, Bierman y Nelson, 2010).

La autorregulación también se ha relacionado con los aprendizajes escolares, en efecto, Blair et al., (2015) midieron los efectos de autorregulación en una muestra longitudinal de criaturas de 48 a 60 meses. Sus resultados indican una relación próxima con el área de las matemáticas y la lectura en los primeros meses, incluso cuando se controlaron las características socio-demográficas familiares. Sin embargo, sus efectos dejaron de ser significativos en lectura cuando se incluyeron las habilidades cognitivas del participante, el vocabulario y la velocidad de procesamiento, pero se mantuvo en las matemáticas. Welsh et al., (2010) comprobaron que existían trayectorias de correlación entre las habilidades cognitivas de la memoria, el control inhibitorio y la flexibilidad con las habilidades de alfabetización y aritmética emergentes durante el primer año en Educación Infantil en niños y niñas 
con una media de 4,49 años de edad, incluso después de controlar las habilidades lingüísticas y el crecimiento del dominio de las habilidades ejecutivas.

Finalmente, cabe comprender que el desarrollo lingüístico ejerce un papel importante en el desarrollo madurativo de la persona, por lo que el desarrollo de un lenguaje pobre a causa de la sordera también provoca una reorganización neuronal en la región del lóbulo frontal y sobre todo una madurez tardía de la corteza prefrontal, debido a la reducción de estímulos auditivos, que podría afectar en cascada a las dificultades en el desarrollo del aprendizaje y a los procesos cognitivos de orden superior como las FE, las cuales condicionan el desarrollo de la alfabetización, el rendimiento académico y el aprendizaje (Conway y Kronenberger, 2009).

2. La relación entre el lenguaje oral y las funciones ejecutivas

Cuando aludimos a la relación entre el pensamiento y el lenguaje hacemos referencia a dos componentes que están interrelacionados y son interdependientes. El aprendizaje del lenguaje se establece gracias a la existencia de capacidades cognitivas que potencian o limitan su desarrollo y, a su vez, el lenguaje es vínculo de expresión y desarrollo del pensamiento, así como también ejercita y estimula el desarrollo cognitivo e intelectual. Esta relación ha provocado numerosa literatura a lo largo de la historia de la Psicología, especialmente rivalizando cuál de las dos capacidades era prioritaria para el desarrollo de la otra (Piaget, 1961; Vygotsky, 1969).

En este sentido, los estudios más recientes sobre la relación entre ambos componentes se realizan en base al análisis de las funciones ejecutivas, ya que se interpreta que el lenguaje se procesaría rápidamente gracias a la aplicación de la fluidez verbal, formando bloques simbólicos a través de la organización-integración y junto con la memoria de trabajo se almacenaría la información, mientras el individuo mantiene el enfoque en el estímulo de interés, integrando la concentración-atención y utiliza la inhibición para resistir la distracción de impulsos (Cleary et al., 2001; Pisoni et al., 2010).

Sin embargo, el salto evolutivo de las FE en las edades comprendidas de tres a seis años puede que se fundamente durante el desarrollo del lenguaje, porque también se origina durante la etapa preescolar. De esta manera, la investigación de las FE en la infancia se ha conducido a indagar a cerca de la relación de interdependencia que se podría establecer entre ambas habilidades en conjunto. De hecho, Vygotsky fue el precursor en prestar atención al desarrollo del lenguaje en interacción con el contexto social como recurso de estimulación de las habilidades cognitivas (Vygotsky, 1969). 
En la actualidad, se continúa con esta línea de investigación para conocer la relación que se establecen entre el lenguaje y los procesos cognitivos durante la infancia, en la que se encuentra una evidente correlación entre la capacidad verbal y las FE en criaturas de tres, cuatro y cinco años (Carlson, Davis y Leach, 2005; Ezrine, 2011; Fuhs y Day, 2011; Gooch, Thompson, Nash, Snowling y Hulme, 2016; Hughes y Ensor, 2007; Lonigan, Lerner, Goodrich, Farrington y Allan, 2016; Weiland, Barata y Yoshikawa, 2014). De hecho, ya se observa está relación con el lenguaje emergente mediante la representación simbólica complementaria de gestos y FE a los dos años (O’Neill y Miller, 2013), por lo que se prosigue el estudio en determinar si esta relación es causal y qué dominio lidera la dirección de influencia sobre la otra. En este sentido, la teoría que recibe más apoyos es la que considera el lenguaje como precursor de las FE, porque permite tratar los procesos cognitivos, con el propósito de regular el comportamiento y el pensamiento de la criatura para alcanzar el objetivo deseado. Esta hipótesis se fundamenta en base a los principios establecidos por la teoría Cognitiva de la Complejidad y el Control (CCC) de (Zelazo et al., 2003), la cual establece que el lenguaje temprano se asocia con las habilidades ejecutivas posteriores, gracias a la asignación de etiquetas a objetos o fenómenos como mecanismo de transición a la representación de conceptos para realizar acciones que precisan de un pensamiento abstracto (Marcovitch y Zelazo, 2009).

Estudios longitudinales afirman que las habilidades lingüísticas de las criaturas promueven el desarrollo de las habilidades ejecutivas posteriores. Kuhn, Willoughby, Wilbourn, Vernon-Feagans y Blair, (2014) observaron que el uso del gesto como intercambio interactivo preliminar en criaturas normo-oyentes de 15 meses de edad predecía el desarrollo de las habilidades comunicativas de los preescolares a los 60 meses y a su vez las capacidades de las FE a los 4 años de edad. Petersen, Bates y Staples, (2015) concluyeron en una muestra de 120 criaturas de 30, 36 y 42 meses de edad normooyentes que el nivel de las habilidades lingüísticas de cada grupo de edad pronosticaba la capacidad de la autorregulación en las edades posteriores evaluadas. En cambio, no hubo relación desde la dirección de la autorregulación con la capacidad linguiística próxima, por lo que avalan que la dirección del efecto es más fuerte desde la capacidad lingüística hasta la autorregulación posterior.

Asimismo, el estudio longitudinal de Marcovitch et al., (2015) sobre las capacidades de las FE emergentes de manera temprana sugiere que el rendimiento de las FE a los 18 meses de edad proviene no sólo del desarrollo de las FE a los 14 meses, sino también de la comprensión del lenguaje y la iniciación a la atención conjunta, por lo que se considera que las FE dependen de las habilidades representativas de la información que recoge la criatura del contexto social. Según los autores, para almacenar, recordar y utilizar la información en los procesos cognitivos, se debe previamente denominar, asociar, representar y analizar esa información mediante un lenguaje simbólico dentro de 
un contexto social para que tenga significado. Finalmente, Kuhn et al., (2016) comprobaron que las criaturas de 15 a 36 meses de edad mostraban correlación entre el vocabulario y las habilidades ejecutivas, así como con la capacidad lograda en el desarrollo de las mismas a la edad 35 y 60 meses. Sin embargo, el vocabulario de los preescolares de los 36 meses no se asociaba a la capacidad ejecutiva a los 60 meses.

Una primera hipótesis de Kuhn et al., (2016) se orientó a considerar la dirección de la asociación desde el punto de vista del vocabulario receptivo, el cual puede actuar como apoyo en el desarrollo de las habilidades ejecutivas al mejorar el habla de las criaturas. Un mecanismo que probablemente explique la relación entre la capacidad verbal y el desarrollo de la FE es el habla autorregulada, donde las criaturas que tienen mayor capacidad verbal son aquellos/as que desempeñan una mayor capacidad para usar el diálogo interno, con la intención de regular y planificar sus acciones, impulsando al mismo tiempo el desarrollo de las FE.

El estudio longitudinal realizado por Fuhs y Day (2011), con una muestra de preescolares normooyentes en edad preescolar y un contexto socioeconómico bajo, evaluó la capacidad verbal mediante tres subescalas de la Escala de Inteligencia Preescolar y Primaria de Wechsler (WPPSI). En cuanto a las FE, se utilizaron dos medidas conductuales de inhibición, dos tareas sobre flexibilidad cognitiva, así como la cumplimentación de dos escalas de valoración (Inhibición y flexibilidad) del Inventario de Calificación de Comportamiento de la Función Ejecutiva (BRIEF) en versión preescolar que mide varios dominios de los comportamientos de la función ejecutiva según la concepción desde diferentes agentes educativos (progenitores o profesorado). En este caso, se recogió información por parte del equipo docente para abordar la relación de las FE con el lenguaje se compararon las FE y la capacidad verbal en dos momentos distintos, periodo estacional de otoño y primavera del mismo año preescolar y se observó que la habilidad verbal fue un predictor significativo de los cambios que se producen en las FE posteriormente. Aunque hay que señalar que sus resultados son correlacionales más que experimentales, por lo que es necesaria una mayor investigación para identificar cómo la habilidad verbal potencia el desarrollo de las FE.

Alarcón-Rubio, Sánchez-Medina y Prieto-García, (2014) realizaron un estudio sobre la mediación verbal en el desarrollo de una actividad que requería flexibilidad cognitiva en criaturas de cuatro a siete años normo-oyentes. Para ello, administraron una prueba de vocabulario receptivo con el test de vocabulario en imágenes de Peabody (PPVT), una versión española de la subescala de similitudes de la batería de inteligencia de Weschsler para preescolar y primaria (WPPSI-III) para evaluar la comprensión verbal de las criaturas, para evaluar su capacidad para construir relaciones y hacer correlaciones analógicas se utilizó la prueba de matrices de color de Raven y la tarea de función 
ejecutiva de cambio dimensional (DGCS) para evaluar la FE durante la infancia. Esta última prueba fue útil, a fin de conocer de qué manera los niños pueden usar reglas de orden superior que les permita cambiar de manera flexible la reglas en la tarea de clasificación de tarjetas de cambio dimensional (DGCS), así como observar la frecuencia de uso del habla privada externalizada según su edad. Sus resultados indicaron que el desempeño de la tarea DCCS se relacionó con el grado de uso del habla privada del niño. Esta relación fue independiente de variables como la edad, el género, las habilidades verbales y la inteligencia, por tanto, la internalización del habla puede favorecer el rendimiento de la flexibilidad cognitiva. Por una parte, la resolución de la tarea DCCS, la edad y la capacidad verbal se han relacionado con la cantidad de elementos correctos en la actividad de flexibilidad y por otra, la cantidad de enunciados de habla privada, parcialmente internalizados por minuto, está significativamente asociada con el cambio cualitativo entre fases. Este estudio confirma los hallazgos por Fernyhough y Fradley, (2005), donde observan en preescolares de cinco y seis años normooyentes, la relación recíproca entre el desempeño de la tarea, la dificultad de su ejecución y el grado de discurso interno que muestra el participante.

Así pues, los estudios anteriores son consistentes con la teoría de Vygotsky, (1969) sobre el papel que ejerce la habilidad verbal en la autorregulación. Concretamente, se considera que la capacidad verbal impulsa el desarrollo de las FE, debido al desarrollo del diálogo interno de las criaturas, o discurso privado que no se externaliza a los demás y que se utiliza como soporte en la resolución de problemas. De esta manera, el lenguaje media como herramienta para reducir la dificultad en la resolución exitosa de las acciones, en las que debe mantener más de una orden, inhibir las respuestas inapropiadas y mantener su atención con el propósito de reducir el grado de dificultad en la resolución de las acciones que requieren de procesos cognitivos (Fuhs y Day, 2011).

Otro factor cognitivo que consideramos relevante para el desarrollo del lenguaje es la inhibición, debido al esfuerzo que debe realizar la persona para desatender los estímulos distractores de su entorno para concentrarse en la ejecución de una tarea, en este caso, la producción o percepción del lenguaje.

La autorregulación ejerce un papel importante en las competencias académicas. McClelland et al., (2007) observaron en preescolares $(\mathrm{N}=310)$ que la puntuación en autorregulación se relacionó de manera significativa con la alfabetización, el vocabulario y las habilidades matemáticas durante el curso escolar de Educación Infantil. Welsh et al., (2010) confirmaron estas conclusiones con un estudio ampliado con 164 preescolares, donde se evaluaron las habilidades de memoria de trabajo y control inhibitorio en tres momentos distintos: en el inicio del curso de preescolar, al acabar el curso y cuando terminaron la etapa de Educación infantil. Ambas habilidades cognitivas predicen el desarrollo de las 
habilidades lingüísticas y aritméticas durante el año escolar y al acabar la etapa infantil. Las dos evaluaciones antes del inicio de la etapa de educación primaria indican la relevancia que ejercen las habilidades ejecutivas de la memoria y la inhibición en el aprendizaje.

El control inhibitorio tiene una íntima relación con el lenguaje demostrado por varios estudios. Así Petersen et al., (2013) realizaron dos estudios, donde analizaron la asociación de la habilidad del lenguaje sobre los problemas de conducta y la direccionalidad de su relación. El primer estudio se realizó en niños/as normo-oyentes $(\mathrm{N}=585)$ de 7 a 13 años, donde se valoró los problemas conductuales, a través de escalas de valoración de los progenitores y docentes. Sus resultados mostraron una relación significativa con la capacidad lingüística, evaluada con un test estandarizado, por tanto, aquellos que mostraban un bajo nivel linguístico expresaban un mayor número de conductas disruptivas. El segundo estudio de Petersen et al., (2013) replicó la anterior investigación, ampliando el número de participantes normo-oyentes $(\mathrm{N}=11.506)$ de 4 a 12 años y evaluando las habilidades del lenguaje y el comportamiento cada dos años. Sus resultados confirmaron de manera consistente la relación predictiva del lenguaje sobre los problemas de conducta posteriores. De hecho, esta relación predictiva se establece ya en edad infantil como demuestra el estudio realizado por Petersen et al., (2015) con una evaluación longitudinal a 159 participantes en 3 momentos distintos (30, 36 y 40 meses) a través de la medición del control inhibitorio con tres tareas y la capacidad lingüística. El análisis de los datos comprobó que el nivel lingüístico tiene un efecto directo en los problemas conductuales posteriores, pero son mediados por la autorregulación, por tanto, el retraso en el lenguaje puede desarrollar una autorregulación pobre y desencadenar en conductas disruptivas. Además, la relación no es bidireccional, por tanto, el lenguaje ejerce una función reguladora en el comportamiento de la persona y desencadena la activación del desarrollo de las FE.

La baja habilidad cognitiva en FE también se expresa a través de las conductas disruptivas, dado que no permiten al niño/a autorregularse. Hughes y Ensor, (2011), utilizando un estudio longitudinal de participantes normo-oyentes $(\mathrm{N}=191)$ de 4 a 6 años de edad según el análisis de las tareas de FE que se administraron (control inhibitorio, memoria de trabajo y planificación), observaron que la variación de la pendiente en las puntuaciones sobre estas áreas de las FE, se correlacionaba con la percepción de los docentes sobre la conducta y la competencia académica de los preescolares. Además, la baja ganancia en las FE predijo de manera significativa la competencia socioemocional, provocando síntomas emocionales, hiperactividad y problemas de conducta.

Espy, Sheffield, Wiebe, Clark y Moehr (2011) evaluaron a criaturas entre 29 y 72 meses (N=243) en diferentes tareas sobre control ejecutivo, definido como el conjunto de habilidades para actuar o 
responder de manera flexible al objetivo. Los autores valoraron diversas FE (memoria espacial, memoria verbal, inhibición y atención visual) a través de varias pruebas estandarizadas, así como, también, con la información de los progenitores, quienes cumplimentaron diferentes cuestionarios acerca del comportamiento de sus hijos/as para determinar a través de un análisis factorial cuál era el modelo factorial que más se ajustaba a la relación entre el control ejecutivo y el comportamiento problemático en todo el amplio espectro. Según los diferentes modelos factoriales, el que más se ajustaba a los datos observados fue la construcción de cuatro grupos: "comportamientos hiperactivos", "comportamientos de desinhibición", "problemas de atención" y "comportamientos desreguladores de emociones", donde la memoria verbal se agrupa dentro de "problemas de atención" y el control inhibitorio se sitúa dentro del grupo de "comportamientos de desinhibición". Particularmente, en el trabajo se registró que el control ejecutivo en edad preescolar se relacionaba de manera directa con los comportamientos externos como la hiperactividad, desatención y desinhibición, así como con aspectos de falta de regulación emocional, cuando controlaron la inteligencia infantil. De hecho, un estudio de meta-análisis sobre preescolares de 3 a 6 años realizado por Schoemaker, Mulder, Deković y Matthys, (2013) apoyan esta hipótesis, pero considera que el déficit en la FE de control-inhibición incide con mayor fuerza sobre el autocontrol de la criatura en edades comprendidas de 4;05 a 6 años en comparación con otras habilidades ejecutivas como la memoria de trabajo y la flexibilidad, por lo que la baja capacidad de inhibición predice la incidencia de problemas conductuales y al desarrollo del lenguaje en edad escolar.

Otra línea de investigación ha sugerido que el lenguaje puede actuar como un facilitador de las FE, en lugar de ser antecesor, ayudando en la asignación de denominaciones durante el ejercicio de una actividad. En este sentido, Kirkham, Cruess y Diamond, (2003) en un estudio empírico, en el que preescolares de tres y cuatro años debían clasificar las mismas cartas según iba cambiando el criterio de forma o color, concluyeron que el grupo de preescolares de tres años obtenía un mejor rendimiento en la tarea de flexibilidad en el cambio según el criterio impuesto, cuando la ejecución de la tarea venía acompañada por el uso de la etiqueta verbal del participante, en comparación con sus compañeros/as que escucharon la etiqueta del experimentador, pero no verbalizaron la asignación del nombre a la clasificación. El apoyo verbal se utilizaba para recordar la dimensión de clasificación de las cartas y permitía su autorregulación. A las mismas conclusiones llegaron, Miller y Marcovitch, (2011), que evaluaron a criaturas mayores de 2 años para conocer si podían beneficiarse de la asignación de etiquetas en imágenes mediante una tarea informatizada, adaptada a su edad, dónde debían buscar el objeto en ubicaciones múltiples. Las criaturas fueron expuestas a cuatro condiciones para ejecutar la tarea (cajas sin apoyo visual, con apoyo visual, con apoyo visual y etiqueta del examinador, con apoyo 
visual y etiqueta del participante). En este trabajo, los participantes obtuvieron mayor rendimiento en el desempeño de la tarea cuando se les solicita que fueran ellos mismos quienes generaran una etiqueta en el lugar donde se había escondido el objeto previamente.

Estos estudios confluyen con las conclusiones de investigaciones anteriores, donde la denominación verbal, como la etiqueta, actúa como mediación verbal en las criaturas para inhibir los distractores y dirigir su atención en el estímulo apropiado (Muller, Zelazo, Hood, Leone y Rohrer, 2004; Yerys y Munakata, 2006). No obstante, sus resultados entran en conflicto con los hallazgos de otros estudios, en los que determinan que la dirección de la relación entre el lenguaje y las FE no está condicionada por el vocabulario, porque no se encontró un efecto en el rendimiento según el uso de asignar etiquetas en la tarea de flexibilidad en el cambio. Concretamente, Müller, Zelazo, Lurye y Liebermann, (2008) realizaron 3 experimentos para indagar la influencia que ejerce la etiqueta en el rendimiento de la flexibilidad cognitiva a través de la tarea DCCS. En el primer experimento, se presentaron las siguientes opciones de etiquetado (estándar de la tarea DCCS, donde se asignó el cambio de clasificación (color/forma de los objetos) sin una inducción verbal, etiquetado inespecífico, que induce a la separación de los objetos mediante preguntas (¿qué color es?, ¿qué forma tiene?) antes y después del cambio de clasificación y, por último, la etiqueta especifica que se realiza también mediante las mismas cuestiones, pero durante cada prueba. Los resultados mostraron que estas diferentes modalidades de asignación no proporcionaron a los niños y las niñas una estructura más conceptual ni tampoco favoreció el cambio atencional a las nuevas asignaciones de características de los objetos, por tanto, no se halló beneficio a la inducción verbal de la etiquetación. En el experimento 2, trataron de examinar con más interés las condiciones de etiquetaje, mediante la realización de una fase de entrenamiento, pero tampoco, encontraron un efecto positivo en el rendimiento. En el experimento 3 se valoró las diferentes formas de etiquetado, presentando la asignación de las categorías en diferente orden, presentando las características de manera conjunta (forma y color) o sólo presentando una de ellas, a fin de mejorar el rendimiento. Sin embargo, tampoco encontraron ningún resultado beneficioso en las diferentes alternativas. En efecto, la denominación verbal no obtiene fácilmente un mejor rendimiento en la flexibilidad cognitiva, debido a la dificultad del cambio de atención restringida a un rasgo, ya que se obtuvo un mejor rendimiento en la tarea de clasificación cuando se realizó con asignación específica.

Otro estudio realizado por Weiland et al., (2014) evaluaron una gran muestra de 400 preescolares de 4 años con dos medidas sobre memoria de trabajo (el componente ejecutivo central y el circuito fonológico). También se midió la flexibilidad cognitiva y el control inhibitorio. En cuanto al lenguaje, se evaluó el vocabulario receptivo de los niños. Las FE evaluadas al comienzo del preescolar predijeron significativamente el vocabulario receptivo al final de curso preescolar, controlando el vocabulario 
receptivo, medido al inicio. Sin embargo, esta relación no fue recíproca, ya que el vocabulario receptivo al comienzo del preescolar no se asoció con las FE medidas al final del curso preescolar, después de controlar las FE en el primer momento.

En definitiva, podemos comprender que existe una relación correlacional entre el lenguaje y las FE, pero la compleja interdependencia de subsistemas de las funciones ejecutivas, que muestran diferente tiempo de desarrollo, junto con otras variables que influyen como otras dimensiones de la capacidad cognitiva, la competencia lingüística o el contexto social, entre otras, producen como acción final una gran variabilidad interindividual sobre el desarrollo neurocognitivo. Además, aunque se controlen estas variables, la diversidad metodológica y las tareas propuestas de evaluación dificultan encontrar un consenso científico sobre la causa-efecto entre ambas dimensiones.

Otra alternativa para abordar esta cuestión es la investigación comparativa entre criaturas normooyentes y con las que presentan dificultades en el desarrollo. De esta manera, se trata de explorar la dirección de esta relación entre las habilidades cognitivas y el lenguaje, aprovechando la oportunidad de conocer cómo evolucionan y se interrelacionan el lenguaje y las FE, a fin de averiguar si el déficit en un dominio, afecta al otro. Por ejemplo, los preescolares con trastorno del espectro autista manifiestan déficit general de las FE en comparación con el grupo control neurotípico (Demetriou et al., 2018; Lai et al., 2017), también, las personas con trastorno por déficit de atención con hiperactividad también mostraban dificultades en el desarrollo de las habilidades cognitivas, concretamente en la memoria de trabajo, fluidez verbal e inhibición, respaldado también por la valoración de los padres (Huang et al., 2016; Mahone y Hoffman, 2007; Skogan et al., 2015; Zhang et al., 2018). Asimismo, en un estudio longitudinal relacionado con el riesgo en el trastorno de aprendizaje de la lectoescritura (dislexia) se ha concluido que las dificultades del lenguaje no causaban déficit en las funciones ejecutivas y el efecto a la inversa expresaba una relación más fuerte, pero no alcanzó a ser significativa. No obstante, las FE a los tres años tienen una repercusión significativa con el desarrollo del lenguaje a los cuatro años (Gooch et al., 2016) y finalmente, las criaturas con retraso severo en habilidades lingüísticas también obtuvieron habilidades ejecutivas más pobres (Acosta Rodríguez, Ramírez Santana y Hernández Expósito, 2017; Henry, Messer y Nash, 2012). También en la etapa infantil de 2 a 6 años con sospecha de Trastorno específico del lenguaje, se observan dificultades ya en los dos dominios que comienzan a diferenciarse, la memoria de trabajo y la inhibición (Vissers, Koolen, Hermans, Scheper y Knoors, 2015).

A pesar de que se observa una correlación significativa entre ambos dominios en grupos con dificultades en el desarrollo, no se puede averiguar quién media la una a la otra, debido a que interviene 
el nivel cognitivo y puede confundir los resultados, por tanto, las aportaciones sobre la relación de las FE con el lenguaje en la población con sordera nos ofrece la oportunidad de explorar su vínculo de manera excepcional, puesto que las dificultades que expresa está población en el lenguaje no provienen de un trastorno neurocognitivo, sino de la falta de experiencias auditivas tempranas, ya que el aprendizaje de las habilidades lingüísticas viene mediado por una condición decisiva como la base sensorial auditiva para un crecimiento evolutivo óptimo (Botting et al., 2017).

\section{RESUMEN}

En resumen, las funciones ejecutivas inician su desarrollo e en la primera etapa de la educación infantil, donde la memoria y la inhibición ejercen un papel relevante y desencadena el ejercicio de desarrollo a otras habilidades ejecutivas más complejas como la flexibilidad, la organización y la planificación. De este modo, las habilidades ejecutivas se estimulan gracias a su reciprocidad con el área del lenguaje, por lo que un lenguaje tardío y pobre limita su desarrollo y puede conducir a una reorganización funcional de las habilidades cognitivas de nivel superior, así como una repercusión negativa en el rendimiento académico y la autoregulación.

Particularmente, se ha demostrado la relación que expresa el lenguaje y la inhibición, la cual se resume en la tabla que se presenta a continuación:

Tabla 1.

Resumen de estudios sobre la relación entre el lenguaje oral y la inhibición.

\begin{tabular}{|c|c|c|}
\hline Autores & Relación lenguaje - inhibición & Valoración de los resultados \\
\hline Petersen et al., (2013) & $\begin{array}{l}\text { Los datos afirmaron la relación } \\
\text { predictiva del lenguaje sobre los } \\
\text { problemas de conducta } \\
\text { posteriores. }\end{array}$ & $\begin{array}{l}\text { Las escalas de valoración de los } \\
\text { progenitores y los docentes muestran } \\
\text { la asociación entre el lenguaje y los } \\
\text { problemas conductuales del } \\
\text { alumnado con sordera. }\end{array}$ \\
\hline Petersen et al., (2015) & $\begin{array}{l}\text { La evaluación longitudinal ha } \\
\text { demostrado que el nivel } \\
\text { lingüístico tiene un efecto } \\
\text { directo en los problemas } \\
\text { conductuales posteriores. }\end{array}$ & $\begin{array}{l}\text { El lenguaje pobre promueve el } \\
\text { desarrollo de problemas disruptivos } \\
\text { en la etapa infantil, aunque la } \\
\text { autorregulación influye en su } \\
\text { frecuencia. }\end{array}$ \\
\hline
\end{tabular}




\begin{tabular}{|c|c|c|}
\hline Autores & $\begin{array}{l}\text { Relación inhibición-conductas } \\
\text { disruptivas }\end{array}$ & Valoración de los resultados \\
\hline Hughes y Ensor, (2011) & $\begin{array}{l}\text { La puntuación en las áreas de las } \\
\text { FE marca la pendiente de la } \\
\text { percepción conductual y la } \\
\text { competencia académica de los } \\
\text { preescolares. }\end{array}$ & $\begin{array}{l}\text { Las puntuaciones en las habilidades } \\
\text { ejecutivas determinan el desarrollo } \\
\text { de la conducta y la competencia } \\
\text { académica según la percepción } \\
\text { subjetiva del equipo docente. }\end{array}$ \\
\hline Espy et al., (2011) & $\begin{array}{l}\text { La medición de tareas de control } \\
\text { ejecutivo en edad preescolar se } \\
\text { relaciona directamente con la } \\
\text { valoración de la regulación } \\
\text { conductual y emocional. }\end{array}$ & $\begin{array}{l}\text { El déficit en el desarrollo de la } \\
\text { función ejecutiva del control } \\
\text { ejecutivo manifiesta dificultades de } \\
\text { autorregulación del comportamiento } \\
\text { conductual externo como la } \\
\text { hiperactividad, desatención y } \\
\text { desinhibición, así como emocional } \\
\text { en población infantil. }\end{array}$ \\
\hline $\begin{array}{l}\text { Schoemaker et al., } \\
\text { (2013) }\end{array}$ & $\begin{array}{l}\text { El meta-análisis demuestra que } \\
\text { los preescolares con déficit en } \\
\text { las FE expresan dificultades en } \\
\text { el autocontrol, pero se intensifica } \\
\text { según el desarrollo del control } \\
\text { inhibitorio. }\end{array}$ & $\begin{array}{l}\text { La baja estimulación de las FE deriva } \\
\text { en una mayor dificultad para la } \\
\text { autorregulación, pero se determina } \\
\text { principalmente por el déficit en el } \\
\text { desarrollo del control inhibitorio. }\end{array}$ \\
\hline
\end{tabular}

Las FE y, en particular la inhibición, ejercen una relación de interdependencia con el lenguaje, pero todavía es ambigua la direccionalidad de la dependencia, por lo que se buscan otras vías de ampliación del conocimiento mediante el estudio de muestra de población con diferentes patologías neurológicas. No obstante, el déficit en esta área deriva dificultades en otras áreas como el autocontrol que intensifica la frecuencia de conductas disruptivas.

Así pues, estos estudios que muestran la relación de las FE con el lenguaje y la limitación en el desarrollo de las FE ante las dificultades en el lenguaje han despertado nuestro interés por aportar un mayor conocimiento acerca del desarrollo de estas habilidades cognitivas y su relación con las habilidades lingüísticas en la infancia, ya que todavía hay escasos estudios sobre las FE emergentes. 


\section{CAPÍTULO 3: EL DESARROLLO DEL LENGUAJE Y LAS HABILIDADES COGNITIVAS EN LAS PERSONAS CON SORDERA}

\section{La competencia lingüística y las funciones ejecutivas en criaturas con sordera}

Lamentablemente, el número de estudios con población infantil con sordera que ha profundidzado en el análisis del comportamiento de las FE y el lenguaje es reducido. La mayoría de estudios son de corte transversal por lo que dificulta obtener conclusiones fiables sobre el cargo que ejerce el lenguaje sobre las FE o al contrario, pero los escasos resultados obtenidos aportan datos valiosos que permiten contemplar su relación de forma cognitivamente más solvente e integrada. En general, la revisión de la literatura científica sobre el desarrollo de las FE en criaturas con sordera muestra que éstas corren el riesgo de presentar dificultades en su desarrollo. No obstante, las causas de estas limitaciones no están bien definidas, dado que se desconoce si provienen de la falta de audición temprana o es la consecuencia derivada de la sordera que provoca el retraso en el lenguaje. Así pues, sugiere la duda de si estas limitaciones se presentan también en personas con sordera, nativas en lengua de signos, ya que, en principio, sólo tendrían afectado el desarrollo auditivo, pero no el desarrollo de la competencia lingüística mediante la lengua de signos. Por ello se inicia esta revisión con los estudios sobre la competencia en FE de la población con sordera según la lengua dominante para exponer en los siguientes apartados el estado de la cuestión en el grupo con IC que utiliza el lenguaje oral.

\subsection{Lengua de signos y funciones ejecutivas}

La diversidad de la población con sordera ofrece una situación heterogénea muy interesante para investigar sobre el efecto que provoca la pérdida auditiva en el desarrollo de la competencia comunicativa y lingüística. En efecto, cabe preguntarse de qué manera se desarrollan las funciones ejecutivas en las personas con sordera, hablantes nativos en lengua de signos, a fin de conocer y profundizar sobre la repercusión que establece el lenguaje y la privación auditiva en el área neurocognitiva.

Hall, Eigsti, Bortfeld y Lillo-Martin, (2018) evaluaron a 116 niños y niñas de 5 a 12 años, clasificados en los siguientes términos: grupo normo-oyente $(\mathrm{N}=45)$, grupo de escolares con sordera, signantes nativos desde el nacimiento $(\mathrm{N}=45)$ y usuarios de implante coclear, con modo de comunicación oral $(n=26)$. Los autores evaluaron las habilidades ejecutivas a través del BRIEF y la realización de pruebas objetivas que medían principalmente inhibición-concentración-atención, memoria visoespacial, planificación y resolución de problemas. Cada una de las habilidades por separado, no revelaron diferencias significativas en las puntuaciones de los escolares con sordera (signante y con IC) respecto a sus compañeros/as normo-oyentes. No obstante, el riesgo fue mayor 
para los usuarios de IC, pero en ningún caso fue estadísticamente significativo. Del mismo modo, la agrupación de estas medidas como una sola variable para conocer el rendimiento general de la función ejecutiva se observó que no se produjeron diferencias significativas entre grupos, pero las razones de riesgo relativo de una o más desviaciones estándar de la media indicó que el grupo de participantes con sordera signantes nativos mostraban un riesgo en el desarrollo de las habilidades ejecutivas de 1.38 en relación con el grupo de niños y niñas normo-oyentes, mientras que la razón de riesgo para los usuarios de IC fue mayor (2.24). En el caso del grupo de usuarios con IC se encontró que también presentan riesgo en comparación con su grupo de iguales con sordera, nativos en lengua de signos de 1.63. Respecto al informe de valoración de los progenitores sobre el comportamiento de las habilidades ejecutivas en su vida cotidiana, estos mismos autores, observaron la tendencia a un mayor riesgo en las subescalas de memoria de trabajo e inhibición del grupo de niños/as con sordera, tanto de los participantes que utilizan el IC, como los nativos en lengua de signos, en comparación con sus compañeros/as normo-oyentes. En cambio, la comparación entre grupos con sordera se indicó un mejor pronóstico en el desarrollo de las habilidades ejecutivas en el grupo de signantes de lengua de signos, debido a que han tenido acceso al lenguaje de manera temprana, pues únicamente presentaban déficit en flexibilidad, control de la emoción, atención, autorregulación, metacognición y el cómputo general de las FE. No obstante, no se detectó en las subescalas que, normalmente, obtienen mayor frecuencia de déficit como la memoria de trabajo y la inhibición. Además, la comparación de los informes del grupo nativo en lengua de signos sobre la muestra normo-oyente reduce las puntuaciones significativas a dos subtipos: flexibilidad y cómputo global de las FE, en contraste con el grupo de escolares con IC que presenta déficit en todos los subtipos frente a las puntuaciones del grupo de referencia normooyente (Hall et al., 2018).

Por otro lado, en lo que respecta a las personas, nativas en lengua de signos, la mayoría de los estudios se han concentrado en sólo un componente de las FE: la memoria a corto plazo, a fin conocer si la limitación en solo un componente (la audición) permite un adecuado desarrollo neurocognitivo de la memoria.

Marschark et al., (2015) comprobaron en un estudio comparativo sobre la memoria viso-espacial, realizado con participantes con sordera $(\mathrm{N}=75)$ de edades comprendidas entre 17 y 35 años con una media de 19,1 años que difería según el uso del apoyo audio protésico del IC, que lo recibieron de media a los 7 años $(\mathrm{N}=33)$ y sin audioprótesis $(\mathrm{N}=42)$. Entre los usuarios de IC, 28 indicaron que tenían conocimientos suficientes de lengua de signos y los que no utilizaban prótesis auditiva indicaron que tenían pleno conocimiento de lengua de signos excepto 6 personas. En cuanto a los participantes normo-oyentes $(\mathrm{N}=45), 8$ eran estudiantes de interpretación de lengua de signos, pero no se 
consideraba que ninguno tuviera fluidez. Así pues, todos los grupos de participantes variaban en sus habilidades de lengua de signos, evaluadas formalmente. Para evaluar la memoria viso-espacial, se aplicó la tarea de Bloques de Corsi y observaron que los grupos no mostraron diferencias significativas en su rendimiento, ni tampoco destacaron entre los grupos con sordera con diferencia de conocimiento en el lenguaje de signos. Además, el análisis de correlaciones asoció el rendimiento de la tarea de los Bloques de Corsi con la modalidad de lenguaje que mayor habilidad mostraban los participantes con sordera, es decir, aquellos que utilizaban el implante coclear mostraban una mayor relación con el lenguaje oral y aquellos que no usaban este dispositivo auditivo, se vinculó con la lengua de signos y la edad de aprendizaje.

De todas formas, la relación entre la capacidad de la memoria espacial con el modo de comunicación no se pone de manifiesto en el caso del rendimiento en la memoria a corto plazo. En efecto, según diferentes estudios los participantes con sordera, independientemente de su lengua dominante, presentan déficit en esta área. Bavelier, Newport, Hall, Supalla y Boutla, (2008) realizaron un estudio sobre el recuerdo de dígitos hacia delante y hacia atrás presentadas en diferentes formatos (signado y oral) en personas adultas con sordera, nativos en lengua de signos y en un grupo normo-oyentes, a fin de indagar acerca del mejor acceso a la retención de la información. Los resultados de las diferentes pruebas respaldaron la conclusión de que las personas con sordera, que utilizan lengua de signos, mostraban una memoria a corto plazo reducida, tanto en orden directo, como inverso, cuando se precisaba la recuperación de los dígitos en orden temporal, pero en cambio, cuando la recuperación de los dígitos era libre, alcanzaban la capacidad comparable al del grupo normo-oyente. Este resultado es interesante porque, refleja las diferencias en el procesamiento o mantenimiento de la información en orden temporal, procesos favorecidos, en mayor medida, por la lengua oral que por la lengua de signos.

Del mismo modo, Hall y Bavelier, (2011) analizaron el proceso de memoria a corto plazo de cada etapa (percepción, codificación y recuerdo) tanto en lengua de signos americana (LSA) como en lengua oral en un grupo normo-oyente bilingüe en lengua de signos y lengua oral $(\mathrm{N}=61)$, que tenían padres con sordera y adquirieron el LSA y el lenguaje oral como primer idioma y $(\mathrm{N}=30)$ eran personas que aprendieron LSA en la adolescencia. Los resultados muestran que el uso de la LSA perjudica a la percepción y codificación de los dígitos en la resolución de la tarea de memoria a corto plazo, en comparación con el desarrollo de la tarea en el modo de expresión oral, dado que el lenguaje oral produce intervalos de dígitos más largos. En cambio, el uso de la LSA intensifica el rendimiento para la recuperación de los dígitos. No obstante, comprobaron que la competencia en LSA no presenta una relación directa con el desarrollo de la memoria. Por ello, Hall y Bavelier, (2011) consideraron que el rendimiento de la recuperación en serie es eficiente cuando se utilizan representaciones lingüísticas verbales, debido a la relación entre elementos verbales como el bucle fonológico y la memoria. Sin 
embargo, como el análisis de los datos proviene de un diseño intra-sujetos con participantes normooyentes, la comparación con los resultados inferiores de las personas usuarias del LSA tampoco se puede interpretar como estrategias mnemotécnicas pobres en dicho colectivo, dado que no se ha encontrado desventajas en las tres etapas de la memoria (percepción, codificación y recuerdo).

Finalmente, el estudio realizado por Marschark, Sarchet y Trani, (2016) con participantes universitarios ( $\mathrm{N}=152), 85$ con sordera y 67 normo-oyentes. Los 85 participantes con sordera, que en su totalidad habían aprendido lengua de signos de forma incidental, sólo 40 alumnos/as habían recibido implantes cocleares. Asimismo, también se recogieron universitarios normo-oyentes $(\mathrm{N}=67)$, de los cuales 33 participantes se habían inscrito en el aprendizaje de la lengua de signos. De este modo, se realizó la evaluación de la memoria de trabajo para conocer las diferencias que podían presentar los participantes según los criterios de sordera/normo-oyente, usuario de IC/sin apoyo audio protésico, con/ sin conocimientos de lengua de signos. El análisis de sus resultados encontró diferencias significativas en el grupo de participantes con sordera en dos de las tareas sobre memoria, en la cual se precisaba de la contribución de la codificación verbal, independientemente del modo de expresión de los participantes (lengua de signos/lengua oral), el nivel en lengua de signos, así como uso o no de IC. Además, se demostró que el rendimiento de la memoria de trabajo estaba íntimamente relacionado con el lenguaje oral cuando la tarea requería de codificación verbal y mantener información secuencial o temporal.

En conclusión, podemos determinar que estos estudios muestran la consistencia de la relación entre el lenguaje y las FE, y, además, ponen en el punto de mira el desarrollo de las tres habilidades ejecutivas más próximas al lenguaje: la memoria de trabajo, la inhibición-concentración y la fluidez del habla, a causa del riesgo evolutivo en las personas con sordera, ya que la privación sensorial temprana perjudica la estimulación del neurodesarrollo, incluso no exime del peligro en aquellos que utilizan la lengua de signos como lengua materna. Al parecer, la falta de exposición temprana al lenguaje durante la primera infancia tiene un mayor impacto negativo en la memoria de trabajo, que la falta de capacidad auditiva y, por tanto, puede ser un factor de protección, porque permite aplicar una estructura abstracta como medio para la autorregulación y la metacognición precozmente (Andrej Kral et al., 2016). No obstante, igualmente, algunos estudios destacan este déficit en las criaturas con sordera, usuarias de IC o nativas en lengua de signos (Botting et al., 2017; Conway y Kronenberger, 2009; Jones et al., 2019). 
1.2. El lenguaje oral y las funciones ejecutivas en las criaturas con implante coclear IC

Los estudios que contemplan la relación entre estas variables se agrupan en tres apartados según las perspectivas con las que se han enfocado los estudios.

a) Estudios transversales en las distintas etapas educativas

Los estudios de corte transversal que se presentan a continuación recogen información acerca del desarrollo de las FE en diferentes edades, a fin de obtener una perspectiva global sobre los procesos de cambio en los diferentes niveles educativos.

En la etapa preescolar hay escasas investigaciones sobre el desarrollo de las FE en el campo de la sordera, que reflejen la relación entre el lenguaje y las FE. Un estudio de gran interés es el de Beer et al., (2014), que evalúa la relación entre el lenguaje y las FE en preescolares de 3 a 6 años, mediante la comparación de un grupo de niños y niñas, usuarios de implante coclear (IC) ( $\mathrm{N}=24)$ y un grupo normo-oyente $(\mathrm{N}=21)$. Concretamente, se evaluaron la memoria a corto plazo, la inhibiciónconcentración y la organización-integración a través de tres pruebas neurocognitivas no verbales, que se seleccionaron para evaluar un área central específica del dominio general ejecutivo-organizacionalintegrador (EOI). También completaron una prueba de inteligencia no verbal y otra sobre el lenguaje a nivel global. A su vez, los progenitores cumplimentaron el cuestionario BRIEF en versión preescolar en las subescalas de control inhibitorio, memoria de trabajo y planificación / organización. Los autores concluyeron que los niños y las niñas con IC obtuvieron puntuaciones más bajas que sus compañeros/as normo-oyentes en la medida de inhibición-concentración y, en cambio, no se encontraron diferencias significativas a nivel grupal en las medidas de memoria visual e integración organizacional.

No obstante, Beer et al., (2014) comprobaron que hay un mayor porcentaje de preescolares con IC que habían obtenido puntuaciones significativamente bajas en comparación con el grupo de referencia en todas las medidas de rendimiento y problemas de comportamiento valorados por los progenitores en el control inhibitorio y la memoria de trabajo, por lo que tienen un mayor riesgo de presencia de dificultades en el desarrollo de las habilidades ejecutivas en niños y niñas con IC en edad preescolar. Además, las correlaciones entre el lenguaje y las pruebas BRIEF de EOI (memoria y planificación) revelaron correlaciones significativas para el grupo de IC, pero no para el grupo de preescolares normooyentes. En este estudio se puede interpretar que el riesgo de retraso en el lenguaje puede agravar las dificultades en el desarrollo de las EOI, o bien que, si se presenta un lenguaje deficitario, precise más que los oyentes, el soporte de las FE. 
La evaluación de niños/as preescolares con sordera son muy escasos, sólo se ha realizado otro estudio reciente en el que Nicastri et al., (2020) valoraron las FE de la flexibilidad, inhibición cognitiva y habilidades de trabajo visoespacial en participantes 3-6 años con IC $(\mathrm{N}=25)$. Las puntuaciones en cada tarea evaluada se compraron con el grupo de referencia normo-oyente, que recoge la Batería de evaluación de Funciones Ejecutivas (BAFE), empleada para evaluar las funciones ejecutivas. Los resultados mostraron que el alumnado con sordera, identificados antes de los 6 meses de edad y que recibieron IC a los 12 meses de edad, presentaba un desempeño apropiado en todas las pruebas. En cambio, aquellos que recibieron un diagnóstico más tardío presentaron más dificultades en el control del control inhibitorio y de la memoria de trabajo visoespacial presentaron más dificultades en el desarrollo. Además, todas las tareas de las FE se correlacionan significativamente con las habilidades lingüísticas (comprensión y expresión), así como también se establece una correlación significativa entre el control inhibitorio y la flexibilidad de atención con los datos demográficos de la edad del diagnóstico y del implante. Sin embargo, no parece afectar la memoria de trabajo viso-espacial. Del mismo modo, el estudio concluye que las habilidades auditivas se correlacionan con la flexibilidad y la inhibición cognitiva. No obstante, aquellos preescolares con mayor edad auditiva solo mostraron mejores resultados en tareas de flexibilidad.

En la etapa educativa escolar, Botting et al.,(2017) realizaron una evaluación del lenguaje y una amplia gama de FE no verbales con un grupo de participantes con sordera $(\mathrm{N}=108)$ de 8-10 años, de los cuales 69 escolares utilizaban audífonos, 42 niños/as usaban IC y de éstos, sólo 12 tenía IC bilateral. En cuanto al modo de comunicación, 31 escolares con sordera se expresaba en lengua de signos, 56 se comunicaba en lenguaje oral y 15 adquirió como su forma principal de comunicación un sistema de signos adaptado a la gramática inglesa. Sin embargo, el estudio comparativo no estableció una separación categoríal del grupo de participantes con sordera según el dispositivo audioprotésico y realizó un análisis de los resultados estableciendo esta diversidad dentro del mismo grupo categorial de participantes con sordera. Los resultados de diferentes pruebas concluyeron que el grupo con sordera mostró un menor desempeño en las tareas de FE, salvo en aquella que evaluaba la fluidez cognitiva visoespacial, incluso después de tener en cuenta la velocidad de procesamiento y la capacidad no verbal. Además, el grupo de escolares con sordera se situaba en un promedio de una desviación típica (DT) por debajo de la media de sus compañeros normo-oyentes, por tanto, sus hallazgos concluyen que el lenguaje, además de correlacionar con las FE, ejerce un papel clave sobre el dessarrollo de las FE, pero no de forma inversa.

Jones et al., (2019) realizaron un estudio longitudinal de dos años, realizando una extensión del estudio de Botting et al., (2017) centrándose en la relación entre el vocabulario y la FE, mediante un 
estudio comparativo de escolares con sordera $(\mathrm{N}=75)$ y normo-oyentes $(\mathrm{N}=82)$ de 6-11 años de edad. En este caso, 44 de los participantes con sordera utilizaban audifonos y 31 IC, de los cuales sólo 9 tenía IC bilateral. Asimismo, 22 niños/as se expresaban en lengua de signos, 40 se comunicaba en lenguaje oral y 13 participantes preferia utilizar un sistema de comunicación adaptado, donde la lengua de signos se aplicada a la gramática del lenguaje oral.

Así pues, en este caso tampoco se dividió al grupo heterogéneo de participantes con sordera según el idioma principal de comunicación, el apoyo audioprostéico o el grado de sordera. Ambos grupos de participantes mejoraron sus puntuaciones en FE y vocabulario en el segundo año, pero el alumnado con sordera continuaban presentando una relevante desventaja frente a sus compañeros/as normooyentes en las tareas ejecutivas de memoria de trabajo de dígitos directos e inversos, memoria de trabajo viso-espacial y flexibilidad en el cambio, a pesar de que las pruebas tenían baja demanda verbal. Curiosamente, se muestra un cambio respecto al estudio realizado anteriormente por Botting et al., (2017), dado que los resultados de la prueba de flexibilidad cognitiva no mostraron diferencias significativas. En cambio, en el estudio de Jones et al., (2019) que realiza una prolongación del estudio de la muestra recogida en el estudio de la muestra recogida en el estudio de Botting et al., (2017). Además, el vocabulario y las FE mostraron una fuerte correlación en la primera evaluación y, a su vez, el vocabulario de ese tiempo predijo el cambio en las puntuaciones de las FE durante la segunda evaluación, incluso cuando se tuvo en cuenta la capacidad de FE anterior, es decir, aquellos que mostraban bajos resultados en lenguaje, también presentaban un bajo desarrollo en las FE.

Figueras, Edwards y Langdon, (2008) compararon las habilidades de FE (planificación, flexibilidad, memoria de trabajo, regulación de impulsos e inhibición) y las habilidades lingüísticas en niños y niñas de 8 a 12 años con sordera, usuarios de implante coclear $(\mathrm{N}=22)$ y con audífonos $(\mathrm{N}=25)$ en comparación con un grupo control de escolares normo-oyentes $(\mathrm{N}=22)$. Sus resultados revelaron que los participantes con sordera, independientemente de si utilizaban IC o audífonos, mostraban niveles significativamente más bajos en lenguaje y en las FE de control de impulsos, inhibición y memoria de trabajo en comparación con el grupo normo-oyente de referencia. Sin embargo, las FE evaluadas dejaron de presentar diferencias significativas cuando se tuvo en cuenta el lenguaje verbal receptivo. Además, la capacidad lingüística se asoció significativamente con las FE en el alumnado, tanto normooyentes, como con sordera, independientemente de si usaban prótesis auditivas o no. Curiosamente, no se encontraron diferencias significativas en el desarrollo del lenguaje oral entre participantes con sordera usuarios de IC y usuarios de audífonos. En efecto, dichos resultados fueron contrarios al supuesto inicial que postulaba que el uso temprano del IC y la aplicación de la terapia auditiva verbal repercutirían diferencias significativas entre los dos grupos de participantes con sordera. No obstante, cabe tener en cuenta que la comparación entre los grupos de criaturas con sordera según el dispositivo 
audio protésico (implante coclear/audífonos) no se ajustó bien para el grado de pérdida auditiva, el número de años que usaron su dispositivo o la edad en la que se aplicó el dispositivo. A pesar de ello, Figueras y sus colaboradores llegaron a la conclusión de que el déficit de estas FE era atribuible al pobre nivel de lenguaje oral.

En la misma línea, Surowiecki et al., (2002) realizaron un estudio comparativo entre escolares con sordera $(\mathrm{N}=48)$, usuarios de IC $(\mathrm{N}=24)$ y con audífonos $(\mathrm{N}=24)$ entre 6 y 14 años, que utilizaban el lenguaje oral como medio de comunicación, a fin de conocer sus diferencias respecto al funcionamiento ejecutivo. Para ello, se empleó la prueba de batería Neuropsicológica de Cambridge (CANTAB) y se evaluaron la memoria visual, la atención y el funcionamiento ejecutivo. El vocabulario se midió con la prueba de vocabulario PPVT y el lenguaje con el test de evaluación clínica de los fundamentos del lenguaje (CELF). Los autores no encontraron diferencias significativas entre los escolares con sordera, usuarios de IC y los que llevaban audífonos, en las habilidades ejecutivas y del lenguaje, incluso cuando se compararon escolares con el grado de sordera profunda, que utilizaba audífonos $(\mathrm{N}=9)$ en comparación otros, usuarios de $\mathrm{IC}(\mathrm{N}=9)$. El análisis de este pequeño grupo $(\mathrm{N}=18)$ de participantes con diferentes dispositivos (IC /audífonos) obtuvieron resultados similares en todas las pruebas de cognición. No obstante, este estudio no incluye a participantes normo-oyentes de la misma edad o referencia de datos estandarizados que posibilite la determinación de considerar si existe algún tipo de déficit en las habilidades ejecutivas o del lenguaje. De todos modos, el análisis de correlación entre las variables estudiadas demostró que, al tratar la edad como una variable constante deja de tener una relación significativa la atención y el funcionamiento ejecutivo y el lenguaje o vocabulario. En cambio, la memoria visual indicó correlación con varias pruebas del test del lenguaje CELF.

En la etapa educativa de secundaria, también se ha observado una persistencia en el déficit de las habilidades ejecutivas. Remine, Care y Brown, (2008) enfocaron su estudio en la relación entre la capacidad del lenguaje y el funcionamiento ejecutivo de resolución y planificación de problemas, autocontrol e inhibición verbal y no verbal en un grupo de 37 estudiantes de 12 a 16 años con sordera profunda, que utilizaba audífonos $(\mathrm{N}=20)$ e implante coclear $(\mathrm{N}=11)$. A pesar de que su modo de comunicación era el lenguaje oral, se midieron las habilidades ejecutivas con dos pruebas estandarizadas (verbal y no verbal) y también se evalúo la capacidad lingüística, así como la cognitiva. Después de controlar la inteligencia, la capacidad del lenguaje expresivo se relacionó con el rendimiento en la medida verbal del funcionamiento ejecutivo, puesto que representó de forma independiente más del $40 \%$ de la variación en el rendimiento de la prueba verbal sobre resolución y planificación de problemas (Prueba D-KEFS 20 Preguntas), ya que según Remine et al., (2008) el 
rendimiento de la FE en resolución de problemas depende del conocimiento semántico y las estrategias de codificación y recuperación utilizadas en el procesamiento de la información entre los diferentes sistemas de memoria. En cambio, los resultados en la tarea de funcionamiento ejecutivo no verbal, obtenidos en la prueba de torre D-KEFS, no se relacionaban con la capacidad lingüística, ni con los de la inteligencia, ni tampoco dieron soporte a la hipótesis de una relación entre la habilidad del lenguaje y la familiaridad con estrategias específicas de resolución de problemas. En esta prueba, de resolución de problemas, los participantes con sordera demostraron a nivel general habilidades de organización y planificación espacial apropiadas para la edad, así como capacidad de aprendizaje de reglas e inhibición, debido a que fueron capaces de aprender reglas, formular y aplicar estrategias efectivas de resolución de problemas y realizar una ejecución precisa en los movimientos para resolver el problema, utilizando el menor número de movimientos, por tanto puede ser de gran utilidad cuando la capacidad lingüística del participante está afectada.

Un estudio reciente realizado por Figueroa, Silvestre y Darbra (2020) en adolescentes con sordera de 12 -16 años $(\mathrm{N}=10)$, implantados antes de los 4 años, evaluaron la comprensión lectora y las FE de la inhibición, la memoria de trabajo y la flexibilidad. El alumnado con sordera mostró un rendimiento inferior en comparación con un grupo control normo-oyente $(\mathrm{N}=20)$. Además, la comprensión lectora parece tener relación con la memoria y la actualización.

b) Estudios en situaciones cotidianas

Estos estudios recogen las aportaciones de los educadores a través de escalas de calificación sobre el desarrollo de las FE del alumnado con sordera en situaciones cotidianas. De esta manera se recogen también la perspectiva del entorno próximo al niño/a sobre las barreras y fortalezas que presenta en el desarrollo de su aprendizaje. La mayoría de los estudios han utilizado el Inventario de Calificación de Comportamiento de la Función Ejecutiva BRIEF, ya sea en la versión para alumnado en la etapa escolar (Gioia, Isquith, Guy y Kenworthy, 2000) o en la preescolar (Gioia, Andrwes y Isquith, 1996) para recoger datos sobre acciones cotidianas donde se pone en prácticas las FE.

Beer, Kronenberger y Pisoni, (2011) recogieron la valoración de 45 progenitores de participantes con IC de 5 a 18 años de edad, mediante la administración del cuestionario BRIEF, cuyas puntuaciones mostraron que los participantes con IC tenían un mayor riesgo en el déficit de las subescalas de inhibición y memoria de trabajo, así como en la regulación de la conducta, en comparación con otras subescalas del BRIEF como la organización, planificación, metacognición y flexibilidad, entre otras. 
Un trabajo parecido fue el realizado por Kronenberger et al., (2014), pero en este caso se obtuvieron datos de dos grupos de edad: preescolar (3-5 años) y escolar (6-17 años) usuarios con IC, así como también de participantes normo-oyentes como muestra control. Sus hallazgos indican que los estudiantes con sordera prelocutivos con IC tenían de 2 a 5 veces mayor riesgo que sus compañeros/as normo-oyentes de tener déficit clínico en la mayoría de los dominios de FE evaluados. Los riesgos que involucra a ambas etapas de edad son en gran parte de los dominios: memoria de trabajo, atención, procesamiento secuencial, resolución de problemas y aprendizaje conceptual. Además, los participantes con sordera en edad escolar aumentaron el riesgo relativo en otras subescalas como en inhibición, donde ascendió la posibilidad de déficit hasta 10 puntos. También encontraron un ascenso de la probabilidad en velocidad del procesamiento, la flexibilidad, el control emocional y la planificación, pero el riesgo aumentó relativamente (3 puntos) poco en comparación con la inhibición.

En la misma línea del estudio anterior, Hintermair (2013) en su estudio sobre el funcionamiento de las habilidades ejecutivas y la competencia comunicativa en el contexto cotidiano de participantes con hipoacusia, también observó dificultades en el comportamiento respecto a las funciones ejecutivas en la práctica diaria y su repercusión en el desarrollo socioemocional, según la valoración del equipo docente responsable de la enseñanza educativa del alumnado con sordera. Para ello, se recogió la valoración del docente de aula responsable del aprendizaje del estudiante con sordera $(\mathrm{N}=214)$, que acudía a centros ordinarios $(\mathrm{N}=69)$ y a centros especializados en la atención de alumnado con sordera $(\mathrm{N}=145)$ en edades comprendidas de 5 a 18 años, con una media de 12.4 años, mediante la cumplimentación de BRIEF. Los resultados del análisis demostraron que las puntuaciones eran bajas y altamente significativas en todas las áreas de FE en comparación con la muestra normativa que presentaba el test como modelo de referencia. Los estudiantes con sordera que acudían a centros ordinarios tuvieron un riesgo significativo en todos los dominios de las FE, salvo en las subescalas de inhibición y planificación/organización. Además, se observó que el alumnado que acudía a centros ordinarios mostraba mejores resultados y mejor nivel de comportamiento que el alumnado de centros específicos. Hintermair, (2013) considera que la razón que justificaba esta diferencia podía residir en la correlación que establecen las variables de FE y la competencia comunicativa para el desarrollo socioemocional de los estudiantes con sordera, es decir, a mayor competencia, menor era la probabilidad de sufrir problemas conductuales.

\section{c) Estudios longitudinales}

Los estudios longitudinales son muy valiosos por la diversidad que presenta el colectivo de personas con sordera y el seguimiento de la misma muestra en el tiempo permite agrupar las diferencias 
individuales en su evolución, por lo que, además, permite obtener conclusiones más precisas y fiables sobre los resultados en el desarrollo de las habilidades ejecutivas y su relación con el lenguaje.

Kronenberger, Pisoni, Henning y Colson (2013) realizaron un estudio a largo plazo para observar la evolución de las habilidades ejecutivas de memoria de trabajo, velocidad en la fluidez verbal y la inhibición-concentración en población con sordera con IC (N=53) de 7 a 25 años en comparación con su grupo de referencia normo-oyentes $(\mathrm{N}=53)$. Sus resultados mostraron los déficits de la sordera a largo plazo, puesto que los participantes con esta condición solo alcanzaban resultados medios en comparación con el grupo control de participantes normo-oyentes. Específicamente, se encontraron diferencias significativas en memoria de dígitos o con procesamiento (hacia delante y hacia atrás), tanto visual, como auditiva. Incluso el 30\% de la muestra de participantes con IC demostró retraso de una desviación estándar o más por debajo de la media. En cambio, los resultados no mostraron diferencias en la memoria espacial. En cuanto a las medidas de la fluidez se encontraron dificultades en el desempeño de todas las tareas con diferencias significativas para la codificación, la correspondencia visual y la fluidez en la recuperación de información. Finalmente, ocurrió lo mismo con las medidas de inhibición-concentración, salvo en la tarea de "stroop color-palabra" cuyos resultados no presentaron una diferencia con significación estadística. Además, cabe resaltar que un porcentaje superior al $10 \%$ de la muestra de participantes con sordera alcanzaron puntuaciones inferiores que se situaban a dos desviaciones típicas o más de la media del grupo en las medidas vinculadas al área de la memoria de trabajo e inhibición-concentración, con la excepción de la tarea de "stroop color-palabra" e "intervalo de dígitos hacia atrás", por tanto, estos resultados pueden indicar un serio riesgo en el desarrollo de estas habilidades ejecutivas que perpetúa a lo largo del tiempo.

Otro estudio a largo plazo en esta línea es el de Castellanos et al., (2016), que trataron de comprender las habilidades del lenguaje expresivo temprano que predicen los resultados neurocognitivos posteriores en una muestra de usuarios de IC $(\mathrm{N}=32)$, después de un año y tres meses de experiencia auditiva. Se utilizó la cumplimentación por los progenitores del inventario de desarrollo comunicativo MacArthur-Bates (Fenson et al., 2006), el cual realiza un registro de las primeras palabras y oraciones en el desarrollo del lenguaje infantil. Normalmente su aplicación se realiza en criaturas de 16 a 30 meses, pero también era válida para niños y niñas cronológicamente mayores con sospechas de retraso en el lenguaje, como es el caso de los preescolares con pérdida auditiva, por tanto, este estudio recogió para la evaluación una muestra de participantes de entre año y medio a casi siete años. Con posterioridad, cuando la muestra alcanzó una media de más de 11 años de experiencia auditiva con el IC, se evaluaron una amplia gama de competencias neurocognitivas con pruebas estandarizadas en las áreas de memoria de trabajo verbal y viso-espacial, velocidad de fluidez, inhibición-concentración, así 
como la evaluación del lenguaje con CELF. El análisis de los resultados indicó que el lenguaje expresivo que se evalúo en un primer momento, cuando la experiencia auditiva de las criaturas era escasa, predijo el lenguaje a largo plazo, el desarrollo de las habilidades ejecutivas de la memoria de trabajo verbal y la velocidad en la fluidez, así como en las habilidades académicas de la competencia lectora.

Posteriormente, Hunter et al., (2017) realizaron una ampliación del estudio de Castellanos et al., (2016) para determinar si la percepción del habla y el lenguaje, evaluadas desde los 6 meses posteriores a la implantación, predice a largo plazo el progreso en el habla y el de las habilidades en FE. Para ello utilizaron las mismas pruebas que utilizaron Castellanos et al., (2016) y parte de la muestra recogida. En este estudio realizaron tres evaluaciones: La primera se pasó cuando los participantes (entre 2 y 6 años de edad) tenían una experiencia auditiva de 6 meses con el implante coclear. La segunda, dos años después de la implantación, es decir, cuando los participantes tenían entre 3-7 años y su experiencia auditiva estaba comprendida entre 17 y 23 meses y la tercera evaluación se realizó durante el periodo de revisión y los participantes ya eran adolescentes y jóvenes adultos (11-27 años) como modo de seguimiento a largo plazo. En las dos primeras evaluaciones se utilizaron varias pruebas estandarizadas para evaluar las habilidades del lenguaje, así como el uso también de evaluaciones no estandarizadas para valorar la percepción del habla del niño/a. En la evaluación de seguimiento a largo plazo (tercera evaluación), los participantes también completaron una batería de evaluaciones neurocognitivas (memoria de trabajo verbal, memoria de trabajo viso-espacial, velocidad de fluidez e inhibición).

El análisis de los datos aportó evidencias sobre la correlación significativa entre la percepción del habla y las habilidades del lenguaje, medidas tanto en el primer, como en el segundo año (6 y 18 meses después de la implantación) con los resultados a largo plazo en el lenguaje. Las habilidades iniciales del lenguaje medidas en el primer tiempo se correlacionaron significativamente con la memoria de trabajo verbal y la velocidad de la fluidez verbal medidas alrededor de 15 años después del implante. Incluso, la correlación con la memoria de trabajo verbal y el lenguaje se mantuvo con el análisis de la segunda evaluación del lenguaje (18 meses después de la implantación coclear). Además, el lenguaje inicial a los seis meses (de implantación) se correlacionó significativamente con siete de las ocho subescalas cognitivas valoradas por los progenitores (comprensión y aprendizaje conceptual, memoria fáctica, atención, velocidad de procesamiento, procesamiento secuencial sostenido, memoria de trabajo y solución de problemas nuevos) y se mantuvieron después de tener en cuenta las variables socio-demográficas, de historial auditivo convencionales y la inteligencia no verbal. Al parecer, para las personas con sordera, usuarios de IC, la percepción del habla y el lenguaje pueden ser marcadores 
clínicamente relevantes para la identificación del riesgo en el desarrollo del lenguaje y de las habilidades ejecutivas a largo plazo.

Por último, el estudio realizado por Kronenberger, Xu y pisoni, (2020) recogen la evaluación longitudinal de alumnado con sordera e IC de 3 a 6 años de edad $(\mathrm{N}=41)$, en comparación con sus iguales normo-oyentes $(\mathrm{N}=40)$ que fueron evaluados anualmente hasta la edad de 7 años en el desarrollo del lenguaje y las habilidades ejecutivas de la memoria y la inhibición. El alumnado con IC obtuvo puntuaciones más bajas que el grupo normo-oyente en las pruebas de atención sostenida, inhibición y memoria de trabajo con medidas que no demandan audición ni lenguaje. Estas bajas puntuaciones se confirman con la lista de verificación de comportamiento informado por los padres (BRIEF), donde también se detectan bajas puntuaciones, en comparación con sus compañeros/as normo-oyentes en inhibición y memoria de trabajo, Por lo tanto, los niños con IC mostraron retrasos en la mayoría de los dominios de la FE en relación con sus iguales normo-oyentes desde los 3 años de edad.

En conclusión, los estudios hasta el momento han podido averiguar que las principales FE en todas las etapas educativas (infantil, primaria y secundaria) están íntimamente vinculadas al lenguaje y al habla. Además, la competencia comunicativa de las criaturas con sordera en los primeros años de experiencia auditiva con implante coclear tiene una relación directa en el desarrollo del lenguaje y las funciones ejecutivas a largo plazo (Hunter et al., 2017). En este sentido, se ha puesto de manifiesto que el déficit auditivo de las criaturas con sordera con un modo de comunicación oral podrían poner en riesgo el desarrollo de las funciones ejecutivas durante el desarrollo evolutivo de la persona con sordera y la confirmación por parte de las revisiones que se han realizado (Kral et al., 2016; Pisoni et al., 2010). Sin embargo, la falta de una muestra de personas con una total falta de percepción auditiva limita esta percepción sobre el desarrollo cognitivo. El lenguaje no predijo los resultados en las puntuaciones de las FE no verbales. Sin embargo, la prueba de memoria de dígitos del WISC-III sí predijo el desarrollo del lenguaje, por tanto, el lenguaje puede ser significativamente predictivo para aquellas habilidades ejecutivas futuras que involucren el lenguaje verbal.

\subsection{Lenguaje oral y memoria de trabajo en alumnado con implante coclear}

El modelo de memoria de trabajo de Baddeley interpreta que el bucle fonológico ejerce de vínculo entre el registro sensorial temprano del habla y la memoria. Este proceso se produce gracias a que el lenguaje oral se emite y se procesa muy rápidamente en unidades lingüísticas representativas, que deben ser codificadas, organizadas e integradas en el recuerdo inmediato (memoria a corto plazo) para 
almacenarlas mediante la manipulación o transformación de la información (memoria de trabajo) y permita completar operaciones mentales posteriores. Como resultado, los componentes de la memoria a corto plazo verbal y la memoria de trabajo verbal, que se desarrollan a través del bucle fonológico y los procesos de control ejecutivo central de la memoria, son esenciales para la eficiencia del procesamiento de aprendizaje del habla y del lenguaje, por tanto, el déficit de ambos componentes afecta directamente al desarrollo del lenguaje, debido a que debe aplicar mecanismos para producir un mensaje oral o escrito coherente (Pisoni y Cleary, 2003) y repercute en diferentes dominios en cascada, como veremos a continuación. De este modo, podemos comprender que las personas con discapacidad auditiva se encuentran en situación de vulnerabilidad en el desarrollo óptimo de esta habilidad cognitiva a causa de su limitación en la percepción auditiva, a pesar de que sea durante un breve período de tiempo hasta que obtiene el apoyo protésico necesario (Harris et al., 2013).

En el caso de la memoria de trabajo verbal, es consistente la demostración de la literatura científica sobre la correlación positiva entre la función de la memoria de trabajo y el desarrollo del lenguaje en criaturas normo-oyentes de 3 a 5 años (Ezrine, 2011), por tanto, los evidentes signos de relación entre las habilidades lingüísticas y la memoria de trabajo nos conducen a profundizar en el conocimiento del desarrollo de esta capacidad cognitiva en las personas con sordera.

La memoria de trabajo verbal juega un papel importante en el desarrollo del lenguaje en edad infantil, por lo que las criaturas que carecen del sentido de la audición en este periodo incipiente del desarrollo dependen en gran medida de la competencia que adquieran en las habilidades cognitivas como la memoria de trabajo para alcanzar un lenguaje equiparable al de sus compañeros/as normooyentes. En cambio, diferentes estudios exponen que la memoria de trabajo verbal de las personas con IC tiene un menor rendimiento, ya que parece que su desarrollo depende en gran medida de la competencia del lenguaje, por tanto, el retraso en su aprendizaje, al inicio de la etapa preescolar, deja secuelas en el desarrollo de las habilidades ejecutivas como la memoria verbal, mostrando los niños y las niñas un intervalo más corto de memorización, en comparación con sus iguales con audición normal (Kronenberger et al., 2014; Nittrouer, Caldwell-Tarr y Lowenstein, 2013; Pisoni, Kronenberger, Roman y Geers, 2011; Wass et al., 2008) y se prolonga en edades posteriores (Harris et al., 2013), aunque los estudios tampoco pueden establecer claramente la causalidad.

En este sentido, AuBuchon, Pisoni y Kronenberger, (2015b), constataron velocidades de procesamiento verbal y codificación más lentas a largo plazo en niños/as, adolescentes y jóvenes con sordera severa o profunda, usuarios de IC $(\mathrm{N}=55)$ de 7 a 25 años en comparación con el grupo de referencia normo-oyente. Además, hallaron que la relación entre dichas habilidades también se expresaba de manera distinta en el grupo de personas con IC respecto al grupo de referencia normo- 
oyente. Así pues, la velocidad de procesamiento verbal o el tiempo para disponer de mecanismos que reactiven las representaciones verbales temporales, se relacionó con la memoria de trabajo verbal y la velocidad de la fluidez del habla en los participantes normo-oyentes, ya que recurrían a mecanismos verbales para regular y controlar su conducta y, por tanto, la velocidad del procesamiento verbal repercutía, a su vez, en el desempeño de las FE. En cambio, en el grupo de participantes con IC la velocidad de procesamiento verbal presentaba correlación con las habilidades lingüísticas, pero no con las habilidades ejecutivas, tal como ocurría en el grupo de referencia, por lo que su manera de procesar la información también puede variar, a pesar de los años de experiencia con su IC. De modo que, cuando las personas con IC utilizan un discurso verbal interno, así como el uso de procesamiento verbal, es posible que se practique de manera tardía.

Curiosamente, un estudio piloto realizado por Kronenberger, Henning, Ditmars y Pisoni, (2018) con una muestra de 9 participantes con IC y 9 participantes normo-oyentes de edades comprendidas entre 8 y 26 años, trató de conocer el papel de la memoria verbal en el procesamiento del lenguaje (velocidad de acceso léxico) a través de la evaluación de una prueba estándar, sin tareas de procesamiento intermedias y de doble tarea de acceso al léxico verbal (recuerdo de dígitos y elección de palabras y pseudopalabras). La muestra del grupo de IC se desempeñó significativamente más lentamente en la condición de doble tarea en comparación con la condición estándar / control. Las medidas de FE de velocidad de fluidez están relacionadas con los tiempos de finalización de ambas tareas (estándar/ control y doble tarea) Sin embargo, en la tarea de condición estándar su relevancia fue muy pequeña y no significativa en la mayoría de los casos, por tanto, el procesamiento de información de doble entrada está fuertemente relacionado con el dominio de las habilidades ejecutivas de la velocidad de la fluidez, en comparación con la condición estándar, la cual tiene una mayor influencia del procesamiento automático rápido, independientemente del dominio de las FE. Además, la edad de inicio de la sordera, la edad auditiva, la edad de la implantación, la duración del uso del implante y el promedio de tonos puros de escucha antes del implante no se correlacionaron significativamente con las puntuaciones de acceso léxico (todas $p<0,10$ ).

Pisoni y Cleary, (2003) recogieron una muestra de escolares con sordera, usuarios de IC, (N=176) durante el período de 1997 hasta el 2000 de 8-9 años, en el que cada año se recogieron 45 participantes con sordera, usuarios de IC y se clasificaron según el modo de comunicación (oral versus comunicación total (lengua de signos acompañado de lenguaje oral), dependiendo del grado de exposición de cada niño a los modos de comunicación, en comparación con un grupo de referencia normo-oyente $(\mathrm{N}=45)$, para analizar la capacidad de la memoria de trabajo. Se aplicaron diversas pruebas: la prueba tradicional del WPPSI para dígitos hacia adelante y hacia atrás, el reconocimiento 
de palabras y discriminación léxica y la discriminación de oraciones. Las puntuaciones de los participantes con sordera fueron notablemente inferiores en ambas direcciones, pero especialmente en el intervalo de dígitos hacia adelante. Además, se observó que el intervalo de dígitos hacia adelante se correlaciona con el modo de comunicación de los participantes. Los escolares que presentaban un entorno de comunicación en el que combinaban lengua de signos y lengua oral (comunicación total) ( $\mathrm{N}=129)$ recordaban intervalos de dígitos más cortos que sus compañeros/as con un modo de comunicación oral (N=87), comprobados durante los cuatro años estudio (1997-2000) con cada grupo de muestra recogida. En cuanto a la relación de la memoria de trabajo con el reconocimiento de las palabras se comprobó que correlacionaba con todas las pruebas realizadas, aunque las correlaciones tenían una significación más alta en la prueba de intervalo de dígitos hacia adelante.

Así pues, los resultados obtenidos sugieren que la capacidad de la memoria de trabajo y el procesamiento de la información verbal a través del reconocimiento de palabras tienen una íntima relación. En consecuencia, el déficit en el desarrollo de la memoria de trabajo de los escolares con IC limita la capacidad de procesar la información en la memoria de trabajo, dado que las estrategias que utiliza para codificar, mantener y recuperar los datos pueden ser menos eficaces y más lentas, por lo que deriva en dificultades en la competencia lingüística.

Este efecto reciproco de dependencia también se observó en un estudio realizado por Stiles, McGregor y Bentler, (2012) con una muestra de 16 niños/as entre 6 y 9 años con grados de sordera de leve a moderada, usuarios de audífonos y 24 niños/as normo-oyentes, donde se evalúo el vocabulario, la capacidad ejecutiva de la memoria con la subprueba de dígitos del WPPSI de forma auditiva y visual, presentadas en una combinación de ambiente silencioso y ruidoso, la prueba de bloques de Corsi para conocer la habilidad visuoespacial, la cual también se administró en un ambiente ruidoso y silencioso y la codificación secuencial para indicar si los participantes utilizan el bucle fonológico para una secuencia visual de elementos presentados. Los resultados mostraron que, salvo la puntuación de la articulación fonológica, no se encontraron diferencias significativas en la memoria de trabajo, ni tampoco en un entorno ruidoso. No obstante, los participantes con sordera expresaron un vocabulario más reducido en comparación con sus iguales normo-oyentes, concretamente, aquellos participantes que obtuvieron baja puntuación en la subprueba de memoria WPPSI, también obtuvieron un rendimiento más bajo en vocabulario.

Estas conclusiones corroboran los resultados del estudio realizado por Lo y Chen, (2017) sobre la memoria de trabajo en relación con el lenguaje. Dicho estudio, comparó la capacidad de preescolares con sordera, usuarios de audífonos $(\mathrm{N}=39)$ y de niños/as normo-oyentes $(\mathrm{N}=20)$ de 5-6 años. Para 
ello utilizaron el test de Evaluación del trastorno del lenguaje para preescolares (LDAP-R) para valorar el lenguaje y WPPSI en la tarea de dígitos para medir la capacidad de la memoria. El análisis de los resultados tuvo en cuenta en la duración de la rehabilitación para conocer el efecto del rendimiento en la memoria de trabajo. Así pues, sus conclusiones mostraron que los preescolares con alto rendimiento en memoria de trabajo tenían la misma capacidad que los normo-oyentes en habilidades lingüísticas en los niveles de expresión y comprensión, mientras que los niños y las niñas con sordera con baja competencia lingüística expresaban una baja puntuación en la tarea de memoria. Además, la duración de la rehabilitación tiene un impacto significativo en el lenguaje ( $p>0,01)$, por tanto, según este estudio, la capacidad de la memoria predice el desarrollo del lenguaje y la duración en la terapia auditiva verbal influye en la media del lenguaje. De este modo, parece demostrarse que los niños y las niñas con sordera presentan una mayor dependencia de la capacidad de la memoria de trabajo para el aprendizaje del lenguaje desde la etapa infantil.

Por otro lado, gracias a los estudios longitudinales podemos comprobar las predicciones de los estudios anteriores. El estudio longitudinal realizado por Pisoni et al., (2011) con participantes con IC evaluados cuando tenían entre 8 y 9 años y en una segunda fase de evaluación cuando los participantes tenían 16 años permitió valorar los efectos que produce la experiencia auditiva. El estudio se focalizó en el desarrollo de la memoria a corto plazo (memoria de dígitos de orden directo) y de trabajo (memoria de dígitos de orden inverso) y la velocidad del procesamiento verbal después de ocho años de uso del IC. Los resultados mostraron que el grupo de participantes con sordera mantenía las dificultades en la memoria a corto plazo y de trabajo verbal después de 8 años de experiencia auditiva con el IC, agrupando la puntuación media en una DT por debajo de la media del grupo de referencia. De esta manera, se manifiesta un retraso constante en esta área en comparación con su grupo de referencia, a pesar del beneficio del uso del IC. No obstante, el rendimiento en los dígitos hacia adelante mejoró en la evaluación de seguimiento y se situaron casi la mitad de los participantes con sordera dentro del rango promedio, por lo que el rendimiento de las habilidades de memoria a corto plazo se incrementa a medida que se desarrolla la persona.

El uso del IC correlacionó de manera positiva con la puntuación de dígitos y las medidas de percepción del habla, vocabulario, lenguaje y lectura, por tanto, en aquellos niños/as que habían alcanzado un mayor rendimiento. En cambio, la prueba de dígitos hacia atrás empeoró en la evaluación de seguimiento, ya que se situaron un $15 \%$ más de participantes con IC una DT por debajo de la media normativa, por tanto, las debilidades en la memoria de trabajo perduran en el tiempo, a pesar del desarrollo psicosocial de la persona con IC. Respecto a la correlación de estas habilidades con el lenguaje y el habla, se observó que la puntuación de los dígitos hacia adelante se vinculó de manera 
significativa con las habilidades lingüísticas en la evaluación de seguimiento, mientras que la puntuación de dígitos hacia atrás sólo se asoció con el procesamiento del lenguaje, por tanto, podemos comprender como la experiencia auditiva que impulsa el desarrollo del lenguaje y el habla favorece el desempeño de la codificación fonológica y la memoria verbal a corto plazo, debido a la secuenciación temporal del sonido en comparación con la tarea de dígitos hacia atrás. Como hemos visto anteriormente, esta tarea se vincula con el procesamiento del lenguaje y, por tanto, depende en mayor medida de la memoria fonológica verbal, más que del desarrollo del lenguaje y el habla en sí, debido a que se requiere de esta habilidad para que la persona codifique la información para posteriormente almacenarla.

Harris et al., (2011) realizaron un estudio de corte longitudinal con participantes con sordera usuarios de IC de 3-15 años ( $\mathrm{N}=110)$ sobre el desarrollo de la memoria a corto plazo y de trabajo, a fin de profundizar en el conocimiento del crecimiento de la capacidad de la memoria y su relación con el aprendizaje del lenguaje. Los autores realizaron la evaluación con cuatro medidas sobre competencia lingüística: la prueba de palabras fonéticas para niños y niñas, el test de vocabulario (PPVT), la prueba de percepción auditiva en ruido para niños y niñas, el test del lenguaje CELF y, en el caso de la memoria, la clásica prueba de dígitos del WPPSI. En el análisis de las puntuaciones se mostró que el desarrollo de la memoria a corto plazo y de trabajo las pruebas de recuerdo de dígitos hacia delante y dígitos hacía atrás estaban alterados. De hecho, aquellos participantes con limitaciones en ambas habilidades de la memoria verbal obtenían peores resultados en las pruebas de lenguaje y habla. En cambio, aquellos que mostraban un mejor rendimiento en una de las dos pruebas de dígitos (hacia delante y hacia atrás) éste se veía relacionado con un mejor desempeño en las habilidades lingüísticas, por lo que el desarrollo de la memoria a corto plazo y de trabajo puede influir en el lenguaje.

Dos años más tarde, Harris et al., (2013) volvieron a repetir el estudio longitudinal, recogiendo parte de la muestra inicial de participantes con IC (N=66) del estudio realizado por Harris et al., (2011), en comparación con sus iguales de edad normo-oyentes de 6 a 16 años y sus resultados volvieron a mostrar que los participantes con IC expresaban un déficit tanto en la prueba de dígitos hacia delante (50.5\% del total del grupo de estudio), como en dígitos hacía atrás (44\%) en general, se encontraban a más de un punto de desviación por debajo de la media en cada rango de edad. En este sentido, la preocupación del déficit en esta habilidad asciende, debido a que estas diferencias ya son visibles de manera llamativa, a los 6 y 7 años (33\% de la muestra obtenía un bajo rendimiento en la prueba de dígitos hacia delante y el $25 \%$ en dígitos hacia atrás). Además, se observó que el punto de inicio y el crecimiento del rendimiento en cada una de las pruebas predicen el rendimiento de las habilidades 
lingüísticas, evaluadas mediante las pruebas de PPVT y su pendiente se correlacionaba con su desarrollo. Las puntuaciones de la tarea de dígitos inversos predijeron el nivel de vocabulario y del lenguaje, pero, en cambio, no correlacionó con su pendiente incluso después de tener en cuenta variables tales como la edad de implantación, la educación de los progenitores y el modo de comunicación, por tanto, podemos comprender que la variabilidad del lenguaje también depende del desempeño de las habilidades de memoria a corto plazo.

El estudio longitudinal, realizado por Ching et al., (2019) confirma estas predicciones con un estudio realizado con escolares con diferentes grados de sordera (leve a severa) $(\mathrm{N}=81)$, que utilizaba audífonos y se expresaba en lenguaje oral. La evaluación del lenguaje, el vocabulario y la memoria de trabajo (tarea de dígitos y tarea de memoria fonológica de consonantes y vocales) y el coeficiente intelectual no verbal desvelan que la puntuación de dígitos hacia adelante a los 5 años predecía el lenguaje receptivo y expresivo a los 9 años, pero no se expresaba esta relación con el vocabulario receptivo o expresivo. Asimismo, la tarea de repetición de consonantes o vocales a los 5 años se relacionaba de manera directa con el lenguaje y vocabulario expresivo, pero no indicaba relevancia con el receptivo a los 9 años, por tanto, aquellos que mostraban una mayor longitud tanto de los dígitos como de las consonantes o vocales indica un mayor nivel en las habilidades lingüísticas y de vocabulario. Además, el coeficiente intelectual no verbal evaluado a los 5 años se relacionaba de manera directa con el lenguaje y el léxico de los 9 años. De modo que, la valoración de las escolares con sordera mediante la memoria de trabajo es de gran utilidad para conocer el nivel de lenguaje en el que se podrían encontrar en un periodo de tiempo a corto-largo plazo, por lo que nos permitirá concretar las necesidades que precisa en el presente para mejorar sus habilidades lingüísticas futuras, dado que el déficit en el lenguaje en los participantes con sordera todavía persiste, puesto que se situaban 1 DT por debajo de la media normativa. Sin embargo, respecto al nivel de vocabulario se encontraban en mejor posición, pues se encontraban a -0.5 de DT, pero dentro de la media del grupo de referencia.

Aunque los diferentes estudios transversales y longitudinales predicen que la memoria a corto plazo y de trabajo verbal presentan un déficit en los participantes con sordera, así como en la relación próxima con el lenguaje, parece ser que la habilidad ejecutiva de la memoria visual no se corresponde de la misma manera como argumentan los siguientes estudios.

Bharadwaj, Maricle, Green y Allman, (2015) observaron 10 participantes entre 7 y 11 años de edad con IC, fueron evaluados en memoria a corto plazo y de trabajo en las modalidades auditiva y visual. Los resultados mostraron que el rendimiento en la memoria visual a corto plazo y las medidas de la 
memoria de trabajo visual se ubicaron dentro del rango promedio. Sin embargo, la memoria auditiva de corto plazo y las medidas de la memoria de trabajo auditiva estuvieron por debajo de la media normativa, al igual que el trabajo de Willis, Goldbart y Stansfield, (2014) quienes resaltaron que los sujetos con sordera mostraban más dificultades para repetir la serie de palabras que la producción fonológica de sílabas. La medida de memoria de trabajo visual no presentaba déficit, al contrario, que Lyxell et al.,(2011) que encontraron que los participantes con IC $(\mathrm{N}=175)$ de 5 a 11 años tenían una capacidad de memoria viso-espacial dentro de la media de la muestra, pero en lo que respecta al rendimiento en la memoria de trabajo verbal mostraba un nivel pobre, ya que sólo el $20 \%$ de los participantes con sordera se encontraban dentro de una desviación estándar de la media, el resto (el $80 \%$ de los escolares con sordera) se encontraba en rangos más bajos. Además, en la tarea de acceso al léxico fonológico obtuvieron un bajo rendimiento, ya que un $10 \%$ de los escolares con sordera se situaban en un punto por bajo de la media, por tanto, las habilidades con una gran carga de procesamiento fonológico presentan un rendimiento deficiente.

Los resultados sobre las medidas de memoria de trabajo verbal y visual estuvieron en línea con los hallazgos obtenidos en estudios anteriores como Lyxell et al., (2008) que estudiaron el rendimiento en memoria de trabajo verbal y habilidades fonológicas y léxicas a fin de conocer su relación con la capacidad lectora en niños y niñas con IC $(\mathrm{N}=31)$ en edades de 6 a 13 años, en comparación con su grupo de iguales de referencia $(\mathrm{N}=96)$, donde los escolares con sordera obtuvieron una gran diferencia en las tareas de memoria de trabajo verbal. En cambio, a pesar de mostrar déficit en el desarrollo eficaz del procesamiento fonológico, logran alcanzar un el buen desarrollo de la competencia lectora. También coincide con Wass et al., (2008) que evaluaron la capacidad de memoria de trabajo, el acceso al léxico y las habilidades fonológicas en escolares con IC (N=19) en relación al nivel del grupo normooyente $(\mathrm{N}=56)$ en edad escolar (5-13años) y encontraron un bajo rendimiento en la memoria de trabajo verbal en los niños y las niñas con IC, así como también en las habilidades de acceso al léxico, ya que los escolares con IC mostraron un rendimiento inferior cuando se comparó con el grupo de iguales en todo el grupo de edades, salvo en memoria viso-espacial. Esto sugiere que los participantes con sordera pueden tener limitaciones en el procesamiento de información verbal y no espacial, a causa del aprendizaje de representaciones fonológicas inapropiadas.

En contraste a los hallazgos constantes del buen rendimiento en la memoria visual del alumnado con sordera, AuBuchon, Pisoni y Kronenberger, (2015a) obtuvieron resultados distintos. Su estudio también utilizó una tarea de recuerdo de dígitos visuales con respuestas de manera manual para eliminar la carga verbal y auditiva de la prueba, además del uso de tareas más tradicionales, donde se utilizaban acciones verbales y auditivas. La muestra de 23 participantes con IC mostró una menor producción de dígitos de forma consistente en las tres modalidades de la tarea de intervalos de dígitos 
(visual, auditiva, visual/motora), por tanto, sus resultados concluyen que los retrasos en memoria de trabajo y a corto plazo no se debe a aspectos de actividad sensorial como la audibilidad o de la planificación motora para la producción de las respuestas, sino que se ciñe a procesos de la codificación y mantenimiento de las representaciones de dígitos de manera mental, dado que utilizan estrategias fonológicas y lingüísticas deficientes durante la tarea. Estos resultados están en consonancia con los hallazgos obtenidos anteriormente por Burkholder y Pisoni, (2003), donde los participantes con sordera de 8-9 años obtuvieron intervalos de dígitos más cortos y una duración de frases más largas con una mayor pausa entre palabras en comparación con sus compañeros/as normo-oyentes, por lo que puede ser a causa de una velocidad de ensayo verbal más lenta.

La mayoría de los estudios anteriores indican que los infantes con pérdida auditiva muestran limitaciones en la capacidad cognitiva de la memoria de trabajo y la memoria a corto plazo a lo largo del periodo escolar de Educación Primaria y persiste en Educación Secundaria, dado que su rendimiento es significativamente menor en comparación con sus iguales normo-oyentes. Estas dificultades se expresan en el procesamiento de la codificación y la secuenciación de la información verbal y no verbal, que impiden afrontar diversas órdenes al mismo tiempo, como en el caso del lenguaje, donde se procesa información fonológica, semántica y sintáctica, debido a que el déficit de audición conduce al desarrollo de representaciones fonológicas deficitarias en la memoria a largo plazo que repercute no sólo al desarrollo del lenguaje, sino también afecta a un menor soporte en la reactivación y recuperación del léxico dentro del almacén de memoria a corto plazo (AuBuchon et al., 2015a; Harris et al., 2013; Pisoni y Cleary, 2003). De hecho, según recogieron Burkholder y Pisoni, (2003) las personas con IC obtuvieron bajos resultados en la recuperación de la información, por lo que las personas con sordera podrían presentar dificultades en el aprendizaje de mecanismos de procesamiento eficiente fonológico para categorizar y mantener la información de manera activa en el recuerdo inmediato bajo condiciones simples, mientras sus compañeros/as normo-oyentes ya las dominan. En contraposición, Nittrouer, Caldwell-Tarr y Lowenstein, (2013) mantiene otra postura frente al origen del déficit en la memoria a corto plazo y de trabajo. Ellos consideran que se debe a dificultades en el almacenamiento fonológico, dado que en su estudio con alumnado con IC de 8 años de edad mostraron una recuperación del orden de la lista de palabras más pobre y los autores consideran que la causa proviene de un acceso deficiente a la estructura fonológica de las palabras.

Independientemente de qué aspectos del lenguaje influyen en las funciones ejecutivas, los estudios parecen indicar que el lenguaje es el desencadenante de impulsar el desarrollo de las habilidades ejecutivas, ya que el nivel de lenguaje proporciona el desempeño de las habilidades. De hecho, aquellos participantes con sordera con bajo nivel de vocabulario y de percepción del habla mostraban, también, 
un nivel inferior en memoria de trabajo verbal e incluso estas dificultades eran persistentes en la etapa de secundaria (Botting et al., 2017; Pisoni et al., 2011).

Por otro lado, también cabe tener en cuenta en el alumnado con sordera la implantación coclear temprana, debido a que mejora notablemente los resultados en el área del lenguaje, su desarrollo cognitivo y su estimulación en el área de la memoria. Mikic, Miric, Nikolic-Mikic, Ostojic y Asanovic, (2014) observaron que los participantes con sordera que fueron implantados antes de los 3 años presentaban mejor rendimiento de la memoria verbal a corto plazo, en comparación con participantes con sordera que fueron implantados tardíamente (entre los 4 y 6 años). Además, se encuentran diferencias significativas en la prueba compleja de repetición de oraciones.

Así pues, las dificultades en el aprendizaje y en la aplicación de estrategias de procesamiento y mantenimiento de la información pueden provenir de la ausencia de experiencias auditivas tempranas y de actividades que impulsen la práctica fonológica y léxica que permita la construcción de un "andamiaje auditivo" integrado en la memoria a largo plazo, antes del desarrollo de un dominio secuencial. En consecuencia, se alteran las capacidades de secuenciación cognitiva, que perjudica a la velocidad de los procesos de memoria de trabajo y a corto plazo (Burkholder y Pisoni, 2003), por lo que aumenta el esfuerzo mental para procesar el lenguaje, ya que implica procesos de comprensión lingüística.

Finalmente, cabe comprender que los desafíos a los que se enfrenta la mayoría de las personas con sordera no sólo residen en la recuperación de las habilidades auditivas para desarrollar el lenguaje oral, sino que también dependen de otras áreas del desarrollo neurocognitivo, como la memoria de trabajo y la memoria a corto plazo para compensar los esfuerzos de la producción y comprensión del lenguaje, ya que diferentes estudios recogen la consistencia de la relación predictiva entre las medidas de memoria de trabajo y a corto plazo verbal y el lenguaje (Ching et al., 2019; Harris et al., 2011, 2013; Kronenberger et al., 2018; Lo y Chen, 2017).

\subsection{Lenguaje oral e inhibición en población con implante coclear}

Las personas con sordera son una población de interés en este campo, debido a sus limitaciones en el desarrollo de un lenguaje equiparable al de sus compañeros/as normo-oyentes. Netten et al., (2015) realizaron su estudio con preescolares con sordera $(\mathrm{N}=85)$ en el que variaba la pérdida auditiva, 61 niños/as utilizaban audífonos y 24 eran usuarios de IC. En el análisis de sus datos no era sorprendente encontrar que el desarrollo de las habilidades comunicativas tiene una correlación íntima con el lenguaje oral y el funcionamiento social. En cambio, destacó que sólo las habilidades comunicativas mostraban relación con el funcionamiento social. Además, la baja consecución de habilidades 
comunicativas en los preescolares con sordera repercutía en un mayor índice de conductas problemáticas. Así pues, esta hipótesis fue apoyada por Barker et al., (2009) que evaluaron a niños/as con sordera grave o profunda $(\mathrm{N}=116)$ en comparación con el grupo de referencia normo-oyente $(\mathrm{N}=69)$ para conocer las relaciones que se establecen entre el lenguaje, la atención y los problemas conductuales en criaturas de 1,5-5 años mediante la cumplimentación de cuestionarios por los progenitores, la observación a través de la grabación de vídeos y las medidas de rendimiento. Así pues, el análisis de los datos demostró que existe una relación entre los problemas conductuales y el bajo nivel de desarrollo de lenguaje oral. Además, las habilidades lingüísticas ejercen un papel importante de manera indirecta en la duración del mantenimiento de la atención y el autocontrol, por lo que puede desencadenar a su vez en el desarrollo de conductas disruptivas infantiles. De este modo, se asume que las habilidades lingüísticas y comunicativas están íntimamente interrelacionadas y, por tanto, el control inhibitorio depende en gran medida de ellas, por lo que el déficit en su desarrollo puede desencadenar dificultades en el comportamiento.

Así pues, como hemos visto anteriormente, las personas con sordera suelen presentar una menor competencia lingüística, por lo que dicha población es de gran interés para conocer el desarrollo de la habilidad ejecutiva de la inhibición. Horn, Davisa, Pisoni y Miyamoto, (2004) evaluaron la relación entre la atención visual sostenida, la inhibición motora y el lenguaje en niños/as con sordera de 4 a 7 años de edad, que habían sido implantados en una media a los 4,4 años. Sus evaluaciones indicaban un bajo rendimiento de la atención a nivel general en los participantes. Sin embargo, las mejores puntuaciones residían en aquellos que habían iniciado el uso del implante precozmente, debido a que su uso anticipado había favorecido la estimulación auditiva y lingüística temprana. En consecuencia, los resultados de los participantes que habían disfrutado del IC más de tres años mostraban correlación entre la inhibición motora, el lenguaje y el vocabulario, pero incluso en el primer año de uso del IC ya se pueden observar efectos positivos en la habilidad de inhibición e inteligibilidad.

Las dificultades en el lenguaje y su falta de estimulación auditiva aumenta el riesgo de déficit en inhibición motora, en comparación con el grupo control de iguales, por tanto, la implantación temprana ejerce un papel relevante, ya que la activación del implante coclear en edades más avanzadas asumen un mayor riesgo de padecer conductas impulsivas y falta de atención, perjudicando la duración de las relaciones sociales con sus iguales, el aprendizaje vivencial del lenguaje y por ende, un desarrollo competente en habilidades lingüísticas. No obstante, aunque la implantación temprana favorezca el desarrollo del control inhibitorio, su beneficio no previene el pobre desempeño en el rendimiento de tareas sobre atención visual, que precisan un control de impulsos en edades posteriores. 
Así pues, es posible que exista la dependencia del desarrollo del control inhibitorio a otras capacidades como la lingüística mediante el uso de estrategias o mecanismos en el proceso de ejecución como el lenguaje interno, el razonamiento verbal, las habilidades para contar, etc. Además, según Horn y sus colegas (2005) el género es una variable a tener en cuenta, dado que las participantes femeninas tuvieron un mejor rendimiento en la tarea de demora que los participantes masculinos.

A las mismas conclusiones llegaron con el estudio realizado por Hoffman, Tiddens y Quittner, (2018), que trataron de conocer la proximidad entre la atención visual y los problemas disruptivos en escolares con sordera, usuarios de IC, en comparación con sus compañeros/as normo-oyentes a través de la aplicación de una tarea estandarizada en edad media de 7 años. Los participantes con sordera mostraron déficit en la atención selectiva, el cual está relacionado con los problemas conductuales, pero no con las habilidades lingüísticas. No obstante, la velocidad de procesamiento en el WPPSI se relacionó con los errores y faltas de ejecución en la tarea de atención, por lo que aquellos que presentaban un mejor procesamiento cognitivo, mostraban un mayor rendimiento en la prueba de atención. De modo que, la capacidad de atención quizás no afecta al nivel lingüístico de manera directa, pero sí al procesamiento de la información. Además, la edad de implantación coclear se relacionó con el tamaño del efecto, el cual es el principal índice del rendimiento en atención selectiva. Incluso, después de 5 años de experiencia con el uso del IC, todavía mostraban déficit en atención, por lo que la sordera perjudica su desarrollo y provoca en cascada a un mayor riesgo en el número de conductas impulsivas, desatentas y con falta de control inhibitorio que se pueden categorizar de manera general como problemas de conducta.

En esta misma línea, Yucel y Derim, (2008) hallaron en escolares con IC de 6 a 11 años que se desempeñaban peor en tareas de atención visual persistente que precisa de un autocontrol e inhibición de impulsos y distracciones en comparación con el grupo de referencia. No obstante, cabe concretar que había una correlación significativa entre errores de falsa alarma y la edad de implantación. De hecho, aquellos participantes que fueron implantados de forma tardía (posterior a los 4 años) cometieron más errores que el grupo control, por lo que presentaban un mayor comportamiento impulsivo y desatento, que perjudica, en definitiva, en la relación con sus iguales. Aunque entre grupos de participantes con sordera, clasificados por la edad de implantación (grupo 1: antes de los 4 años y grupo 2: después de los cuatro años) no mostraron diferencias significativas, el grupo 1 tuvo puntuaciones similares al grupo control y los errores que cometieron fueron indicativos de sobrerreacción, autocontrol insuficiente e impaciencia. Además, el grupo 2 mostró ser menos maduro, por lo que obtuvieron más errores en las tareas de atención. 
A pesar de los escasos conocimientos acerca de la asociación entre la inhibición-concentración y el lenguaje en la edad infantil y menos todavía con criaturas con sordera, es evidente la transcendencia de las FE en el desarrollo del lenguaje, el aprendizaje y el comportamiento para alcanzar un buen desarrollo socio-emocional, por tanto, los déficits en estas habilidades condicionan no sólo su desarrollo, sino también repercute en la calidad de vida. De hecho, los estudios anteriores ponen de manifiesto que el alumnado con IC tiene un peor rendimiento en las FE como la memoria de trabajo y la inhibición, así como en las habilidades lingüísticas en comparación con sus compañeros normooyentes, por lo que su sordera provoca que las habilidades cognitivas se desarrollen de manera distinta. Por ello, se hace necesario realizar estudios sobre intervención en las habilidades ejecutivas para obtener un conocimiento más profundo sobre sus beneficios en el aprendizaje durante la etapa de educación infantil y así indagar el impacto que ejerce en el desarrollo del lenguaje en los primeros años de vida y sus efectos a largo plazo.

\section{RESUMEN}

En conclusión, del capítulo, los estudios realizados en personas con sordera y su gran heterogeneidad de población ha ampliado el conocimiento acerca de la relación del lenguaje y las funciones ejecutivas. Para resumir las aportaciones expuestas se presenta una síntesis comprensiva en forma de tablas de cada bloque de las temáticas tratadas.

1. Lengua de signos y funciones ejecutivas:

Aunque de manera notablemente reducida, hay una población de personas con sordera que utilizan la lengua de signos como modo de comunicación preferente o dominante. El estudio de las características diferenciales en la población con sordera de nacimiento, entre los grupos que tienen como primera lengua la de signos o los que tienen la oral, representa una oportunidad para diferenciar los efectos del contenido lingüístico que tienen ambas lenguas, de los soportes que aplican como el espacial preponderante en la lengua de signos, y el temporal, preponderante en la oral. Se muestran en la tabla 2 los estudios seleccionados. 
Tabla 2.

Resumen de estudios sobre lengua de signos y funciones ejecutivas.

\begin{tabular}{lll}
\hline \multicolumn{1}{l}{ Autores } & Conclusiones del estudio & Valoración de los resultados \\
\hline Hall, Eigsti, & A pesar de no mostrar desigualdades en las & El uso de la lengua de signos y la \\
Bortfeld y & punutaciones de las FE de los participantes & estimulación auditiva se presentan \\
Lillo-Martin, & con sordera (usuarios de IC y signantes) y & como medios de protección frente al \\
$(2018)$ & normo-oyentes. Los participantes con déficit en el desarrollo de las FE y el \\
& sordera, usuarios de IC mostraron un acceso temprano al lenguaje como el \\
& mayor riesgo en el desarrollo de las FE en caso de los participantes nativos en & con de \\
& comparación con sus compañeros/as con lengua de signos reduce el riego de & léficit.
\end{tabular}

Marschark et El rendimiento de la tarea de la memoria Las personas con sordera, al., (2015) espacial no dista según el uso del lenguaje independientemente de su modo de dominante (oral o signada) en comunicación presentan un buen participantes con sordera rendiimento en la capaciad de la memoria espacial.

Bavelier, Las personas con sordera, que utilizan Newport, lengua de signos, indican una seriación de Las personas con sordera que utilizan Hall, Supalla números más corta en orden directo e y Boutla, inverso, pero el recuerdo de dígitos libre (2008) alcanzaba un rendimiento equiparable al del grupo normo-oyente.

la lengua de signos presentan dificultades en el procesamiento $\mathrm{o}$ mantenimiento de la información en orden temporal posiblemente debido al déficit en el lenguaje oral que se desarrolla con un soporte temporal.

Hall $\quad y \quad$ El análisis del proceso de memoria a corto Bavelier, plazo determina que la lengua de signos La lengua de signos no demostró una (2011) afecta a la percepción y codificación de los dígitos, pero sirve de gran apoyo para el recuerdo de los números.

relación directa con la memoria sin un apoyo lingüístico, pero que no se pueden asignar a un pobre desarrollo de estrategias de recuerdo.

Marschark, Los participantes con sordera Las personas con sordera presentan Sarchet y independientemente de su modo de dificultades en la ejecución de tareas Trani, (2016) comunicación (oral o signada) presentan en las que se precise de una doble déficit en dos tareas de memoria, en las tarea, codificación verbal y temporal. que predomina el uso del lenguaje. 
Como hemos podido conocer, la lengua de signos no reduce el riesgo de déficit de las FE y el uso temprano del lenguaje (oral o signado) se muestra como una variable positiva frente al impacto de la sordera en el aprendizaje.

2. Lenguaje oral y funciones ejecutivas en las criaturas con IC:

Las investigaciones dirigidas a la ampliación de conocimiento del desarrollo ejecutivo en las distintas etapas educativas son variables. Los estudios sobre alumnado con sordera en la etapa de educación infantil, educados en la modalidad oral son muy escasos y encontramos únicamente dos estudios. Beer et al., (2014) indica que en esta etapa ya se detectan diferencias significativas con respecto a los preescolares normo-oyentes en las FE de la memoria a corto plazo verbal, la inhibiciónconcentración y la organización-integración. Sin embargo, Nicastri et al., (2020) muestra que los preescolares implantados antes de los 12 meses de edad muestran un desarrollo de las FE de inhibición, memoria de trabajo visoespacial y flexibilidad apropiadas a su edad.

En cambio, en la etapa escolar se han concentrado la mayoría de las investigaciones, que coinciden que la dificultad del alumnado con sordera en el desarrollo de sus habilidades ejecutivas, y que, sobre todo la incidencia de estos déficits se sitúa en la memoria de trabajo verbal y la inhibición. A continuación, se expone en las tablas 3 y 4 un breve resumen de las aportaciones científicas en edad escolar.

Tabla 3.

Resumen de estudios sobre lenguaje oral y funciones ejecutivas en las criaturas con IC en edad escolar.

\begin{tabular}{llll}
\hline Autores & \multicolumn{2}{l}{ Conclusiones del estudio } & Valoración de los resultados \\
\hline Botting et & El grupo con sordera mostró un menor & Los escolares con sordera expresan \\
al.,(2017) & desempeño en las tareas de FE, salvo en déficit en las FE con mayor peso en el \\
& aquella que evaluaba la fluidez cognitiva lenguaje, a pesar de controlar el \\
& visoespacial, incluso después de tener en lenguaje y la velocidad de \\
& cuenta la velocidad de procesamiento y la procesamiento. De modo que el \\
& capacidad no verbal. & lenguaje ejerce un papel determinante \\
& & en las FE.
\end{tabular}




\begin{tabular}{|c|c|c|}
\hline $\begin{array}{l}\text { Jones et al., } \\
\text { (2019) }\end{array}$ & $\begin{array}{l}\text { La evaluación longitudinal demostró que las } \\
\text { FE mejoran progresivamente, pero en los } \\
\text { participantes con sordera persiste el déficit en } \\
\text { la habilidad ejecutiva de la memoria. } \\
\text { Además, la puntuación del vocabulario en el } \\
\text { primer año predijo la evolución del desarrollo } \\
\text { de las FE. }\end{array}$ & $\begin{array}{l}\text { Las FE } \text { se desarrollan } \\
\text { progresivamente, pero las personas } \\
\text { con sordera no logran alcanzar } \\
\text { niveles equiparables a sus } \\
\text { compañeros/as normo-oyentes. } \\
\text { Además, el lenguaje no sólo influye } \\
\text { en el desarrollo de las FE, sino que, } \\
\text { además, el vocabulario, determina su } \\
\text { evolución. }\end{array}$ \\
\hline
\end{tabular}

Figueras, Sus resultados revelaron que la capacidad Afirma la consistencia del papel Edwards y lingüística se asoció significativamente con relevante que ejerce el lenguaje en el Langdon, las FE para el grupo de participantes normo- desarrollo de las FE.

(2008) oyentes y con sordera, independientemente de si usaban prótesis auditivas o no.

Surowiecki Los dos grupos de participantes con El tipo de prótesis auditiva no parece et al., (2002) diferentes dispositivos (IC /audífonos) ser un indicador de las diferencias obtuvieron resultados similares en todas las significativas en el desarrollo de las pruebas de cognición y del lenguaje. habilidades ejecutivas.

En cuanto a la etapa de secundaria, también se encuentran pocas investigaciones que aporten conocimiento acerca del desarrollo de las FE en la adolescencia. No obstante, los escasos estudios apuntan que la capacidad del lenguaje expresivo se relaciona con el rendimiento de las habilidades ejecutivas, debido a que se mantiene una correlación significativa entre ambas áreas (Remine et al., 2008), así como también se establece relación entre la comprensión lectora y las FE (Figueroa, Silvestre, et al., 2020). No obstante, es necesario realizar una mayor profundización para comprender la influencia del lenguaje y las FE en la adolescencia.

Por otro lado, se cuenta con estudios que utilizan las escalas de calificación por parte de los medios educativos. Este tipo de pruebas permiten comprender las dificultades que expresa el déficit de las FE en la actividad cotidiana, que se presentan en la tabla 4. 
Tabla 4.

Resumen de estudios sobre escalas de calificación.

\begin{tabular}{|c|c|c|}
\hline Autores & Conclusiones del estudio & Valoración de los resultados \\
\hline $\begin{array}{l}\text { Beer, } \\
\text { Kronenberger } \quad \mathrm{y} \\
\text { Pisoni, (2011) }\end{array}$ & $\begin{array}{l}\text { Los progenitores valoraron que los } \\
\text { participantes con IC tenían mayor } \\
\text { riesgo de déficit en inhibición y } \\
\text { memoria de trabajo }\end{array}$ & $\begin{array}{l}\text { La recogida de una muestra de } 5 \text { a } 18 \text { años } \\
\text { con IC detectó déficit en el desarrollo de } \\
\text { las FE principales. }\end{array}$ \\
\hline $\begin{array}{l}\text { Kronenberger et } \\
\text { al., (2014) }\end{array}$ & $\begin{array}{l}\text { Los participantes con IC tenían de } \\
2 \text { a } 5 \text { veces mayor riesgo de tener } \\
\text { déficit en la mayoría de los } \\
\text { dominios de FE. }\end{array}$ & $\begin{array}{l}\text { Los participantes de edad preescolar y } \\
\text { escolar presentan una mayor probabilidad } \\
\text { de presentar déficit en FE. }\end{array}$ \\
\hline Hintermair (2013) & $\begin{array}{l}\text { Los participantes con sordera } \\
\text { presentaban riesgo significativo de } \\
\text { déficit en de las FE }\end{array}$ & $\begin{array}{l}\text { Los participantes con sordera muestran } \\
\text { mayor probabilidad de riesgo en el } \\
\text { desarrollo de las FE desde la niñez hasta } \\
\text { la adolescencia. }\end{array}$ \\
\hline
\end{tabular}

Los estudios realizados en participantes con sordera han concluido que existe un mayor riesgo de déficit en las habilidades ejecutivas y en particular en aquellas próximas al área del lenguaje, debido a la repercusión de la competencia lingüística sobre el desarrollo cognitivo.

Los estudios longitudinales nos permiten comprobar cómo evoluciona el desarrollo de las FE en períodos de tiempo más extensos, por lo que es de gran interés conocer sus aportaciones para obtener una visión general de las dificultades que presenta el colectivo del alumnado con sordera en su diversidad. 
Tabla 5.

Resumen de estudios longitudinales.

\begin{tabular}{|c|c|c|}
\hline Autores & Conclusiones del estudio & Valoración de los resultados \\
\hline $\begin{array}{l}\text { Kronenberger et } \\
\text { al., (2013) }\end{array}$ & $\begin{array}{l}\text { Significativas puntuaciones inferiores en } \\
\text { memoria a corto plazo y de trabajo, así como } \\
\text { en la fluidez y la inhibición. }\end{array}$ & $\begin{array}{l}\text { La evaluación longitudinal de } \\
\text { participantes con sordera } \\
\text { demuestra que su déficit } \\
\text { permanece a lo largo del } \\
\text { desarrollo. }\end{array}$ \\
\hline $\begin{array}{l}\text { Castellanos, } \\
\text { Pisoni, } \\
\text { Kronenberger y } \\
\text { Beer, (2016) }\end{array}$ & $\begin{array}{l}\text { La evaluación inicial del lenguaje expresivo } \\
\text { predijo el desarrollo de las habilidades } \\
\text { lingüísticas posteriores, las FE y el } \\
\text { rendimiento académico. }\end{array}$ & $\begin{array}{l}\text { El nivel de lenguaje inicial } \\
\text { orienta el desarrollo de las FE y } \\
\text { repercute en las habilidades } \\
\text { académicas. }\end{array}$ \\
\hline $\begin{array}{l}\text { Hunter et al., } \\
(2017)\end{array}$ & $\begin{array}{l}\text { La percepción del habla y del lenguaje } \\
\text { correlaciona con las habilidades lingüísticas, } \\
\text { el nivel de desarrollo de la memoria de trabajo } \\
\text { verbal, la velocidad de la fluidez verbal y la } \\
\text { valoración conductual de los progenitores. }\end{array}$ & $\begin{array}{l}\text { La percepción del habla y el } \\
\text { lenguaje marcan el desarrollo } \\
\text { posterior de las FE y son } \\
\text { clínicamente relevantes para la } \\
\text { identificación del posible riesgo } \\
\text { a largo plazo. }\end{array}$ \\
\hline $\begin{array}{l}\text { Hunter et al., } \\
(2017)\end{array}$ & $\begin{array}{l}\text { Las habilidades iniciales del lenguaje se } \\
\text { correlacionaron significativamente con la } \\
\text { memoria de trabajo verbal y la velocidad de la } \\
\text { fluidez verbal medidas } 15 \text { años después del } \\
\text { implante. }\end{array}$ & $\begin{array}{l}\text { El lenguaje en los primeros años } \\
\text { influye en el desarrollo de las } \\
\text { FE futuras. }\end{array}$ \\
\hline $\begin{array}{l}\text { Kronenberger et } \\
\text { al., (2020) }\end{array}$ & $\begin{array}{l}\text { Se detecta déficit en atención sostenida, } \\
\text { inhibición y memoria de trabajo en alumnado } \\
\text { con IC en edades de 3-6 años. La lista de } \\
\text { verificación de comportamiento también } \\
\text { detecta bajas puntuaciones en inhibición y } \\
\text { memoria de trabajo. }\end{array}$ & $\begin{array}{l}\text { Las habilidades cognitivas } \\
\text { tempranas de memoria e } \\
\text { inhibición muestran retraso en } \\
\text { el desarrollo en el alumnado con } \\
\text { IC desde los } 3 \text { años de edad. }\end{array}$ \\
\hline
\end{tabular}


3. Lenguaje oral y memoria de trabajo en alumnado con IC:

Las investigaciones dirigidas a la profundización de la memoria y el lenguaje en participantes con sordera conducen a las conclusiones que se presentan en las tablas 6 y 7 .

Tabla 6.

Resumen de estudios de lenguaje oral y memoria de trabajo en alumnado con IC.

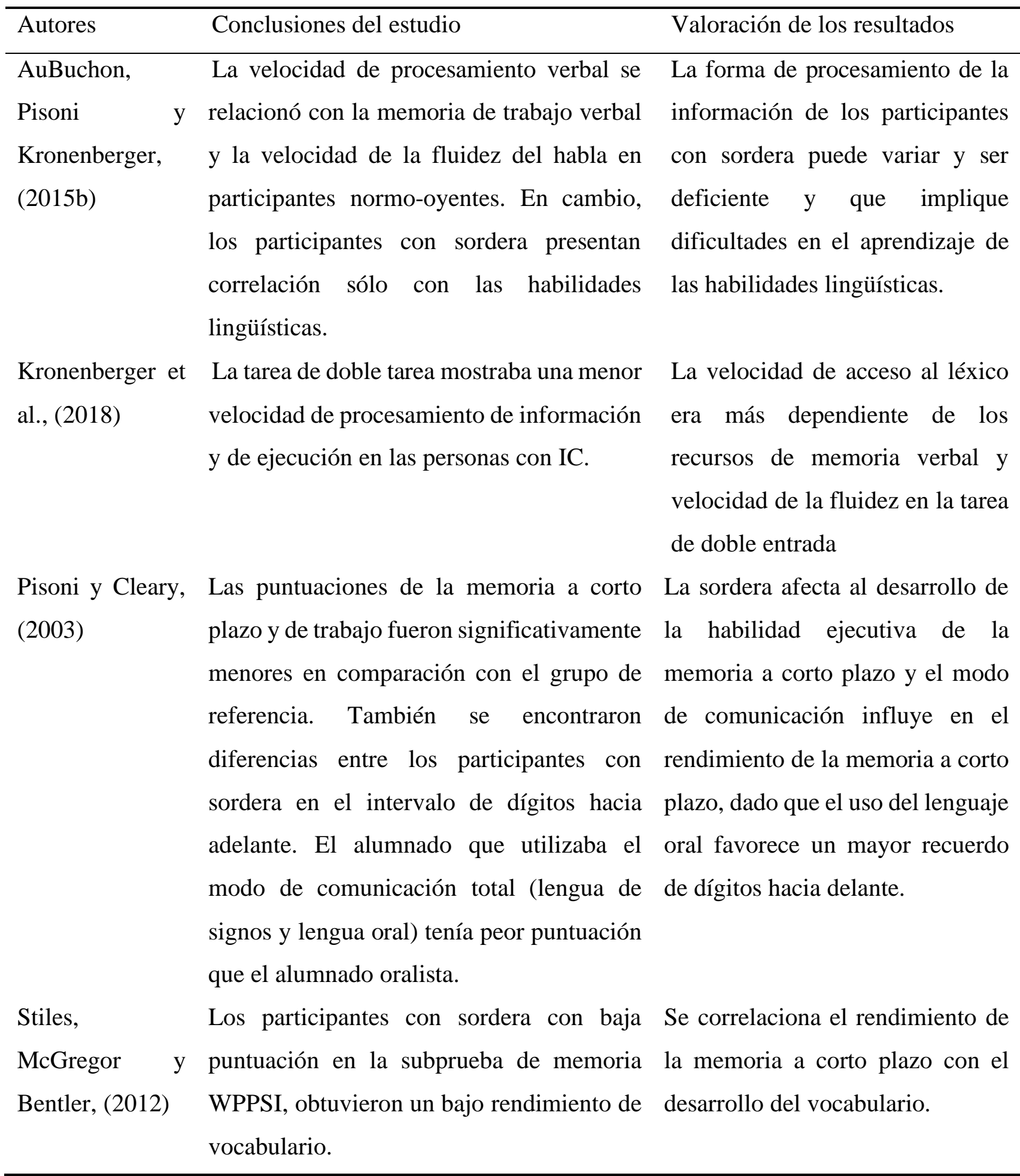




\begin{tabular}{lll}
\hline Lo y Chen, Los preescolares con sordera de alto La capacidad de la memoria \\
(2017) & rendimiento en memoria de trabajo predice el desarrollo del lenguaje y \\
& mostraban niveles equiparables de lenguaje los participantes con sordera \\
& $y$ aquellos/as con bajo rendimiento dependen en mayor medida del \\
& expresaban una baja puntuación en la tarea rendimiento en la memoria de \\
& de memoria. & trabajo para el aprendizaje del \\
& lenguaje.
\end{tabular}

Estos estudios demuestran la relación que presenta el lenguaje con la memoria de a corto plazo y el déficit de su desarrollo en los participantes con sordera. A continuación, presentamos las conclusiones a las que han llegado los estudios longitudinales.

Tabla 7.

Resumen de estudios de lenguaje oral y memoria de trabajo en alumnado con IC.

\begin{tabular}{|c|c|c|}
\hline Autores & Conclusiones del estudio & Valoración de los resultados \\
\hline $\begin{array}{l}\text { Harris et al., } \\
(2011)\end{array}$ & $\begin{array}{l}\text { Los participantes con limitaciones en ambas } \\
\text { habilidades de la memoria verbal obtenían } \\
\text { peores resultados en las pruebas de lenguaje y } \\
\text { habla. }\end{array}$ & $\begin{array}{l}\text { La memoria a corto plazo y de } \\
\text { trabajo puede influir en el } \\
\text { lenguaje y predecir su } \\
\text { desarrollo. }\end{array}$ \\
\hline $\begin{array}{l}\text { Harris et al., } \\
(2013)\end{array}$ & $\begin{array}{l}\text { Las puntuaciones de la tarea de memoria a corto } \\
\text { plazo y de trabajo presentan un déficit } \\
\text { significativo. El punto de inicio y el crecimiento } \\
\text { del rendimiento se correlacionan con el } \\
\text { lenguaje. }\end{array}$ & $\begin{array}{l}\text { Las puntuaciones en la tarea de } \\
\text { memoria a corto plazo y de } \\
\text { trabajo predicen el rendimiento } \\
\text { del lenguaje. }\end{array}$ \\
\hline $\begin{array}{l}\text { Ching } \\
\text { Cupples } \\
\text { Marnane, } \\
\text { (2019) }\end{array}$ & $\begin{array}{l}\text { Los participantes que evocaban una mayor } \\
\text { longitud de dígitos y de consonantes o vocales } \\
\text { indicaban un mayor nivel en las habilidades } \\
\text { lingüísticas y de vocabulario. }\end{array}$ & $\begin{array}{l}\text { El rendimiento de la memoria de } \\
\text { trabajo permite pronosticar el } \\
\text { nivel de lenguaje futuro de los } \\
\text { participantes. }\end{array}$ \\
\hline
\end{tabular}

Las investigaciones citadas confirman no sólo la relación entre la memoria a corto plazo y el lenguaje, sino también la predicción del desarrollo del lenguaje según el rendimiento en la habilidad ejecutiva de la memoria. Sin embargo, la memoria a corto plazo de carácter visual no presenta las mismas características de interdependencia y, además, tampoco muestra una mayor incidencia en el déficit de su desarrollo en los participantes con sordera. 
Estos estudios transversales, de cohorte y longitudinales nos han permitido identificar la estrecha relación que muestra el lenguaje y el habla con el factor neurocognitivo de la memoria, así como la detección de dificultades en el desarrollo óptimo de la memoria verbal a corto plazo y de trabajo en personas con sordera y su persistencia a lo largo del tiempo, incluso para aquellas personas que utilizan un IC y se benefician de su uso. La interdependencia de dichos factores contribuye a la comprensión sobre los motivos de la variabilidad en los resultados del habla y el lenguaje en niños y niñas con sordera, ya que el retraso en el aprendizaje del lenguaje oral contribuye a un déficit en la estimulación del área de la memoria y limita la ejecución de operaciones cognitivas a nivel superior, cuando debe organizar y almacenar el lenguaje.

\section{Inhibición y lenguaje en alumnado con IC}

En cuanto a la relación de la inhibición y el lenguaje, no se han realizado tantos estudios que sobre la memoria. En la tabla 8 se presentan las conclusiones más relevantes:

Tabla 8 .

Resumen de estudios sobre inhibición y lenguaje.

\begin{tabular}{|c|c|c|}
\hline Autores & Conclusiones del estudio & Valoración de los resultados \\
\hline $\begin{array}{l}\text { Netten et } \\
\text { al., (2015) }\end{array}$ & $\begin{array}{l}\text { Las bajas habilidades comunicativas de } \\
\text { los preescolares con sordera mostraban un } \\
\text { mayor índice de conductas problemáticas. }\end{array}$ & $\begin{array}{l}\text { Se observa la correlación significativa } \\
\text { entre las habilidades comunicativas y el } \\
\text { índice de frecuencia de conductas } \\
\text { disruptivas. }\end{array}$ \\
\hline $\begin{array}{l}\text { Barker et } \\
\text { al., (2009) }\end{array}$ & $\begin{array}{l}\text { Relación directa entre los problemas } \\
\text { conductuales y el bajo nivel de desarrollo } \\
\text { de lenguaje oral en los participantes con } \\
\text { sordera. Las habilidades lingüísticas se } \\
\text { relacionan de manera indirecta en la } \\
\text { duración de la atención y el autocontrol. }\end{array}$ & $\begin{array}{l}\text { Las habilidades lingüísticas y } \\
\text { comunicativas están íntimamente } \\
\text { interrelacionadas y, por tanto, el control } \\
\text { inhibitorio depende en gran medida de } \\
\text { ellas, por lo que el déficit en su desarrollo } \\
\text { puede desencadenar dificultades en el } \\
\text { comportamiento. }\end{array}$ \\
\hline $\begin{array}{l}\text { Horn et al., } \\
(2004)\end{array}$ & $\begin{array}{l}\text { Bajo rendimiento de la atención a nivel } \\
\text { general en los participantes. Las mejores } \\
\text { puntuaciones se situaban en los } \\
\text { participantes con sordera que utilizaron } \\
\text { tempranamente el implante coclear. }\end{array}$ & $\begin{array}{l}\text { Los participantes con sordera muestran un } \\
\text { bajo desarrollo de la atención, pero el uso } \\
\text { temprano del implante coclear beneficia } \\
\text { su desarrollo. }\end{array}$ \\
\hline
\end{tabular}




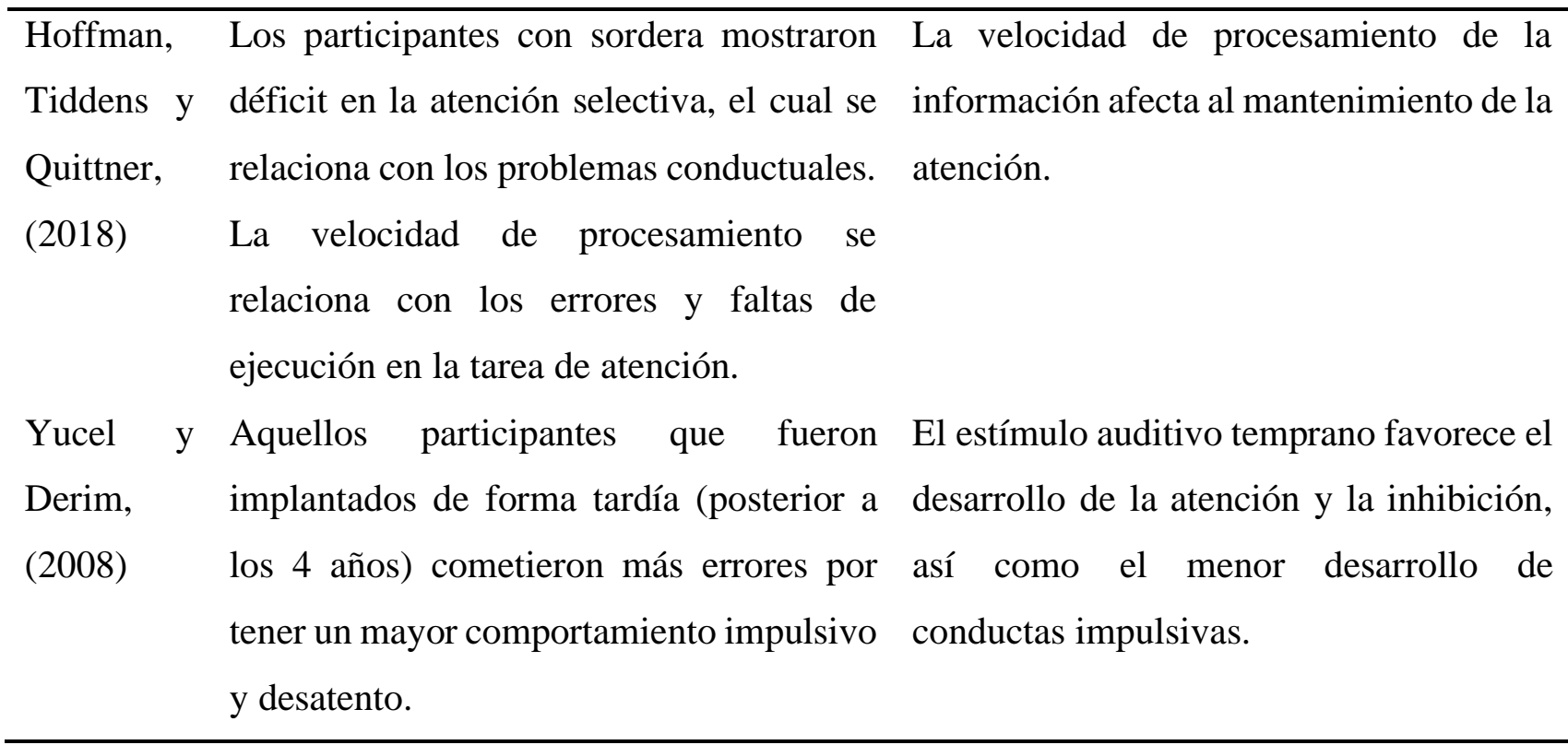




\section{CAPÍTULO 4. LAS DIVERSAS INTERVENCIONES EN LA ESTIMULACIÓN DE LAS HABILIDADES COGNITIVAS}

\section{La intervención en FE dirigido a alumnado con sordera}

Diferentes estudios de intervención sobre el entrenamiento de las FE desde diferentes enfoques metodológicos, aplicados tanto en niños/as normo-oyentes, como con preescolares con dificultades de aprendizaje han demostrado los beneficios que se obtienen en el desarrollo de las FE. Diamond, Barnett, Thomas y Munro (2007) pusieron en práctica el programa "Tools of the Mind" en un grupo de preescolares $(\mathrm{N}=85)$ en comparación con otro grupo $(\mathrm{N}=62)$ que participaron en un programa de alfabetización. Sus resultados demostraron una mejora significativa en la inhibición cognitiva en aquellos que utilizan el programa de "Tools of the Mind". Röthlisberger, Neuenschwander, Cimeli, Michel y Roebers (2011) también obtuvo mejoras significativas en las habilidades ejecutivas de la memoria de trabajo y la flexibilidad cognitiva, después de aplicar un programa de intervención con alumnado normo-típico (N=135) de 5-6 años. Volckaert y Noël, (2015) establecieron un programa de intervención en FE para 24 niños/as con desarrollo típico de 5 años en comparación con un grupo control (N=23). El grupo de entrenamiento superó significativamente al grupo control en la mayoría de las tareas de control inhibitorio y también en dos de las tres tareas de memoria de trabajo, así como en aquella que precisaba flexibilidad cognitiva. Del mismo modo, el estudio de Rosas, Espinoza, Porflitt y Ceric, (2019) reafirma el impacto positivo de las actividades colectivas centradas en el desarrollo de las FE en alumnado normo-típico y coindice con los resultados obtenidos en este estudio, dado que la estimulación aportó de forma consistente diferencias significativas en las tres evaluaciones sobre las FE.

En cambio, apenas se encuentra literatura científica en programas de intervención con grupo de participantes con sordera por lo que no tenemos evidencias suficientes sobre los beneficios que aporta al aprendizaje y el desarrollo de habilidades cognitivas en este colectivo. De todas formas, las pocas contribuciones que se han podido recopilar únicamente centran sus estudios en la etapa escolar.

Es de gran utilidad la intervención en preescolar, debido a que los estudios citados con anterioridad al respecto muestran que el alumnado con sordera presenta retraso en FE ya en la etapa de preescolar y que, obviamente, hay consenso sobre la eficiencia de la atención temprana. Sin embargo, junto a la revisión de los estudios con criaturas normo-oyentes de preescolar puede ser sugerente la síntesis del estado de conocimiento de los estudios en edad escolar que se presenta a continuación.

Kronenberger et al., (2011) completaron un programa de intervención en memoria mediante un programa con TICS que aplicaron durante un mes en 9 participantes con sordera, usuarios de IC en 
edades comprendidas entre 7-15 años. La estimulación consistía en el uso del programa Cogmed desde un ordenador en la residencia familiar en sesiones diarias de 30-40 minutos (5 días a la semana) durante un período de 5 semanas, por tanto, completaron un entrenamiento de 25 días. El programa consta de 12 ejercicios diferentes basados en habilidades auditivas, visoespaciales y de memoria de trabajo. Los participantes fueron evaluados antes y después de la intervención en pruebas objetivas de memoria de trabajo y lenguaje. Así mismo, se aplicó la escala de calificación sobre las FE (BRIEF) valorada por los progenitores, un mes después para valorar el seguimiento. Los resultados demostraron un mejor rendimiento en memoria a corto plazo, aumentando las diferencias significativas un mes después de la intervención y un mayor tiempo en la ejecución en la tarea de memoria espacial, que también fueron consistentes con la escala de valoración pasada a los progenitores, las cuales mostraron un beneficio en la repetición de oraciones incluso seis meses después.

Nunes, Barros, Evans y Burman, (2014) realizaron un estudio similar con 73 escolares con sordera (22 niños y niñas usaban implante coclear y 51 de ellos tenían audífonos de edades entre 5 y 11 años en comparación con un grupo control de iguales con sordera $(\mathrm{N}=77)$, de los cuales 26 utilizaban implante coclear y 51 tenían audífonos. La media de edad de todos los escolares (participantes y grupo control) fue de 8 años y 5 meses. La intervención consistía en 3 actividades virtuales, donde debían ejecutar las actividades que se mostraban en el ordenador dirigidas por el docente y 3 actividades virtuales, expuestas en una página web sobre memoria de trabajo, en el que utilizaban estrategias visuales y verbales combinadas con la supervisión de un docente. El análisis de los datos demostró que los diferentes grados de sordera no expresaban diferencias significativas, por lo que no se relacionó los factores demográficos con los resultados de la intervención, pero la edad fue una variable influyente, debido a su variabilidad. Así pues, a pesar de controlar la edad como covariable, la evaluación de la memoria de trabajo antes y después de la intervención indicó un mejor rendimiento en la tarea en comparación con el grupo control.

Al parecer los programas de intervención interactivos suponen una repercusión positiva para el impulso del crecimiento de las habilidades ejecutivas en personas con sordera. Además, la intervención fundamentada en ejercicios aeróbicos que ponen en práctica las FE benefició también al alumnado con sordera, en el estudio de Xiong et al., (2018). En efecto, los autores aplicaron un programa de intervención sobre ejercicios aeróbicos a 18 participantes con sordera de 9 a 13 años, asignados de manera aleatoria en el grupo experimental $(\mathrm{N}=8)$ y en el grupo control $(\mathrm{N}=10)$. El programa consistía en 4 sesiones a la semana de 45 minutos durante 11 semanas con una intensidad moderada de ejercicios aeróbicos. Las medidas utilizadas para evaluar el desarrollo neuropsicológico se efectuaron de manera objetiva mediante tareas que valoraron las FE principales (inhibición, memoria de trabajo y 
flexibilidad), así como también se examinó la materia blanca del cerebro. Así pues, la intervención mejoró de forma significativa las tres habilidades ejecutivas y la materia blanca del cerebro, es decir se modifican las microestructuras cerebrales, concretamente de la parte izquierda, en comparación con el grupo control, por tanto, los ejercicios aeróbicos también presentan un beneficio en el desarrollo de las FE en personas con sordera.

A pesar de que los estudios existentes con participantes con sordera, estén limitados en la etapa escolar y sean minoritarios, los estudios experimentales en personas con sordera también demuestran un claro impulso en el crecimiento de las habilidades neurocognitivas (Kronenberger et al., 2011; Nunes et al., 2014; Xiong et al., 2018) y sus aportaciones nos permiten dibujar la posibilidad de mejorar las FE que todavía expresan déficit en edad escolar a causa de su íntima relación con el lenguaje y su afectación por el impacto de la sordera.

Con todo ello, el análisis de las investigaciones experimentales aporta una gran información a la literatura científica sobre la estimulación de las áreas neurocognitivas, ya que los beneficios de la intervención cognitiva favorecen a personas normo-oyentes, escolares con dificultades en el aprendizaje y alumnado con sordera. Al mismo tiempo los estudios han revelado que el entrenamiento cognitivo trasciende tanto a la etapa de educación primaria, como a la etapa de educación infantil, por lo que aumenta la relevancia de la estimulación en atención temprana a fin de favorecer el aprendizaje en los años de mayor plasticidad cerebral y así reducir el déficit en FE a largo plazo. No obstante, el análisis de los programas de intervención de Diamond, (2012) concluyeron con la exposición de ciertas características que cabe tener en cuenta para que su estimulación obtenga beneficios (Diamond y Lee, 2011; Diamond y Ling, 2016) que se resumen a continuación.

Los programas de intervención favorecen el crecimiento de las FE entrenadas, por tanto, es conveniente aplicar tareas o actividades que impliquen el desafío de varias habilidades cognitivas. Otra variable que cabe tener en cuenta es la temporalidad de la estimulación, debido a que los estudios con mayor duración y prolongación en el tiempo han obtenido mejores resultados. La presentación y ejecución de las actividades pueden influir en los resultados del programa, por lo que se debe presentar siempre la misma organización de los contenidos, por tanto, es necesario analizar el mayor número de variables que intervienen para determinar que los resultados provienen de la estimulación cognitiva y no a otros factores relacionadas. Los beneficios en las FE se encuentran cuando se pone a prueba su práctica, por tanto, aquellos con un déficit en su rendimiento demuestra un mayor crecimiento cuando se estimulan. De hecho, las mejorías en las habilidades cognitivas se prolongan en el tiempo (1, 3 o 6 meses), pero se reduce la intensidad de sus mejorías o se reduce sólo a algunas, que mostraban una 
mayor exigencia cognitiva y, finalmente, los programas de entrenamiento físico deben fundamentarse en actividades dirigidas al desarrollo de las FE para que tengan un impacto positivo sobre la misma.

En conclusión, con los estudios citados, se hace evidente la urgencia de avanzar en el conocimiento sobre la estimulación en niños/as con IC en edad preescolar, dado el creciente número de implantados cocleares y el riesgo potencial de retrasos en las funciones ejecutivas en la población con sordera. También, existe la necesidad de ampliar el conocimiento sobre las habilidades ejecutivas que expresan déficit y de qué manera afecta en conductas cotidianas de los niños con IC, ya que las funciones ejecutivas actualmente no se analizan dentro de las evaluaciones clínicas periódicas de niños/as con IC y, por tanto, se tiene poca información sobre el desarrollo evolutivo de las habilidades cognitivas en preescolares con sordera.

\section{RESUMEN}

Para resumir a continuación se presentan los resultados de las investigaciones y las conclusiones más relevantes referentes a los programas de intervención.

Tabla 9.

Resumen de estudios de los programas de intervención.

\begin{tabular}{lll}
\hline Autores & Conclusiones del estudio & Valoración de los resultados \\
\hline Kronenberger, & Programa de intervención en memoria & El programa benefició el desarrollo \\
et al (2011) & mediante un programa con TICS. & de la memoria a corto plazo y la \\
& Mejor rendimiento en memoria a corto ejecución de la tarea de capacidad \\
& plazo, menor tiempo en la ejecución en la espacial. & \\
& tarea de memoria espacial según la & Además, favorece el desarrollo de \\
& valoración de los progenitores. & actividades conductuales. \\
& & \\
Nunes, Barros, & 3 actividades virtuales y 3 actividades & La estimulación cognitiva en \\
Evans & manuales sobre memoria de trabajo. & participantes con sordera en edad \\
Burman, & La evaluación de la memoria de trabajo & escolar favoreció el rendimiento en la \\
$(2014)$ & antes y después de la intervención indicó & ejecución de las tareas de memoria. \\
& un mejor rendimiento en la tarea en & \\
& comparación con el grupo control. & \\
\hline
\end{tabular}




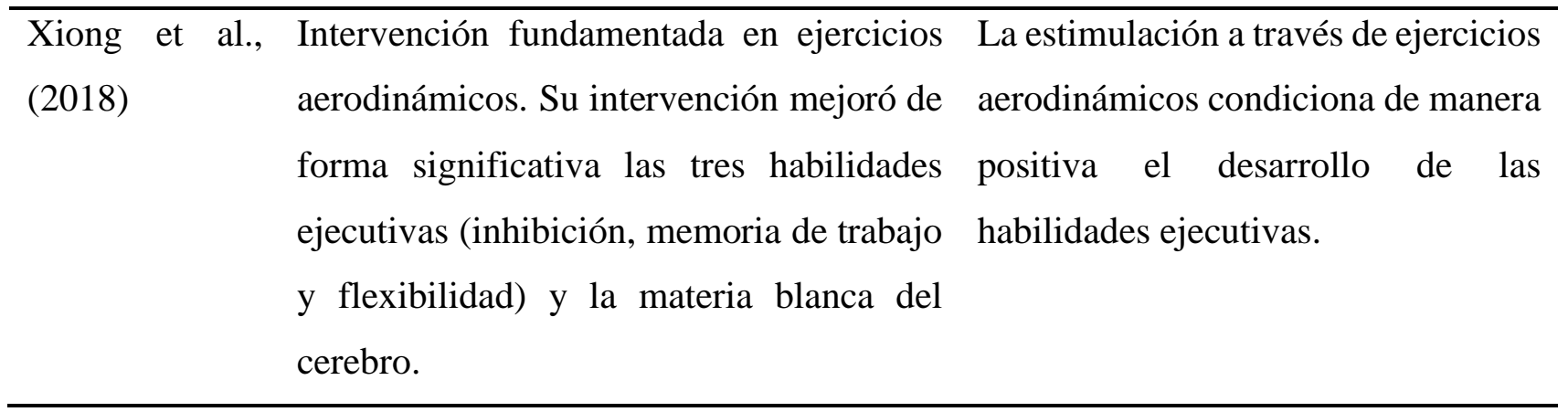

Los diferentes programas de intervención alientan sobre el beneficio que supone para los participantes con sordera, dado que favorecen el desarrollo de las funciones ejecutivas, que se han visto afectadas a causa de la privación auditiva. 


\section{PARTE II. DISEÑO METODOLÓGICO DE LA INVESTIGACIÓN}

\section{CAPITULO 5. MARCO GENERAL DE LA INVESTIGACIÓN EMPÍRICA Y OBJETIVOS}

La revisión teórica desarrollada en los capítulos anteriores ha pretendido fundamentar la descripción de las FE, especialmente de la memoria y la inhibición, debido a su implicación en el aprendizaje y su estrecha relación con el lenguaje. La fundamentación conceptual se ha acotado a los trabajos de investigación relacionados con alumnado, afectado de sordera en su primera infancia, a fin de construir el estado actual de la cuestión, en algunas temáticas todavía poco estudiadas y relevantes para el desarrollo y el aprendizaje.

El motivo de la investigación se centra en indagar el desarrollo de los procesos cognitivos vinculados al aprendizaje de la población infantil con sordera, debido a que el impacto de la hipoacusia congénita en los primeros años de vida, aunque se beneficie del implante coclear, afecta al aprendizaje espontáneo del lenguaje oral. De este modo, la investigación que se detallará a continuación, se ha centrado en la indagación del efecto que la falta de audición tiene en dos de las más relevantes FE, en tanto en cuanto son habilidades que se adquieren. A saber: a) la memoria para recordar, reorganizar e incorporar información en la memoria a largo plazo gracias a la estimulación de la memoria de trabajo verbal, b) la inhibición para controlar todo estimulo ajeno que impida atender al mensaje. Además, el estudio de este campo adquiere una mayor relevancia, debido a que las FE se estructuran y desarrollan de forma paralela con el lenguaje, por lo que presentan una relación de interdependencia.

Dentro de este marco general, a partir de la revisión en el marco teórico, se constatan una serie de cuestiones pendientes que se abordan en los dos nuevos estudios.

En primer lugar, se examina la relación entre ciertas funciones ejecutivas y el lenguaje en población normo-oyente y en población con IC, revisando los trabajos de Beer et al., 2014; Figueras et al., 2008; Hunter et al., 2017; Jones et al., 2019 y Kral et al., 2016. En ellos se constata que se producen correlaciones en el desarrollo desde la primera infancia y se prolonga hasta la adolescencia, pero resultan poco concluyentes, ya que apenas se ha abordado la etapa infantil o preescolar (en este trabajo se utilizarán ambos términos como sinónimos) representando al os participantes de entre 3 y 6 años. Por ello, en este trabajo se pretende indagar acerca de cuál es el nivel de interdependencia que presenta el lenguaje y las FE primarias (memoria e inhibición) en los participantes con sordera en edad preescolar y si la condición auditiva establece relaciones diferenciales en comparación con su grupo de iguales normo-oyentes.

Según nuestro conocimiento, no existen estudios con población española y parece de gran valor conocer cuál es la situación actual de la población con sordera, usuarios de IC, a través de la recogida 
de una muestra representativa del alumnado con sordera de la Comunidad Valenciana y Catalana, que comparten el uso de la lengua co-oficial.

En segundo lugar, sobre los trabajos diferenciales, los estudios más recientes realizados por Castellanos et al., 2016, Jones et al., 2019, Kronenberger et al., 2013, 2018; Marschark et al., 2016, que se han presentado en los apartados anteriores detectan que los participantes con sordera, independientemente de la modalidad de comunicación, y de la etapa escolar presentan dificultades en las funciones ejecutivas. En efecto, tanto en primaria como en secundaria presentan déficit en las puntuaciones de las tareas ejecutivas, donde hay un mayor predominio del lenguaje, por lo que el alumnado con sordera no llega a alcanzar un nivel equiparable a sus iguales normo-oyentes. Sin embargo, salvo el estudio realizado por Beer et al., (2014) y Kronenberger et al., (2020) que revelan déficit en el desarrollo de las FE del alumnado preescolar con sordera, no se ha profundizado en las FE primarias (memoria e inhibición) en la etapa de educación infantil. También en este caso, existe un vacío en el marco científico sobre estudios con población española infantil con sordera usuarios de IC, por lo que se pretende adquirir un conocimiento amplio y general del nivel de desarrollo de las FE en población preescolar a partir de un grupo particular. Al mismo tiempo, se parte, en este trabajo, de una perspectiva educativa inclusiva por lo que la población utilizada -con y sin afectación auditiva- estaba escolarizada en aulas ordinarias.

Finalmente, esta tesis pretende profundizar en los procesos de aprendizaje intencional de las FE que se desarrollan durante la infancia (inhibición y memoria) en el alumnado con implante coclear, ya que, aunque hay algunas evidencias de que la sordera puede influir en el desarrollo espontáneo de las mismas, el conocimiento de los procesos de aprendizaje intencional de las FE puede aportar información acerca de los aspectos diferenciales sobre cómo se produce en el alumnado con sordera y sugerir practicas pedagógicas adaptadas para estimularlas, que beneficien al desarrollo del lenguaje.

En síntesis, este estudio tiene los siguientes objetivos generales:

a) Valoración de las FE (memoria e inhibición) y su relación con el nivel de desarrollo del lenguaje.

b) Efecto de la edad en el desarrollo de las FE

c) Efecto de la intervención en el desarrollo de las FE

Para alcanzar estos objetivos se han realizado dos estudios, ambos ubicados en el marco de una educación inclusiva, donde convive la población infantil con pérdida auditiva y normo-oyente.

En el primer estudio se emprende el análisis del estado de dos de funciones ejecutivas primarias (memoria e inhibición) en la población infantil con sordera usuaria de IC en la región territorial de la 
Comunidad Valenciana y de Cataluña, por compartir el uso común de la lengua cooficial. La muestra representativa recoge todo el grupo de edad de la etapa educativa infantil de 3-6 años para englobar la evolución del desarrollo de las FE en edad preescolar.

Posteriormente, se realizó un segundo estudio, dirigido a la aplicación de un programa piloto de intervención en las habilidades ejecutivas, con una parte de los participantes del estudio previo (con sordera y normo-oyentes) mediante la realización de actividades educativas que fomentan la ejecución de los procesos cognitivos de la memoria y la inhibición. En este sentido, el objeto de estudio fue indagar en la capacidad de mejoría que pueden tener estas habilidades ejecutivas a través de su implicación en actividades funcionales en situaciones de actividades funcionales de juego dirigido en grupo, tanto en participantes con sordera, como normo-oyentes.

Este segundo estudio se considera piloto, debido a la escasez de estudios previos o de intervención con preescolares y se ubica dentro del contexto geográfico de la Comunidad Valenciana, donde participa un centro educativo de integración preferente de alumnado con sordera enmarcado en la atención educativa desde una perspectiva inclusiva. En concreto, la estimulación en las habilidades ejecutivas se situó en un aula de $2^{\text {o }}$ ciclo de educación infantil, donde participaron todo el grupo-clase, formado por alumnado normo-oyente y con IC.

Para los dos estudios, los criterios de selección de la muestra de población normo-oyente fueron los siguientes:

- Presentar una audición y lenguaje dentro del rango normal de desarrollo.

- No presentar antecedentes por enfermedad neurológica o del desarrollo, que precise de un tratamiento crónico o de adaptaciones educativas en la escuela o en el hogar.

- Expresarse, acorde a su edad, en el idioma principal con el que se realiza la evaluación de las habilidades cognitivas castellano o catalán.

- Comunicarse de manera habitual en castellano o catalán en la escuela y residencia familiar.

Los criterios de inclusión de la muestra infantil con sordera, usuarios de implante coclear, fueron comunes para los dos estudios, pero se recogió muestra de participantes diferentes. Los criterios de selección que se aplicaron para la selección de la población fueron los siguientes:

- Haber recibido el implante coclear antes de los tres años.

- Presentar una pérdida auditiva congénita.

- El grado de pérdida auditiva debe ser severa o profunda bilateral (>90). 
- Expresarse en el idioma principal con el que se realiza la evaluación de las habilidades cognitivas castellano o catalán.

- Comunicarse de manera habitual en castellano o catalán en la escuela y/o en su residencia familiar.

- Estar inscrito en un programa logopédico, bien a nivel particular y/o en el centro educativo en régimen de educación auditiva para propiciar el desarrollo de las habilidades lingüísticas y auditivas.

- No debe presentar ninguna discapacidad adicional, a parte de la pérdida auditiva.

- Estar escolarizado en centros educativos ordinarios.

En los dos estudios se emplearon, como técnicas de recogida de datos para la valoración de las competencias lingüísticas y mentales los siguientes instrumentos de evaluación:

1) Lenguaje. Escala de Desarrollo del Lenguaje de Reynell (1997). Esta escala se ha revisado para adecuarla a la evaluación de niños/as con discapacidad auditiva (Edwards, Fletcher, Garman, Hughes, 1997) y evalúa tanto la comprensión, como la expresión.

La escala de la comprensión (LOC), está formada por la suma de 67 ítems, divididos en 10 secciones dispuestas en orden evolutivo (palabras simples, relaciones básicas entre palabras, agentes y acciones, atributos y relaciones espaciales, estructuras sintácticas complejas e inferencias y aspectos gramaticales) (Edwards et al., 1997).

La escala de expresión (LOEX), recoge 67 ítems, dividido en tres secciones: Estructura del lenguaje, Vocabulario a través de objetos, dibujos y palabras y contenido a través de la descripción de dibujos (Edwards et al., 1997).

2) Las capacidades mentales evaluadas fueron:

- Inteligencia Manipulativa (IM), evaluada de forma breve, siguiendo las aportaciones de Sattler, (1992), mediante la prueba de cubos de la Wechsler Intelligence Scale for Children - IV (WISC-IV)

- FE-Memoria: Evaluada en 5 subpruebas: (1) La memoria narrativa (MN), (2) La memoria verbal (MMV) y (3) La memoria espacial (MESP) mediante la Batería Neuropsicológica infantil Nepsy-II (Korkman et al., 2007) (Korkman et al., 2007), (4 y 5) La Memoria de trabajo mediante las pruebas de dígitos (Dígitos hacia adelante- DDW y dígitos hacia atrásDAW) de la Wechsler Intelligence Scale for Children - IV (WISC-IV). 
- FE-Inhibición: Evaluada en dos sub-pruebas:(1) La inhibición motora (IM) mediante la Batería Neuropsicológica infantil Nepsy-II (Korkman et al., 2007) y (2) la Inhibición cognitiva (IC) Mediante la tarea de "día y noche” prueba de Stroop para población infantil (Gerstadt, Hong y Diamond, 1994). 


\section{CAPÍTULO 6. ESTUDIO 1 DESCRIPTIVO-COMPARATIVO}

1. Justificación, propósitos y fines de la investigación

La recopilación de estudios recientes ha despertado el interés por realizar un análisis descriptivocomparativo de las FE que se desarrollan durante la etapa infantil en la población con sordera con IC, motivado por la escasez de estudios dedicados al tema en esas edades tempranas o con población sorda usuaria de IC. De esta manera, se pretende conocer si el alumnado con sordera y usuarios de IC presenta procesos evolutivos diferenciados en el desarrollo de las FE de la memoria y la inhibición durante la etapa infantil a causa de su sordera congénita y a pesar del uso del IC de forma temprana.

Este estudio recoge una muestra representativa del alumnado con sordera, situada dentro de la zona de la comunidad valenciana y catalana, debido a su proximidad geográfica y las características lingüísticas que comparten.

Los objetivos se agrupan a continuación según las temáticas que se plantean en la investigación:

I. Respecto al nivel de Lenguaje

a. Establecer las diferencias que presenta el alumnado infantil con IC en el desarrollo del lenguaje oral expresivo y comprensivo con respecto al grupo de referencia normooyente

II. Respecto a las Funciones Ejecutivas de Memoria e inhibición

a. Identificar las diferencias que presenta el alumnado con IC en el desarrollo de las habilidades ejecutivas de la memoria y la inhibición en relación con niños/as normooyentes y si las diferencias demuestran la existencia de un posible déficit en comparación con el grupo de referencia normo-oyente.

b. Determinar la relación que establece el lenguaje con las funciones ejecutivas de la memoria y la inhibición.

III. Respecto a la edad de los participantes

a. Identificar si las dificultades del alumnado con IC en el desarrollo de la memoria y la inhibición afectan más al grupo de edad de 3-4 años o 5-6 años.

Las hipótesis que se exponen se han planteado a priori para contrastar su confirmación o refutación con la recogida de información de la muestra representativa.

I. El alumnado con sordera en la etapa infantil muestra déficit en el nivel del lenguaje expresivo y comprensivo en comparación con sus compañeros/as normo-oyentes. 
II. El alumnado con sordera en la etapa infantil muestra un déficit en el desarrollo de las habilidades ejecutivas de la memoria y la inhibición en comparación con sus iguales normo-oyentes.

III. Se muestra una relación significativa entre el lenguaje y las habilidades ejecutivas de la memoria y la inhibición en edad infantil.

IV. El grupo de alumnado con sordera de 3-4 años no muestra diferencias significativas en comparación con su grupo de iguales normo-oyentes en las FE de memoria e inhibición, debido a que todavía las habilidades ejecutivas son inmaduras para ambos grupos de participantes (normo-oyentes y con sordera).

\section{Diseño metodológico}

El estudio es una investigación educativa mixta (cuantitativa-cualitativa) de carácter descriptivocomparativo (Bisquerra, 2009) que trata sobre el análisis de las habilidades ejecutivas de memoria e inhibición en la población infantil con sordera prelocutiva de 3-6 años y usuaria de implante coclear y su influencia sobre el desarrollo del lenguaje oral. De esta manera, se alcanza una visión real del problema a través del posicionamiento teórico en el que se tiene en cuenta los factores que intervienen en el desarrollo de las habilidades cognitivas, atendiendo a las competencias en el lenguaje oral. Para su estudio, se establece la comparación entre participantes de entre 3 a 6 años afectados de sordera y participantes con desarrollo-típico, a fin de comprender e interpretar los fenómenos particulares que se desarrollan en un espacio y tiempo determinado.

El trabajo sigue una modalidad ex-post facto, debido a que se realiza la recogida de datos de una manera pasiva, sin intermediación en el cambio o la intervención de las variables, a fin de obtener información de las habilidades cognitivas de memoria e inhibición y competencia lingüística de la muestra de población infantil con implante coclear en comparación con el grupo de población normotípico. De esta manera, hemos utilizado una metodología cuantitativa, que permita obtener datos de manera objetiva y cuantificable para establecer un análisis estadístico comparativo que nos permita vislumbrar aspectos ambiguos de la afectación auditiva en el aprendizaje. 


\subsection{Participantes}

Los participantes fueron un total de 69 distribuidos por edad, género y nivel auditivo como describe la Tabla 10

Tabla 10.

Descripción de los participantes según edad, audición y género.

\begin{tabular}{|c|c|c|c|c|c|}
\hline \multicolumn{2}{|c|}{ Edad } & $3 ; 00-3 ; 11$ & $4 ; 00-4 ; 11$ & $5 ; 00-6 ; 00$ & TOTAL \\
\hline \multirow[t]{2}{*}{ Audición } & sordera & 7 & 7 & 18 & 32 \\
\hline & oyente & 12 & 5 & 20 & 37 \\
\hline \multirow[t]{2}{*}{ Género } & hombre & 7 & 5 & 24 & 36 \\
\hline & mujer & 12 & 7 & 14 & 33 \\
\hline
\end{tabular}

Tabla 11.

Descripción del grupo de participantes según edad y condiciones protésicas.

\begin{tabular}{lcccc}
\hline Edad & & $3 ; 00-3 ; 11$ & $4 ; 00-4 ; 11$ & $5 ; 00-6 ; 00$ \\
\hline Implante & unilateral & 3 & 4 & 13 \\
& bilateral & 4 & 3 & 5 \\
Ganancia & $10-20$ & 1 & 9 & 3 \\
auditiva & $20-30$ & 6 & & 14 \\
& $>40$ & & 3 & 1 \\
\hline
\end{tabular}

La selección de la muestra se estableció de manera no probabilística e intencional para poder escoger una muestra homogénea, debido a la diversidad de la población infantil con hipoacusia prelocutiva, que proviene de diferentes centros educativos y asociaciones de atención especializada en alumnado con sordera de la provincia de Valencia, Tarragona, Baix Llobregat y Barcelona, así como de la asociación de atención a personas con deficiencia auditiva de Valencia y Castellón.

El grupo total de participantes con hipoacusia prelocutiva con implante coclear fue de 32 y el grupo de referencia normo-típico se ha formado con un total de 37. Tal como se muestra en la tabla 11, los participantes con sordera, todos ellos son usuarios de implante coclear, unilateral o bilateral con ganancias auditivas entre 10-40 dB. De todos modos, no se tuvo en cuenta las ganancias auditivas o el uso de uno o dos implantes, así como tampoco el género de los participantes.

Para establecer ambos grupos de muestras homogéneas se establecieron las condiciones de participación descritas en la página 78 del capítulo 5. 


\subsection{Instrumentos de Recolección de Datos}

Los instrumentos que se detallan en el capítulo 5 se pasaron a todos participantes de edades comprendidas entre 3 y 6 años. La evaluación del alumnado con sordera se realizó en coordinación con las logopedas o docentes de audición y lenguaje, que acudían al centro educativo para que pudieran estar presentes y reducir el tiempo de interrupción de las actividades programadas. En cambio, la evaluación del alumnado normo-oyente se realizó sin la presencia del tutor/a del aula o del docente de audición y lenguaje.

\subsection{Procedimiento}

Para realizar la investigación se contactó, en primer lugar con los centros educativos de referencia en la inclusión de niños y niñas con hipoacusia en la Comunidad Valenciana, pero las dificultades en el acceso a un número suficiente de participantes comportó la búsqueda de otros recursos como asociaciones y centros especializados en el campo de la sordera dentro de la Comunidad Valenciana y de otras provincias cercanas con el fin de alcanzar el número de participantes necesarios para que se considerase un estudio con suficiente validez y fiabilidad. En este caso, se establecieron relaciones de colaboración con la Asociación de padres y amigos del sordo (ASPAS) de la provincia de Castellón y Valencia, así como de los Centros Educativos para Deficientes Auditivos (CREDA) de Tarragona, Barcelona y Baix Llobregat, que atienden a alumnado con sordera en centros educativos. La selección de los centros educativos donde se encontraba cada alumno/a con sordera se realizó teniendo en cuenta los siguientes requisitos de inclusión: Atención educativa preferente dentro del aula de referencia, uso preferente de la lengua oral como modalidad de comunicación, coordinación con los diferentes apoyos educativos para anticipar los contenidos curriculares, eliminación de barreras físicas que impida el contacto ocular y facial del docente con el alumnado con sordera y la asistencia de atención educativa para favorecer el desarrollo de la comunicación y el lenguaje oral.

A todos los centros y las diferentes entidades se envió un documento informativo para obtener el permiso de las asociaciones y de las familias para evaluar los niños y niñas con sordera y se realizaron reuniones informativas con los centros educativos.

Una vez obtenidos los consentimientos informados, adjuntados en el anexo 3, para la evaluación de los participantes con sordera, se estableció la coordinación de las fechas más convenientes para la evaluación del alumnado entre la logopeda, que atiende al alumnado, para que pudiera estar presente durante la evaluación y la examinadora. Las pruebas se administraron individualmente durante dos sesiones para cada niño o niña, distribuyendo aleatoriamente el orden de aplicación de las pruebas. 
Una vez recogidas las evaluaciones individuales, se realizó el análisis de los datos. Posteriormente, se organizó una reunión con el equipo directivo de cada CREDA de Cataluña, donde se recogió muestra (Tarragona, Baix Llobregat y Cataluña), así como con las respectivas asociaciones de atención al alumnado con sordera (ASPAS) de Valencia y Castellón para explicar los resultados y proponer orientaciones educativas para favorecer la estimulación de la memoria y la inhibición de los participantes con sordera.

La recogida de la muestra de niños/as normo-oyentes se realizó en el centro educativo, donde se implantó el estudio de intervención cognitiva (estudio 2). El procedimiento para la concesión de los permisos del centro educativo y las familias del alumnado normo-oyente siguió los mismos pasos que la muestra del alumnado con sordera, el cual se detalla en el capítulo VII.

\section{Resultados}

En este apartado se describe las distintas operaciones estadísticas a las que se han sometido los datos obtenidos mediante el uso del paquete estadístico SPSS número 24.00. Para los análisis estadísticos se realizaron pruebas de comparación de medias para las variables que cumplen el criterio de normalización y pruebas de U de Mann-Whitney, para las variables que no lo cumplen.

3.1 Comparación entre participantes con sordera y normo-oyentes en lenguaje e inteligencia manipulativa. Toda la muestra.

La comparación entre grupos de participantes se ha realizado mediante la agrupación de los participantes según el criterio auditivo (con implante coclear y normo-oyente), considerando la muestra unificada respecto a la edad y la relevancia de la dificultad de percibir sonidos del habla, a pesar de la rehabilitación institucional y la derivada por el uso del implante coclear. Se han realizado dos comparaciones: Una a nivel general con toda la población de la etapa infantil con sordera y normooyente, por lo tanto, con edades comprendidas entre 3 a 6 años y un segundo bloque de comparaciones en la que se analiza las diferencias entre los dos grupos de edad (3 y 4$)$ y (5 y 6) años.

En primer lugar, se comparó el nivel cognitivo y lingüístico de ambas poblaciones. En el nivel de inteligencia manipulativa (evaluada, de forma breve, mediante la prueba de cubos del NEPSY-II) destaca la no existencia de diferencias significativas entre ambas poblaciones. La media obtenida en la prueba fue de 8,38 (desviación de 2,97) para la población con sordera y de 7,87 (desviación de 3,11) para la normo-oyente. Con estos datos, la diferencia de medias otorga valores de t de 0,69 y, por lo tanto, no significativos. En cambio, tal y como se muestra en la tabla 12 en la variable del lenguaje se 
muestra una diferencia de las puntuaciones entre ambas poblaciones, por tanto, el alumnado con sordera ya expresa retraso en el lenguaje en las edades comprendidas entre 3 y 6 años.

\section{Tabla 12.}

Valoraciones de lenguaje en las dos muestras: alumnado con sordera y alumnado normo-oyente

\begin{tabular}{llclll}
\cline { 2 - 4 } Pruebas & \multicolumn{3}{c}{ Medias (DT) } & \multicolumn{1}{c}{} \\
\cline { 2 - 3 } & $\mathrm{SD}(\mathrm{N}=32)$ & $\mathrm{NO}(\mathrm{N}=39)$ & $t$ & $p$ & $d$ \\
\hline LOC & $43,34(11,99)$ & $50,26(4,24)$ & $-3,10$ & 0,00 & 0,76 \\
LOEX & $28,84(13,96)$ & $36,87(6,39)$ & $-3,20$ & 0,00 & 0,73
\end{tabular}

$\overline{\mathrm{LOC}}=$ Lenguaje oral comprensivo; LOEX= Lenguaje oral expresivo; SD: alumnado con sordera; NO: alumnado normooyente
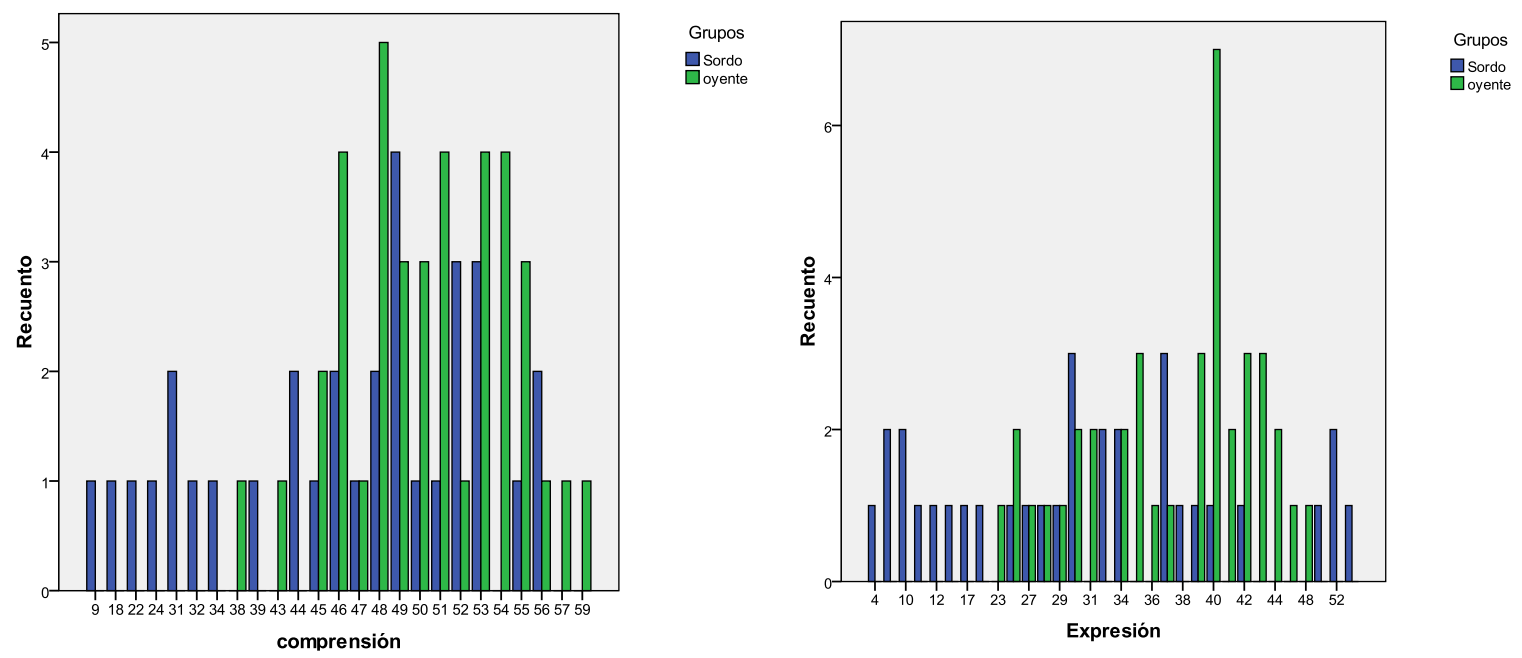

Figura 1 a y $b$. Comparación entre grupos de participantes con sordera y normo-oyentes sobre el nivel de lenguaje comprensivo y expresivo. ${ }^{1}$

El lenguaje se ha examinado según la comprensión y expresión y en ambos presentan diferencias significativas. En el lenguaje comprensivo (LOC), la puntuación del alumnado con sordera difiere del grupo de referencia 7 puntos, acompañado de gran tamaño de dispersión en la desviación típica $(11,99)$. La media del alumnado con sordera muestra que presentan generalmente dificultades en la comprensión de oraciones con una gramática compleja (gerundio, verbos en forma pasiva, adverbios de modo, oraciones de relativo...) por lo que debe comprender toda la oración para escoger la opción

\footnotetext{
${ }^{1}$ La figura 1 a y b muestran en el eje $\mathrm{X}$ las puntuaciones obtenidas por la tarea de comprensión y expresión, según las puntuaciones obtenidas por el total de participantes y en el eje Y la frecuencia de los participantes que obtienen esa puntuación, diferenciados entre participantes con sordera y normo-oyentes.
} 
correcta. Además, también cometieron muchos fallos en la comprensión de inferencias verbales sobre una imagen en la que se presentaban diferentes personajes y acciones. En cambio, el alumnado nomooyente no presenta dificultades en la comprensión de oraciones con una estructura gramatical compleja, por tanto, supera al alumnado con sordera.

En el lenguaje expresivo (LOEX) también se produce la discrepancia de puntuaciones en el alumnado con sordera, dado que existe gran variabilidad entre los logros de los participantes y además muestra bajas puntuaciones. La media del alumnado con sordera recoge que presenta dificultades en la expresión de oraciones correctas, en el uso de formas verbales en gerundio, así como de diferentes complementos oracionales (adverbio de modo o lugar, complemento directo, complemento indirecto). La construcción de las oraciones tendía a ser simples (sujeto, verbo en presente de indicativo y complemento). Del mismo modo, cometen bastantes errores en la construcción de estructuras complejas que deben imitar, por lo que tienden a simplificar la estructura de las oraciones y en la construcción de oraciones negativas e interrogativas, a pesar de darles el modelo de oración. En consecuencia, también encontraron dificultades en la corrección de errores, el desarrollo de estructuras complejas y de inferencias verbales. En cambio, en el alumnado normo-oyente sus dificultades se concentran en la corrección de errores y la construcción de oraciones negativas e interrogativas.

En el gráfico sobre la comprensión del lenguaje oral (figura 1 a), la mayor frecuencia para ambos grupos de población se sitúa en el valor 48 (de ellos 5 normo-oyentes y 4 con sordera). Sin embargo, se aprecia que las puntuaciones del alumnado con sordera se distribuyen sobre valores bajos, aunque logran aproximarse, en menor medida, a valores superiores. Además, visualmente, el gráfico de datos refleja una curva irregular de frecuencias, por lo que representa la variabilidad de sus resultados. En cambio, el grupo de referencia normo-oyente acota sus rangos de puntuación en valores superiores y llega incluso a alcanzar valores máximos (59). Además, la distribución de las puntuaciones se describe en una curva de resultados homogénea.

El diagrama de barras del lenguaje expresivo (figura 1 b) indica dispersión entre las puntuaciones de ambos grupos de participantes, aunque hay una mayor distribución en el grupo de alumnos con sordera, ya que aparecen frecuencias en ambos extremos de valores. Además, no se aprecia una mayor frecuencia en algún valor en concreto, como ocurre con el grupo de referencia, pero llegan a valores máximos. El grupo normo-oyente reduce la dispersión de puntuaciones en los rangos superiores, pero no llegan a superar al alumnado con sordera. 
3.2. Comparación entre participantes con sordera y normo-oyentes en las tareas de la función ejecutiva de la memoria

La FE de la memoria se ha evaluado mediante la valoración de cuatro habilidades, reseñadas en el capítulo anterior:

1. La memoria narrativa (MN), evaluada mediante la prueba correspondiente de la batería Nepsy II de Korkman et al., (2007), consiste en el recuerdo oral de una narración corta. Para ello, el alumnado debe escuchar atentamente la narración de una historia y posteriormente narrarla de forma libre y responder a preguntas cerradas sobre la misma. El alumnado de 3 años presentaba el apoyo de una lámina y en la evaluación del alumnado de edades posteriores no recogen este recurso visual.

2. La memoria de material verbal (MNV) se ha evaluado mediante la prueba correspondiente de la misma prueba Nepsy-II de Korkman et al., (2007), consistente en la repetición de oraciones correctamente cada vez más prolongadas. Su evaluación se inicia con oraciones de tres palabras y se van ampliando progresivamente hasta alcanzar oraciones de trece palabras.

3. La memoria espacial (MESP) procedente de la misma prueba que las dos anteriores y fundamentada en el recuerdo de distintos contenidos y su posición espacial en la tabla. Su dificultad aumenta por la incorporación de elementos distractores que se asemejan al contenido, por lo que el participante debe fijarse bien en la elección de las piezas apropiadas y situarlas adecuadamente dentro del espacio de la tabla.

4. La memoria de dígitos (en dos versiones: repetición directa/hacia delante y repetición inversa/hacia atrás, tomada de la prueba: Weschsler (WISC-IV). La memoria de dígitos hacia delante (DDW) consistente en la repetición de dígitos en el mismo orden que los pronunciados por el evaluador. Se pasan tres ítems de dos ensayos cada uno, iniciando la repetición con dos números y ampliando progresivamente los números hasta cuatro dígitos. Esta prueba está vinculada al análisis de la memoria verbal a corto plazo.

Por otra parte, la versión de repetición de dígitos en orden inverso -hacia atrás-, recoge la misma pauta de ítems que en la versión de orden directa. En este caso, el participante debe realizar dos funciones: recordar el número de dígitos y transformar la orden de números de forma inversa. De esta forma se evalúa la memoria de trabajo verbal.

Aquellas taras con mayor carga del lenguaje son la memoria narrativa verbal y la memoria de material verbal, debido a que precisan retener mayor información. En cambio, la memoria de dígitos directos -hacia delante e inversa- hacia atrás, requiere un mínimo de lenguaje, ya que solo debe 
recordar ciertos dígitos (no más de 5) y la memoria espacial no precisa de él. De este modo, podemos ver el nivel que presenta el alumnado en diferentes habilidades, en la cual está implicado el lenguaje en mayor o menor medida.

Tabla 13.

Resultado de diferencias entre las dos muestras con participantes con sordera y normo-oyentes en la habilidad ejecutiva de la memoria.

\begin{tabular}{|c|c|c|c|c|c|c|}
\hline \multirow[b]{2}{*}{ Pruebas } & $\mathrm{SD}(\mathrm{N}=32)$ & \multicolumn{3}{|l|}{$\mathrm{NO}(\mathrm{N}=39)$} & & \\
\hline & \multicolumn{2}{|c|}{ Medias (DT) } & & $t$ & $p$ & $d$ \\
\hline $\mathrm{MN}$ & $22,34(13,65)$ & $26,72(8,02)$ & & $-1,67$ & ,09 & ,39 \\
\hline MMV & $11,91(6,17)$ & $20,33(5,14)$ & & $-6,27$ &, 00 & 1,48 \\
\hline MESP & $52,94(13,14)$ & $45,64(4,58)$ & & 3,39 & ,00 &, 74 \\
\hline & & & $\mathrm{U}$ & $\mathrm{Z}$ & $p$ & $d$ \\
\hline DDW & $3,93(1,58)$ & $5,41(0,81)$ & 294,00 & $-4,0$ & ,00 & 1,17 \\
\hline DAW & $1,18(1,40)$ & $1,25(1,55)$ & 623,50 &,- 00 & ,99 &, 04 \\
\hline
\end{tabular}

$\mathrm{MN}=$ Memoria narrativa; MMV= Memoria de material verbal; MESP= Memoria espacial; DDW= Memoria de dígitos hacia delante; DAW=Memoria de dígitos hacia atrás; $\mathrm{SD}=$ alumnado con sordera; NO; alumnado con normo-oyentes

La prueba de memoria narrativa acota las desigualdades entre grupos, por tanto, sus diferencias no se consideran significativas. No obstante, cabe destacar que el mayor número de puntuaciones se recogen en la narración a través de preguntas guiadas. En cambio, la prueba de memoria de material verbal, en la cual deben repetir oraciones de complejidad creciente, presenta un contraste de las puntuaciones entre grupos de más de 10 puntos, donde el alumnado con sordera presenta bajas puntuaciones (como muestra la Figura 2a). La media de sus puntuaciones muestra que solo han sido capaces de recordar sin cometer errores oraciones de seis palabras, donde se utilizan verbos personales de modo indicativo. Además, el tamaño del efecto de las diferencias en la memoria de material verbal es alta, dado que supera el 0,80 . 

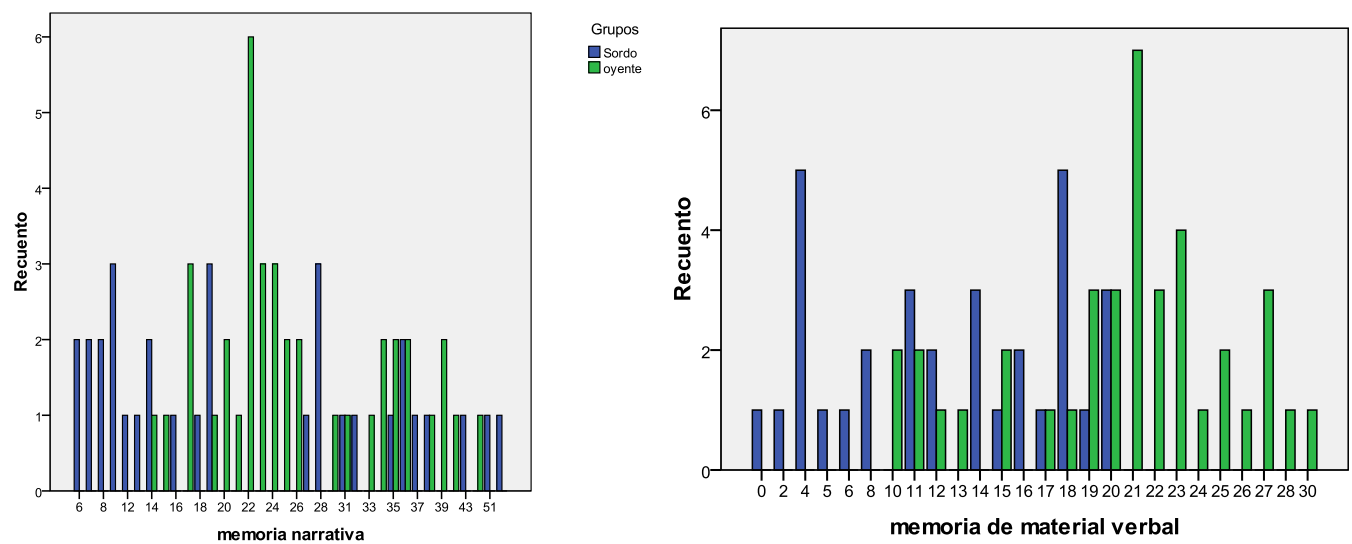

Grupos

吕 Sordo

Figura 2 a y b. Comparación entre los grupos de participantes con sordera y normo-oyentes sobre el rendimiento en la memoria narrativa y memoria de material verbal ${ }^{2}$

Tal como se muestra en la figura 2, la memoria narrativa, que evalúa el recuerdo de la narración de forma libre, guiada (mediante preguntas abiertas) y a través del reconocimiento (respuesta si/no), acota las desigualdades entre grupos y no muestra diferencias significativas, aunque las puntuaciones del alumnado con sordera son menores. Respecto a la otra gráfica (2 b), la memoria de material verbal (MMV) la puntuación de los niños y las niñas con sordera es mucho más baja que la de sus compañeros y compañeras normo-oyentes. Además, podemos apreciar dos valores con mayor frecuencia en el gráfico de memoria de material verbal (figura 2 b), debido a la diferencia que se encuentra entre la franja de edad 3-4 años y 5-6 años.

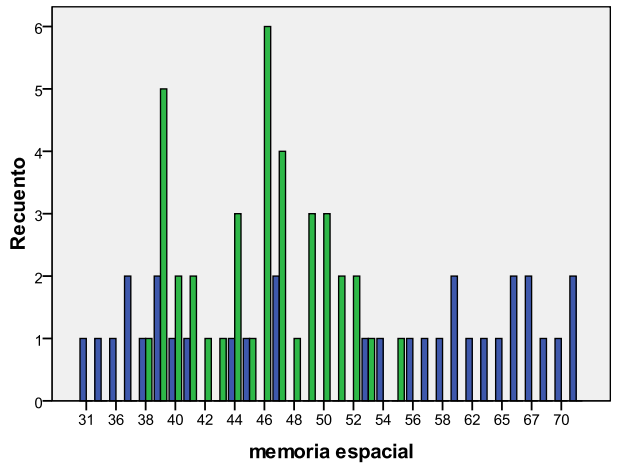

Grupos

品ordo

Figura 3. Comparación entre grupos de participantes con sordera y normo-oyentes en el rendimiento en la memoria espacial. $^{3}$

${ }^{2}$ La figura 2 a y b muestran en el eje $\mathrm{X}$ las puntuaciones obtenidas por el total de participantes en la tarea de memoria narrativa y memoria de material verbal y en el eje Y la frecuencia de los participantes que obtienen esa puntuación según sean participantes con sordera y normo-oyentes.

${ }^{3}$ Esta figura hace referencia a los valores obtenidos en la tarea de memoria espacial, donde se indica en el eje $\mathrm{X}$ las puntuaciones obtenidas por los participantes y en el eje Y la frecuencia de los participantes que obtienen esa puntuación. 
La alta puntuación del alumnado con sordera en memoria espacial es un aspecto positivo, dado que no sólo se sitúa en un nivel de desarrollo equivalente al de sus iguales, sino que los supera. El gráfico muestra como el alumnado con sordera distribuye sus puntuaciones a lo largo del rango de valores, sin marcar una mayor incidencia en ningún valor en concreto, por lo que la curva de sus puntuaciones es bastante aplanada y dispersa y se encuentra una gran diversidad de niveles. De esta forma no es posible concretar en qué aspecto de la prueba comenten más errores (contenido, situación espacial y elemento distractor). En cambio, el grupo de alumnado normo-oyentes acota el rango de sus puntuaciones entre 38-55 y destaca una mayor frecuencia en el valor 46. El grupo se sitúa, de media, en el recuerdo de la posición espacial de 6 elementos sin error (elección entre 12 tarjetas). Además, esta prueba presenta relevancia en el tamaño del efecto $(0,74)$.
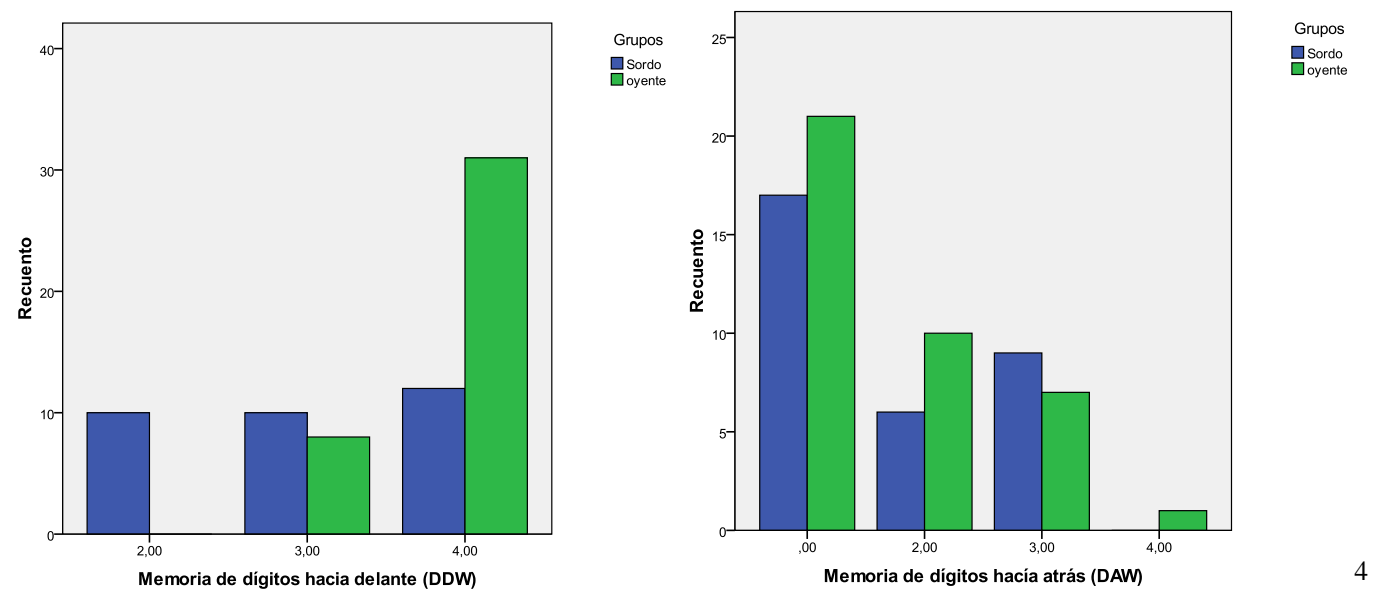

Figura 4 a y $b$. Comparación entre grupos de participantes con sordera e IC y normo-oyentes en el rendimiento en la memoria verbal a corto plazo y de trabajo.

En cuanto a las tareas que no cumplen los requisitos de homogeneidad (estadísticamente descritas en la tabla 13), las puntuaciones de la memoria de dígitos directos o hacia delante (memoria verbal a corto plazo), en la que tan solo se necesita recordar números sin realizar ningún tipo de procesamiento mental que modifica el recuerdo simple, muestra diferencias significativas entre grupos (ver, también figura 4 a). El contraste de puntuaciones coge relevancia, dado que el tamaño del efecto es bastante alto. En cambio, los resultados de la tarea de dígitos hacia atrás (memoria verbal de trabajo), en la que deben modificar el orden del recuerdo de los dígitos de manera inversa, son similares, por lo que el valor $p$ es mucho mayor que el nivel de significancia. Los datos se muestran gráficamente en la figura

${ }^{4}$ La figura 4 a y b muestran los valores recogidos según la tarea de memoria de dígitos hacia delante (a) y la memoria de dígitos hacia atrás (b). En el eje X se presenta las puntuaciones obtenidas por el total de participantes y en el eje Y la frecuencia de participantes que alcanzan esa puntuación, según sean participantes con sordera y normo-oyentes. 
4 b. Esta semejanza de las puntuaciones parece ser debida a la dificultad de la tarea y la baja resolución en ambos grupos.

En la tarea de dígitos hacia delante muestra que las puntuaciones del alumnado con sordera se sitúan entre el rango de valores más bajo (0-2 dígitos) y se distribuye sobre el resto de valores, sin predominar en ningún valor en particular. En cambio, el grupo de referencia normo-oyente se sitúa en el rango de valores de 3 dígitos y predomina entre los participantes el recuerdo de 4 dígitos, por tanto, las desigualdades entre grupos son significativas, dado que se encuentran diferencias en el rango mínimo de dígitos que son capaces de recordar (con sordera 0-2 dígitos y normo-oyentes 3 dígitos).

El gráfico sobre la memoria de dígitos hacía atrás (figura 4 b) muestra mayor equidad de nivel entre grupos. A pesar de que el alumnado con sordera se centra en valores comprendidos entre el 0 y el 1 , también aparecen distribuidos en los valores 2 y 3 . Del mismo modo ocurre con el grupo de alumnado normo-oyente, que también presenta numerosos niños y niñas en las puntuaciones más bajas, demostrando su dificultad.

\subsubsection{Correlaciones entre variables de la función ejecutiva de la memoria y el lenguaje}

Los datos correlacionales entre las variables de Lenguaje y Memoria ofrecen los resultados expuestos en la tabla 14. La cual analiza la correlación entre variables según la agrupación de los participantes por la categoría alumnado con sordera y alumnado normo-oyente. De esta manera podemos observar las diferencias que se encuentran en la interrelación entre variables según el estado auditivo de los participantes (con sordera / normo-oyente).

Tabla 14.

Correlaciones de Spearman de las variables de lenguaje y función ejecutiva de la memoria.

\begin{tabular}{|c|c|c|c|c|c|c|c|c|c|c|c|c|}
\hline & \multicolumn{2}{|c|}{ LOEX } & \multicolumn{2}{|l|}{$\mathrm{MN}$} & \multicolumn{2}{|l|}{ MMV } & \multicolumn{2}{|c|}{ DDW } & \multicolumn{2}{|l|}{ DAW } & \multicolumn{2}{|c|}{ MESP } \\
\hline & $\mathrm{SD}$ & $\mathrm{NO}$ & SD & $\mathrm{NO}$ & SD & $\mathrm{NO}$ & SD & $\mathrm{NO}$ & SD & $\mathrm{NO}$ & SD & $\mathrm{NO}$ \\
\hline $\mathrm{LOC}$ &, $49 * *$ &, $85 * *$ &, $31 *$ &, $60 * *$ & $48 * *$ &, $79 * *$ &,- 05 &, $51 * *$ & ,37* &, $55 * *$ &,- 09 &, 34 \\
\hline LOEX & 1 & 1 &, $69 * *$ &, $70 * *$ &, $76^{* * *}$ &, $75 * *$ &, 23 &, $48 * *$ &, $53 * *$ &, $58 * *$ &,- 19 &, 34 \\
\hline $\mathrm{MN}$ & & & 1 & 1 &, $63 * *$ &, $67 * *$ &, $35^{*}$ &, $60 * *$ &, $63 * *$ &, $63 * *$ &,- 02 &, 25 \\
\hline MMV & & & & & 1 & 1 &, 30 & $63 * *$ &, $53 * *$ & $59 * *$ &,- 14 &, $36^{*}$ \\
\hline DDW & & & & & & & 1 & 1 &, $31 *$ &, $63 * *$ & ,07 &, 27 \\
\hline DAW & & & & & & & & & 1 & 1 &,- 08 &, 40 \\
\hline
\end{tabular}

$\mathrm{LOC}=$ Lenguaje oral comprensivo; LOEX= Lenguaje oral expresivo; MN = Memoria narrativa; MMV= Memoria de material verbal; MESP $=$ Memoria espacial; DDW= Memoria de dígitos hacia delante; DAW=Memoria de dígitos hacia atrás 
A nivel general ambos grupos establecen una relación significativa entre las diferentes habilidades de la memoria y el lenguaje expresivo y comprensivo, con algunos niveles más bajos para la población afectada con sordera. Resulta de interés establecer cómo la tarea de memoria de dígitos directa parece resultar independiente del nivel demostrado en comprensión y expresión para el grupo de participantes sordos, siendo que dicha tarea expresa una relación significativa con todas las variables, tanto de la memoria, como del lenguaje para el grupo de alumnado normo-oyente.

Por el contrario, la tarea de dígitos hacia atrás muestra relación significativa con las habilidades ejecutivas de la memoria y del lenguaje tanto en el alumnado con sordera, como normo-oyente. Solo muestra un menor grado de interacción con la variable de lenguaje compresivo en el grupo de alumnado con sordera.

Finalmente, la tarea de la memoria espacial no presenta relación con el lenguaje en el alumnado con sordera y normo-oyente. La memoria espacial solo presenta una correlación significativa $(\mathrm{p}<.05)$ con la tarea de memoria de material verbal en el grupo de participantes normo-oyentes.

3.3. Comparación entre participantes con sordera y normo-oyentes en las tareas de la función ejecutiva de la inhibición

A continuación, se presenta el análisis descriptivo-comparativo de la función ejecutiva de la inhibición y su relación con las diferentes variables evaluadas. Las variables de la inhibición no cumplían con los estándares de normalidad a nivel estadístico, por tanto, se realizaron análisis noparamétricos.

Según las pruebas no paramétricas, ambas tareas de la función ejecutiva de la inhibición muestran diferencias significativas entre los grupos (ver tabla 15).

La Inhibición cognitiva (IC) fue evaluada mediante la prueba Stroop adaptada a población infantil conocida como "día y noche" (Gerstadt, Hong y Diamond, 1994), consistente en la presentación de 10 tarjetas con 5 tarjetas en las que se representa la imagen de un sol y otras 5 en las que se representa la imagen de una luna. El participante debe decir "noche" cuando vea la imagen del sol y "día" cuando vea la imagen de la luna.

La inhibición motora (IM) fue evaluada, tal como se referencia en el capítulo 5, utilizando la prueba de la batería Nepsy-II (Korkman et al., 2007) que consiste en permanecer en una misma posición (persistencia motora) durante 75 segundos y de inhibir el impulso de responder a distractores auditivos. 
Tabla 15.

Resumen de las pruebas no paramétricas sobre la habilidad ejecutiva de la inhibición. Toda la población.

\begin{tabular}{lcccccc}
\hline & $\mathrm{SD}(\mathrm{N}=32)$ & \multicolumn{2}{c}{$\mathrm{NO}(\mathrm{N}=39)$} & & \\
\hline Pruebas & & Media (DT) & $\mathrm{U}$ & $\mathrm{Z}$ & $p$ & $d$ \\
\hline INC & $8,16(1,29)$ & $5,82(3,09)$ & 387,50 & $-2,73$ &, 00 &, 32 \\
INM & $24,59(7,04)$ & $17,79(7,25)$ & 244,00 & 1024,00 &, 00 &, 55 \\
\hline
\end{tabular}

INC= Inhibición cognitiva; INM= Inhibición motora
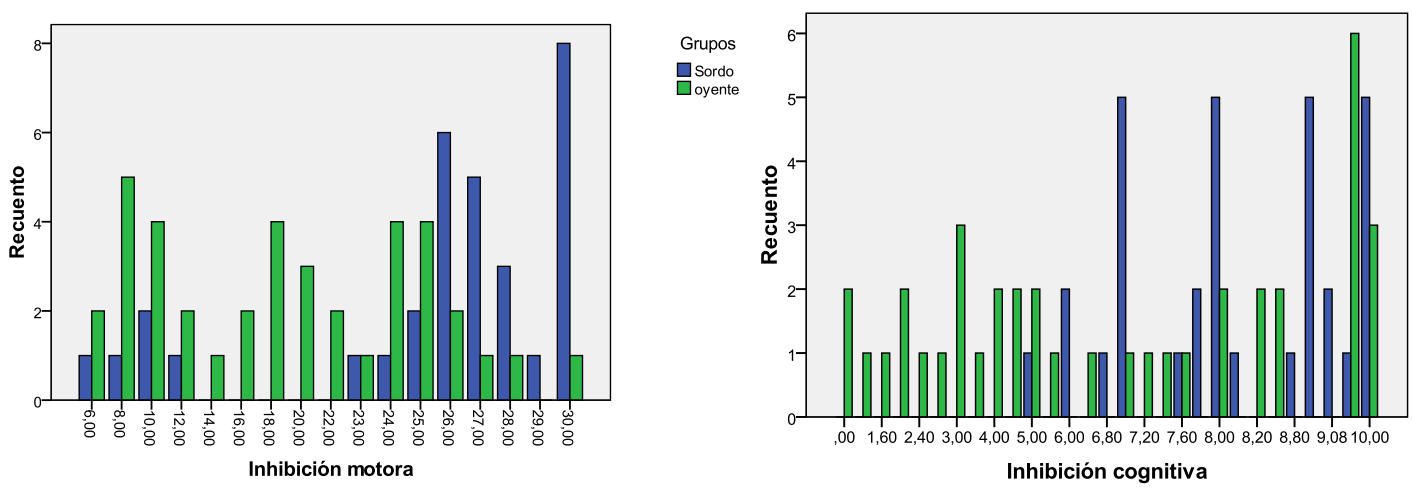

Figura 5 a y b. Comparación entre grupos de participantes con sordera y normo-oyentes del rendimiento en la inhibición. ${ }^{5}$

Según las pruebas no paramétricas, ambas tareas de la función ejecutiva de la inhibición muestran un mejor rendimiento de la población sorda. Las medias en la inhibición cognitiva fueron significativamente más altas para la población sorda (valor de z de 2,73 y significación al 0,00), demostrando que presenta mejor nivel de rendimiento a la hora de controlar los distractores visuales (inhibición cognitiva), como se expone en la tabla 15. El gráfico de inhibición cognitiva (Figura 5 a) recoge la variabilidad en las puntuaciones del alumnado normo-oyente, que se distribuyen entre todos los valores, pero destaca una mayor concentración en la incidencia en el último valor superior. En el caso de los participantes con sordera, sus puntuaciones se acotan en los valores superiores, dado que en la ejecución de la prueba apenas presentaron errores en la realización de la prueba.

Del mismo modo ocurre con los resultados en la inhibición motora, donde el alumnado con sordera supera a sus compañeros/as normo-oyentes y obtiene una significación al 0,00. No obstante, en el gráfico podemos apreciar que el alumnado con sordera parece presentar dos agrupaciones de mayor

${ }^{5}$ La figura 5 a y b muestran los valores recogidos según la tarea de inhibición motora (a) e inhibición cognitiva (b). En el eje X se presenta las puntuaciones obtenidas por el total de participantes y en el eje Y la frecuencia de participantes que alcanzan dicha puntuación según la clasificación del grupo de participantes con sordera y normo-oyentes. 
incidencia. En este caso se corresponde a las diferencias que se encuentran entre rangos de edad (3-4 años y 5-6años). Los valores inferiores se asocian a edades de 3-4 años y los rangos superiores a la edad de 5-6 años. En el gráfico de la inhibición motora (Figura 5 b) se presenta una alta frecuencia del alumnado con sordera en el valor máximo del rango de puntuación (30), destacando su incidencia por encima del grupo de alumnado de referencia. También se observan dos distribuciones de frecuencias en las puntuaciones, por un lado, se presenta cierta frecuencia de puntuaciones en los valores bajos y, por otro lado, se acota una mayor incidencia de frecuencias en los valores superiores. Por el contrario, el alumnado normo-oyente realiza una distribución de sus puntuaciones a lo largo de los todos los valores lo que indica una gran variabilidad de los resultados en esta prueba.

\subsubsection{Correlaciones entre variables de la función ejecutiva de la inhibición y el lenguaje}

Tabla 16.

Correlaciones de Spearman de las variables de lenguaje y la función ejecutiva de la inhibición en los participantes con sordera (SD) y normo-oyentes (NO).

\begin{tabular}{|c|c|c|c|c|}
\hline Pruebas & & INC & & INM \\
\hline & SD & $\mathrm{NO}$ & SD & $\mathrm{NO}$ \\
\hline LOC & ,34 &, $44 * *$ & 28 & ,27 \\
\hline LOEX & ,44* &, $62 * *$ &, $37^{*}$ &, $77 * *$ \\
\hline INC & & &, 32 &, $52 * *$ \\
\hline
\end{tabular}

La relación de las variables de la función ejecutiva de la inhibición con las habilidades lingüísticas es distinta según el rasgo auditivo de los participantes. El alumnado normo-oyente muestra una relación significativa entre la inhibición cognitiva y ambas habilidades lingüísticas (comprensión y expresión). Sin embargo, el alumnado con sordera solo refleja relación con el lenguaje expresivo.

Por otro lado, la inhibición motora no muestra relación con el lenguaje comprensivo con ningún grupo, pero en el lenguaje expresivo se observa una correlación significativa con el alumnado normooyente y moderada con el alumnado con sordera.

3.4 Comparación entre participantes con sordera y normo-oyentes en las tareas de la función ejecutiva de la memoria, separados en dos grupos en función de la edad.

Para tener un mayor conocimiento sobre la relación que establece la FE de la memoria y el lenguaje, se analiza las FE por grupos de edad: 3-4 años y 5-6 años, dado que las FE muestran un cambio evolutivo importante en la etapa infantil. A los tres años, las FE no se desarrollan como habilidades independientes, pero a medida que crecen y adquieren un mayor dominio del lenguaje, gracias a las 
experiencias sociales, se establece la memoria y la inhibición como FE diferenciadas (Willoughby et al., 2012).

Tabla 17.

Resultado de diferencias estadísticas entre participantes con sordera (SD) y normo-oyentes (NO) en la función ejecutiva de la memoria en el grupo de edad 3-4 años y 5-6 años.

\begin{tabular}{|c|c|c|c|c|c|c|c|c|c|c|}
\hline \multicolumn{6}{|c|}{$3-4$ años } & \multicolumn{5}{|c|}{5 - 6 años } \\
\hline & SD & $\mathrm{NO}$ & & & & SD & $\mathrm{NO}$ & & & \\
\hline & $(\mathrm{N}=14)$ & $(\mathrm{N}=18)$ & & & & $(\mathrm{N}=18)$ & $(\mathrm{N}=21)$ & & & \\
\hline & \multicolumn{2}{|c|}{ Medias (DT) } & $t$ & $p$ & $d$ & & & $t$ & $p$ & $d$ \\
\hline LOC & $40,64(12,94)$ & $48,78(4,83)$ & $-2,46$ &, 020 & ,83 & $45,44(11,11)$ & $51,52(3,28)$ & $-2,40$ & ,003 & ,74 \\
\hline LOEX & $23,86(13,65)$ & $31,83(5,62)$ & $-2,05$ &, 05 &, 74 & $32,72(13,29)$ & $41,19(2,87)$ & $-2,64$ &, 01 &, 88 \\
\hline $\mathrm{MN}$ & $14,00(6,50)$ & $20,39(3,27)$ & $-3,62$ &, 00 & 1,24 & $28,83(14,35)$ & $32,65(6,57)$ & $-1,07$ &, 35 &, 34 \\
\hline MMV & $8,93(5,41)$ & $17,11(5,36)$ & $-4,26$ &, 00 & 1,51 & $14,22(5,84)$ & $23,30(2,81)$ & $-6,19$ & ,00 & 1,97 \\
\hline \multirow[t]{2}{*}{ MESP } & $42,00(7,80)$ & $45,33(4,14)$ & $-1,55$ &, 16 &, 53 & $61,44(9,65)$ & $45,70(5,05)$ & 6,39 &, 00 & 2,04 \\
\hline & \multicolumn{2}{|c|}{ Medias (DT) } & $\mathrm{U}$ & $p$ & $d$ & \multicolumn{2}{|c|}{ Medias (DT) } & $U$ & $p$ & $d$ \\
\hline$\overline{\mathrm{DDW}}$ & $2,71(0,72)$ & $3,72(1,04)$ & 38,00 & ,00 & 1,12 & $3,33(0,84)$ & $3,85(0,35)$ & 108,50 &, 02 &, 81 \\
\hline DAW & $0,50(1,01)$ & $0,44(1,04)$ & 121,50 &, 89 &, 05 & $1,77(0,31)$ & $1,35(0,27)$ & 188,00 & ,98 & 1,42 \\
\hline
\end{tabular}

LOC= Lenguaje oral comprensivo; LOEX= Lenguaje oral expresivo; MN = Memoria narrativa; MMV= Memoria de material verbal; $\mathrm{MESP}=$ Memoria espacial; $\mathrm{DDW}=$ Memoria de dígitos hacia delante; DAW=Memoria de dígitos hacia atrás

La tabla 17 presenta, los datos comparativos entre pequeños-mayores (sordos y oyentes) demuestran que se produce modificación positiva excepto el alumnado normo-oyente en memoria espacial. La prueba de memoria narrativa mejora en edades superiores, ya que son capaces de narrar más fragmentos del cuento de forma libre. No obstante, su alta dispersión muestra la alta variabilidad. En la tarea de memoria de material verbal, el alumnado con sordera sólo alcanza la mitad de las puntuaciones del grupo de referencia, pero mejora considerablemente a los 5-6 años, ya que llegan a recordar oraciones de 8 palabras, en las que se emplean verbos reflexivos.

La memoria espacial tiene medias de puntuaciones semejantes en el caso del alumnado normooyente, por lo que las diferencias no son notables. Sin embargo, el alumnado con sordera mejora sus puntuaciones considerablemente en edades de 5-6 años, ya que son capaces de escoger entre 12 tarjetas aquellas que debe recordar ( 6 tarjetas). Sus errores se suelen concentrar cuando debe recordar 8 tarjetas y tiene que escoger entre 16. 
En cuanto al lenguaje, la media de puntuaciones de los participantes con sordera mejora tanto en comprensión y expresión cuando se encuentran en edades de 5-6 años, pero siguen manteniendo diferencias significativas con respecto a sus compañeros/as normo-oyentes. A los 3-4 años, el alumnado con sordera llega a comprender y realizar órdenes directas con un elemento, pero cuando debe combinar dos elementos para ejecutar la orden muestra dificultades y comenten numerosos errores. A los 5-6 años, supera estas dificultades y sus errores comienzan a acentuarse con la comprensión de oraciones con varios complementos de la oración y la elección entre cuatro dibujos alternativos, que represente la oración.

Respecto al nivel expresivo, el alumnado con sordera tiene más dificultades en su desarrollo, por lo que se acentúan las diferencias con sus compañeros/as normo-oyentes a la edad de 5-6 años. A la edad de 3-4 años son capaces de denominar objetos y con apoyo de juguetes y el inicio de la estructura de la oración pueden construir la forma verbal en presente de indicativo. Sin embargo, presentan dificultades en la construcción de oraciones con otros tiempos verbales. En cambio, a la edad de 5-6 años estas dificultades se superan, pero se encuentra un mayor número de errores en recordar oraciones de 3 y 4 elementos, ya que les cuesta reproducir la misma oración modelo y tienden a realizar simplificaciones a través de la supresión de diferentes complementos de la oración.

Las pruebas que no cumplen los criterios de normalidad son aquellas referidas a la memoria a corto plazo y la memoria de trabajo a través de las tareas de dígitos hacia delante y hacia atrás. En este caso, en la tarea de dígitos hacía delante se observa una desigualdad de puntuaciones que deriva en una diferencia significativa entre grupos, que se inicia a los 3-4 años y se prolonga hasta los 5-6 años, donde el alumnado con sordera mantiene bajas puntuaciones. Sin embargo, la tarea de dígitos hacía atrás, donde deben ejercer una doble tarea de recuerdo no se indican diferencias relevantes entre los grupos. Además, estas diferencias se reducen en el rango de edad 5-6 años.

Por otro lado, el tamaño del efecto de $d$ de Cohen tiene un gran peso en la memoria narrativa, ya que supera el 0,80. Este efecto también coge la misma relevancia en la memoria de material verbal y la memoria de dígitos hacía delante. Estas variables tienen un gran peso del lenguaje y su efecto refleja la repercusión en el grupo de alumnado con sordera. Por otro lado, la memoria espacial tiene un efecto medio en el grupo de alumnado con sordera, así como del lenguaje comprensivo.

Por último, el tamaño del efecto de Cohen muestra una gran repercusión en la memoria de material verbal, la tarea de dígitos hacía delante y hacía atrás, la memoria espacial y ambas habilidades 
lingüísticas, dado que la d de Cohen supera el 0,80 . Solo la memoria narrativa tiene una pequeña repercusión.

3.5. Comparación entre participantes con sordera y normo-oyentes en las tareas de la función ejecutiva de la inhibición, separados en dos grupos en función de la edad.

La tabla comparativa entre grupos de edad muestra la evolución del desarrollo de la FE de la inhibición, donde se podrá observar con mayor detalle las diferencias entre grupos de edad. Esta tabla comparativa permite delimitar las diferencias significativas a un grupo de edad concreto, a fin de favorecer la comprensión de las posibles causas de las desigualdades en las puntuaciones entre grupos.

Tabla 18.

Resultado comparativo entre participantes de 3-4 años y 5-6 años (con sordera y normo-oyentes) en las tareas sobre la habilidad ejecutiva de la inhibición.

\begin{tabular}{|c|c|c|c|c|c|c|c|c|c|c|}
\hline \multirow[b]{3}{*}{ Pruebas } & \multicolumn{2}{|c|}{$3-4$ años } & & & & \multicolumn{3}{|c|}{$5-6$ años } & & \\
\hline & \multicolumn{5}{|c|}{$\mathrm{SD}(\mathrm{N}=14) \quad \mathrm{NO}(\mathrm{N}=18)$} & \multicolumn{5}{|c|}{$\mathrm{SD}(\mathrm{N}=18) \quad \mathrm{NO}(\mathrm{N}=21)$} \\
\hline & \multicolumn{2}{|c|}{ Medias (DT) } & \multirow{2}{*}{$\begin{array}{c}\frac{t}{t} \\
6,35\end{array}$} & \multirow{2}{*}{$\begin{array}{l}p \\
, 00\end{array}$} & \multirow{2}{*}{$\frac{d}{2,17}$} & \multicolumn{2}{|c|}{ Medias (DT) } & \multirow{2}{*}{$\begin{array}{c}t \\
1,18\end{array}$} & \multirow{2}{*}{$\begin{array}{l}p \\
, 24\end{array}$} & $d$ \\
\hline INC & $7,97(1,12)$ & $3,86(2,42)$ & & & & $8,31(1,43)$ & $7,49(2,61)$ & & & ,38 \\
\hline INM & $20,42(8,89)$ & $13,05(6,47)$ & 2,82 &, 01 & ,94 & $27,83(2,12)$ & $22,15(5,13)$ & 4,36 &, 00 & ,77 \\
\hline
\end{tabular}

INC= Inhibición cognitiva; INM= Inhibición motora

La tabla comparativa muestra que el alumnado con sordera presenta un mejor rendimiento en las tareas de la habilidad ejecutiva de la inhibición que sus iguales normo-oyentes. No obstante, el alumnado normo-oyente se pone al mismo nivel cuando alcanzan edades de 5-6 años. En el caso de la inhibición cognitiva, el alumnado con sordera apenas muestra errores para cambiar la denominación de las imágenes y su rendimiento se mantiene a la edad de 5-6 años. En el caso de la prueba de inhibición motora, sus puntuaciones muestran que el alumnado con sordera supera al alumnado normooyente, tanto a la edad de 3-4 años, como a los 5-6 años. Sus puntuaciones demuestran la capacidad de inhibir los estímulos auditivos y mantener la capacidad de no moverse. 


\section{CONCLUSIONES Y DISCUSIÓN DEL PRIMER ESTUDIO}

Este primer estudio recoge los datos sobre el desarrollo evolutivo de las funciones ejecutivas en la etapa de Educación infantil del alumnado con sordera y normo-oyente. De esta manera, el propósito de este estudio fue investigar y realizar un análisis descriptivo-comparativo del lenguaje oral y las habilidades ejecutivas de la memoria y la inhibición durante las edades preescolares de 3 a 6 años. Para ello se probaron cuatro hipótesis: (a) El alumnado con sordera en la etapa infantil muestra déficit en el nivel del lenguaje expresivo y comprensivo en comparación con sus compañeros/as normo-oyentes, (b) el alumnado con sordera en la etapa infantil muestra un déficit en el desarrollo de las habilidades ejecutivas de la memoria y la inhibición en comparación con sus iguales normo-oyentes, (c) se muestra una relación significativa entre el lenguaje y las habilidades ejecutivas de la memoria y la inhibición en edad infantil y (d) el grupo de alumnado con sordera de 3-4 años no muestra diferencias significativas en comparación con su grupo de iguales normo-oyentes en las FE de memoria e inhibición, debido a que todavía las habilidades ejecutivas son inmaduras para ambos grupos de participantes (normo-oyentes y con sordera).

Así pues, los resultados del estudio fueron consistentes con la primera hipótesis (a), dado que el alumnado con sordera muestra diferencias significativas en el desarrollo del lenguaje, tanto la vertiente comprensiva, como expresiva. La población preescolar con sordera registra puntuaciones significativamente inferiores, a pesar del uso del IC y la exposición a estimulación auditiva. Estos resultados coinciden con las conclusiones recogidas en los estudios realizados por Beer et al., (2014), Geers y Nicholas, (2013) y Kronenberger et al., (2020) donde también demuestran que la población infantil con sordera e IC presenta déficit significativo en el lenguaje. Al mismo tiempo, el alto rango de variabilidad dentro de los subgrupos es una característica común a otros estudios, donde coinciden que la población con sordera es heterogénea y depende de otros factores para establecer un nivel de lenguaje equiparable al de sus iguales (Pisoni et al., 2017). No obstante, a pesar de que en nuestros datos se registra evolución positiva con la edad, las diferencias interpoblacionales siguen siendo persistentes.

La segunda hipótesis de este estudio fue que el alumnado con sordera obtendría puntuaciones significativamente peores en memoria e inhibición en comparación con sus iguales normo-oyente para los participantes de 3-6 años. Los resultados son consistentes con la hipótesis para las pruebas referidas a la memoria verbal, dado que se encuentran diferencias significativas en la memoria narrativa, memoria de material verbal (recuerdo de oraciones de extensión cada vez más larga) y la memoria de dígitos de orden directo. 
Estos datos coinciden con otros estudios como el de Mikic et al., (2014), donde también demuestra el alumnado preescolar con implante coclear expresa déficit en el recuerdo de oraciones, así como diversos estudios transversales con alumnado con sordera e IC en la etapa escolar que recogen déficit en la memoria de dígitos (Mikic et al., 2014; Pisoni et al., 2011; Pisoni y Cleary, 2003), así como en estudios longitudinales (Harris et al., 2013) que recogen muestra en edad preescolar. Por otro lado, las puntuaciones en la memoria de dígitos de orden inverso son equiparables entre ambos grupos (normooyente y con sordera). Esta semejanza de las puntuaciones parece ser debida a la dificultad de la tarea y la baja resolución en ambos grupos. De hecho, Kronenberger et al., (2020) no incluyó la prueba de dígitos de orden inverso (hacia atrás) porque consideraron que era un gran desafío para los participantes en edad preescolar, ya que debían recordar los dígitos, sino también aplicar procesos cognitivos como la atención y aplicar una codificación fonológica rápida.

En contraposición, la alta puntuación del alumnado con sordera en memoria espacial hace que superen a sus compañeros/as normo-oyentes, por lo que sus diferencias significativas demuestran que tienen un mejor rendimiento en esta área. Estos datos son comunes a los resultados del estudio de Beer et al., (2014), que utilizó el mismo instrumento de evaluación para evaluar al alumnado preescolar con IC, así como el estudio realizado por Nicastri et al., (2020), donde los preescolares con IC tampoco muestran déficit en la habilidad de memoria de trabajo visoespacial. Este aspecto positivo se mantiene en edades superiores, donde en el alumnado con IC en edad escolar tampoco se encuentra déficit (Lyxell et al., 2011; Wass et al., 2008).

En cuanto a la inhibición, se observa que el alumnado con sordera obtiene un mejor rendimiento en ambas habilidades (cognitiva y motora) en comparación con sus iguales normo-oyentes. Sin embargo, los datos positivos sobre el desarrollo de la inhibición motora se contraponen a las conclusiones obtenidas por otros estudios sobre sordera, que identifican déficit en esta habilidad inhibitoria en diferentes etapas, entre las cuales se encuentra Horn et al., (2004) que recoge alumnado preescolar con IC de 4-7 años y los estudios Yucel y Derim, (2008) y Hoffman et al., (2018) con muestra de la etapa escolar. No obstante, todos estos estudios usaron la misma tarea para evaluar la inhibición de la respuesta motora, por lo que este podría ser el motivo por el cual coinciden en el déficit del alumnado con sordera en esta habilidad inhibitoria. En cuanto a los resultados positivos en la inhibición cognitiva, los datos aquí expresados coinciden con el estudio reciente realizado por Nicastri et al., (2020) con alumnado con sordera en edad preescolar.

Así pues, podemos concluir que se cumplen los objetivos y se verifican las hipótesis respecto a identificar las diferencias entre grupos de participantes (con sordera y normo-oyentes) en edades 
preescolares y aportar un mayor conocimiento sobre el desarrollo de las FE, pues son escasos los estudios en estas edades. En este estudio se ha detectado la existencia de un posible déficit en comparación con su grupo de iguales normo-oyentes en el desarrollo del lenguaje y la memoria verbal. Sin embargo, no se observa un bajo rendimiento significativo en la memoria espacial y en la habilidad ejecutiva de la inhibición.

Por otro lado, la tercera hipótesis postulaba que existiera una relación significativa entre el lenguaje y las habilidades ejecutivas de la memoria y la inhibición en edad infantil. Los resultados recogen una estrecha relación entre el lenguaje y las funciones ejecutivas de la memoria para el alumnado con sordera y normo-oyente, salvo la memoria espacial, la cual no establece correlación con el lenguaje. Esta falta de relación coincide con el estudio realizado por Beer et al., (2014) con alumnado preescolar con IC, donde tampoco encontraron una relación estrecha entre la memoria espacial y el lenguaje. En cambio, hay contradicciones con un trabajo actual: el estudio realizado por Nicastri et al., (2020) con alumnado preescolar con IC en el que se recoge una relación significativa entre la memoria visoespacial y las habilidades lingüísticas evaluadas, aunque en este caso, puede que las diferencias sean atribuibles al uso de las pruebas utilizadas para evaluar el lenguaje en el estudio de Nicastri y colaboradores y el que aquí se concluye.

En cuanto a la relación entre el lenguaje y la inhibición, los datos muestran una correlación significativa entre el lenguaje expresivo y la inhibición cognitiva para el alumnado con sordera. Estos resultados coinciden con el estudio realizado por Nicastri et al., (2020), donde coincide en la correlación significativa en comprensión, pero en sus conclusiones, a diferencia del presente trabajo, Nicastri y sus colaboradores también reflejaron una relación significativa con la producción léxica, que ahora no ha resultado significativa. Sin embargo, en el presente trabajo, la relación entre el lenguaje y la inhibición cognitiva es diferente según la condición auditiva, dado que para el alumnado normooyente solo establece correlación con el lenguaje comprensivo y para el alumnado con sordera con el lenguaje expresivo. Esto podría deberse a que el alumnado normo-oyente precisa comprender la interferencia lingüística para realizar inhibir la consigna y en cambio, el alumnado con sordera al mostrar una menor competencia lingüística tiene una mayor facilidad para inhibir la interferencia lingüística.

En el caso a la inhibición motora, su correlación con el lenguaje también muestra una relación con el lenguaje expresivo, tanto para el alumnado con sordera y normo-oyente. No obstante, no hay estudios que recojan el estudio del rendimiento de esta habilidad ejecutiva y su relación con el lenguaje. En relación a ello, el estudio realizado por Kronenberger et al., (2014) recoge en sus conclusiones que 
es posible que la capacidad de mantener la atención y la concentración sean menos relevantes para el desarrollo del lenguaje en el alumnado con IC que para sus iguales normo-oyentes, ya que la interacción entre el estado de audición y la inhibición-concentración no fue significativa. Por tanto, el alumnado con IC parece ser menos dependiente del procesamiento del lenguaje para controlar la inhibición y la concentración. De todos modos, debido al escaso número de estudios sobre la FE de la inhibición, es recomendable realizar más investigaciones en el campo de la sordera con un conjunto más amplio de medidas de inhibición-concentración para comprender mejor la relación entre este dominio de la FE y el lenguaje.

Por último, la cuarta hipótesis trataba de comprobar que algunas de las funciones ejecutivas evaluadas no mostrarían un bajo rendimiento para los más pequeños de las dos poblaciones, debido a que las tareas evaluadas no son tan dependientes del lenguaje a los 3-4 años. Sin embargo, los datos del estudio indican que el bajo rendimiento de la memoria es visible (en todas las tareas evaluadas) ya a la edad de 3-4 años y se mantienen a la edad de 5-6 años, excepto en la memoria narrativa, que en edades posteriores aumentan la media de sus puntuaciones y sus diferencias con respecto al grupo de iguales normo-oyentes dejan de ser significativas. En cambio, la cuarta hipótesis se confirma para la inhibición, ya que la muestra de preescolares más pequeños (3-4 años) no presenta un riesgo en el desarrollo, pero que tampoco se manifiestan dificultades a la edad de 5-6 años.

Así pues, los resultados parecen indicar que la variable audición influye en la relación entre las variables ejecutivas y las habilidades lingüísticas. Es decir, el alumnado con sordera no necesita comprender el lenguaje para realizar una tarea de inhibición cognitiva, pero el grupo de participantes normo-oyentes sí que precisa tanto comprender, como expresar el lenguaje para ejecutar la tarea de inhibición cognitiva. Estas diferencias nos llevan a la conclusión de que el alumnado con sordera no precisa comprender las interferencias lingüísticas para establecer la consigna de la tarea de inhibición cognitiva, dado que su bajo desarrollo lingüístico le permite depender menos de él. En cambio, el alumnado normo-oyente depende del lenguaje para ejecutar la actividad inhibitoria. Por otro lado, tanto el alumnado con sordera y normo-oyente dependen del lenguaje expresivo para realizar la tarea de inhibición motora, dado que ambas habilidades pertenecen al campo de la expresión motriz y trata de resistir la producción motoras.

Este estudio estaría en consonancia con las conclusiones recogidas por el estudio realizado por Kronenberger, el al 2020, dado que también demuestra un déficit en las FE de la memoria en edades de 3-6 años en comparación con sus iguales normo-oyentes. No obstante, Kronenberger y sus colegas 
del 2020 recogen que la población infantil con sordera también presenta déficit en la inhibición, pero en este estudio no se expresa este riesgo en el desarrollo.

Por otro lado, la comparación de los datos de las FE recogidos en dos rangos de edad de la etapa infantil (3-4 años y 5-6 años) muestra un mejor rendimiento en las tareas ejecutivas de la memoria y la inhibición en edades superiores, ya que las FE maduran. Además, influye el desarrollo del lenguaje que permite al alumnado, tanto normo-oyente, como con sordera, adquirir un mayor número de estrategias verbales para la resolución de las tareas ejecutivas. De hecho, en los resultados del estudio 1 se muestra como ambos grupos de participantes (con sordera y normo-oyentes) presentan mejores puntuaciones en las pruebas de lenguaje, cuando se encuentran en el rango de edad de 5-6 años y la comparación entre grupos de edad (3-4 años y 5-6 años) refleja diferencias significativas $(p<.01)$. 


\section{CAPÍTULO 7. ESTUDIO 2 ESTUDIO PILOTO DE INTERVENCIÓN EDUCATIVA SOBRE LAS FE}

1. Justificación, propósitos y fines de la investigación

El primer estudio nos ha permitido trazar una visión global sobre el desarrollo de dos de las FE relevantes en el aprendizaje del lenguaje en la etapa infantil en alumnado con sordera, usuarios de IC. Los resultados del estudio recogen un posible déficit en la FE de la memoria, salvo en la tarea de retención de dígitos de orden inverso. En cambio, el rendimiento en la habilidad ejecutiva de la inhibición no muestra retraso en su desarrollo, sino un mejor resultado en comparación con la muestra representativa de la población normo-oyente.

Por otro lado, la evaluación del lenguaje refleja la situación actual del alumnado preescolar con sordera. Sus resultados muestran la todavía persistencia de déficit en el lenguaje expresivo y comprensivo en edad infantil, a pesar del uso temprano del implante coclear. Además, las habilidades lingüísticas establecen una relación significativa con las FE de la memoria y la inhibición tanto en el alumnado con sordera, como con el alumnado normo-oyente.

Estas conclusiones han promovido el interés por indagar acerca de los cambios que genera la estimulación cognitiva de la memoria y la inhibición en el alumnado infantil mediante la aplicación de un programa de intervención educativa desde una perspectiva inclusiva, donde recibe estimulación todo el alumnado del grupo clase, entre los que se encuentra el alumnado con sordera.

La revisión de los programas de intervención en las FE (capítulo 4) ha demostrado que estos programas benefician el desarrollo de las habilidades cognitivas del alumnado con sordera en edad escolar, pero no se han encontrado programas de intervención en población infantil con sordera, por tanto, existe un vacío en el campo de investigación sobre estimulación cognitiva en edad preescolar. Por ello se ha realizado un estudio piloto de intervención en las FE en edad preescolar, dirigidas al alumnado con sordera y normo-oyente, que pertenecen a un centro educativo de la provincia de Valencia, con el fin de identificar los beneficios en el desarrollo de las FE a través de actividades de juego dirigido.

Los objetivos del estudio 2 se exponen a continuación:

1. Dotar de propuestas de actividades de intervención para la estimulación en estas áreas, así como su aplicación, a fin de comprobar sus efectos. 
2. Analizar si el entrenamiento en estas habilidades mejora el desarrollo de los participantes con sordera y normo-oyentes en un periodo breve ( 1 mes) y si esos cambios se mantienen durante un tiempo (3 meses)

Las hipótesis del estudio 2 que orienta el trabajo de investigación son las siguientes:

1. Los efectos de la estimulación cognitiva mediante la realización de tareas cognitivas, impulsadas por actividades funcionales en situaciones de juego dirigido, favorecen el desarrollo de las FE de la memoria y la inhibición del alumnado con sordera.

2. Los beneficios de la estimulación infantil perduran 3 meses después de su intervención para el alumnado con sordera.

3. A pesar del buen desarrollo de las FE en el alumnado normo-oyente, la estimulación cognitiva también beneficia su desarrollo.

2. Diseño metodológico del estudio 2

La complejidad del diseño de un programa de intervención, la limitación temporal de la investigación y la dificultad para encontrar centros escolares con alumnado con sordera, dispuestos a participar en el estudio, dirigió la formación de un estudio cuasi experimental, donde se recogen grupos no equivalentes sin grupo control (Bisquerra, 2009).

El diseño de un programa de intervención piloto aporta una aproximación sobre el efecto que produce la intervención educativa en las habilidades ejecutivas de la memoria y la inhibición de manera temprana, que beneficien a todo el alumnado. Según la revisión de estudios sobre intervención en las habilidades ejecutivas pueden estimular al alumnado y paliar posibles déficits en edades posteriores.

Así pues, se ha diseñado un programa de intervención piloto (estudio 2), donde se abordó la estimulación mediante actividades en situaciones de juego dirigido inclusivos que fomentan la memoria y la atención. Las sesiones combinaron dos modos de intervención: sesiones organizadas por todo el grupo-clase y sesiones en pequeños grupos de niños/as con IC y normo-oyentes de 4-5 años.

La estimulación de la memoria y la inhibición se realizó en un período de un mes en sesiones de 30 minutos 4 días a la semana para analizar los cambios que produce en las habilidades cognitivas en la etapa de educación infantil, ya que es un campo en el que todavía no se ha abordado para obtener una aproximación de los cambios que se producen en las habilidades cognitivas, implicadas en el aprendizaje y el lenguaje, y conocer si el efecto se mantiene, se recoge información de las FE a través 
de la evaluación previa a la intervención (pretest), después de la estimulación (post-test) y tres meses después de la intervención (seguimiento).

Las actividades se dirigen a estimular la memoria y la atención mediante la combinación de actividades de recuerdo (visual, verbal, corporal...) con órdenes, imágenes o nombres, donde también se estimulaba la atención-concentración-inhibición.

El diseño de las actividades que se han programado para la intervención se desarrolló en base a los estudios de intervención, fundamentados en actividades de juego dirigido en participantes normotípicos en edad preescolar (Röthlisberger et al., 2011; Volckaert y Noël, 2015), así como otros juegos de mesa que implican el desarrollo de la memoria y la inhibición-atención-concentración a través de la selección de la acción o consigna correcta entre diferentes opciones. Algunas de las actividades de juego dirigido que se han aplicado son conocidos como, por ejemplo: memory, tangram, cucús tras, Simón dice, entre otras.

La duración de las sesiones también se fundamentó según la revisión de los estudios sobre intervención, en los cuales la duración de las sesiones oscilaba entre las 12 y 20 sesiones de 15-30 minutos (Blakey y Carroll, 2015; Röthlisberger et al., 2011; Thorell, Lindqvist, Nutley, Bohlin y Klingberg, 2009; Traverso, Viterbori y Usai, 2015).

\subsection{Participantes}

Se escogió una muestra de manera no probabilística, gracias a la accesibilidad a un centro educativo de Valencia, interesado en el desarrollo del proyecto de estudio. Para ello, se utilizó el mismo criterio de selección de la muestra, descrito en el capítulo 5.

El grupo total de participantes con hipoacusia prelocutiva e implante coclear fue un total de 4 participantes y el grupo de referencia normo-oyente se ha formado con un total de 26 alumnos/as. Las condiciones de escolarización se establecen según el criterio de edad con carácter general para todo el alumnado de acuerdo con la normativa vigente en materia de admisión para cada etapa educativa, es decir, que el alumnado se agrupó en dos aulas ( $2^{\circ}$ ciclo: 4 años, $3^{\circ}$ ciclo: 5 años) (DECRETO 104/2018). El alumnado con sordera, al tratarse de alumnado con necesidades educativas especiales, se escolarizaron en las aulas ordinarias, ya que sus necesidades pueden ser atendidas en el centro. Por un adecuado equilibrio de la atención educativa, el alumnado con sordera la ratio en el aula ordinaria vendrá determinada de acuerdo con lo que establece el artículo 47 de la Orden 20/2019, de 30 de abril en la que se regula la atención educativa del alumnado con necesidades educativas especiales escolarizados en centros de Educación Infantil y Educación Primaria. Así pues, se reduce la ratio en 
las unidades ordinarias que escolarizan alumnado con necesidades educativas especiales que, de acuerdo con el informe sociopsicopedagógico, requiere apoyo de grado 3 y 4 , con el objeto de facilitar una atención más personalizada a sus necesidades. Por ello, El número máximo de alumnado de estas características será, con carácter general, de 2 por unidad. Proveer los medios humanos y materiales necesarios, la oferta en Educación Infantil y Educación Primaria, si hay una alumna o un alumno con estas características, la ratio se reduce en dos puestos; si hay dos, la ratio se reduce en cinco puestos.

La descripción del alumnado según el criterio de edad, género y condición de audición se presenta en las tablas 19 y 20.

Tabla 19.

Descripción por grupos de participantes.

\begin{tabular}{|c|c|c|c|c|}
\hline \multicolumn{2}{|c|}{ Edad } & $4 ; 00-4 ; 11$ & $5 ; 00-6 ; 00$ & Total \\
\hline \multirow[t]{2}{*}{ Participantes } & SD & 3 & 1 & 4 \\
\hline & NO & 10 & 16 & 26 \\
\hline \multirow[t]{2}{*}{ Género } & hombre & 8 & 11 & 19 \\
\hline & mujer & 5 & 6 & 11 \\
\hline
\end{tabular}

SD: Alumnado con sordera; NO: alumnado normo-oyente

Tabla 20.

Descripción demográfica del grupo de alumnado con sordera.

\begin{tabular}{lc|cc}
\hline Edad & \multicolumn{2}{c}{$4 ; 00-4 ; 11$} & $5 ; 00-6 ; 00$ \\
\hline Implante & Unilateral & 2 & 1 \\
& Bilateral & 1 & 1 \\
Ganancia auditiva & $20-30$ & 3 & \\
& $>40$ & 30 & \\
\hline
\end{tabular}

Las condiciones para la inclusión en la muestra de participantes con sordera y normo-oyentes son las mismas que en el estudio 1 que se resumen en el capítulo 5 para unificar criterios de igualdad y homogeneidad.

\subsection{Instrumentos de Recolección de Datos}

Los instrumentos se pasaron en las mismas condiciones de evaluación que se indican en el capítulo 5, es decir, se evaluaron las FE de la memoria y la inhibición, utilizando las mismas pruebas, así como para valorar el lenguaje, salvo en las evaluaciones post-test y de seguimiento, donde no se volvieron a pasar la prueba de lenguaje. 


\subsection{Procedimiento}

La recogida de la muestra de niños/as normo-oyentes se realizó en el centro educativo, donde se implantó el estudio de intervención cognitiva. El procedimiento para la concesión de los permisos del centro educativo y las familias del alumnado normo-oyente siguió los mismos pasos para la formación de la muestra del alumnado con sordera, el cual se detalla en el capítulo V.

Para realizar la investigación de intervención se contactó con los centros educativos de referencia en la integración de niños y niñas con hipoacusia en la Comunidad Valenciana, pero la limitación en la disposición e interés de los centros educativos en participar condicionaron la elección del centro para la intervención hacia el diseño de un estudio piloto (estudio 2).

En este estudio participó un centro educativo de Educación Infantil y Primaria de integración preferente de alumnado con sordera de la provincia de Valencia. En él participaron dos aulas inclusivas de $2^{\circ}$ ciclo de Educación Infantil, que acogían alumnado con sordera, de edades comprendidas entre 4-5 años que cumplían con los requisitos de participación.

En el mes de marzo, se recogió el consentimiento del equipo directivo y progenitores para la evaluación de todos los participantes y se estableció la coordinación de los horarios más convenientes con las tutoras de cada aula y la examinadora para realizar la evaluación. En los meses entre abril y mayo se administraron las pruebas individualmente. Las evaluaciones previas a la intervención consistían en dos sesiones individuales para cada niño o niña, distribuyendo aleatoriamente los instrumentos. En el caso de los participantes con sordera fueron evaluados de manera individual durante sus sesiones de audición y lenguaje y estuvo presente durante la evaluación la maestra de audición y lenguaje. Los participantes normo-oyentes fueron evaluados en sesiones individuales sin la presencia de su tutora o la maestra de audición y lenguaje.

Una vez realizada la evaluación preliminar, se procedió a la intervención educativa en memoria e inhibición en el alumnado de 4-5 años, durante el mes de abril-mayo. La distribución del alumnado dependía del tipo de actividad que se iba a realizar, el material que se empleaba y la atención que precisaba cada actividad para realizarla adecuadamente. Cuando las sesiones estaban dirigidas a la distribución del alumnado en pequeños grupos de 4-5 participantes, se realizaban dentro del aula y se estructuraba por rincones para que cada grupo de participantes estuviera en un rincón del aula y realizarán una actividad distinta y pautada por la maestra del aula. De esta manera, se formó un rincón para la estimulación cognitiva, en el cual la investigadora era el apoyo en la ejecución de la actividad. 
Por otro lado, las actividades en gran grupo consistían en dinámicas de juego dirigido, dónde participaba todo el grupo-clase. Para que el alumnado comprendiera las mismas instrucciones del juego se utilizaba el apoyo visual de imágenes que marcaban los cambios de orden.

La descripción de cada actividad, así como las referencias en las que se fundamentan y las habilidades que se desarrollan se recogen en la tabla 1 del anexo.

Cada sesión se organizó siempre siguiendo la misma estructura:

a) El alumnado acudía al aula de psicomotricidad.

b) Explicación previa de la actividad con varios ejemplos, de forma clara y con apoyo visual.

c) Realización de la propia actividad para estimular la memoria y la inhibición.

d) Valoración de la actividad.

Una vez finalizada la intervención, en el mes de junio se volvió a evaluar las habilidades ejecutivas para comprobar si su rendimiento había mejorado y se realizó una evaluación de seguimiento 3 meses después, durante el mes de octubre. En septiembre, se organizó una reunión con el equipo directivo de cada centro educativo, tutores y tutoras de aula y docentes de audición y lenguaje, para informar sobre la evaluación del alumnado y dotar de orientaciones educativas para favorecer la estimulación de la memoria y la inhibición.

\section{Resultados}

3.1.Comparación entre participantes con sordera y normo-oyentes en las tareas de la función ejecutiva de la memoria según las tres evaluaciones.

El siguiente apartado recoge las pruebas evaluativas de la memoria entre las cuales se presentan: la memoria narrativa, la memoria de material verbal, la memoria de dígitos hacia delante, la memoria de dígitos hacia atrás y la memoria espacial. Así pues, se exponen las diferentes tablas que recogen el análisis no paramétrico de los resultados obtenidos en los tres momentos de evaluación según cada grupo de participantes. Con el fin de identificar las diferencias significativas entre evaluaciones, se presenta la media, la desviación típica, el rango de puntuación mínimo y máximo en los tres momentos evaluados (pretest, post-test y seguimiento). 
Tabla 21.

Comparación entre pretest, post-test y seguimiento de todas las variables evaluadas en el grupo de participantes con sordera (líneas inferiores) y normo-oyentes (líneas superiores).

\begin{tabular}{|c|c|c|c|c|c|c|}
\hline \multicolumn{7}{|c|}{ Grupo normo-oyente $\mathrm{N}=26$} \\
\hline & \multicolumn{2}{|c|}{ Pretest } & \multicolumn{2}{|c|}{ Post-test } & \multicolumn{2}{|c|}{ Seguimiento } \\
\hline & $\mathrm{M}(\mathrm{DT})$ & Min-Max & $\mathrm{M}(\mathrm{DT})$ & $\begin{array}{l}\text { Min- } \\
\text { Max }\end{array}$ & $\mathrm{M}(\mathrm{DT})$ & Min-Max \\
\hline $\mathrm{MN}$ & $30,38(7,17)$ & $20-45$ & $44,81(10,54)$ & $22-56$ & $43,85(8,72)$ & $26-56$ \\
\hline MMV & $22,77(3,35)$ & $14-30$ & $25,27(5,27)$ & $12-33$ & $25,00(5,09)$ & $14-32$ \\
\hline DDW & $5,58(, 70)$ & $4-6$ & $5,88(, 43)$ & $4-6$ & $5,73(, 66)$ & $4-6$ \\
\hline DAW & $1,81(1,49)$ & $0-4$ & $3,31(1,56)$ & $0-6$ & $3,00(1,35)$ & $0-6$ \\
\hline MESP & $45,50(4,88)$ & $38-55$ & $46,31(4,84)$ & $38-58$ & $66,73(7,24)$ & $46-72$ \\
\hline \multicolumn{7}{|c|}{ Grupo sordo $\mathrm{N}=4$} \\
\hline $\mathrm{MN}$ & $22,00(10,98)$ & $13-38$ & $25,75(20,40)$ & $13-56$ & $28,75(6,18)$ & $25-38$ \\
\hline MMV & $10,25(6,65)$ & $5-20$ & $17,00(7,43)$ & $12-28$ & $16,75(6,50)$ & $8-23$ \\
\hline DDW & $3,25(1,89)$ & $2-6$ & $4,75(1,25)$ & $6-4$ & $4,50(1,73)$ & $3-6$ \\
\hline DAW & ,75 (,95) & $0-2$ &, $75(1,50)$ & $0-3$ &, $50(1,00)$ & $0-2$ \\
\hline MESP & $42,25(2,75)$ & $39-45$ & $40,00(3,55)$ & $37-45$ & $52,75(11,87)$ & $44-70$ \\
\hline
\end{tabular}

$\mathrm{MN}=$ Memoria narrativa; MMV= Memoria de material verbal; MESP= Memoria espacial; DDW= Memoria de dígitos hacia delante; DAW=Memoria de dígitos hacia atrás

La valoración de la memoria en los tres tiempos (pretest, post-test y seguimiento) nos dan una aproximación acerca de la repercusión de la estimulación en edad infantil. Así pues, la tabla 21 recoge los resultados obtenidos por el alumnado con sordera (en líneas inferiores) y normo-oyente (en líneas superiores) y nos permite tener una idea general de la evolución de cada grupo de participantes. 

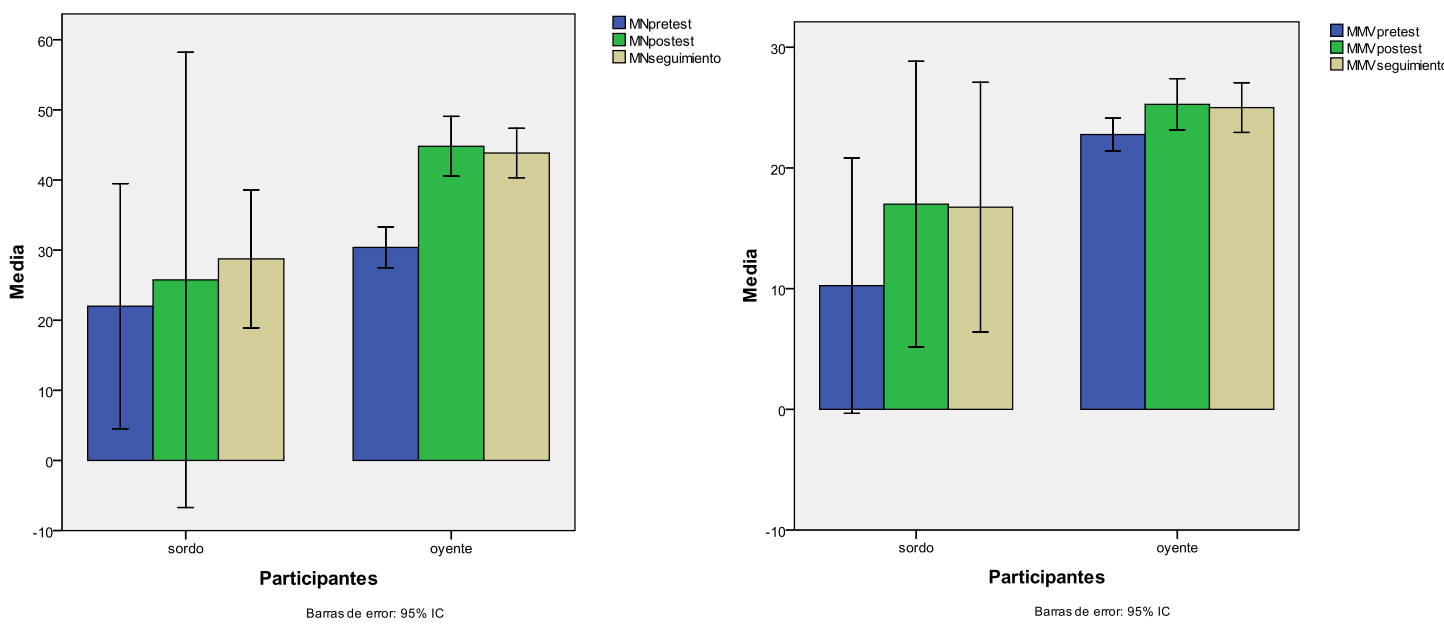

Figura 6 a y $b$. Medias en las pruebas de memoria narrativa y memoria de material verbal. Comparación entre grupos de participantes con sordera y normo-oyentes. ${ }^{6}$

El grupo de participantes normo-oyentes presenta en la evaluación pretest de MN una media de 30,38, pero sus puntuaciones ascienden significativamente más de 10 puntos en la evaluación posttest. Después de 3 meses sin intervención, al realizar la evaluación de seguimiento, la media de sus puntuaciones bajó 1 punto, pero a pesar de ello seguían siendo altas.

El alumnado con sordera no muestra una evolución tan pronunciada. Sus puntuaciones ascienden de forma gradual en cada evaluación, por lo que se identifica como una tendencia al cambio significativo. Su evolución se observa en un mayor número de aciertos en las preguntas guiadas y cerradas sobre la narración, pero el alumnado todavía mostraba dificultades persistentes en la narración libre del cuento. Además, como se aprecia en el gráfico en la memoria narrativa (figura 6 a), el alumnado normo-oyente demostró un mayor progreso después de la intervención y posteriormente, en el seguimiento, se mantenían todavía altas. Por su parte, el alumnado con sordera mejora su puntuación después de la intervención, pero la alta desviación típica redujo la significación estadística. Tres meses después de la estimulación (evaluación de seguimiento) continúa mejorando su puntuación y, además, desciende la variabilidad de sus puntuaciones.

Respecto a la tarea de la memoria de material verbal, el alumnado normo-oyente mejora ligeramente sus puntuaciones en la evaluación post-test ( 3 puntos) y se mantienen cuando se evalúan 3 meses

${ }^{6}$ La figura 6 a y b se muestran los valores recogidos según la tarea de memoria narrativa (a) y memoria de material verbal (b). En el eje X se presenta al número de participantes según la clasificación con sordera y normo-oyente en los tres momentos de evaluación (pre-test, post-test y seguimiento) y en el eje Y la frecuencia de participantes que alcanzan esa puntuación. 
después (evaluación de seguimiento). Aunque, estas diferencias no son muy marcadas, son significativas en comparación con la evaluación pretest. De este modo, son capaces de retener oraciones con una longitud de 11 palabras, en las que aparecen oraciones subordinadas y verbos en diferentes tiempos verbales. En este caso, el alumnado con sordera muestra un cambio pronunciado en la evaluación post-test, dado que aumenta 7 puntos de media, que se mantiene en la evaluación de seguimiento. De este modo, se observa como el alumnado comienza a retener oraciones de 5 palabras y progresivamente recuerda frases en las que aparecen complementos circunstanciales. No obstante, sigue resaltando una desviación típica bastante alta, por lo que persiste una gran variabilidad de las puntuaciones entre alumnos/as.

En el gráfico (figura 6 b) se puede observar no solo la diferencia significativa en la media entre grupos, sino también la gran dispersión que muestra la población con sordera, dado que en las tres evaluaciones presenta una desviación típica muy alta. Además, podemos observar que las puntuaciones entre grupos de participantes son significativamente distintas e incluso la puntuación que alcanza el grupo con sordera en la evaluación de seguimiento no supera el resultado de la evaluación pretest del grupo normo-oyente.

En cuanto a la tarea de memoria de dígitos directos, el alumnado normo-oyente aumenta su media ligeramente en las tres evaluaciones, por lo que no se detectan desigualdades significativas. Sin embargo, la tarea de memoria de dígitos inversos supera la media en la evaluación post-test y se conservan en la evaluación de seguimiento. Es un gran cambio, dado que en la evaluación inicial solo llega a recordar en orden inverso dos dígitos y después de la intervención son capaces de retener tres.

Por otro lado, el alumnado con sordera mejora su media después de la intervención (post-test) y llega a conservar sus puntuaciones en la evaluación de seguimiento, pero la baja muestra de participantes resta relevancia a estos resultados y no llegan a considerarse como una diferencia estadísticamente significativa. De este modo, la resolución de la prueba comienza por el recuerdo de tres dígitos de manera poco afianzada, dado que solo superan uno de los dos ensayos y, después de la estimulación son capaces de resolver los dos ensayos de tres dígitos en orden directo. En cambio, las evaluaciones de la tarea de dígitos inversos (hacia atrás) indica una media similar en las puntuaciones e incluso empeora en la evaluación de seguimiento. 

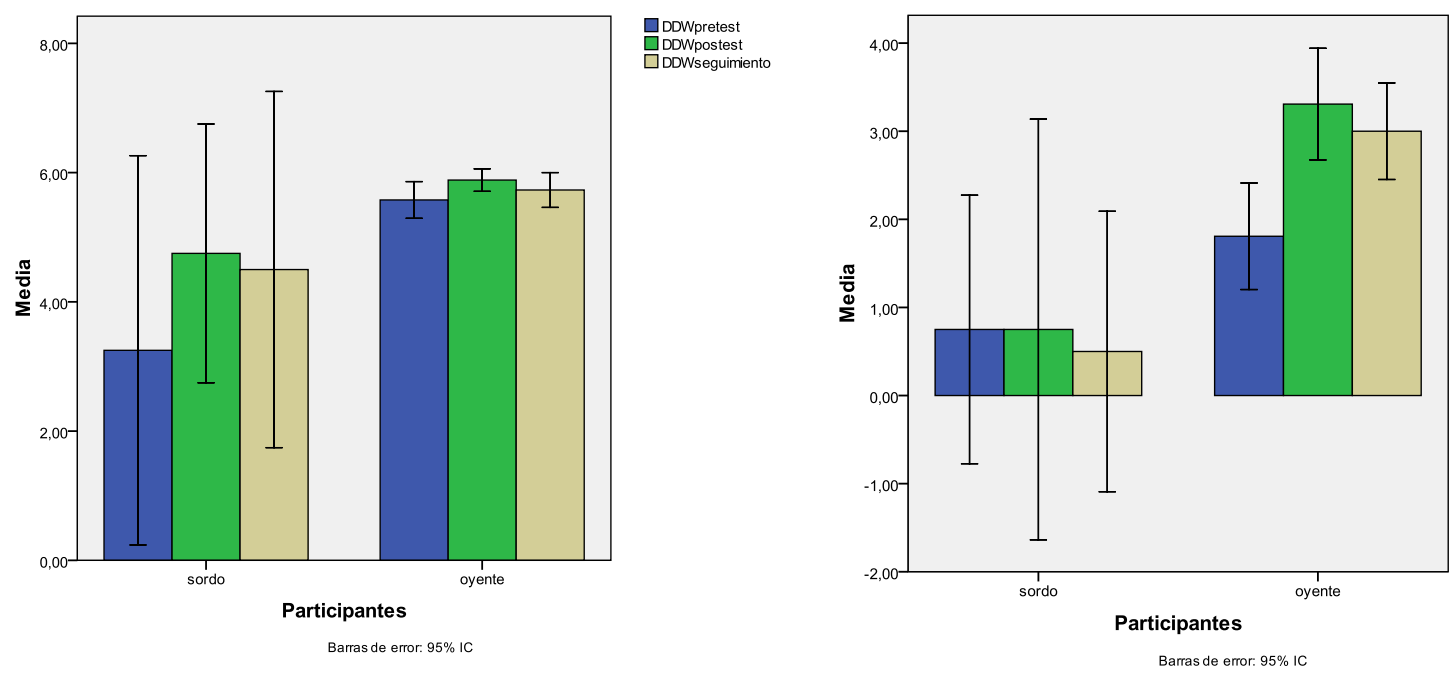

Figura 7 a y $b$. Medias en las pruebas de la memoria de dígitos hacia delante y hacia atrás. Comparación entre grupos de participantes con sordera y normo-oyentes. ${ }^{7}$

El diagrama de barras de la memoria de dígitos de orden directo e indirecto (hacia delante y hacia atrás) refleja claramente la gran variabilidad de resultados que presentan los participantes con sordera, ya que el alumnado presenta gran heterogeneidad en el nivel de lenguaje comprensivo y expresivo, por tanto, afecta también en la resolución de la tarea de dígitos, a pesar de que utiliza un contenido de lenguaje mínimo.

El alumnado con sordera y normo-oyente muestra un efecto similar en la memoria de dígitos directos. La evaluación post-test muestra una puntuación superior a la evaluación pretest, pero en la evaluación de seguimiento descienden sus puntuaciones ligeramente, aunque se mantienen todavía en niveles altos. No obstante, llama la atención la alta dispersión de las puntuaciones del alumnado con sordera, por lo que se muestra claramente la alta variabilidad en el rendimiento. En cuanto a la tarea de dígitos hacia atrás, se observa un claro contraste de las puntuaciones entre grupos de participantes. Los resultados del alumnado con sordera no mejoran después de la intervención y tres meses después desciende la media notablemente. En cambio, los participantes normo-oyentes mejoran significativamente en la evaluación post-test y se mantienen altas después de 3 meses (evaluación de seguimiento).

\footnotetext{
${ }^{7}$ La figura 7 a y b se muestran los valores recogidos según la tarea de memoria de dígitos hacia delante (a) y la memoria de dígitos hacia atrás (b). En el eje $\mathrm{X}$ se representa al grupo de participantes, según sean con sordera y normo-oyentes, en los tres momentos de evaluación (pre-test, post-test y seguimiento) y en el eje Y la frecuencia media de participantes que alcanzan esa puntuación.
} 

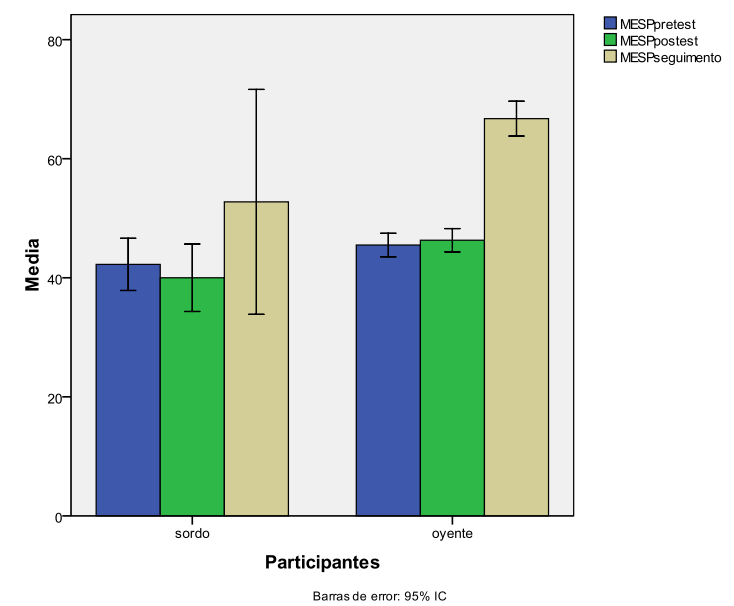

Figura 8. Medias en las pruebas de la memoria espacial. Comparación entre grupos de participantes con sordera y normo-oyentes. ${ }^{8}$

La memoria espacial tiene una evolución distinta en comparación con el resto de tareas evaluadas. El alumnado normo-oyente aumenta sus puntuaciones en la evaluación post-test de manera moderada, pero en la evaluación de seguimiento, tres meses después de la intervención, ha aumentado sus puntuaciones de forma notable, por lo que la comparación entre las tres valoraciones da como resultado un contraste significativo. Estos resultados concuerdan con otros estudios como Holmes, Gathercole y Dunning, 2009; Thorell, Lindqvist, Nutley, Bohlin y Klingberg, (2009) donde también a través de la intervención con participantes normo-oyente aumentaron las puntuaciones en esta habilidad de manera significativa.

En el caso del alumnado con sordera se produce un cambio similar. La evaluación post-test no refleja mejoras en las puntuaciones, sino que desciende la media dos puntos. En cambio, la evaluación de seguimiento resalta que la media aumentó significativamente hasta alcanzar 10 puntos de diferencia, por lo que también destaca desigualdades en sus puntuaciones, como se refleja en el gráfico. La frecuencia de los errores se recoge en la elección apropiada del contenido y el espacio, a partir de la incorporación de nuevas tarjetas como variables distractoras.

La siguiente tabla trata de definir las diferencias entre los participantes según la comparación entre las diferentes evaluaciones, a fin de conocer las desigualdades entre los resultados.

\footnotetext{
${ }^{8}$ La figura 8 muestra los valores recogidos según la tarea de memoria espacial. En el eje X se presenta al grupo de participantes según la clasificación dicotómica (con sordera y normo-oyentes) en las tres evaluaciones (pre-test, post-test y seguimiento) y en el eje Y la frecuencia media de participantes que alcanzan esa puntuación.
} 
Tabla 22.

Comparación entre pretest, post test y seguimiento de todas las variables evaluadas según todo el grupo de participantes $(n=30)$.

\begin{tabular}{lccc}
\hline Valores Z & Pretest-Post-test & Pretest -Seguimiento & Post-test -Seguimiento \\
\hline MN & $-4,56^{* *}$ & $-4,31^{* *}$ &, 25 \\
MMV & $-3,41^{* *}$ & $-2,76^{* *}$ &,- 04 \\
DDW & $-2,50^{*}$ & $-2,30^{*}$ &,- 94 \\
DAW & $-3,38^{* *}$ & $-3,05^{* *}$ & $-4,73^{* *}$ \\
MESP &,- 37 & $-4,72^{* *}$ & $-4,78^{* *}$ \\
\hline
\end{tabular}

** Diferencias estadísticamente significativas $(\mathrm{p}<.01) *$ Diferencias estadísticamente significativas $(\mathrm{p}<.05)$

$\mathrm{MN}=$ Memoria narrativa; MMV= Memoria de material verbal; MESP $=$ Memoria espacial; $\mathrm{DDW}=$ Memoria de dígitos hacia delante; DAW=Memoria de dígitos hacia atrás

En la tabla de comparación de todo el grupo de participantes se observa cambios significativos al realizar comparaciones entre evaluaciones. En la comparación de la evaluación pretest-post-test y pretest- seguimiento se encuentran diferencias significativas en la tarea de memoria narrativa y en la memoria de material verbal y memoria de dígitos hacia delante, pero sus diferencias dejan de ser significativas cuando se compara la evaluación post-test - seguimiento. En cambio, la tarea de memoria de dígitos hacia atrás muestra que sus diferencias son persistentes en la comparación de las tres evaluaciones, manteniendo las desigualdades entre las puntuaciones. Por último, la memoria espacial no produce cambio significativo en la comparación de la evaluación pretest - post-test. Sin embargo, la comparación de las evaluaciones posteriores (pretest-seguimiento y post-test - seguimiento) muestra diferencias significativas.

Por otro lado, se ha podido realizar un análisis comparativo entre evaluaciones según cada grupo de participantes, donde se observa que el alumnado normo-oyente expresa un mayor número de tareas ejecutivas que presentan contraste significativo en comparación con sus iguales con sordera. Estos resultados se recogen en el anexo 2, en la tabla 25 y muestra también las puntuaciones del chi 2, según la comparación entre grupos de participantes (con sordera y normo-oyentes).

El efecto de la intervención denota en ambos grupos (con sordera y normo-oyentes) un beneficio en las puntuaciones en la FE de la memoria, dado que mejoran a grandes rasgos las puntuaciones de las tareas después de la intervención y todavía se mantienen tres meses después. Estos cambios positivos alertan de que la FE de la memoria se puede estimular de forma temprana. Además, las diferencias significativas de cada tarea evaluativa de la FE de la memoria según cada grupo de participantes (con sordera y normo-oyentes) se exponen más detalladamente en el anexo 2, donde se encuentran las tablas de la 27 a la 29. En ellas se muestran las puntuaciones obtenidas en la comparativa de las evaluaciones. 
Este campo es todavía desconocido, dado que todavía no se han realizado estudios de intervención en las FE en alumnado con sordera en edad preescolar a través de actividades de juego dirigido de mesa y actividades funcionales en situación de juego inclusivo en pequeño grupo de 4-5 alumnos/as y gran grupo (todo el grupo-clase). Los escasos estudios de intervención se han dirigido a la población con sordera e IC de etapa escolar y han mostrado un efecto positivo en el desarrollo de las FE de la memoria a través de la aplicación de actividades virtuales y aeróbicas (Nunes et al., 2014; Xiong et al., 2018).

\subsection{Análisis descriptivo-comparativo de la función ejecutiva de la inhibición}

En este apartado realizaremos un análisis descriptivo de las pruebas evaluadas sobre la FE de la inhibición en los tres tiempos (pretest, post-test y seguimiento) en cada grupo de participantes (normooyentes y con sordera). La agrupación de los participantes también permite establecer un análisis comparativo de los resultados que han obtenido en cada evaluación, a fin de comprobar cómo influye la estimulación cognitiva en el alumnado según la condición auditiva.

Así pues, la siguiente tabla recoge la media, la desviación típica y los rangos mínimos y máximos del grupo de participantes normo-oyentes $(\mathrm{N}=26)$ y con sordera $(\mathrm{N}=4)$, a fin de poder establecer un análisis comparativo de las puntuaciones obtenidas en cada evaluación (pretest, post-test y seguimiento).

Tabla 23.

Comparación entre pretest, post-test y seguimiento en las funciones ejecutivas de Inhibición.

\begin{tabular}{lcc|cc|cc}
\hline \multicolumn{2}{c}{ Pretest } & \multicolumn{2}{c}{ Grupo normo-oyente N=26 } & \multicolumn{2}{c}{ Seguimiento } \\
\hline & M (DT) & Min- & M (DT) & $\begin{array}{c}\text { Min- } \\
\text { Máx. }\end{array}$ & M (DT) & Min-Máx. \\
& & Máx. & & $8-10$ & $9,38(, 80)$ & $8-10$ \\
INC & $7,46(2,41)$ & $0-10$ & $9,73(, 66)$ & $11-30$ & $28,73(1,88)$ & $24-30$ \\
\hline INM & $21,62(5,16)$ & $10-30$ & $28,88(3,98)$ & \multicolumn{2}{c}{} \\
\hline \multicolumn{7}{c}{ Grupo sordo N=4 } \\
\hline INC & $9,95(, 57)$ & $6,20-7,60$ & $9,25(, 95)$ & $8-10$ & $8,50(1,29)$ & $7-10$ \\
INM & $14,50(9,14)$ & $8-28$ & $30,00(, 00)$ & $30-30$ & $28,25(2,36)$ & $25-30$ \\
\hline
\end{tabular}

INC= inhibición cognitiva; INM= inhibición motora 

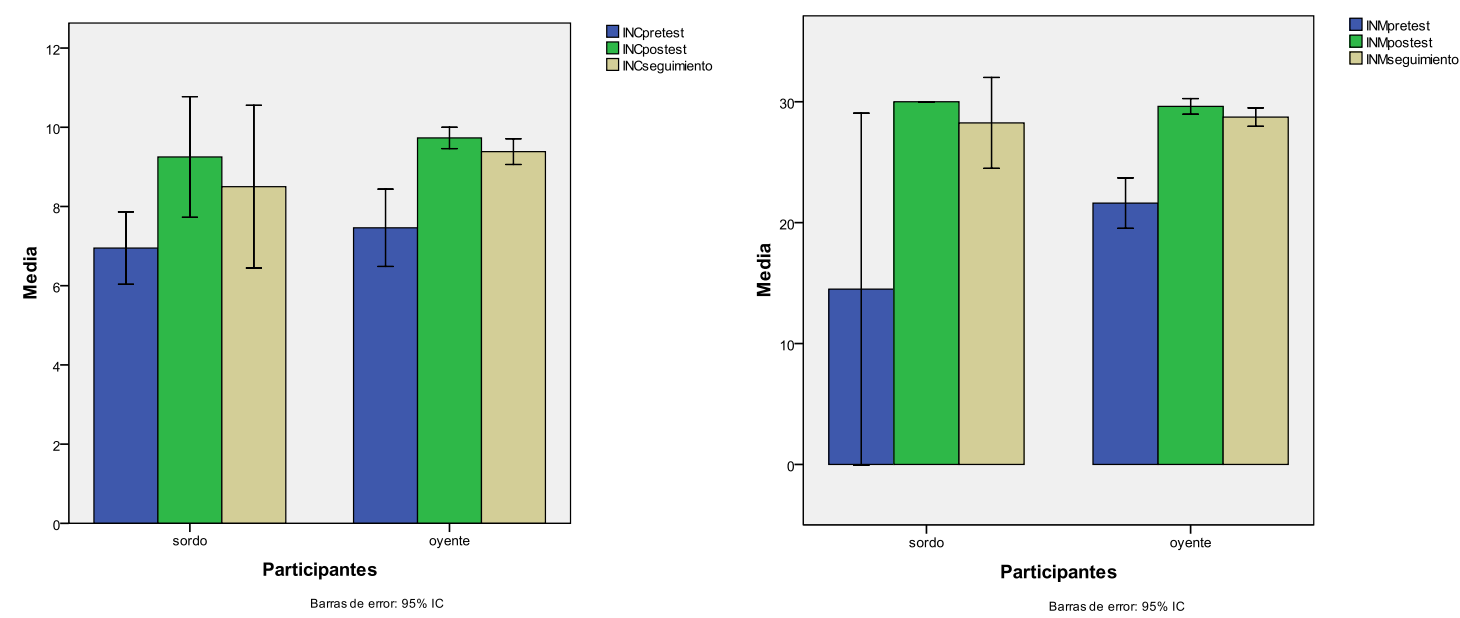

Figura 9 a y b. Medias en las pruebas de inhibición cognitiva y motora. Comparación entre grupos de participantes con sordera y normo-oyentes. ${ }^{9}$

En el grupo de participantes normo-oyentes, la inhibición cognitiva incrementa su puntuación dos puntos después de la intervención (post-test) y, posteriormente, se mantiene estable en los resultados de la evaluación de seguimiento, por lo que se constatan diferencias significativas con la evaluación pretest.

Estos resultados coinciden con otro estudio de intervención que aplica actividades de juego dirigido para la estimulación de las FE. Volckaert y Noël, (2015) mostraron que el grupo de intervención $(\mathrm{N}=24)$ de 5 años mejoraron sus puntuaciones de forma significativa en la mayoría de las tareas de control inhibitorio y superó al grupo de control $(\mathrm{N}=23)$. Además, resolvieron las tareas en menos tiempo en presencia de estímulos distractores.

Como se puede observar en el gráfico (figura 9 a), la inhibición cognitiva presenta resultados similares en ambos grupos de participantes, ya que tanto el alumnado con sordera, como el alumnado normo-oyente aumenta sus puntuaciones considerablemente en la evaluación post-test y en la evaluación de seguimiento desciende ligeramente, pero todavía conserva valores altos.

Las puntuaciones de la inhibición motora también mejoraron en la evaluación post-test en ambos grupos (con sordera y normo-oyentes) y llegan a alcanzar resultados similares, que se mantuvieron en

${ }^{9}$ La figura 9 a y b se muestran los valores recogidos según la tarea de inhibición cognitiva (a) e inhibición motora (b). En el eje X se presenta al grupo de participantes según la clasificación dicotómica (con sordera y normo-oyentes) en las tres evaluaciones (pre-test, post-test y seguimiento) y en el eje Y la frecuencia media de participantes que alcanzan esa puntuación. 
la evaluación de seguimiento, por tanto, también destaca una diferencia significativa en comparación con la evaluación pretest (figura 9 b).

Por otro lado, la siguiente tabla trata de resumir si existen diferencias entre evaluaciones comprendiendo al grupo de participantes como único grupo de estudio, a fin de comprobar las diferencias que se encuentran después de la intervención y si su efecto perdura tres meses después.

Tabla 24.

Comparación entre pretest, post test y seguimiento de las variables evaluadas de inhibición en todo el alumnado ( $n=30$ participantes).

\begin{tabular}{lccc}
\hline Valores Z & PRETEST & PRETEST & POSTEST \\
& - & - & - \\
& POST-TEST & SEGUIMIENTO & SEGUIMIENTO \\
\hline INC & $-4,16^{* *}$ & $-3,94^{* *}$ & $-1,81$ \\
INM & $-4,26^{* *}$ & $-4,57^{* *}$ & $-1,45$ \\
\hline
\end{tabular}

INC= Inhibición cognitiva; INM= Inhibición motora

** Diferencias estadísticamente significativas $(\mathrm{p}<.01)$

* Diferencias estadísticamente significativas $(\mathrm{p}<.05)$

La tarea de la inhibición cognitiva y motora refleja que todo el alumnado presenta un cambio significativo cuando se comparan las puntuaciones obtenidas entre la evaluación pretest y post-test. Además, este efecto se mantiene cuando se compara con la evaluación de seguimiento. No obstante, la comparación de la evaluación post-test y de seguimiento indica que no se encuentran diferencias significativas en las puntuaciones, por lo que no destaca un mayor rendimiento después de la evaluación post-test.

Por otro lado, se ha realizado un análisis comparativo entre evaluaciones según cada grupo de participantes, a fin de obtener un análisis más detallado sobre las diferencias obtenidas, las cuales se encuentran en el anexo 2, en las tablas 30-32. La comparación entre la evaluación pretest y post-test muestra que el alumnado normo-oyente obtiene diferencias significativas $(\mathrm{p}<.01)$ en todas las tareas de la inhibición. La comparación entre evaluación pretest y seguimiento mantiene las diferencias significativas $(\mathrm{p}<.01)$ en todas las tareas evaluadas para el alumnado normo-oyente. En cambio, el alumnado con sordera sólo muestra una tendencia próxima al cambio $(\mathrm{p}<.05)$ en la tarea de inhibición motora. La comparación entre la evaluación post-test y de seguimiento reduce las diferencias significativas, ya que sólo se mantienen en la inhibición motora $(\mathrm{p}<.05)$ y el alumnado con sordera no llega a mostrar tendencia al cambio $(\mathrm{p}<.05)$ en ninguna tarea evaluada. 


\section{CONCLUSIONES Y DISCUSIÓN DEL ESTUDIO 2}

En este segundo estudio se aportan los datos sobre el beneficio de la estimulación en las funciones ejecutivas para el alumnado con sordera y normo-oyente en la etapa de Educación infantil. Así se puede desarrollar un análisis comparativo de las mejoras que se encuentran después de la estimulación (post-test) y se mantienen después de un tiempo corto sin intervención (tres meses). Para ello se probaron tres hipótesis: (a) La estimulación cognitiva favorece el desarrollo de las FE de la memoria en el alumnado con sordera; (b) Los beneficios de la estimulación infantil perduran 3 meses después de la intervención; (c) la estimulación cognitiva también beneficia al alumnado normo-oyente, a pesar del buen desarrollo de las FE.

Así pues, los resultados del estudio no fueron consistentes con la primera hipótesis (a), dado que el alumnado con sordera no muestra un claro beneficio en el desarrollo de la FE de la memoria. Probablemente, el reducido número de participantes y la gran variabilidad en sus resultados perjudica a una resolución estadísticamente significativa. Sus puntuaciones solo muestran diferencias significativas en memoria espacial y una tendencia próxima al cambio en la tarea de memoria de material verbal. De todos modos, la media de las puntuaciones en la memoria muestra una evolución progresiva de sus puntuaciones después de la intervención, lo cual puede indicar que la intervención cognitiva favorece su rendimiento. Este es el primer estudio que recoge datos sobre intervención educativa desde una perspectiva educativa, ecológica e inclusiva con alumnado preescolar con IC. Hasta donde se conoce, los programas de intervención con población con sordera se han dirigido a la estimulación del alumnado en etapa escolar desde un enfoque individualista e interactivo.

La segunda hipótesis, en la que se refiere al mantenimiento de sus beneficios después de 3 meses, se corrobora con los datos recogidos. El alumnado con sordera mantiene las mejoras que obtuvieron en el rendimiento de las FE de la memoria. Por tanto, sus beneficios, aunque no sean estadísticamente significativos, perduran 3 meses después de la intervención. Así pues, este estudio es el primero que indica los posibles efectos positivos de la estimulación cognitiva en alumnado con IC en edad preescolar mediante un programa piloto. En efecto, hasta el momento solo se ha comprobado sus beneficios con participantes con IC en edad escolar a través de actividades interactivas (Kronenberger et al., 2011; Nunes et al., 2014) y aeróbicas (Xiong et al., 2018).

La tercera hipótesis se dirige a la atención del alumnado normo-oyente, a fin de comprobar si la estimulación cognitiva también beneficia su desarrollo. Así pues, los resultados demuestran que el alumnado normo-oyente ha mejorado significativamente en el rendimiento de todas las tareas 
evaluativas de la memoria, salvo la memoria de dígitos directos, así como también mejora significativamente en las tareas evaluativas de la inhibición. De modo que la intervención beneficia el desarrollo cognitivo para el alumnado normo-oyente en edad infantil. Estos resultados coinciden con los hallazgos de distintos estudios que evidencian que la estimulación de las habilidades ejecutivas mediante educativas de intervención temprana promueve el desarrollo de las FE de memoria e inhibición en edad temprana desde una perspectiva ecológica, lúdica y educativa.

Los datos coinciden con diferentes estudios que han aplicado actividades funcionales semejantes de juego dirigido al alumnado normo-oyente preescolar, donde la intervención mejoró significativamente el control inhibitorio (Diamond et al., 2007; Rosas et al., 2019), la memoria verbal (Röthlisberger et al., 2011) o ambas habilidades (control inhibitorio y memoria verbal) (Volckaert y Noël, 2015).

Así pues, este estudio ha permitido comprobar que es posible estimular las FE como la memoria y la inhibición en edad preescolar, ya que se recoge por primera vez que la intervención temprana a través de actividades funcionales de juego cooperativo puede favorecer el desarrollo de las FE, tanto a alumnado con sordera, como normo-oyente. Sus posibles beneficios no solo se reflejan una vez se acaba la intervención (post-test), sino que también perduran tres meses después.

Los menores logros alcanzados con la población sorda permiten concebir una reflexión crítica respecto a la generación de tareas o actividades que no sean adaptadas de las realizadas para población oyente y compromete a los educadores de criaturas con dificultades auditivas a diseñar tareas más cercanas a la capacidad comprensiva e interpretativa de los pacientes carentes de audición.

Este estudio es de gran interés por la relación que presenta las FE con el lenguaje como demuestra en el estudio anterior ( estudio 1) y se corrobora con otros estudios (Beer et al., 2014; Castellanos et al., 2016; Harris et al., 2013; Kronenberger et al., 2020). Por tanto, la estimulación cognitiva temprana puede favorecer a largo plazo y de manera indirecta al desarrollo de las habilidades lingüísticas, que se ven afectadas por la sordera congénita a edades tempanas. 


\section{PARTE III. REFLEXIONES DE LA INVESTIGACIÓN}

\section{CAPÍTULO 8. Conclusiones de la investigación y proyección de propuestas}

\section{Discusión}

Los dos estudios que componen esta investigación pretenden contribuir a conocer cuál es el nivel de desarrollo evolutivo de las FE de la memoria y la inhibición en el alumnado con sordera en edad preescolar y qué relación establecen con la adquisición del lenguaje oral (estudio 1) y verificar si se producen cambios después de una intervención breve en estas dos habilidades cognitivas (estudio 2). Estos estudios se han llevado a cabo en muestras con alumnado, de la etapa de educación infantil, de entre 3 y 6 años, con sordera y normo-oyente. Ambos estudios presentan como novedad la investigación con población de edades anteriores a los 6 años, dado que hasta el momento hay escasos estudios que centren su investigación en conocer el nivel de rendimiento de las FE emergentes en edad preescolar y su relación con el aprendizaje del lenguaje oral.

La elección de estas dos relevantes FE (memoria e inhibición) está fundamentada por la aproximación encontrada por la literatura entre una función ejecutiva muy relacionada con el lenguaje (la memoria en varios de sus subtipos) y otra menos relacionada, pero igualmente relevante para la vida cotidiana como la inhibición, ya que ambas son las primeras que inician su desarrollo de manera temprana (Horn et al., 2004; Kronenberger et al., 2014).

En el trabajo se planteó en primer lugar si las diferencias encontradas en el desarrollo evolutivo de las FE en el alumnado con sordera en edad escolar (como demuestran muchos estudios) comienzan a ser visibles en edad preescolar. Por tanto, el objetivo del trabajo fue comprobar si la sordera congénita en niños menores de seis años, usuarios de IC, determina cambios en el rendimiento evolutivo de las FE, asociadas al lenguaje, ya que ambos se ven afectados en la etapa escolar, según los datos registrados en los trabajos transversales de escolares (Botting et al., 2017; Figueras et al., 2008; Jones et al., 2019), así como en estudios en adolescentes (Figueroa, Silvestre, et al., 2020) y longitudinales (Kronenberger et al., 2013, 2014, 2020).

En el primer estudio, del trabajo que se reseña, se investigó si el rendimiento de las FE de la memoria y la inhibición del alumnado usuarios de IC presenta alteraciones -en comparación con sus compañeros/as normo-oyentes- que puedan contribuir a la variabilidad en el desarrollo del lenguaje en la etapa infantil en ambas poblaciones. Para poder estudiar dichos aspectos se plantearon en el primer 
estudio objetivos, que hicieran referencia a las áreas evaluadas (memoria e inhibición y lenguaje), así como al posible efecto de la edad, diferenciando dos grupos (3-4 y 5-6 años).

La memoria verbal ha sido muy poco estudiada en la etapa de preescolar. Los escasos estudios de corte transversal que recogen población prescolar con IC y población normo-oyente, como grupo de referencia, no han evaluado la memoria verbal (Beer et al., 2014; Nicastri et al., 2020) y el único estudio longitudinal en alumnado de la etapa infantil con IC (de 3-6 años, $\mathrm{N}=41$ ) determina déficit en la memoria verbal solamente a través de la evaluación de la prueba de dígitos de orden directo (Kronenberger et al., 2020).

Dado, el poco conocimiento del desarrollo de la memoria verbal en preescolar con IC, que se ha puesto de manifiesto en la revisión, el presente estudio explora dos de sus competencias no estudiadas todavia en esta etapa. Se trata de dos de sus componentes, que, por su posible relación con el lenguaje, también pueden tener riesgo de adquisición en el alumnado con IC. A saber: la memoria de narraciones (MN, en las siglas del trabajo) y la memoria de repeticiones de oraciones (MMV).

Por ello, esta primera parte del trabajo trata de averiguar si las evidencias científicas que demuestran retraso en la habilidad ejecutiva de la memoria en edad escolar, comienzan a ser evidentes en edad preescolar. Además, la aportación novedosa de este primer estudio es la ampliación de las pruebas para evaluar el desarrollo de la memoria, valorando tanto habilidades verbales (memoria narrativa, memoria de material verbal, memoria de dígitos), como no verbales (memoria espacial), a fin de determinar en qué habilidades es posible un retraso.

El presente estudio aporta una aproximación de los posibles déficits en el alumnado con sordera en la etapa infantil respecto a su grupo de iguales normo-oyentes a través del análisis comparativo de diferentes subtipos de memoria verbal y su correlación significativa con el lenguaje. En él se observan no solo dificultades en el rendimiento de la memoria de dígitos, sino también se detectan diferencias significativas con respecto a sus iguales normo-oyentes por su bajo rendimiento en otros subtipos de la memoria verbal como la memoria narrativa (recuerdo de una narración) y la memoria de material verbal (recuerdo de repetición de oraciones). Además, la comparación entre grupos de edad (3-4 años y 5-6 años) alerta de que sus diferencias no dejan de ser significativas cuando maduran y tienen una mayor experiencia auditiva.

Los resultados demuestran un posible déficit en la memoria verbal, que fue evaluada con distintas tareas, y establece una correlación significativa con el lenguaje. Respecto a la memoria de dígitos de orden directo muestra que el $31 \%$ del alumnado con sordera solo resolvió dos números de orden directo. En cambio, el alumnado normo-oyente supera el orden directo de dos y tres dígitos sin 
dificultad. Estos resultados coinciden con el estudio realizado por Kronenberger et al., (2020), en el cual también se muestra una media aproximada en la repetición de dígitos de orden directo de dos dígitos para el alumnado con sordera y de tres dígitos para el alumnado normo-oyente. Sin embargo, Kronenberger y sus colegas del 2020 no detectaron diferencias significativas entre las puntuaciones. No obstante, la resolución de la tarea de memoria de dígitos hacia atrás mostró que gran parte del alumnado (normo-oyente y con sordera) no supieron resolverla hasta la edad de 5 años. De modo que las posibles diferencias que podrían encontrarse entre el alumnado con sordera y normo-oyente no se reflejan totalmente en el presente estudio.

Por otro lado, la incorporación novedosa de ampliar el uso de diferentes pruebas en memoria verbal (además de la prueba de dígitos, ampliamente utilizado en estudios de edad escolar) ha permitido evaluar otros componentes de esta área, donde se ha reseñado que también pueden tener riesgo en el desarrollo la memoria narrativa y la memoria de material verbal, dado que sus puntuaciones son significativamente diferentes en comparación con sus iguales normo-oyentes. Los resultados de estas variables mostraron que el $18 \%$ del alumnado con sordera se encuentra en uno o dos rangos por debajo de la desviación típica en la tarea evaluativa de la memoria narrativa, así como el $25 \%$ en la tarea de la memoria de material verbal. Probablemente estas bajas puntuaciones sean consecuencia de la exigencia de repeticiones exactas para la evaluación, así como la dificultad de las criaturas sordas de recordar y repetir frases de más de 8 palabras y responden reduciendo las respuestas, eliminando partes relevantes de la oración. Esta situación también ocurre con el recuerdo inmediato de una historia, debido a que el alumnado con sordera argumenta la historia de forma general y olvida recordar aspectos concretos como el nombre, la descripción de los personajes y acontecimientos que no son de relevancia para la narración del cuento. Por tanto, estos resultados podrían indicarnos que el alumnado con sordera en edad preescolar podría presentar déficit en el desarrollo de la FE de la memoria verbal. Además, la baja puntuación en la memoria de material verbal concuerda con las conclusiones del estudio de Mikic et al., (2014), que también recoge población preescolar con IC, pero no fue comparado con un grupo control de iguales normo-oyente

La literatura corrobora el posible riesgo de déficit en la memoria verbal para el alumnado con IC, debido a que en la etapa preescolar se encuentran déficit en su rendimiento (Mikic et al., 2014) y apoyan estas conclusiones los estudios longitudinales, en los que incluyen también a niños/as con IC en edad preescolar (Harris et al., 2011, 2013; Kronenberger et al., 2020). Además, sus dificultades perduran en edades superiores, dado que todavía se encuentran riesgo en su desarrollo en alumnado con sordera durante la etapa escolar (Figueras et al., 2008; Jones et al., 2019; Nittrouer et al., 2013; 
Pisoni y Cleary, 2003) y al parecer también se mantiene en la etapa de secundaria (Figueroa et al., 2020).

El análisis de los grupos por separado (normo-oyentes vs sordera) parece mostrar diferencias en las correlaciones según la condición auditiva. El alumnado normo-oyente establece una íntima relación de todas las variables de las FE de la memoria verbal y el lenguaje. Sin embargo, el alumnado con IC no establece relación con la memoria de dígitos de orden directo. Este hallazgo en la memoria de dígitos de orden directo puede sugerir un posible aprendizaje diferenciado en comparación con sus compañeros/as normo-oyentes, que destaca ya en la etapa infantil, en el área encargada del procesamiento y almacenamiento del lenguaje. Este aspecto justificaría en parte por qué el alumnado presenta un posible retraso en el lenguaje y la variabilidad en el desarrollo de la competencia lingüística, coincidiendo con otros estudios (Conway et al., 2011; Davidson et al., 2011; Markman et al., 2011; Niparko et al., 2010; Pisoni et al., 2017). En efecto, se puede hacer la conjetura de que la privación auditiva prelingüística de manera temporal hasta el uso del IC influya no solo al desarrollo del habla y al lenguaje, sino también al desarrollo de habilidades ejecutivas como la memoria (Beer et al., 2014; Castellanos et al., 2016; Kronenberger et al., 2013).

Con todo ello, se puede comprender, según los resultados de varias investigaciones, que la memoria verbal parece ejercer un papel importante en el desarrollo del habla y el lenguaje, porque permite la codificación y procesamiento de las representaciones fonológicas y léxicas (Pisoni et al., 2011). En efectoun buen nivel en las habilidades lingüísticas podría favorecer la codificación verbal y el desempeño de la memoria de trabajo podría ser más rápido y eficaz (Conway et al., 2011). Así pues, el trabajo que se describe define correlaciones, de forma que el alumnado con bajo rendimiento del lenguaje también presenta un bajo rendimiento en la memoria, coincidiendo con las aportaciones de otros trabajos (Botting et al., 2017; Lo y Chen, 2017; Stiles et al., 2012).

Por otro lado, la alta puntuación del alumnado con sordera en memoria espacial es un aspecto positivo, dado que no sólo se sitúa en un nivel de desarrollo equivalente al de sus iguales, sino que los supera. Este hallazgo es consistente con los estudios previos, donde tampoco recogen diferencias en las tareas de memoria espacial y visoespacial en edad infantil (Beer et al., 2014; Nicastri et al., 2020) y en edad escolar (Kronenberger et al., 2013; Lyxell et al., 2008; Wass et al., 2008), por tanto, demuestra que las dificultades de la sordera no estan ligadas al propio procesamiento memorístico, sino a las condiciones linguisticas que tiene el material verbal. 
Así pues, la focalización de las dificultades memorísticas del colectivo del alumnado con IC en la memoria verbal constituye un aspecto importante para abordar en futuras investigaciones, dado que el tipo de tarea empleada y los estimulos que se utilizan pueden variar en las estrategias que utiliza el alumnado con sordera para resolverlas. Así pues, diferentes estudios utilizaron tareas visuales que precisaban, en cierta medida, de mediación verbal para resolver la tarea y observaron que el alumnado con IC mostraba déficit en comparación con sus iguales normo-oyentes, a pesar de que la presentación y la respuesta fuera visual (Cleary et al., 2001; Kronenberger et al., 2013). Por tanto, parece ser que que la falta de experiencias tempranas auditivas en el alumnado con sordera, a pesar del uso temparno del IC, se podría relacionar con una capacidad de procesamiento de la información verbal menos eficaz y más lenta cuando las actividades requieren de un procesamiento secuencial, en el que implica la descodificación y manipulación auditivo-verbal de la información lingüística, tanto en modalidad visual, como auditiva (AuBuchon et al., 2015b; Conway et al., 2011; Harris et al., 2013; Pisoni y Cleary, 2003).

En la misma línea anterior se podría interpretar la relación entre la memoria espacial y el lenguaje. En efecto, en el presente trabajo la memoria espacial no se relacionó con el lenguaje en ninguno de los grupos de participantes (con sordera y normo-oyentes), coincidiendo con el estudio realizado por Beer et al., (2014) que utilizó la misma prueba que se administró en este trabajo. Sin embargo, hay contradicciones con diferentes estudios, dado que parece ser que según el tipo de tarea que se utilice, se encuentra relación significativa entre la memoria espacial y el lenguaje. De hecho, en el estudio de Nicastri et al., (2020) con otra tarea de memoria espacial reveló la existencia de la correlación con habilidades lingüísticas en alumnado preescolar con IC y otros estudios han demostrado resultados semejantes con alumnado en edad escolar con IC (Figueras et al., 2008; Jones et al., 2019; Surowiecki et al., 2002). Una posible interpretación a dicha relación es atribuirla al tipo de tarea visoespacial, que para resolverla, precise de una codificiación verbal de los estímulos visuales. De hecho, el estudio longitudinal de Jones y sus colegas del 2019 recoge la relación unidireccional del vocabulario en el desarrollo de las FE de la inhibición motora, la inhibición cognitiva, la memoria de trabajo y la memoria espacial tanto para el alumnado con IC y normo-oyente. Además, el estudio a lo largo del dos años corroboró que el alumnado con sordera, que presentaba bajo vocabulario en comparación con sus iguales normo-oyentes, todavía se desempeñaba peor que sus compañeros/as normo-oyentes en las tareas de memoria de trabajo y la tarea de inhibición cognitiva, por tanto, el lenguaje parece ser que tiene una gran influencia en el desarrollo apropiado de las FE. 
En el presente estudio también se evalúo la inhibición para conocer la implicación en los procesos de aprendizaje del lenguaje y los posibles riesgos en su desarrollo en edad infantil, debido a que también hay escasos estudios sobre el rendimiento de la inhibición (Beer et al., 2014; Horn et al., 2004; Kronenberger et al., 2020; Nicastri et al., 2020). Como ya se ha reseñado, la literatura parecen mostrar retraso en su desarrollo de esta función ejecutiva en preescolares sordos. Sin embargo, los resultados no son concluyentes, dado que la edad de implantación no se ha tenido en cuenta en todos los estudios y al parecer influye en el desarrollo adecuado de la inhibición (Horn et al., 2004; Nicastri et al., 2020). Además, cabe destacar que tampoco se ha establecido en todos los estudios la relación con el lenguaje oral (Beer et al., 2014; Kronenberger et al., 2020), por lo que dificulta una mayor comprensión sobre su implicación en el lenguaje oral. Dado el vacio existente en este sentido, en el trabajo que nos ocupa, los datos indicaron que el alumnado con sordera obtenían mejores puntuaciones que el alumnado normo-oyente. Por tanto, sus diferencias no se deben a un posible riesgo en el desarrollo en la FE de la inhibición, coincidiendo con el estudio realizado por Nicastri et al., (2020).

Una posible interpretación del buen desarrollo de la inhibición es que el bajo desarrollo del lenguaje limita la adquisición del contenido léxico asociado a la representación de la imagen de la tarea (sol luna) y la asignación de la norma aplicada para la tarea de inhibición cognitiva (expresar de forma oral "noche" cuando vea la imagen del sol y decir "día" cuando vea la imagen de la luna). El desconocimiento de la representación del léxico asociado a cada palabra puede representar una menor exigencia verbal y facilita la capacidad del niño para aceptar el cambio de palabras según las exigencias de la tarea sin establecer ningún tipo de memorización de las reglas que pueda inducir a los niños/as a dar respuestas más impulsivas. En cambio, aquellos participantes con mayor nivel de lenguaje expresivo y comprensivo deben no solo regular la capacidad para enfocar la atención en la tarea, sino también precisan codificar, almacenar y reproducir correctamente las reglas de la actividad, por lo que requiere de una mayor exigencia verbal y, por tanto, tiende a un mayor número de errores (Nicastri et al., 2020). Por esa razón, el alumnado normo-oyente establecería una relación entre el lenguaje comprensivo y la inhibición cognitiva y, en cambio, en el alumnado con sordera, la inhibición cognitiva se correlaciona con el lenguaje expresivo, dado que para él no precisa comprender para ejecutar la tarea inhibitoria.

Por otro lado, la inhibición motora se relaciona con el lenguaje expresivo en ambos grupos de participantes. Dichas correlaciones coinciden en parte con el estudio realizado por Nicastri et al., (2020) que obtuvieron en sus resultados una correlación significativa tanto con la comprensión y el lenguaje expresivo. Esta relación puede ser porque el lenguaje (externo e interno) sea un mediador 
para favorecer la regulación del comportamiento a través de la reflexión, guiando las acciones que se van a cometer con una planificación mental previa (Remine et al., 2008). De este modo, el déficit prolongado en el lenguaje puede desarrollar conductas impulsivas en el alumnado con sordera como se observa en estudios que recogen alumnado en edad preescolar (Barker et al., 2009; Horn et al., 2004, 2005) y escolar (Hoffman et al., 2018; Yucel y Derim, 2008).

No obstante, se necesita más investigación dadas las contradicciones en los resultados con los estudios anteriores y el reducido número de investigaciones en etapa preescolar indican la necesidad de más investigación para identificar el nivel de rendimiento de la inhibición, la relación con el lenguaje y aumentar nuestra comprensión de los factores que intervenien en el aprendizaje. Además, la realización de la tarea de inhibición cognitiva es posible que no fuera un ejercicio de autocontrol en el alumnado con sordera, dado que la mayoría de los participantes no mostraron ningún error en la ejecución de la tarea, a diferencia de sus compañeros/as normo-oyentes. Cabe suponer que el alumnado con sordera tiene una mayor facilidad para establecer un cambio en la denominación de palabras durante la tarea (inhibición cognitiva) a causa del menor lenguaje, por lo que no precisa de estrategias de autocontrol.

El segundo estudio, se deriva de los resultados del anterior y trata de abordar la comprensión del comportamiento de las funciones ejecutivas vinculadas al lenguaje desde una perspectiva educativa, inclusiva y ecológica. El estudio pretende aportar conocimientos científicos acerca de los efectos positivos de la estimulación temprana de habilidades cognitivas como las funciones ejecutivas e incentivar su desarrollo para reducir el déficit y beneficiar el aprendizaje del lenguaje oral, lo cual podría permitir integrar actividades de este tipo dentro del currículum de Educación infantil. Con ello es posible promover el desarrollo de niños/as con patologías que afectan a áreas cognitivas y de lenguaje.

La novedad del segundo estudio es la intervención en las incipientes FE (memoria e inhibición) a través de actividades funcionales en situaciones de juego en población con sordera y normo-oyente en edad preescolar desde una perspectiva inclusiva. Los escasos estudios que aplican programas de estimulación en alumnado con sordera recogen población de etapa escolar, por lo que hasta el momento todavía no se había realizado un programa de intervención en población infantil con IC que aporte datos sobre los posibles beneficios de la intervención temprana en las FE.

En primer lugar, después de la aplicación del ciclo de aprendizaje se observó (en el post-test) ya un mayor rendimiento de las puntuaciones en el alumnado normo-oyente en todas las tareas de la FE de 
la memoria, salvo en la memoria de dígitos de orden directo. Estos datos coinciden con otros estudios, donde la muestra de población con desarrollo normo-típico presenta un mejor rendimiento en la memoria espacial después de la intervención (Holmes et al., 2009; Thorell et al., 2009), así como en el desempeño de resolver la tarea de palabras en orden inverso (Traverso et al., 2015).

En segundo lugar, el aumento de las puntuaciones del alumnado con sordera fue significativo en la memoria espacial y mostró una tendencia significativa al progreso en la memoria de material verbal. Estos resultados estan en consonancia con los del estudio de intervención de Kronenberger et al., (2011) con alumnado con IC en edad escolar, ya que la intervención mejoró significativamente el rendimiento de la prueba de repetición de oraciones y, este logro, se mantuvo 6 meses después. Sin embargo, no se encontraron cambios en la memoria narrativa y la tarea de dígitos hacía delante y hacia atrás. En este mismo sentido se encuentra el estudio de Nunes et al., (2014), que encuentra mejoras significativas después de la intervención en memoria de trabajo. No todos los estudios previos al que se comenta recogen cambios en el miso sentido. Por ejemplo, el trabajo de Xiong et al., (2018) encontraron mejoras en la memoria de trabajo, inhibición y flexibilidad en estudiantes escolares, pero utilizaron ejercicios de carácter distintos a los utilizados por la mayoría de estudios, ejercicios aerobicos.

El alumnado normo-oyente obtuvo diferencias significativas en la inhibición cognitiva, coincidiendo con estudios previos como Volckaert y Noël, (2015) y Röthlisberger et al., (2011), de los cuales se tomaron en este estudio diversas actividades, aplicadas en sus programas de intervención. También aumentó significativamente el rendimiento de las puntuaciones en la tarea de inhibición motora, tanto para el alumnado normo-oyente y con sordera, pero estos resultados no pudieron ser contrastados con estudios anteriores por ser un campo todavía incipiente. El estudio de Xiong et al., (2018) es uno de los pocos estudios que reporta cambios en la inhibición cognitiva después de la intervención en alumnado escolar con IC, por tanto, es necesario profundizar en este campo y conocer los efectos de la estimulación, así como un mayor conocimiento de la influencia que ejerce sobre el lenguaje en el alumnado con IC en edad infantil, dado que hay escasos estudios que corroboren su relación en esta etapa (Horn et al., 2004; Nicastri et al., 2020).

En definitiva, los efectos de la estimulación cognitiva en edad infantil son una aportación relevante en el campo de la investigación de las FE, que hasta el momento no se había realizado en alumnado con IC. Sus beneficios, según se han recogido en el estudio 2, parecen ser notables tanto para el alumnado con sordera, como normo-oyente y perduraron hasta 3 meses después de la estimulación, 
pero requieren de un mayor número de participantes con sordera para recoger una mayor fiabilidad y validez de los resultados.

Así pues, sería necesario realizar más investigaciones sobre la memoria de trabajo verbal para comprender mejor la capacidad del alumnado preescolar con sordera en procesar la información al mismo tiempo que realiza otras operaciones mentales, así como el control inhibitorio para conocer la influencia en el procesamiento y el desarrollo del lenguaje en el alumnado con sordera, ya que tal y como se recoge en el estudio 1 y se corrobora con estudios previos (Botting et al., 2017; Castellanos et al., 2014; Ching et al., 2019; Figueras et al., 2008; Harris et al., 2011, 2013; Horn et al., 2004; Hunter et al., 2017; Lo y Chen, 2017; Pisoni et al., 2011; Remine et al., 2008) las FE incipientes presentan fuertes asociaciones con el lenguaje.

Estas relaciones anuncian que puede existir una interacción reciproca e interdependencia entre el lenguaje, las experiencias sensoriales y el desarrollo neurocognitivo (Castellanos et al., 2014; Davidson et al., 2014; Kral et al., 2016; Kronenberger et al., 2014, 2020). No obstante, es necesario estudiar si realmente estos cambios en el rendimiento de las FE pueden beneficiar al desarrollo del lenguaje para considerar el entrenamiento cognitivo como una herrramienta para facilitar y mejorar el procesamiento y desarrollo del habla y del lenguaje a través de estudios longitudinales en la etapa infantil. En este sentido, hasta donde se conoce, sólo se ha realizado un estudio longitudinal con alumnado preescolar con sordera e IC (Kronenberger et al., 2020), donde se determina que la población infantil con sordera presenta déficit en las FE de la memoria y la inhición. Además, Kronenberger y sus colegas del 2020 mostraron que el lenguaje predice el desarrollo de la memoria de trabajo verbal para el alumnado con sordera y normo-oyente. Además, también se recogió que la inhibición cognitiva y la memoria de trabajo verbal eran predictivas del desarrollo del lenguaje solo en el alumnado con IC, por tanto en ellos sí que se establece una relación reciproca entre el lenguaje y las FE. Estas conclusiones dan soporte a posibles hipótesis sobre los efectos de la privación auditiva en los primeros años de vida, a pesar de la temprana implantación, en el aprendizaje de patrones secuenciales cognitivos (Conway et al., 2011, 2012; Kral et al., 2016; Pisoni et al., 2017), así como el valor potencial de integrar el desarrollo de las FE las intervenciones educativas para el alumnado con IC.

\section{Limitaciones}

Algunas restricciones han limitado la generalización de los resultados encontrados en esta tesis. En el caso de este trabajo cabe destacar que la muestra era pequeña y condicionó el análisis de los datos. Sin embargo, la restricción de la selección por ciertos requisitos de inclusión para establecer un patrón 
homogéneo de la muestra redujo considerablemente el número de participantes y se amplió la recogida de alumnado a otras provincias colindantes a la Comunidad Valenciana. Además, durante la recogida de la muestra, también se solicitó ciertos datos demográficos y clínicos a tener en cuenta para el posterior análisis de los datos, como la edad exacta de implantación, pero muchos de los profesionales que atendían al alumnado no colaboró en la cumplimentación de la información o no tenía esa información disponible.

Otro factor que ha condicionado el trabajo de investigación ha sido la colaboración de centros educativos para aplicar un programa de intervención en la estimulación cognitiva con alumnado con sordera. La escasa participación cambió el planteamiento de la investigación hacia la implantación de un programa piloto para comprobar los efectos de la intervención. Por ello, el segundo estudio recoge una pequeña muestra de alumnado con sordera y no permitió la creación de un grupo control de participantes con IC que -en las mismas condiciones- no hubiera participado en la intervención, por lo que solo se pudo realizar un análisis estadístico limitado. Además, las actividades establecidas para la estimulación cognitiva fueron adaptadas de otros estudios aplicados en alumnado normo-oyente, ya que los escasos estudios con alumnado con sordera no presentaban actividades desde una perspectiva ecológica y educativa, por lo que precisa para próximos estudios la creación de material dirigido a la atención de las necesidades del alumnado con sordera para garantizar su aprendizaje sin barreras en el acceso a la información.

En cuanto a la evaluación de las FE tanto del primer, como del segundo estudio, se realizó únicamente con pruebas directas a los preescolares. Estas restricciones no permiten corroborar los resultados a través de otras técnicas de evaluación como check-list de comportamiento ejecutivo en las que impliquen a agentes educativos (progenitores, maestros/as y logopedas) y realizar una comparación con otros estudios que integraron este tipo de pruebas.

Finalmente, el trabajo de investigación evaluó las habilidades de las FE en un momento determinado, la etapa infantil, pero aún no se dispone de datos suficientes sobre estudios longitudinales para valorar la evolución de las FE en la etapa infantil. Por tanto, deja un campo abierto a la investigación la forma de maduración de estas habilidades, cuando las competencias lingüísticas se desarrollen y requieren de una mayor carga cognitiva. También, es de interés para futuras investigaciones recoger una mayor participación de centros educativos para aplicar el programa de estimulación cognitiva, a fin de establecer un mayor número de participantes y formar un grupo control para conocer con detalle el efecto que produce la estimulación en el aprendizaje. 


\section{Conclusiones}

Los estudios que se han desarrollado en este trabajo de investigación nos conducen a exponer las siguientes conclusiones:

La evaluación del alumnado preescolar con IC muestra que éste podría tener riesgo en el desarrollo de la FE de la memoria verbal. Esta posible alteración de su desarrollo se manifiesta en las bajas puntuaciones las tareas de la FE de la memoria que precisa de una implicación del lenguaje expresivo y comprensivo: memoria narrativa, memoria de material verbal y memoria de dígitos de orden directo e inverso. En efecto, se pueden constatar las dificultades en la memoria verbal a corto plazo y de trabajo en la etapa infantil, dado que el bajo rendimiento se encuentra en todas las tareas evaluativas de la memoria verbal desde los tres años.

Por otro lado, a pesar de que el grupo afectado por sordera del estudio 2 no muestra claras evidencias sobre un efecto significativamente positivo en los resultados, en comparación con sus iguales normooyentes, obtuvieron mejoras en sus puntuaciones después de la intervención y se mantuvieron después de 3 meses. Este cambio no significativo en sus puntuaciones redujo sensiblemente sus diferencias en el rendimiento de las FE con sus iguales normo-oyentes. Además, también se ven beneficiados de esta estimulación el grupo de iguales de referencia (normo-oyentes), dado que también mejoran significativamente su rendimiento en las FE de la memoria y la inhibición y perduran el efecto positivo incluso 3 meses después de la intervención.

Así pues, es conveniente la creación de material de trabajo elaborado para la atención específica del alumnado con sordera, que no sean una adaptación de ejercicios usados con población normo-oyente, para que el alumnado con sordera pueda acceder sin dificultad a la comprensión y ejecución de las actividades planteadas. Es necesario aplicar recursos de apoyo y estrategias de intervención educativas para garantizar el aprendizaje del alumnado con sordera, sobre todo en la etapa infantil, dado que su lenguaje en edad preescolar todavía no llega a alcanzar niveles equiparables a sus iguales normooyentes.

El valor potencial del desarrollo de las FE en el aprendizaje y su íntima relación con el lenguaje hace especialmente sugerente la incorporación en la actividad ordinaria del aula de actividades estimulantes de las FE, ya que puede beneficiar no solo al alumnado con sordera, sino también al alumnado normo-oyente que precise refuerzo en el desarrollo de las habilidades ejecutivas. Para ello se puede plantear la intervención desde diferentes formas de agrupación (en pareja, en pequeño grupo, 
en gran grupo) pero siempre todas ellas enfocadas desde una perspectiva ecológica e inclusiva para favorecer la interacción y colaboración entre iguales.

La educación inclusiva requiere también del establecimiento de redes de colaboración, apoyo y ayuda del profesorado ya que comprendemos que su participación es clave para lograr el éxito en la intervención (Rappoport y Echeita, 2018). De este modo, la coordinación se debe establecer entre el maestro/a de audición y lenguaje, como especialista educativo de atención al alumnado con sordera, y el tutor/a del aula ordinaria para organizar actividades orientadas a la estimulación de las FE que se desarrollan de manera temprana como la memoria y la inhibición. Estas actividades se pueden promover a través de diferentes enfoques metodológicos, pero como se ha podido comprobar con el estudio 2, a través de actividades de juego dirigido que favorezca la atención dividida y el recuerdo de órdenes sencillas también se favorece el desarrollo de las habilidades ejecutivas.

Por último, el soporte y la orientación a las familias es un aspecto clave para que las criaturas sordas puedan mejorar las estrategias comunicativas y mejoren el desarrollo incipiente de las FE. Para ello, es conveniente dar espacio a la familia para que participe en las sesiones de intervención y ofrecer diferentes actividades cotidianas que inviten a la estimulación del lenguaje de su hijo/a con sordera (Silvestre, 2010). De esta manera, se favorece la memoria a través del recuerdo de sonidos y palabras y la inhibición mediante la atención conjunta con los progenitores. De hecho, cuando los padres participan en programas para padres cambian algunos de los comportamientos comunicativos que mantienen con sus hijo/as con sordera y brinda mayor oportunidades de toma de turno por lo que favorece al desarrollo del lenguaje (Kruythoff-Broekman, Wiefferink, Rieffe y Uilenburg, 2019). 


\section{REFERENCIAS BIBLIOGRAFICAS}

Acosta Rodríguez, V., Ramírez Santana, G. M., y Hernández Expósito, S. (2017). Funciones ejecutivas y lenguaje en subtipos de niños con trastorno específico del lenguaje. Neurología, 32(6), 355362. https://doi.org/10.1016/j.nrl.2015.12.018

Alarcón-Rubio, D., Sánchez-Medina, J. A., y Prieto-García, J. R. (2014). Executive function and verbal self-regulation in childhood: Developmental linkages between partially internalized private speech and cognitive flexibility. Early Childhood Research Quarterly, 29(2), 95-105. https://doi.org/10.1016/J.ECRESQ.2013.11.002

La Convención Internacional sobre los Derechos del Niño, (1989). https://www.boe.es/boe/dias/1990/12/31/pdfs/A38897-38904.pdf

AuBuchon, A. M., Pisoni, D. B., y Kronenberger, W. G. (2015a). Short-Term and Working Memory Impairments in Early-Implanted, Long-Term Cochlear Implant Users Are Independent of Audibility and Speech Production. Ear and Hearing, 36(6), 733-737. https://doi.org/10.1097/AUD.0000000000000189

AuBuchon, A. M., Pisoni, D. B., y Kronenberger, W. G. (2015b). Verbal processing speed and executive functioning in long-term cochlear implant users. Journal of Speech, Language, and Hearing Research : JSLHR, 58(1), 151-162. https://doi.org/10.1044/2014_JSLHR-H-13-0259

Baddeley, A. (2003). Working memory and language: an overview. Journal of Communication Disorders, 36(3), 189-208. https://doi.org/10.1016/S0021-9924(03)00019-4

Barker, D., Quittner, A., Fink, N., Eisenberg, L., Tobey, E., y Niparko, J. (2009). Predicting behavior problems in deaf and hearing children: The influences of language, attention, and parent-child communication. Development and Psychopathology, 21(2), 373-392. https://doi.org/10.1017/S0954579409000212.Predicting

Barkley, R. A. (1997). Behavioral inhibition, sustained attention, and executive functions: constructing a unifying theory of ADHD . Behavioral Inhibition, Sustained Attention, and Executive Functions : Constructing a Unifying Theory of ADHD. Psychological Bulletin, 121(1), 65-94. https://doi.org/10.1037/0033-2909.121.1.65 
Bavelier, D., Newport, E. L., Hall, M., Supalla, T., y Boutla, M. (2008). Ordered short-term memory differs in signers and speakers: implications for models of short-term memory. Cognition, 107(2), 433-459. https://doi.org/10.1016/j.cognition.2007.10.012

Beer, J., Kronenberger, W. G., Castellanos, I., Colson, B. G., Henning, S. C., y Pisoni, D. B. (2014). Executive Functioning Skills in Preschool-Age Children With Cochlear Implants. Journal of Speech, Language, and Hearing Research, 57, 1521-1534. https://doi.org/10.1044/2014

Beer, J., Kronenberger, W. G., y Pisoni, D. B. (2011). Executive function in everyday life: implications for young cochlear implant users. Cochlear Implants International, 12(sup1), S89-S91. https://doi.org/10.1179/146701011X13001035752570

Bharadwaj, S. V., Maricle, D., Green, L., y Allman, T. (2015). Working memory, short-term memory and reading proficiency in school-age children with cochlear implants. International Journal of $\begin{array}{lll}\text { Pediatric } \quad \text { Otorhinolaryngology, } & \text { 1647-1653), }\end{array}$ https://doi.org/10.1016/J.IJPORL.2015.07.006

Bisquerra, R. (coord. . (2009). Metodología de la investigación educativa $\left(2^{\circ}\right)$. La muralla.

Blair, C., y Razza, R. P. (2007). Relating Effortful Control, Executive Function, and False Belief Understanding to Emerging Math and Literacy Ability in Kindergarten Author ( $s$ ): Clancy Blair and Rachel Peters Razza Published by: Wiley on behalf of the Society for Research in Child D. 78(2), 647-663. https://doi.org/10.1111/j.1467-8624.2007.01019.x

Blair, C., Ursache, A., Greenberg, M., y Vernon-Feagans, L. (2015). Multiple aspects of self-regulation uniquely predict mathematics but not letter-word knowledge in the early elementary grades. Developmental Psychology, 51(4), 459-472. https://doi.org/10.1037/a0038813

Blakey, E., y Carroll, D. J. (2015). A short executive function training program improves preschoolers' working memory. Frontiers in Psychology, 6(NOV), 1-8. https://doi.org/10.3389/fpsyg.2015.01827

Borregón Sanz, S. (2016). Hipoacusia y Sordera. Manual del conocimiento de la sordera y de la persona sorda a la intervención educativa (Ciencias d).

Botting, N., Jones, A., Marshall, C., Denmark, T., Atkinson, J., y Morgan, G. (2017). Nonverbal 
Executive Function is Mediated by Language: A Study of Deaf and Hearing Children. Child Development, 88(5), 1689-1700. https://doi.org/10.1111/cdev.12659

Burkholder, R. A., y Pisoni, D. B. (2003). Speech timing and working memory in profoundly deaf children after cochlear implantation. $J$ Exp Child Psychol, 85(1), 63-88. https://doi.org/10.1109/TMI.2012.2196707.Separate

Carlson, S. M., Davis, A. C., y Leach, J. G. (2005). Less Is More: Executive Function and Symbolic Representation in Preschool Children. Psychological Science, 16(8), 609-616. https://doi.org/10.1111/j.1467-9280.2005.01583.x

Castellanos, I., Kronenberger, W. G., Beer, J., Henning, S. C., Colson, B. G., y Pisoni, D. B. (2014). Preschool speech intelligibility and vocabulary skills predict long-term speech and language outcomes following cochlear implantation in early childhood. Cochlear Implants International, 15(4), 200-210. https://doi.org/10.1179/1754762813Y.0000000043

Castellanos, I., Pisoni, D. B., Kronenberger, W. G., y Beer, J. (2016). Early expressive language skills predict long-term neurocognitive outcomes in cochlear implant users: Evidence from the MacArthur-Bates Communicative Development Inventories. American Journal of SpeechLanguage Pathology, 25(3), 381-392. https://doi.org/10.1044/2016_AJSLP-15-0023

Ching, T. Y. C., Cupples, L., y Marnane, V. (2019). Early Cognitive Predictors of 9-Year-Old Spoken Language in Children With Mild to Severe Hearing Loss Using Hearing Aids. Frontiers in Psychology, 10. https://doi.org/10.3389/fpsyg.2019.02180

Cleary, M., Pisoni, D. B., y Geers, A. E. (2001). Some measures of verbal and spatial working memory in eight- and nine-year-old hearing-impaired children with cochlear implants. Ear and Hearing, $22(5), 395-411$.

Colletti, L., Mandalà, M., Zoccante, L., Shannon, R. V., y Colletti, V. (2011). Infants versus older children fitted with cochlear implants: Performance over 10 years. International Journal of Pediatric Otorhinolaryngology, 75(4), 504-509. https://doi.org/10.1016/j.ijporl.2011.01.005

Colletti, V., Carner, M., Miorelli, V., Guida, M., Colletti, L., y Fiorino, F. G. (2005). Cochlear Implantation at under 12 months: Report on 10 Patients. The Laryngoscope, 115(3), 445-449. https://doi.org/10.1097/01.mlg.0000157838.61497.e7 
Conway, C. M., y Kronenberger, W. G. (2009). The importance of sound for cognitive sequencing abilities: The auditory scaffolding hypothesis. Current Directions in Psychological Science, 18, 275-279. https://doi.org/10.1111/j.1467-8721.2009.01651.x.The

Conway, C. M., Louis, S., Karpicke, J., y Henning, S. C. (2012). Nonverbal Cognition in Deaf Children Following Cochlear Implantation: Motor Sequencing Disturbances Mediate Language Delays. Dev Neuropsychol, 36(2), 237-254. https://doi.org/10.1080/87565641.2010.549869.Nonverbal

Conway, C. M., Pisoni, D. B., Anaya, E. M., Karpicke, J., y Henning, S. C. (2011). Implicit sequence learning in deaf children with cochlear implants. Dev Sci, 14(1), 69-82. https://doi.org/10.1111/j.1467-7687.2010.00960.x.Implicit

Davidson, L. S., Geers, A. E., Blamey, P. J., Tobey, E. A., y Brenner, C. A. (2011). Factors contributing to speech perception scores in long-term pediatric cochlear implant users. Ear and Hearing, 32(1 Suppl), 19S. https://doi.org/10.1097/aud.0b013e3181ffdb8b

Davidson, L. S., Geers, A. E., y Nicholas, J. G. (2014). The effects of audibility and novel word learning ability on vocabulary level in children with cochlear implants. Cochlear Implants International, 15(4), 211-221. https://doi.org/10.1179/1754762813Y.0000000051

Demby, K. P., Riggs, S. A., y Kaminski, P. L. (2017). Attachment and Family Processes in Children's Psychological Adjustment in Middle Childhood. Family Process, 56(1), 234-249. https://doi.org/10.1111/famp.12145

Demetriou, E. A., Lampit, A., Quintana, D. S., Naismith, S. L., Song, Y., Pye, J. E., Hickie, I., y Guastella, A. J. (2018). Autism spectrum disorders: a meta-analysis of executive function. Molecular Psychiatry, 23(5), 1198-1204. https://doi.org/10.1038/mp.2017.75

Diamond, A., Barnett, W. S., Thomas, J., y Munro, S. (2007). THE EARLY YEARS: Preschool Program Improves Cognitive Control. Science, 318(5855), 1387-1388. https://doi.org/10.1126/science. 1151148

Diamond, Adele. (2012). Activities and Programs That Improve Children's Executive Functions. In Current Directions in Psychological Science (Vol. 21, Issue 5, pp. 335-341). https://doi.org/10.1177/0963721412453722 
Diamond, Adele. (2013). Executive Functions. Annual Review of Psychology, 64, 135. https://doi.org/10.1146/ANNUREV-PSYCH-113011-143750

Diamond, Adele, y Lee, K. (2011). Interventions shown to aid executive function development in children 4 to 12 years old. Science (New York, N.Y.), 333(6045), 959-964. https://doi.org/10.1126/science.1204529

Diamond, Adele, y Ling, D. S. (2016). Conclusions about interventions, programs, and approaches for improving executive functions that appear justified and those that, despite much hype, do not. Developmental Cognitive Neuroscience, 18, 34-48. https://doi.org/10.1016/j.dcn.2015.11.005

Edwards, S., Fletcher, P., Garman, M., Hughes, A., Letts, C., y Sinka, I. (1997). The Reynell Developmental Language Scales: III (RDLS-III). NFER-NELSON.

Espy, K. A., Sheffield, T. D., Wiebe, S. A., Clark, C. A. C., y Moehr, M. J. (2011). Executive control and dimensions of problem behaviors in preschool children. Journal of Child Psychology and Psychiatry and Allied Disciplines, 52(1), 33-46. https://doi.org/10.1111/j.14697610.2010.02265.x

Ezrine, G. A. (2011). Effects of language on the development of executive functions in preschool children. Dissertation Abstracts International: Section B: The Sciences and Engineering. https://scholarworks.gsu.edu/cps_diss/41

Fenson, L., Marchman, V. A., Donna J Thal, P. D., Phillip S Dale, P. D., J Steven Reznick, P. D., y Elizabeth Bates, P. D. (2006). MacArthur-Bates Communicative Development Inventories.

Fernyhough, C., y Fradley, E. (2005). Private speech on an executive task: relations with task difficulty and task performance. Cognitive Development, 20(1), 103-120. https://doi.org/10.1016/J.COGDEV.2004.11.002

Ferrández Mora, J. A., y Villalba Pérez, A. (1996). Atención educativa de los alumnos con necesidades educativas especiales derivadas de una deficiencia auditiva.

Figueras, B., Edwards, L., y Langdon, D. (2008). Executive function and language in deaf children. Journal of Deaf Studies and Deaf Education, 13(3), 362-377. https://doi.org/10.1093/deafed/enm067 
Figueroa, M., Darbra, S., y Silvestre, N. (2020). Reading and Theory of Mind in Adolescents with Cochlear Implant. The Journal of Deaf Studies and Deaf Education, 25(2), 212-223. https://doi.org/10.1093/deafed/enz046

Figueroa, M., Silvestre, N., y Darbra, S. (2020). Specific EF-Related Tasks and Reading in Adolescents With Typical Hearing or a Cochlear Implant. Communication Disorders Quarterly, 152574012097610. https://doi.org/10.1177/1525740120976109

Fuhs, M. W., y Day, J. D. (2011). Verbal ability and executive functioning development in preschoolers at head start. Developmental Psychology, 47(2), 404-416. https://doi.org/10.1037/a0021065

Ganek, H., McConkey Robbins, A., y Niparko, J. K. (2012). Language outcomes after cochlear implantation. In Otolaryngologic Clinics of North America (Vol. 45, Issue 1, pp. 173-185). Elsevier. https://doi.org/10.1016/j.otc.2011.08.024

Geers, A. E., Hayes, H., y Louis, S. (2009). Spoken Language Scores of Children Using Cochlear Implants Compared to Hearing Age-Mates at School Entry. Journal of Deaf Studies and Deaf Education. https://doi.org/10.1093/deafed/enn046

Geers, A. E., y Nicholas, J. G. (2013). Enduring Advantages of Early Cochlear Implantation for Spoken Language Development. Journal of Speech, Language, and Hearing Research, 56, 643653. https://doi.org/10.1044/1092-4388(2012/11-0347)throughout

Geers, A. E., Nicholas, J. G., y Sedey, A. L. (2003). Language skills of children with early cochlear $\begin{array}{lllll}\text { implantation. } & \text { Ear } & \text { Hearing, } & \text { 24(1 }\end{array}$ https://doi.org/10.1097/01.aud.0000051689.57380.1b

Gerstadt, C. L., Hong, Y. J., y Diamond, A. (1994). The relationship between cognition and action: performance of children 312-7 years old on a stroop- like day-night test. Cognition, 53(2), 129153. https://doi.org/10.1016/0010-0277(94)90068-X

Gioia, G. A., Isquith, P. K., Guy, S. C., y Kenworthy, L. (2000). TEST REVIEW Behavior Rating Inventory of Executive Function. Child Neuropsychology, 6(3), 235-238. https://doi.org/10.1076/chin.6.3.235.3152 
Gioia, G., Andrwes, K., y Isquith, P. (1996). Behavior rating inventory of executive function-preschool version (BRIEF-P). http://www.v-psyche.com/doc/Clinical Test/Behavior Rating INventory of Executive Function Preschool Version.doc

Goberis, D., Beams, D., Dalpes, M., Abrisch, a, Baca, R., y Yoshinaga-Itano, C. (2012). The missing link in language development of deaf and hard of hearing children: pragmatic language development. Seminars in Speech and Language, 33(4), 297-309. https://doi.org/10.1055/s$0032-1326916$

Gonzáles Pérez, T. (2011). Modelos de escolarización: trayectoria histórica de la educación especial. Educação e Filosofia, 25(50), 691-716. https://doi.org/10.14393/revedfil.issn.01026801.v25n50a2011-13

González Moll, G. (2004). La atención educativa de los sordos en el contexto español. Historia, actualidad, futuro. XVI Congreso Nacional FEPAL. El Profesor de Audición y Lenguaje Ante El Nuevo Milenio, 107-137.

Gooch, D., Thompson, P., Nash, H. M., Snowling, M. J., y Hulme, C. (2016). The development of executive function and language skills in the early school years. Journal of Child Psychology and Psychiatry and Allied Disciplines, 57(2), 180-187. https://doi.org/10.1111/jcpp.12458

Gordon, K. A., Jiwani, S., y Papsin, B. C. (2013). Benefits and detriments of unilateral cochlear implant use on bilateral auditory development in children who are deaf. Frontiers in Psychology, 4. https://doi.org/10.3389/fpsyg.2013.00719

Hall, M. L., y Bavelier, D. (2011). Short-term memory stages in sign vs. speech: The source of the serial span discrepancy. Cognition, 120(1), 54-66. https://doi.org/10.1016/j.cognition.2011.02.014

Hall, M. L., Eigsti, I.-M., Bortfeld, H., y Lillo-Martin, D. (2018). Executive Function in Deaf Children: Auditory Access and Language Access. Journal of Speech, Language, and Hearing Research, 61(8), 1970-1988. https://doi.org/10.1044/2018_JSLHR-L-17-0281

Harris, M. S., Kronenberger, W. G., Gao, S., Hoen, H. M., Miyamoto, R. T., y Pisoni, D. B. (2013). Verbal Short-Term Memory Development and Spoken Language Outcomes in Deaf Children With Cochlear Implants. Ear and Hearing, 34(2), 179-192. 
https://doi.org/10.1097/AUD.0b013e318269ce50

Harris, M. S., Pisoni, D. B., Kronenberger, W. G., Gao, S., Caffrey, H. M., y Miyamoto, R. T. (2011). Developmental trajectories of forward and backward digit spans in deaf children with cochlear implants. Cochlear Implants International, 12 Suppl 1 (Suppl 1$)$, S84-8. https://doi.org/10.1179/146701011X13001035752534

Henry, L. A., Messer, D. J., y Nash, G. (2012). Executive functioning in children with specific language impairment. Journal of Child Psychology and Psychiatry, 53(1), 37-45. https://doi.org/10.1111/j.1469-7610.2011.02430.x

Higuero, R., y Juárez, A. (2010). Abordaje global y temprano de las sorderas infantiles. In Manual Básico de Formación Especializada sobre Discapacidad Auditiva (pp. 275-286).

Hintermair, M. (2013). Executive functions and behavioral problems in deaf and hard-of-hearing students at general and special schools. Journal of Deaf Studies and Deaf Education, 18(3), 344359. https://doi.org/10.1093/deafed/ent003

Hípola Sánchez, M. del P. (2004). Psicología y lenguaje. La comunicación y el lenguaje. In Manual Básico de Formación Especializada sobre Discapacidad Auditiva (pp. 168-184).

Hoffman, M., Tiddens, E., y Quittner, A. L. (2018). Comparisons of visual attention in school-age children with cochlear implants versus hearing peers and normative data. Hearing Research, 359, 91-100. https://doi.org/10.1016/J.HEARES.2018.01.002

Holmes, J., Gathercole, S. E., y Dunning, D. L. (2009). Adaptive training leads to sustained enhancement of poor working memory in children. Developmental Science, 12(4), F9-F15. https://doi.org/10.1111/j.1467-7687.2009.00848.x

Holt, R. F., y Svirsky, M. A. (2008). An exploratory look at pediatric cochlear implantation: Is earliest always best? Ear and Hearing, 29(4), 492-511. https://doi.org/10.1097/AUD.0b013e31816c409f

Horn, D. L., Davis, R. A. O., Pisoni, D. B., y Miyamoto, R. T. (2005). Development of visual attention skills in prelingually deaf children who use cochlear implants. Ear and Hearing, 26(4), 389-408. https://doi.org/10.1097/00003446-200508000-00003

Horn, David L., Davisa, R. A. O., Pisoni, D. B., y Miyamoto, R. T. (2004). Visual attention, behavioral 
inhibition and speech/language outcomes in deaf children with cochlear implants. Int Congr Ser, 1273(6), 332-335. https://doi.org/10.1038/jid.2014.371

Huang, F., Sun, L., Qian, Y., Liu, L., Ma, Q.-G., Yang, L., Cheng, J., Cao, Q.-J., Su, Y., Gao, Q., Wu, Z.-M., Li, H.-M., Qian, Q.-J., y Wang, Y.-F. (2016). Cognitive Function of Children and Adolescents with Attention Deficit Hyperactivity Disorder and Learning Difficulties: A Developmental Perspective. Chinese Medical Journal, 129(16), 1922. https://doi.org/10.4103/0366-6999.187861

Hughes, C., y Ensor, R. (2007). Executive function and theory of mind: Predictive relations from ages 2 to 4. Developmental Psychology, 43(6), 1447-1459. https://doi.org/10.1037/00121649.43.6.1447

Hughes, C., y Ensor, R. (2011). Individual differences in growth in executive function across the transition to school predict externalizing and internalizing behaviors and self-perceived academic success at 6 years of age. Journal of Experimental Child Psychology, 108(3), 663-676. https://doi.org/10.1016/j.jecp.2010.06.005

Hunter, C. R., Kronenberger, W. G., Castellanos, I., y Pisoni, D. B. (2017). Early postimplant speech perception and language skills predict long-term language and neurocognitive outcomes following pediatric cochlear implantation. Journal of Speech, Language, and Hearing Research, 60(8), 2321-2336. https://doi.org/10.1044/2017_JSLHR-H-16-0152

Jimenez Lara, A., Huete García, A., y Arías García, M. (2019). Alumnado con discapacidad y educación inclusiva en España. Observatorio Estatal de La Discapacidad, 1-409. www.observatoriodeladiscapacidad.info

Jones, A., Atkinson, J., Marshall, C., Botting, N., St Clair, M. C., y Morgan, G. (2019). Expressive Vocabulary Predicts Nonverbal Executive Function: A 2-year Longitudinal Study of Deaf and Hearing Children. Child Development. https://doi.org/10.1111/cdev.13226

Kelly, C., Morgan, G., Bannard, C., y Matthews, D. (2020). Early pragmatics in deaf and hard of hearing infants. Pediatrics, 146(Supplement 3), S262-S269. https://doi.org/10.1542/peds.20200242E

Kirkham, N. Z., Cruess, L., y Diamond, A. (2003). Helping children apply their knowledge to their 
behavior on a dimension-switching task. Developmental Science, 6(5), 449-467. https://doi.org/10.1111/1467-7687.00300

Korkman, M., Kirk, U., y Kemp, S. (2007). NEPSY-II: Clinical and interpretive manual. TX: The Psychological Corporation.

Kral, A. (2013). Auditory critical periods: A review from system's perspective. In Neuroscience (Vol. 247, pp. 117-133). Pergamon. https://doi.org/10.1016/j.neuroscience.2013.05.021

Kral, Andrej, Kronenberger, W. G., Pisoni, D. B., y O’Donoghue, G. M. (2016). Neurocognitive factors in sensory restoration of early deafness: A connectome model. The Lancet Neurology, 15(6), 610-621. https://doi.org/10.1016/S1474-4422(16)00034-X

Kronenberger, W. G., Colson, B. G., Henning, S. C., y Pisoni, D. B. (2014). Executive functioning and speech-language skills following long-term use of cochlear implants. Journal of Deaf Studies and Deaf Education, 19(4), 456-470. https://doi.org/10.1093/deafed/enu011

Kronenberger, W. G., Henning, S. C., Ditmars, A. M., y Pisoni, D. B. (2018). Language processing fluency and verbal working memory in prelingually deaf long-term cochlear implant users: A pilot study. Cochlear Implants International, 19(6), 312-323. https://doi.org/10.1080/14670100.2018.1493970

Kronenberger, W. G., Pisoni, D. B., Henning, S. C., y Colson, B. G. (2013). Executive functioning skills in long-term users of cochlear implants: A case control study. Journal of Pediatric Psychology, 38(8), 902-914. https://doi.org/10.1093/jpepsy/jst034

Kronenberger, W. G., Xu, H., y Pisoni, D. B. (2020). Longitudinal development of executive functioning and spoken language skills in preschool-aged children with cochlear implants. Journal of Speech, Language, and Hearing Research, 63(4), 1128-1147. https://doi.org/10.1044/2019_JSLHR-19-00247

Kronenberger, W., Pisoni, D., Henning, S., Colson, B., y Hazzard, L. (2011). Working Memory Training for Children With Cochlear Implants : A study. J Speech Lang Hear Res., 54(4), 1182 1196. https://doi.org/10.1044/1092-4388(2010/10-0119).Working

Kruythoff-Broekman, A., Wiefferink, C., Rieffe, C., y Uilenburg, N. (2019). Parent-implemented early 
language intervention programme for late talkers: parental communicative behaviour change and child language outcomes at 3 and 4 years of age. International Journal of Language \& Communication Disorders, 54(3), 451-464. https://doi.org/10.1111/1460-6984.12451

Kuhn, L. J., Willoughby, M. T., Vernon-Feagans, L., Blair, C. B., Cox, M., Blair, C., Burchinal, P., Burton, L., Crnic, K., Crouter, A., Garrett-Peters, P., Greenberg, M., Lanza, S., Mills-Koonce, R., Werner, E., y Willoughby, M. (2016). The contribution of children's time-specific and longitudinal expressive language skills on developmental trajectories of executive function. $\begin{array}{lllll}\text { Journal of } & \text { Experimental }\end{array}$ https://doi.org/10.1016/j.jecp.2016.03.008

Kuhn, L. J., Willoughby, M. T., Wilbourn, M. P., Vernon-Feagans, L., y Blair, C. B. (2014). Early communicative gestures prospectively predict language development and executive function in early childhood. Child Development, 85(5), 1898-1914. https://doi.org/10.1111/cdev.12249

Lai, C. L. E., Lau, Z., Lui, S. S. Y., Lok, E., Tam, V., Chan, Q., Cheng, K. M., Lam, S. M., y Cheung, E. F. C. (2017). Meta-analysis of neuropsychological measures of executive functioning in children and adolescents with high-functioning autism spectrum disorder. Autism Research, 10(5), 911-939. https://doi.org/10.1002/aur.1723

Lammers, M. J. W., Venekamp, R. P., Grolman, W., y van der Heijden, G. J. M. G. (2014). Bilateral cochlear implantation in children and the impact of the inter-implant interval. The Laryngoscope, 124(4), 993-999. https://doi.org/10.1002/lary.24395

Levrez, C., Bourdin, B., Le Driant, B., D’Arc, B. F., y Vandromme, L. (2012). The Impact of Verbal Capacity on Theory of Mind in Deaf and Hard of Hearing Children. American Annals of the Deaf, 157(1), 66-77. https://doi.org/10.1353/aad.2012.1610

Liu, M., Wu, L., Wu, W., Li, G., Cai, T., y Liu, J. (2018). The relationships among verbal ability, executive function, and theory of mind in young children with cochlear implants. International Journal of Audiology, 57(12), 875-882. https://doi.org/10.1080/14992027.2018.1498982

Lo, M., y Chen, P. H. (2017). Working memory capacity as a factor influencing the relationship between language outcome and rehabilitation in mandarin-speaking preschoolers with congenital hearing impairment. Frontiers in Psychology, 8(MAR), 357. https://doi.org/10.3389/fpsyg.2017.00357 
Lonigan, C. J., Lerner, M. D., Goodrich, J. M., Farrington, A. L., y Allan, D. M. (2016). Executive function of Spanish-speaking language-minority preschoolers: Structure and relations with early literacy skills and behavioral outcomes. Journal of Experimental Child Psychology, 144, 46-65. https://doi.org/10.1016/j.jecp.2015.11.003

Lyxell, B., Sahlén, B., Wass, M., Ibertsson, T., Larsby, B., Hällgren, M., y Mäki-Torkko, E. (2008). Cognitive development in children with cochlear implants: relations to reading and communication. International Journal of Audiology, 47 Suppl 2(788822252), S47-52. https://doi.org/10.1080/14992020802307370

Lyxell, B., Wass, M., Sahlén, B., Uhlén, I., Samuelsson, C., Asker-Árnason, L., Ibertsson, T., MäkiTorkko, E., Larsby, B., y Hällgren, M. (2011). Development of cognitive and reading skills in deaf children with CIs. Cochlear Implants International, 12(sup1), S100-S198. https://doi.org/10.1179/146701011X13001035752688

Mahone, E. M., y Hoffman, J. (2007). Behavior Ratings of Executive Function among Preschoolers with ADHD. The Clinical Neuropsychologist, 21(4), 569-586. https://doi.org/10.1080/13854040600762724

Manrique Rodríguez, M., y Irujo Huarte, A. (2004). Desarrollo evolutivo y mecanismos de la audición. In Manual básico de formación especializada sobre discapacidad auditiva (pp. 20-35).

Marcovitch, S., O’Brien, M., Calkins, S. D., Leerkes, E. M., Weaver, J. M., y Levine, D. W. (2015). A longitudinal assessment of the relation between executive function and theory of mind at 3,4 , and 5 years. Cognitive Development, 33, 40-55. https://doi.org/10.1016/j.cogdev.2014.07.001

Marcovitch, S., y Zelazo, P. D. (2009). A hierarchical competing systems model of the emergence and early development of executive function. Developmental Science, 12(1), 1-18. https://doi.org/10.1111/j.1467-7687.2008.00754.x

Markman, T. M., Quittner, A. L., Eisenberg, L. S., Tobey, E. A., Thal, D., Niparko, J. K., y Wang, N. Y. (2011). Language development after cochlear implantation: An epigenetic model. In Journal of Neurodevelopmental Disorders (Vol. 3, Issue 4, pp. 388-404). J Neurodev Disord. https://doi.org/10.1007/s11689-011-9098-z

Marschark, Marc, Sarchet, T., y Trani, A. (2016). Effects of Hearing Status and Sign Language Use 
on Working Memory. Journal of Deaf Studies and Deaf Education, 21(2), 148-155. https://doi.org/10.1093/deafed/env070

Marschark, Marc, Spencer, L. J., Durkin, A., Borgna, G., Convertino, C., Machmer, E., Kronenberger, W. G., y Trani, A. (2015). Understanding language, hearing status, and visual-spatial skills. Journal of Deaf Studies and Deaf Education, 20(4), 310-330. https://doi.org/10.1093/deafed/env025

May-Mederake, B. (2012). Early intervention and assessment of speech and language development in young children with cochlear implants. International Journal of Pediatric Otorhinolaryngology, 76(7), 939-946. https://doi.org/10.1016/j.ijporl.2012.02.051

McClelland, M. M., Cameron, C. E., Connor, C. M., Farris, C. L., Jewkes, A. M., y Morrison, F. J. (2007). Links between behavioral regulation and preschoolers' literacy, vocabulary, and math skills. Developmental Psychology, 43(4), 947-959. https://doi.org/10.1037/0012-1649.43.4.947

Medina García, M. (2018). La educación inclusiva como mecanismo de garantía de la igualdad de oportunidades y no discriminación de las personas con discapacidad. Una propuesta de estrategias pedagógicas inclusivas. Universidad de Jaén. http://hdl.handle.net/10953/

Meristo, M., y Hjelmquist, E. (2009). Executive Functions and Theory-of-Mind Among Deaf Children: Different Routes to Understanding Other Minds? Journal of Cognition and Development, 10(12), 67-91. https://doi.org/10.1080/15248370902966552

Meristo, M., Strid, K., y Hjelmquist, E. (2016). Early conversational environment enables spontaneous belief attribution in deaf children. Cognition, 157, 139-145. https://doi.org/10.1016/j.cognition.2016.08.023

Mikic, B., Miric, D., Nikolic-Mikic, M., Ostojic, S., y Asanovic, M. (2014). Age at implantation and auditory memory in cochlear implanted children. Cochlear Implants International, 15(sup1), S33-S35. https://doi.org/10.1179/1467010014Z.000000000191

Miller, M. R., Müller, U., Giesbrecht, G. F., Carpendale, J. I., y Kerns, K. A. (2013). The contribution of executive function and social understanding to preschoolers' letter and math skills. Cognitive Development, 28(4), 331-349. https://doi.org/10.1016/j.cogdev.2012.10.005 
Miller, S. E., y Marcovitch, S. (2011). Toddlers benefit from labeling on an executive function search task. Journal of Experimental Child Psychology, 108(3), 580-592. https://doi.org/10.1016/j.jecp.2010.10.008

Monfort, M. (2004). Consideraciones metodológicas según etapas educativas y áreas curriculares. In Manual Básico de Formación Especializada sobre Discapacidad Auditiva (pp. 350-359).

Mood, D., Szarkowski, A., Brice, P. J., y Wiley, S. (2020). Relational factors in pragmatic skill development: Deaf and hard of hearing infants and toddlers. In Pediatrics (Vol. 146, Issue Supplement 3, pp. S246-S261). American Academy of Pediatrics. https://doi.org/10.1542/peds.2020-0242D

Müller, U., Zelazo, P. D., Hood, S., Leone, T., y Rohrer, L. (2004). Interference Control in a New Rule Use Task: Age-Related Changes, Labeling, and Attention. Child Development, 75(5), 1594-1609. https://doi.org/10.1111/j.1467-8624.2004.00759.x

Müller, U., Zelazo, P. D., Lurye, L. E., y Liebermann, D. P. (2008). The effect of labeling on preschool children's performance in the Dimensional Change Card Sort Task. Cognitive Development, 23(3), 395-408. https://doi.org/10.1016/J.COGDEV.2008.06.001

Netten, A. P., Rieffe, C., Theunissen, S. C. P. M., Soede, W., Dirks, E., Korver, A. M. H., Konings, S., Oudesluys-Murphy, A. M., Dekker, F. W., y Frijns, J. H. M. (2015). Early identification: Language skills and social functioning in deaf and hard of hearing preschool children. International Journal of Pediatric Otorhinolaryngology, 79(12), 2221-2226. https://doi.org/10.1016/J.IJPORL.2015.10.008

Nicastri, M., Giallini, I., Amicucci, M., Mariani, L., de Vincentiis, M., Greco, A., Guerzoni, L., Cuda, D., Ruoppolo, G., y Mancini, P. (2020). Variables influencing executive functioning in preschool hearing-impaired children implanted within 24 months of age: an observational cohort study. European Archives of Oto-Rhino-Laryngology, 1, 3. https://doi.org/10.1007/s00405-020-063437

Nicholas, J. G., y Geers, A. E. (2013). Spoken language benefits of extending cochlear implant candidacy below 12 months of age. Otology and Neurotology, 34(3), 532-538. https://doi.org/10.1097/MAO.0b013e318281e215 
Nicholas, J. G., y Geers, A. E. (2018). Sensitivity of expressive linguistic domains to surgery age and audibility of speech in preschoolers with cochlear implants. Cochlear Implants International, 19(1), 26-37. https://doi.org/10.1080/14670100.2017.1380114

Niparko, J. K., Tobey, E. A., Thal, D. J., Eisenberg, L. S., Wang, N. Y., Quittner, A. L., y Fink, N. E. (2010). Spoken language development in children following cochlear implantation. JAMA Journal of the American Medical Association, 303(15), 1498-1506. https://doi.org/10.1001/jama.2010.451

Nittrouer, S., Caldwell-Tarr, A., y Lowenstein, J. H. (2013). Working memory in children with cochlear implants: Problems are in storage, not processing. International Journal of Pediatric Otorhinolaryngology, 77(11), 1886-1898. https://doi.org/10.1016/J.IJPORL.2013.09.001

Nunes, T., Barros, R., Evans, D., y Burman, D. (2014). Improving deaf children's working memory through training. International Journal of Speech and Language Pathology and Audiology, 2(2), 51-66. https://doi.org/10.12970/2311-1917.2014.02.02.1

Paatsch, L. E., y Toe, D. M. (2014). A comparison of pragmatic abilities of children who are deaf or hard of hearing and their hearing peers. Journal of Deaf Studies and Deaf Education, 19(1), 119. https://doi.org/10.1093/deafed/ent030

Palacios Blanco, S. (2004). Intervención educativa: El sistema educativo y el alumnado con discapacidad auditiva. In Manual básico de formación especializada sobre discapacidad auditiva (pp. 324-335).

Peirats, J., y Marín, D. (2018). Evolución de la educación especial: desde los orígenes hasa el modelo inclusivo. In Intervención psicoeducativa en alumnado con necesidades específicas de apoyo educativo.

Pérez Dalmeda, M. E., y Chhabra, G. (2019). Modelos teóricos de discapacidad: un seguimiento del desarrollo histórico del concepto de discapacidad en las últimas cinco décadas. Revista Española de Discapacidad, 7(1), 7-27. https://doi.org/10.5569/2340-5104.07.01.01

Petersen, I. T., Bates, J. E., D’Onofrio, B. M., Coyne, C. A., Lansford, J. E., Dodge, K. A., Pettit, G. S., y Van Hulle, C. A. (2013). Language ability predicts the development of behavior problems in children. Journal of Abnormal Psychology, 122(2), 542-557. https://doi.org/10.1037/a0031963 
Petersen, I. T., Bates, J. E., y Staples, A. D. (2015a). The Role of Language Ability and Self-Regulation in the Development of Inattentive-Hyperactive Behavior Problems. Dev Psychopathol., 27(913), 221-237. https://doi.org/10.1017/S0954579414000698.AH

Petersen, I. T., Bates, J. E., y Staples, A. D. (2015b). The role of language ability and self-regulation in the development of inattentive-hyperactive behavior problems. Development and Psychopathology, 27(1), 221-237. https://doi.org/10.1017/S0954579414000698

Peterson, N., Pisoni, D. B., y Miyamoto, R. T. (2010). Cochlear implants and spoken language processing abilities: Review and assessment of the literature. Restor Neurol Neurosci., 28(2), 237-250. https://doi.org/10.3233/RNN-2010-0535

Piaget, J. (1961). La formación del símbolo en el niño: imitacion, juego y sueño, imagen y representacion, tr. de Jose Gutierrez. Fondo de la Cultura Económica.

Pisoni, D. B., y Cleary, M. (2003). Measures of Working Memory Span and Verbal Rehearsal Speed in Deaf Children after Cochlear Implantation. Ear Hear, 24, 1-23. https://doi.org/10.1097/01.AUD.0000051692.05140.8E.Measures

Pisoni, D. B., Kronenberger, W. G., Harris, M. S., y Moberly, A. C. (2017). Three challenges for future research on cochlear implants. World Journal of Otorhinolaryngology - Head and Neck Surgery, 3(4), 240-254. https://doi.org/10.1016/j.wjorl.2017.12.010

Pisoni, D. B., Kronenberger, W. G., Roman, A. S., y Geers, A. E. (2011). Measures of Digit Span and Verbal Rehearsal Speed in Deaf Children After More Than 10 Years of Cochlear Implantation. Ear and Hearing, 32(1 Suppl), 60S-74S. https://doi.org/10.1097/AUD.0b013e3181ffd58e

Pisoni, D., Conway, C., Kronenberg, C., Henning, S., y Anaya, E. (2010). Executive Function, Cognitive Control, and Sequence Learning in Deaf Children with Cochlear Implants (M; Marschark y P. E. Spencer (eds.); The Oxford). Oxford University Press.

Postle, B. R., Brush, L. N., y Nick, A. M. (2004). Prefrontal cortex and the mediation of proactive interference in working memory. Cognitive, Affective and Behavioral Neuroscience, 4(4), 600608. https://doi.org/10.3758/CABN.4.4.600

Rappoport, S., y Echeita, G. (2018). El docente, los profesionales de apoyo y las prácticas de 
enseñanza. Perspectiva Educacional, 57(3), 3-27.

Remine, M. D., Care, E., y Brown, P. M. (2008). Language Ability and Verbal and Nonverbal Executive Functioning in Deaf Students Communicating in Spoken English. Journal of Deaf Studies and Deaf Education, 13(4), 531-545. https://doi.org/10.1093/deafed/enn010

Rinaldi, P., Baruffaldi, F., Burdo, S., y Caselli, M. C. (2013). Linguistic and pragmatic skills in toddlers with cochlear implant. International Journal of Language and Communication Disorders, 48(6), 715-725. https://doi.org/10.1111/1460-6984.12046

Rosas, R., Espinoza, V., Porflitt, F., y Ceric, F. (2019). Executive Functions Can Be Improved in Preschoolers Through Systematic Playing in Educational Settings: Evidence From a Longitudinal Study. Frontiers in Psychology, 10. https://doi.org/10.3389/fpsyg.2019.02024

Röthlisberger, M., Neuenschwander, R., Cimeli, P., Michel, E., y Roebers, C. M. (2011). Improving executive functions in 5- and 6-year-olds: Evaluation of a small group intervention in prekindergarten and kindergarten children. Infant and Child Development. https://doi.org/10.1002/icd

Sattler, J. M. (1992). Assessment of children: WISC-III and WPPSI-R supplement. Sattler, Jerome M.

Schoemaker, K., Bunte, T., Wiebe, S. A., Espy, K. A., Deković, M., y Matthys, W. (2012). Executive function deficits in preschool children with ADHD and DBD. Journal of Child Psychology and Psychiatry and Allied Disciplines, 53(2), 111-119. https://doi.org/10.1111/j.14697610.2011.02468.x

Schoemaker, K., Mulder, H., Deković, M., y Matthys, W. (2013). Executive functions in preschool children with externalizing behavior problems: A meta-analysis. Journal of Abnormal Child Psychology, 41(3), 457-471. https://doi.org/10.1007/s10802-012-9684-X

Silvestre, N., y Laborda, C. (2005). Los inicios de la comunicación y la adquisición del lenguaje oral en el alumnado con sordera. In La sordera desde la diversidad cultural y lingüística. Construyendo centros inclusivos en la educación del alumnado con sordera (Masson, pp. 83114).

Silvestre, Núria. (2010). Les famílies que tenen criatures amb necessitats educatives específiques: les 
famílies oïdores que tenen criatures sordes. EDUCAR, 45, 99-115. https://www.redalyc.org/articulo.oa?id=342130834007

Skogan, A. H., Zeiner, P., Egeland, J., Urnes, A.-G., Reichborn-Kjennerud, T., y Aase, H. (2015). Parent ratings of executive function in young preschool children with symptoms of attentiondeficit/-hyperactivity disorder. Behavioral and Brain Functions: BBF, 11, 16. https://doi.org/10.1186/s12993-015-0060-1

Socher, M., Lyxell, B., Ellis, R., Gärskog, M., Hedström, I., y Wass, M. (2019). Pragmatic Language Skills: A Comparison of Children With Cochlear Implants and Children Without Hearing Loss. Frontiers in Psychology, 10. https://doi.org/10.3389/fpsyg.2019.02243

Stiles, D. J., McGregor, K. K., y Bentler, R. A. (2012). Vocabulary and Working Memory in Children Fit With Hearing Aids. Journal of Speech, Language, and Hearing Research, 55(1), 154-167. https://doi.org/10.1044/1092-4388(2011/11-0021)

Sundqvist, A., Lyxell, B., Jönsson, R., y Heimann, M. (2014). Understanding minds: Early cochlear implantation and the development of theory of mind in children with profound hearing impairment. International Journal of Pediatric Otorhinolaryngology, 78(3), 538-544. https://doi.org/10.1016/J.IJPORL.2013.12.039

Surowiecki, V. N., Sarant, J., Maruff, P., Blamey, P. J., Busby, P. A., y Clark, G. M. (2002). Cognitive processing in children using cochlear implants: The relationship between visual memory, attention, and executive functions and developing language skills. Annals of Otology, Rhinology and Laryngology, 111(5 II), 119-126. https://doi.org/10.1177/00034894021110s524

Szarkowski, A., Young, A., Matthews, D., y Meinzen-Derr, J. (2020). Pragmatics development in deaf and hard of hearing children: A call to action. Pediatrics, 146(Supplement 3), S310-S315. https://doi.org/10.1542/peds.2020-0242L

Thorell, L. B., Lindqvist, S., Nutley, S. B., Bohlin, G., y Klingberg, T. (2009). Training and transfer effects of executive functions in preschool children. Developmental Science, 12(1), 106-113. https://doi.org/10.1111/j.1467-7687.2008.00745.x

Tobey, E. A., Thal, D., Niparko, J. K., Eisenberg, L. S., Quittner, A. L., Wang, N.-Y., y Team, the Cd. I. (2013). Influence Of Implantation Age On School-Age Language Performance In Pediatric 
Cochlear Implant Users. International Journal of Audiology, 52(4), 219-229. https://doi.org/10.3109/14992027.2012.759666

Torres, A. N. (2004). Intervención Educativa. Revisión histórica de los distintos planteamientos pedagógicos en la educación del sordo. In Manual Básico de Formación Especializada sobre Discapacidad Auditiva (pp. 314-321).

Traverso, L., Viterbori, P., y Usai, M. C. (2015). Improving executive function in childhood: evaluation of a training intervention for 5-year-old children. Frontiers in Psychology. https://doi.org/10.3389/fpsyg.2015.00525

Trinidad, G., y Jáudenes, C. (coord. . (2011). Sordera infantil. Del diagnóstico precoz a la inclusión educativa. Confederación Española de Familias de Personas Sordas (FIAPAS).

Villalba, A. (2010). Implicaciones de la sordera: repercusiones en el desarrollo lingüístico, cognitivo, afectivo y social. In Manual Básico de Formación Especializada sobre Discapacidad Auditiva (pp. 185-204).

Vissers, C., Koolen, S., Hermans, D., Scheper, A., y Knoors, H. (2015). Executive functioning in preschoolers with specific language impairment. Frontiers in Psychology, 6(OCT), 1-8. https://doi.org/10.3389/fpsyg.2015.01574

Vlastarakos, P. V., Proikas, K., Papacharalampous, G., Exadaktylou, I., Mochloulis, G., y Nikolopoulos, T. P. (2010). Cochlear implantation under the first year of age-The outcomes. A critical systematic review and meta-analysis. In International Journal of Pediatric Otorhinolaryngology (Vol. 74, Issue 2, pp. 119-126). Elsevier. https://doi.org/10.1016/j.ijporl.2009.10.004

Volckaert, A. M., y Noël, M.-P. (2015). Training executive function in preschoolers reduce externalizing behaviors. Trends in Neuroscience and Education, 4(1-2), 37-47. https://doi.org/10.1016/j.tine.2015.02.001

Vygotsky, L. S. (1969). Thought and language (Translated and edited by Eugenia Hanfmann and Gertrude Vakar). MIT Press.

Wass, Ma., Ibertsson, Ti., Lyxell, B., Sahlén, B., Hällgren, M., Larsby, B., y Mäki-Torkko, E. (2008). 
Cognitive and linguistic skills in Swedish children with cochlear implants - measures of accuracy and latency as indicators of development. Scandinavian Journal of Psychology, 49(6), 559-576. https://doi.org/10.1111/j.1467-9450.2008.00680.x

Weiland, C., Barata, M. C., y Yoshikawa, H. (2014). The Co-Occurring Development of Executive Function Skills and Receptive Vocabulary in Preschool-Aged Children: A Look at the Direction of the Developmental Pathways. Infant and Child Development, 23(1), 4-21. https://doi.org/10.1002/icd.1829

Welsh, J. A., Nix, R. L., Blair, C., Bierman, K. L., y Nelson, K. E. (2010). The development of cognitive skills and gains in academic school readiness for children from low-income families. Journal of Educational Psychology, 102(1), 43-53. https://doi.org/10.1037/a0016738

Willis, S., Goldbart, J., y Stansfield, J. (2014). The strengths and weaknesses in verbal short-term memory and visual working memory in children with hearing impairment and additional language learning difficulties. International Journal of Pediatric Otorhinolaryngology, 78(7), 1107-1114. https://doi.org/10.1016/J.IJPORL.2014.04.025

Willoughby, M. T., Wirth, R. J., y Blair, C. B. (2012). Executive function in early childhood: longitudinal measurement invariance and developmental change. Psychological Assessment, 24(2), 418-431. https://doi.org/10.1037/a0025779.Executive

Xiong, X., Zhu, L. N., Dong, X. X., Wang, W., Yan, J., y Chen, A. G. (2018). Aerobic Exercise Intervention Alters Executive Function and White Matter Integrity in Deaf Children: A Randomized Controlled Study. Neural Plasticity, 2018. https://doi.org/10.1155/2018/3735208

Yerys, B. E., y Munakata, Y. (2006). When Labels Hurt but Novelty Helps: Children's Perseveration and Flexibility in a Card-Sorting Task. Child Development, 77(6), 1589-1607. https://doi.org/10.1111/j.1467-8624.2006.00961.x

Yoshinaga-Itano, C. (2003). From Screening to Early Identification and Intervention: Discovering Predictors to Successful Outcomes for Children With Significant Hearing Loss. Journal of Deaf Studies and Deaf Education, 8(1), 11-30. https://doi.org/10.1093/deafed/8.1.11

Yoshinaga-Itano, Christine. (2011). Risk and Resiliency of Infants/Toddlers Who Are Deaf: Assessment and Intervention Issues. In Resilience in Deaf Children (pp. 87-115). 
Yoshinaga-Itano, Christine, Sedey, A. L., Wiggin, M., y Mason, C. A. (2018). Language Outcomes Improved Through Early Hearing Detection and Earlier Cochlear Implantation. Otology \& Neurotology, 39(10), 1256-1263. https://doi.org/10.1097/MAO.0000000000001976

Yucel, E., y Derim, D. (2008). The effect of implantation age on visual attention skills. International $\begin{array}{llll}\text { Journal of } & \text { Pediatric } & \text { Otorhinolaryngology, }\end{array}$ https://doi.org/10.1016/j.ijporl.2008.02.017

Zelazo, P. D., Müller, U., Frye, D., Marcovitch, S., Argitis, G., Boseovski, J., Chiang, J. K., Hongwanishkul, D., Schuster, B. V, y Sutherland, A. (2003). The development of executive function in early childhood. Monographs of the Society for Research in Child Development, 68(3), vii-137. http://www.ncbi.nlm.nih.gov/pubmed/14723273

Zhang, H.-F., Shuai, L., Zhang, J.-S., Wang, Y.-F., Lu, T.-F., Tan, X., Pan, J.-X., y Shen, L.-X. (2018). Neuropsychological Profile Related with Executive Function of Chinese Preschoolers with Attention-Deficit/Hyperactivity Disorder: Neuropsychological Measures and Behavior Rating Scale of Executive Function-Preschool Version. Chinese Medical Journal, 131(6), 648-656. https://doi.org/10.4103/0366-6999.226893 


\section{ANEXOS}

Anexo 1. Actividades implementadas en el programa de intervención

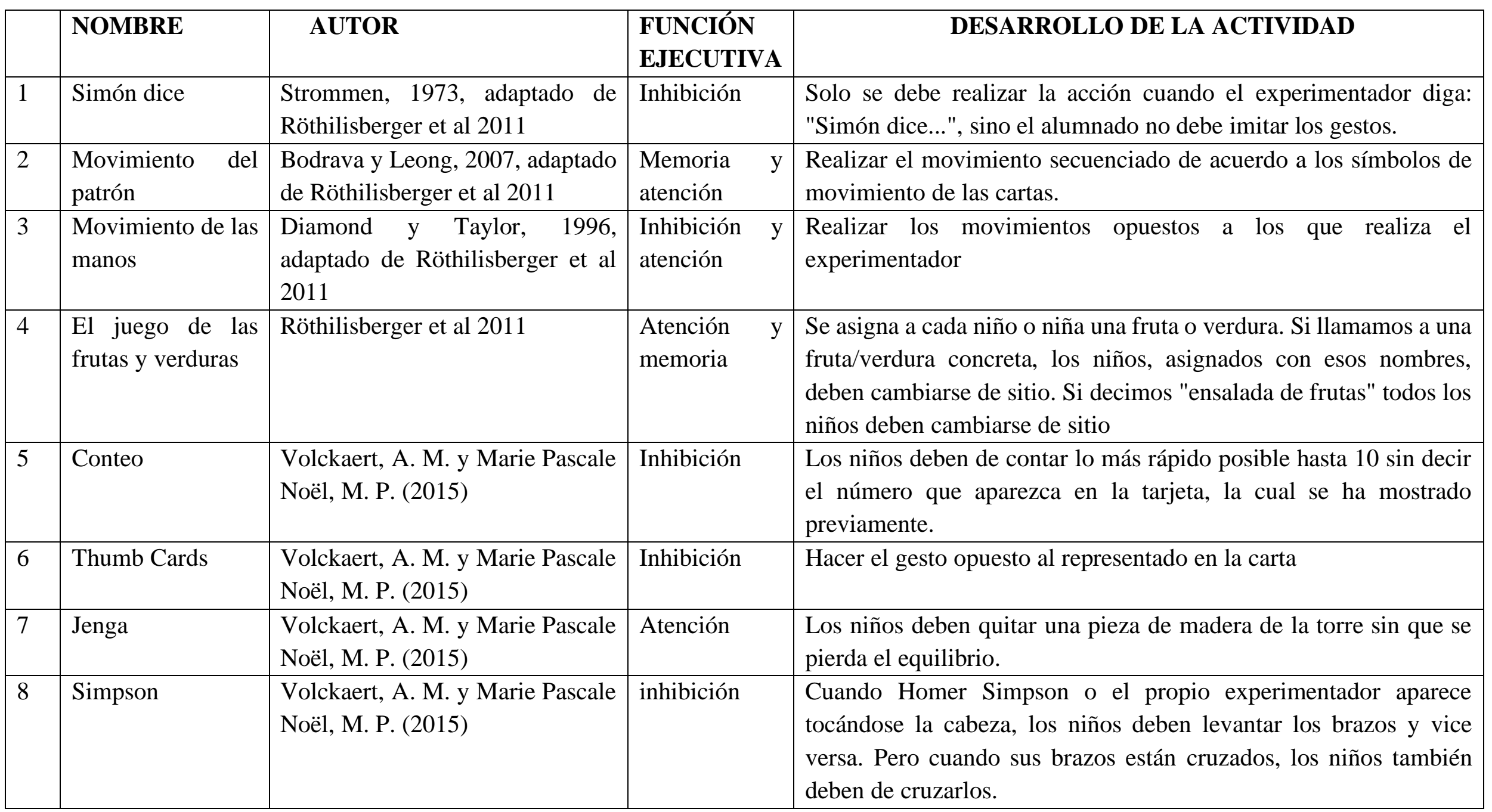




\begin{tabular}{|c|c|c|c|c|}
\hline 9 & Cocotaki & $\begin{array}{l}\text { Volckaert, A. M. y Marie Pascale } \\
\text { Noël, M. P. (2015) }\end{array}$ & Inhibición & $\begin{array}{l}\text { Cartas con imágenes de animales. Al juego se le puede añadir varias } \\
\text { reglas para aumentar la dificultad. Entre ellas, por ejemplo, hacer } \\
\text { todos los sonidos de los animales, salvo cuando salga un gallo. }\end{array}$ \\
\hline 10 & Las Palmadas & & $\begin{array}{l}\text { Atención } \\
\text { inhibición }\end{array}$ & $\begin{array}{l}\text { Los niños se sientan formando un círculo, un poquito separados } \\
\text { unos de otros. El facilitador les explica que él va a contar hasta cinco } \\
\text { (5) y cuando pronuncie la cifra "cinco" todos deben dar una } \\
\text { palmada. Al pronunciar los otros números no es necesario dar la } \\
\text { palmada, sino simplemente se aproximan las palmas de las manos. } \\
\text { El facilitador dirige el juego normalmente } 2 \text { o } 3 \text { veces, después } \\
\text { comienza a equivocarse al decir "tres" o cualquier otro número en } \\
\text { lugar del cinco. } \\
\text { Separa y une rápidamente las manos como si fuese a dar una } \\
\text { palmada, pero sin darla. El que se equivoca debe sentarse más atrás } \\
\text { y continúa jugando fuera del círculo hasta que no se equivoque y } \\
\text { pueda sentarse en el círculo nuevamente. }\end{array}$ \\
\hline
\end{tabular}




\begin{tabular}{|c|c|c|c|}
\hline & & & $\begin{array}{l}\text { en un número. Al parar los participantes deberán ejecutar la } \\
\text { conducta correspondiente, el que se equivoque sale del círculo. }\end{array}$ \\
\hline 12 & $\begin{array}{l}\text { Tres instrumentos, } \\
\text { tres acciones. }\end{array}$ & $\begin{array}{l}\text { Memoria } \\
\text { atención }\end{array}$ & $\begin{array}{l}\text { Se tocan tres instrumentos u objetos que suenen diferente } \\
\text { sucesivamente al que cada uno se le otorga una acción que debe ser } \\
\text { realizada por los participantes, al tocar el tambor o caja: los niños } \\
\text { hacen un sonido con la boca tapando y destapándola ("a lo indio"), } \\
\text { al escuchar el sonido de otro instrumento los niños levantan las } \\
\text { manos moviendo los dedos, al oír la guitarra los participantes } \\
\text { aplauden. }\end{array}$ \\
\hline 13 & $\begin{array}{l}\text { Corazones de } \\
\text { colores }\end{array}$ & $\begin{array}{l}\text { Memoria } \\
\text { atención }\end{array}$ & $\begin{array}{l}\text { Pondremos música, corazones de diferentes colores formando un } \\
\text { círculo. Norma: solo los niños y niñas que se queden en el corazón } \\
\text { rojo deben saltar. Los demás no. Se pueden ir añadiendo normas. }\end{array}$ \\
\hline 14 & Canción gestual & $\begin{array}{l}\text { Memoria } \\
\text { atención }\end{array}$ & $\begin{array}{l}\text { Recordar la canción y los gestos que acompañan a la canción } \\
\text { http://teaching2and3yearolds.com/learning-songs-for-circle-time/ }\end{array}$ \\
\hline 16 & Ritmos con aros & $\begin{array}{l}\text { Memoria } \\
\text { inhibición }\end{array}$ & $\begin{array}{l}\text { Hacer ritmos que lleven al niño a atender si debe realizar un gesto } \\
\text { con el aro cuando suene un tono u otro cuando el tono sea diferente. }\end{array}$ \\
\hline 17 & $\begin{array}{l}\text { Repetición de } \\
\text { ritmos }\end{array}$ & Memoria & $\begin{array}{l}\text { Repetir ritmos de tonos acompañados de imágenes visuales que } \\
\text { permitan recordar el tono que deben realizar en cada uno de ellos. }\end{array}$ \\
\hline
\end{tabular}


Anexo 2. Análisis estadístico de los diferentes momentos de evaluación (pretest, post-test y seguimiento) en cada tarea evaluada de las FE de la memoria y la inhibición según cada grupo de participantes (con sordera y normo-oyentes).

Tabla 25.

Comparación entre pretest, post-test y seguimiento de las variables evaluadas sobre memoria según el grupo de participantes con sordera y normo-oyentes.

\begin{tabular}{|c|c|c|c|c|c|c|c|c|c|c|c|c|}
\hline & \multicolumn{4}{|c|}{ Pretest } & \multicolumn{4}{|c|}{ Post-test } & \multicolumn{2}{|c|}{ Seguimiento } & & \\
\hline & \multicolumn{2}{|c|}{$\mathrm{NO} N=26$} & \multicolumn{2}{|c|}{$\mathrm{SD} \mathrm{N}=4$} & \multicolumn{2}{|c|}{$\mathrm{NO} N=26$} & \multicolumn{2}{|c|}{$\mathrm{SD} \mathrm{N}=4$} & $\mathrm{NO}$ & $\mathrm{SD}$ & $\mathrm{NO}$ & $\mathrm{SD}$ \\
\hline & M (DT) & Min-Max & $\mathrm{M}$ (DT) & Min-Max & $\mathrm{M}(\mathrm{DT})$ & Min-Max & $\mathrm{M}$ (DT) & Min-Max & $\mathrm{M}$ & & & \\
\hline $\mathrm{MN}$ & $30,38(7,17)$ & $20-45$ & $22,00(10,98)$ & $13-38$ & $44,81(10,54)$ & $22-56$ & $25,75(20,40)$ & $13-56$ & $43,85(8,72)$ & $28,75(6,18)$ & $32,99 * *$ & 1,50 \\
\hline MMV & $22,77(3,35)$ & $14-30$ & $10,25(6,65)$ & $5-20$ & $25,27(5,27)$ & $12-33$ & $17,00(7,43)$ & $12-28$ & $25,00(5,09)$ & $16,75(6,50)$ & $11,84 * *$ & 4,93 区 \\
\hline DDW & $5,58(, 70)$ & $4-6$ & $3,25(1,89)$ & $2-6$ & $5,88(, 43)$ & $4-6$ & $4,75(1,25)$ & $6-4$ & $5,73(, 66)$ & $4,50(1,73)$ & $6,22 *$ & 3,45 \\
\hline DAW & $1,81(1,49)$ & $0-4$ &, $75(, 95)$ & $0-2$ & $3,31(1,56)$ & $0-6$ &, $75(1,50)$ & $0-3$ & $3,00(1,35)$ &, $50(1,00)$ & $14,17 * *$ & 1,00 \\
\hline MESP & $45,50(4,88)$ & $38-55$ & $42,25(2,75)$ & $39-45$ & $46,31(4,84)$ & $38-58$ & $40,00(3,55)$ & $37-45$ & $66,73(7,24)$ & $\begin{array}{c}52,75 \\
(11,87) \\
\end{array}$ & $36,07 * *$ & $7,60 *$ \\
\hline
\end{tabular}

** Diferencias estadísticamente significativas $(\mathrm{p}<.01) *$ Diferencias estadísticamente significativas $(\mathrm{p}<.05)$ 区 Tendencia al cambio, próximo a $(\mathrm{p}<.05)$

$\mathrm{MN}=$ Memoria narrativa; MMV= Memoria de material verbal; MESP= Memoria espacial; $\mathrm{DDW}=$ Memoria de dígitos hacia delante; DAW=Memoria de dígitos hacia atrás 
Tabla 26.

Comparación entre pretest, post-test y seguimiento de las variables evaluadas sobre memoria según el grupo de participantes con sordera y normo-oyentes.

\begin{tabular}{ccccc|ccc|c|c|c|c}
\hline \multicolumn{9}{c|}{ Pretest } & \multicolumn{4}{c|}{ Post-test } & \multicolumn{2}{c}{ Seguimiento } \\
\hline
\end{tabular}

** Diferencias estadísticamente significativas $(\mathrm{p}<.01) *$ Diferencias estadísticamente significativas $(\mathrm{p}<.05)$ 囚 Tendencia al cambio, próximo a (p<.05)

INC= Inhibición cognitiva; INM= Inhibición motora

Tabla 27.

Comparación entre pretest, post-test y seguimiento de las variables evaluadas sobre memoria según el grupo de participantes con sordera y normo-oyentes.

\begin{tabular}{|c|c|c|c|c|c|c|c|c|c|c|c|c|c|c|}
\hline \multicolumn{8}{|c|}{$\mathrm{NO} N=26$} & \multicolumn{7}{|c|}{$\mathrm{SD} \mathrm{N}=4$} \\
\hline & \multirow{2}{*}{$\frac{\text { Pretest }}{\mathrm{M}(\mathrm{DT})}$} & \multicolumn{6}{|c|}{ Post-test } & \multicolumn{3}{|c|}{ Pretest } & \multicolumn{2}{|c|}{ Post-test } & \multirow[b]{2}{*}{ ET } & \multirow[b]{2}{*}{$\mathrm{Z}$} \\
\hline & & Min-Max & ET & $\mathrm{M}(\mathrm{DT})$ & Min-Max & ET & $\mathrm{Z}$ & $\mathrm{M}(\mathrm{DT})$ & Min-Max & ET & $\mathrm{M}(\mathrm{DT})$ & Min-Max & & \\
\hline $\mathrm{MN}$ & $30,38(7,17)$ & $20-45$ & 1,40 & $44,81(10,5)$ & $22-56$ & 2,06 & $-4,46 * *$ & $22,00(10,98)$ & $13-38$ & 5,49 & $25,75(20,40)$ & $13-56$ & 10,20 & ,73 \\
\hline MMV & $22,77(3,35)$ & $14-30$ &, 65 & $25,27(5,27)$ & $12-33$ & 1,03 & $-2,86 * *$ & $10,25(6,65)$ & $5-20$ & 3,32 & $17(7,43)$ & $12-28$ & 3,71 & $-1,84$ 凶 \\
\hline DDW & $5,57(, 70)$ & $4-6$ &, 13 & $5,88(, 43)$ & $4-6$ & ,08 & $-2,12 *$ & $3,25(1,89)$ & $2-6$ & ,94 & $4,75(1,25)$ & $3-6$ & 62 & $-1,41$ \\
\hline DAW & $1,80(1,49)$ & $0-4$ &, 29 & $3,30(, 30)$ & $0-6$ &, 30 & $-2,12^{*}$ &, $75(, 95)$ & $0-2$ &, 47 & ,75 (1,50) & $0-3$ &, 75 &, 00 \\
\hline MESP & $45,50(4,88)$ & $38-55$ & ,95 & $46,31(4,84)$ & $38-58$ & ,95 & $-0,69$ & $42,25(2,75)$ & $39-45$ & 1,37 & $40(3,55)$ & $37-45$ & 1,78 & $-1,60$ \\
\hline
\end{tabular}

** Diferencias estadísticamente significativas $(\mathrm{p}<.01) *$ Diferencia significativa $(\mathrm{p}<.05)$ \endencia al cambio, próximo a $(\mathrm{p}<.05)$

$\mathrm{MN}=$ Memoria narrativa; $\mathrm{MMV}=$ Memoria de material verbal; $\mathrm{MESP}=\mathrm{Memoria}$ espacial; $\mathrm{DDW}=\mathrm{Memoria}$ de dígitos hacia delante; $\mathrm{DAW=Memoria} \mathrm{de} \mathrm{dígitos} \mathrm{hacia} \mathrm{atrás}$ 
Tabla 28

Comparación entre pretest y seguimiento de las variables evaluadas sobre memoria según el grupo de participantes con sordera y normooyentes.

\begin{tabular}{|c|c|c|c|c|c|c|c|c|c|c|c|c|c|c|}
\hline \multicolumn{8}{|c|}{$\mathrm{NO} \mathrm{N}=26$} & \multicolumn{7}{|c|}{$\mathrm{SD} \mathrm{N}=4$} \\
\hline & Pretest & & & Seguim & iento & & & $\operatorname{Pr}$ & test & & Seguim & ento & & \\
\hline & $\mathrm{M}$ (DT) & Min-Max & ET & $\mathrm{M}(\mathrm{DT})$ & Min-Max & ET & $\mathrm{Z}$ & $\mathrm{M}$ (DT) & Min-Max & ET & $\mathrm{M}(\mathrm{DT})$ & Min-Max & ET & $\mathrm{Z}$ \\
\hline $\mathrm{MN}$ & $30,38(7,17)$ & $20-45$ & 1,40 & $43,85(8,72)$ & $26-56$ & 1,71 & $-4,17 * *$ & $22,00(10,98)$ & $13-38$ & 5,49 & $28,75(6,18)$ & $25-38$ & 3,09 & -0.92 \\
\hline MMV & $22,77(3,35)$ & $14-30$ &, 65 & $25,00(5,09)$ & $14-32$ & 1,00 & $-2,33^{*}$ & $10,25(6,65)$ & $5-20$ & 3,32 & $16,75(6,50)$ & $8-23$ & 3,25 & -1.60 \\
\hline DDW & $5,57(, 70)$ & $4-6$ &, 13 & $5,73(, 66)$ & $4-6$ & ,13 & $-1,63$ & $3,25(1,89)$ & $2-6$ & ,94 & $4,50(1,73)$ & $3-6$ &, 86 & $-1,84$ 区 \\
\hline DAW & $1,80(1,49)$ & $0-4$ & ,29 & $3,00(1,35)$ & $0-6$ & ,26 & $-3,14 * *$ & ,75 $(, 95)$ & $0-2$ &, 47 &, $50(1,00)$ & $0-2$ &, 50 & $-1,00$ \\
\hline MESP & $45,50(4,88)$ & $38-55$ & ,95 & $66,73(7,24)$ & $46-72$ & 1,42 & $-4,43 * *$ & $42,25(2,75)$ & $39-45$ & 1,37 & $52,75(11,87)$ & $44-70$ & 5,93 & $-1,82$ 区 \\
\hline
\end{tabular}

** Diferencias estadísticamente significativas ( $\mathrm{p}<.01) *$ Diferencias estadísticamente significativas ( $\mathrm{p}<.05)$ 区Tendencia al cambio p. próximo a $\mathrm{p}<.05$

$\mathrm{MN}=$ Memoria narrativa; $\mathrm{MMV}=$ Memoria de material verbal; MESP= Memoria espacial; $\mathrm{DDW}=\mathrm{Memoria}$ de dígitos hacia delante; $\mathrm{DAW=Memoria} \mathrm{de} \mathrm{dígitos} \mathrm{hacia} \mathrm{atrás}$

Tabla 29.

Comparación entre post-test y seguimiento de las variables evaluadas sobre memoria según el grupo de participantes con sordera y normooyentes.

\begin{tabular}{|c|c|c|c|c|c|c|c|c|c|c|c|c|c|c|}
\hline \multicolumn{8}{|c|}{$\mathrm{NO} \mathrm{N}=26$} & \multicolumn{7}{|c|}{$\mathrm{SD} \mathrm{N}=4$} \\
\hline & Post-test & & & Seguim & iento & & & $\mathrm{Po}$ & st-test & & Seguim & ento & & \\
\hline & M (DT) & Min-Max & ET & M (DT) & Min-Max & ET & $\mathrm{Z}$ & M (DT) & Min-Max & ET & $\mathrm{M}(\mathrm{DT})$ & Min-Max & ET & $\mathrm{Z}$ \\
\hline $\mathrm{MN}$ & $44,81(10,54)$ & $22-56$ & 1,40 & $43,85(8,72)$ & $26-56$ & 2,06 & $-0,66$ & $25,75(20,40)$ & $13-56$ & 10,20 & $28,75(6,18)$ & $25-38$ & 3,09 & $-0,36$ \\
\hline MMV & $25,27(5,27)$ & $12-33$ & 65 & $25,00(5,09)$ & $14-32$ & 1,03 & $-0,14$ & $17,00(7,43)$ & $12-28$ & 3,71 & $16,75(6,50)$ & $8-23$ & 3,25 & $-0,18$ \\
\hline DDW & $5,88(, 43)$ & $4-6$ & ,13 & $5,73(, 66)$ & $4-6$ & ,08 &, 00 & $4,75(1,25)$ & $3-6$ & ,62 & $4,50(1,73)$ & $3-6$ &, 86 &, 00 \\
\hline DAW & $3,30(1,56)$ & $(0-6)$ &, 29 & $3,00(1,35)$ & $0-6$ &, 30 & $-1,00$ &, $75(1,50)$ & $0-3$ &, 75 &, $50(1,00)$ & $0-2$ &, 50 & $-1,00$ \\
\hline MESP & $46,31(4,84)$ & $38-58$ & ,95 & $66,73(7,24)$ & $46-72$ & 0,95 & $-4,46 * *$ & $40,00(3,55)$ & $37-45$ & 1,78 & $52,75(11,87)$ & $44-70$ & 5,93 & $-1,84 区$ \\
\hline
\end{tabular}

** Diferencias estadísticamente significativas $(\mathrm{p}<.01) *$ Diferencias estadísticamente significativas $(\mathrm{p}<.05)$ 区Tendencia al cambio p. próximo a $\mathrm{p}<.05$

$\mathrm{MN}=$ Memoria narrativa; $\mathrm{MMV}=$ Memoria de material verbal; $\mathrm{MESP}=$ Memoria espacial; $\mathrm{DDW}=$ Memoria de dígitos hacia delante; $\mathrm{DAW=Memoria} \mathrm{de} \mathrm{dígitos} \mathrm{hacia} \mathrm{atrás}$ 
Tabla 30.

Comparación entre pretest, post-test y seguimiento de las variables evaluadas sobre inhibición según el grupo de participantes con sordera y normo-oyentes.

\begin{tabular}{|c|c|c|c|c|c|c|c|c|c|c|c|c|c|c|}
\hline \multicolumn{8}{|c|}{$\mathrm{NO} N=26$} & \multicolumn{7}{|c|}{$\mathrm{SD} \mathrm{N}=4$} \\
\hline & Pretest & & & Post-t & & & & & retest & & Post & est & & \\
\hline & $\mathrm{M}$ (DT) & Min-Max & ET & $\mathrm{M}$ (DT) & $\begin{array}{l}\text { Min- } \\
\text { Max }\end{array}$ & ET & $\mathrm{Z}$ & $\mathrm{M}$ (DT) & Min-Max & ET & $\mathrm{M}$ (DT) & Min-Max & ET & $\mathrm{Z}$ \\
\hline INC & $7,461(2,41)$ & $0-10$ & 47 & $9,73(, 66)$ & $8-10$ &, 13 & $-3,80 * *$ & $6,950(, 57)$ & $6,20-7,60$ & 5,49 & $9,25(, 95)$ & $8-10$ & 10,20 & $-1,82$ 区 \\
\hline INM & $21,62(5,16)$ & $10-30$ & 1,01 & $28,88(3,98)$ & $11-30$ &, 78 & $-4,42 * *$ & $14,50(9,14)$ & $8-28$ & 3,32 & $30,00(, 00)$ & $30-30$ & 3,71 & $-1,82$ 区 \\
\hline
\end{tabular}

** Diferencias estadísticamente significativas $(\mathrm{p}<.01) *$ Diferencia significativa $(\mathrm{p}<.05)$ Tendencia al cambio, próximo a $(\mathrm{p}<.05)$

$\mathrm{INC}=$ Inhibición cognitiva; INM= Inhibición motora

Tabla 31.

Comparación entre pretest y seguimiento de las variables evaluadas sobre inhibición según el grupo de participantes con sordera y normooyentes.

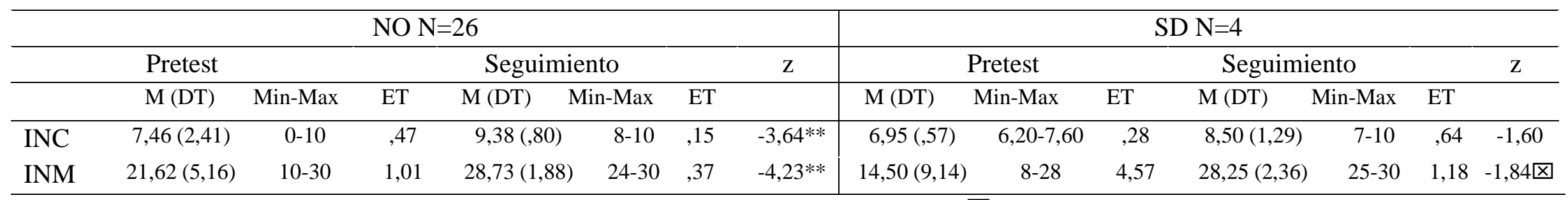

** Diferencias estadísticamente significativas $(\mathrm{p}<.01) *$ Diferencias estadísticamente significativas $(\mathrm{p}<.05)$ 区Tendencia al cambio p. próximo a p <.05

$\mathrm{INC}=$ Inhibición cognitiva; INM= Inhibición motora 
Tabla 32.

Comparación entre post-test y seguimiento de las variables evaluadas sobre inhibición según el grupo de participantes con sordera y normooyentes.

\begin{tabular}{|c|c|c|c|c|c|c|c|c|c|c|c|c|c|c|}
\hline \multicolumn{8}{|c|}{$\mathrm{NO} \mathrm{N}=26$} & \multicolumn{7}{|c|}{$\mathrm{SD} \mathrm{N}=4$} \\
\hline \multicolumn{3}{|c|}{ Post-test } & \multicolumn{4}{|c|}{ Seguimiento } & \multirow[t]{2}{*}{$\mathrm{Z}$} & \multicolumn{2}{|c|}{ Post-test } & \multicolumn{3}{|c|}{ Seguimiento } & \multirow{2}{*}{\multicolumn{2}{|c|}{$\mathrm{Z}$}} \\
\hline & $\mathrm{M}(\mathrm{DT})$ & Min-Max & ET & $\mathrm{M}(\mathrm{DT})$ & Min-Max & ET & & $\mathrm{M}(\mathrm{DT})$ & Min-Max & ET & $\mathrm{M}(\mathrm{DT})$ & Min-Max & & \\
\hline INC & $7,46(2,41)$ & $0-10$ &, 47 & $9,38(, 80)$ & $8-10$ &, 15 &, 14 & $9,25(, 95)$ & $8-10$ &, 47 & $8,50(1,29)$ & $7-10$ &, 64 & $-1,34$ \\
\hline INM & $21,62(5,16)$ & $10-30$ & ,31 & $28,73(1,88)$ & $24-30$ &, 37 & $-1,93 *$ & $30,00(, 00)$ & $30-30$ &, 00 & $28,25(2,36)$ & $25-30$ & 1,18 & $-1,34$ \\
\hline
\end{tabular}

** Diferencias estadísticamente significativas $(\mathrm{p}<.01) *$ Diferencias estadísticamente significativas (p<.05) 囚Tendencia al cambio p. próximo a p <.05

$\mathrm{INC}=$ Inhibición cognitiva; INM= Inhibición motora 
Anexo 3. Documentos de información y confidencialidad de datos

\section{DOCUMENTO DE CONFIDENCIALIDAD DE DATOS}

En relación al estudio sobre intervención en memoria y atención que se realiza en el colegio, en el que participa vuestro hijo o hija, los miembros del equipo de investigación de la Universidad Jaume I junto con la Universidad Autónoma de Barcelona, que llevan a cabo el mencionado estudio se compromete a seguir con la más absoluta reserva su obligación de no utilizar los datos, registros e informes de este estudio vinculado con la mejora de las condiciones de vida de las personas sordas y de sus familias, a excepción de la divulgación científica anónima, de acuerdo con la Ley Orgánica 15/1999 de Protección de Carácter Personal y la Ley Orgánica 1/1996 de Protección Jurídica del menor.

Marta Boronat Barbeta

Yo, padre/madre/tutor del niño o niña:

Declara conocer y estar de acuerdo con los términos expuestos en el presente documento.

Firmado:

(Nombre y apellidos del padre, madre o tutor/a.)

de 2018 


\section{HOJA DE INFORMACIÓN PARA LAS FAMILIAS}

\section{INTRODUCCIÓN}

A través de esta hoja informativa se le invita a participar en un proyecto de investigación realizado en alumnos sordos con implante coclear y alumnos sin sordera. Por favor, lea detenidamente la información que le proporcionamos a continuación. Necesitamos su ayuda para observar los beneficios del implante coclear en la comunicación y otros aspectos cognitivos como la memoria. Es importante su colaboración para que se sepa más acerca de la comunidad sorda y que las barreras para personas con sordera sean menores en el futuro. La participación en el estudio es voluntaria de modo que puede abandonar la investigación en cualquier momento. Asimismo, puede hacer cuantas preguntas quiera antes o después de iniciar la investigación y uno de los responsables de la investigación se las resolverá. El estudio ha sido aprobado por el Comité de Ética en la Experimentación Animal y Humana (CEEAH) de la Universidad Autónoma de Barcelona y Jaume I.

\section{JUSTIFICACIÓN Y OBJETIVO DEL ESTUDIO}

Desde la implementación del implante coclear muchas de las habilidades lingüísticas de las personas sordas se han visto beneficiadas por la ganancia auditiva que este proporciona. A pesar de ello, determinados aspectos del lenguaje como el nivel de vocabulario y la gramática del alumnado sordo están frecuentemente retrasados con respecto a los oyentes en la niñez, los cuales son un medio fundamental para el aprendizaje y tiene un peso importante en el éxito académico y social.

No está claro cuál es el aspecto que dificulta a las personas con sordera lograr un nivel gramatical y de vocabulario como el de sus compañeros y por qué hay tanta diferencia entre el alumnado pesar de tener en cuenta el tipo de procesador que utiliza el implante coclear, la edad de aparición de la sordera, el modo de comunicación, la duración del uso del implante coclear y la edad de implantación. No obstante, se ha observado que las personas sordas desarrollan de forma tardía aspectos cognitivos como la memoria y la atención, las cuales están relacionadas con el lenguaje.

Por esa razón, este proyecto tiene como objetivo el desarrollo de un programa de intervención educativa, donde se estimularán los procesos cognitivos de memoria y atención en niños y niñas con sordera de Educación Infantil de 3 a 6 años y observar así cómo mejoran estos aspectos e influyen en el rendimiento del desarrollo oral. 


\section{¿QUIÉN REALIZA LA INVESTIGACIÓN?}

El estudio lo realiza el Departamento de Psicología Evolutiva, Educativa, Social y Metodología de la Facultad de Psicología Evolutiva y de la Educación de la Universidad Jaume I en el marco del Doctorado de Educación codirigido con Departamento de Psicología Básica, Evolutiva y de la Educación de la Facultad de Psicología de la Universidad Autónoma de Barcelona. La investigadora que lleva a cabo el estudio es Marta Boronat Barbeta.

\section{¿CÓMO SE VA A REALIZAR?}

Inicialmente se seleccionarán personas de entre 3-6 años con sordera y debe haber recibido el implante coclear antes de los tres años de edad. Al mismo tiempo, se buscarán a personas sin sordera de la misma edad y sexo que su compañero. A todos los participantes se les evaluará en tres sesiones de sus competencias comunicativas y cognitivas. Será preciso registrar en formato audio algunas de las respuestas a las pruebas del estudio. Por último, se analizarán las diferencias entre los grupos y los participantes podrán conocer los resultados una vez concluido el estudio.

\section{BENEFICIOS POTENCIALES}

Las personas con sordera contribuirán al conocimiento de sus propias dificultades facilitando la prevención y la búsqueda de soluciones y/o programas de rehabilitación de las personas con sordera a lo largo de su desarrollo. Recuerde que el desarrollo del lenguaje oral y el aprendizaje son dos aspectos claves tanto en el ámbito educativo como en el profesional o el social. Si su hijo no forma parte del grupo de personas con sordera estará contribuyendo a que se conozca más acerca de los beneficios del implante coclear y de las dificultades que entraña el déficit auditivo.

\section{PROTECCIÓN DE LOS DERECHOS DEL PARTICIPANTE}

Sus datos serán confidenciales, independientemente de si finaliza el estudio o no. Su nombre será codificado para que sus respuestas no sean reconocibles por ninguna persona, excepto el investigador, preservando la confidencialidad. Los datos obtenidos no se utilizarán con ningún otro propósito del que figura en esta investigación y pasarán a formar parte de un fichero de datos del que será responsable el investigador principal. En cualquier momento puede abandonar el estudio y revocar su deseo de participar en él. 